NASA

Technical

Paper

3607

April 1996

Flight Evaluation of Advanced

Controls and Displays for Transition and Landing on the NASA V/STOL Systems Research Aircraft

James A. Franklin, Michael W. Stortz, Paul F. Borchers, and

Ernesto Moralez III

National Aeronautics and Space Administration 



\section{NASA \\ Technical \\ Paper \\ 3607}

1996

Flight Evaluation of Advanced

Controls and Displays for Transition and Landing on the NASA V/STOL Systems Research Aircraft

James A. Franklin, Michael W. Stortz, Paul F. Borchers, and

Ernesto Moralez III, Ames Research Center, Moffett Field, California

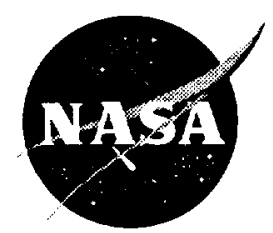

National Aeronautics and Space Administration 



\section{Contents}

Somenclature





\section{Nomenclature}

$a_{y} \quad$ lateral acceleration, $\mathrm{ft} / \mathrm{sec}^{2}$

$\mathrm{D}_{\mathrm{x}}, \mathrm{D}_{\mathrm{y}} \quad$ stick complementary filter inverse time constant, $\sec ^{-1}$

g acceleration due to gravity, $\mathrm{ft} / \mathrm{sec}^{2}$

$\mathrm{h}$ altitude, $\mathrm{ft}$

$\dot{\mathrm{h}}, \mathrm{V}_{\mathrm{Z}} \quad$ inertial vertical velocity, $\mathrm{ft} / \mathrm{sec}$

$\dot{\mathrm{h}}_{\mathrm{c}} \quad$ vertical velocity command, $\mathrm{ft} / \mathrm{sec}$

$\mathrm{N}_{\mathrm{F}}$ fan revolutions per minute (rpm), percent

p roll rate, deg/sec

q pitch rate, $\mathrm{deg} / \mathrm{sec}$

qbar dynamic pressure, $\mathrm{lb} / \mathrm{ft}^{2}$

r yaw rate, $\mathrm{deg} / \mathrm{sec}$

s Laplace operator

$\mathrm{V}_{\mathrm{af}} \quad$ filtered airspeed, $\mathrm{ft} / \mathrm{sec}$

$V_{\text {cas }} \quad$ calibrated airspeed, knots

$\mathrm{V}_{\mathrm{tI}} \quad$ ground speed with lower limit of $100 \mathrm{ft} / \mathrm{sec}$

$\mathrm{V}_{\mathrm{X}} \quad$ heading reference inertial longitudinal velocity, ft/sec

$\mathrm{V}_{\mathrm{y}} \quad$ heading reference inertial lateral velocity, $\mathrm{ft} / \mathrm{sec}$

$\beta \quad$ sideslip angle, deg

$\gamma \quad$ flightpath angle, deg

$\gamma_{\mathrm{q}} \quad$ quickened flightpath angle, deg

$\delta_{\mathrm{A}} \quad$ aileron deflection, deg

$\delta_{\text {lat }}, \delta_{\phi} \quad$ lateral stick deflection, in.

$\delta_{\phi_{\mathrm{T}}} \quad$ lateral stick trim servo, in.

$\delta_{\text {long }}, \delta_{\theta} \quad$ longitudinal stick deflection, in.

$\delta_{\theta_{\mathrm{T}}} \quad$ longitudinal stick trim servo, in.

$\delta_{p}, \delta_{\psi} \quad$ pedal deflection, deg

$\delta_{\mathrm{S}} \quad$ stabilator deflection, deg

$\delta_{\mathrm{S}_{\mathrm{tw}}} \quad$ Iongitudinal stick thumbwheel, percent

$\delta_{\mathrm{T}}$

$\delta_{t_{\text {tw }}}$

$\delta_{\mathbf{X}}$

$\delta_{y}$ $\delta_{\text {yrcs }} \quad$ yaw reaction control deflection, percent

$\theta \quad$ pitch attitude, deg

$\theta_{\mathrm{c}} \quad$ commanded pitch attitude, deg

$\theta_{\mathrm{j}} \quad$ thrust vector angle, deg

$\sigma_{\mathrm{u}}, \sigma_{\mathrm{v}}, \sigma_{\mathrm{w}}$ longitudinal, lateral, and vertical quickening inverse time constants, $\mathrm{sec}^{-1}$

$\phi \quad$ bank angle, deg

$\psi \quad$ heading, deg

$\Omega_{0} \quad$ control input quickening inverse time constant, $\sec ^{-1}$

ar flightpath inverse time constant, $\mathrm{sec}^{-1}$

Acronyms

BW bandwidth

FCC flight control computer

GPS Global Positioning System

HQR handling-qualities rating

HUD head-up display

IGE in ground effect

IMC instrument meteorological conditions

INU inertial navigation unit

1/O input/output

JPT jet pipe temperature

POT potentiometer

RCS reaction control system

RLG ring laser gyro

RMDU remote multiplexer/demultiplexer unit

rms root mean square

SAS stability augmentation system

SKP station-keeping point

STOL short takeoff and landing

STOVL short takeoff/vertical landing

TRC translational-rate command

VMC visual meteorological conditions

VMS Vertical Motion Simulator

VSRA V/STOL Systems Research Aircraft

V/STOL vertical/short takeoff and landing

XMTR transmitter 



\title{
Flight Evaluation of Advanced Controls and Displays for Transition and Landing on the NASA V/STOL Systems Research Aircraft
}

\author{
JAMES A. FRANKLIN, MICHAEL W. STORTZ, PAUL F. BORCHERS, AND ERNESTO MORALEZ III \\ Ames Research Center
}

\section{Summary}

Flight experiments were conducted on Ames Research Center's V/STOL Systems Research Aircraft (VSRA) to assess the influence of advanced control modes and head-up displays (HUDs) on flying qualities for precision approach and landing operations. Evaluations were made for decelerating approaches to hover followed by a vertical landing and for slow landings for four control/ display mode combinations: the basic YAV-8B stability augmentation system (SAS); attitude command for pitch, roll, and yaw; tlightpath/acceleration command with translational rate command in the hover; and height-rate damping with translational-rate command. Head-up displays used in conjunction with these control modes provided flightpath tracking/pursuit guidance and deceleration commands for the decelerating approach and a mixed horizontal and vertical presentation for precision hover and landing. Flying qualities were established and control usage and bandwidth were documented for candidate control modes and displays for the approach and vertical landing. Minimally satisfactory bandwidths were determined for the translational-rate command system. Test pilot and engineer teams from the Naval Air Warfare Center, the Boeing Military Airplane Group, L ockheed Martin, McDonnell Douglas Acrospace, Northrop Grumman, Rolls-Royce, and the British Defence Research Agency participated in the program along with NASA research pilots from the Ames and Lewis Research Centers. The results, in conjunction with related groundbased simulation data, indicate that the flightpath/ longitudinal-acceleration command response type in conjunction with pursuil tracking and deceleration guidance on the HUD would be essential for operation to instrument minimums significantly lower than the minimums for the AV-8B. It would also be a superior mode for performing slow landings where precise control to an austere landing area such as a narrow road is demanded. The translational-rate command system would reduce pilot workload for demanding vertical landing tasks abourd ship and in confined land-based sites.

\section{Introduction}

For many years Ames Research Center has conducted a program on advanced control and display technology applied to the low-speed, precision flight operations of short takeoff/vertical landing (STOVL) aircraft in adverse weather. This work is motivated by the control requirements for these aircraft that are predicated on the operational environment to which they are exposed. For military use, these aircraft are required to operate from conventional airfields, austere sites, aircraft carriers, or small aviation-capable vessels. The capability for hover and low-speed flight and for rapidly transitioning between wing- and propulsion-borne flight permits STOVL aircraft to operate into confined spaces associated with austere sites and decks of small ships. In principle, STOVL aircraft should he able to accomplish these operations under weather conditions that would be prohibitive for conventional aircraft. However, these operations demand precision of control of position, velocity, and attitude, the ability to quickly arrest closure rates in limited confines, and the capability to do so under challenging conditions of winds, turbulence, and low visibility. Such requirements exceed those imposed on conventional fixed-wing counterparts to a considerable degree. Currently, the shiphoard capability of STOVL aircraft involves a constant-speed stabilized descent in instrument meteorological conditions (IMC) to a minimum altitude of $300 \mathrm{ft}$ with a visual range of $1 \mathrm{mi}$, followed by deceleration to hover in visual meteorological conditions (VMC).

Recovery to the ship is restricted to landing areas at least the size provided by amphibious assault ships (LPH or LHA) on the order of $50 \times 50 \mathrm{ft}$ and in sea state 3 or less The impediment to routine vertical flight operations of this class of aircraft in adverse weather and low-visibility conditions stems from poor flying qualities that are a consequence of the complex interaction of kinematics, acrodynamics, and propulsive forces and moments during the transition from wing- to propulsion-borne llight and during propulsion-borne operations. The pilot's control problem is aggravated by an additional control requircment related to the transition (e.g., thrust vectoring and startup and control of lift-augmenting devices). The challenge to the designer is to determine the appropriate 
control response types and the associated cockpit displays and inceptors that will provide the desired operational capability with the associated precision and minimum pilot effort required to perform the requisite tasks. Of equal importance is the requirement for and ability to integrate the STOVL aircraft's flight and propulsion controls that will provide the desired level of controllability over the full range of STOVL operations.

This research program has involved analytical studies and ground-based simulation experiments to develop and evaluate control response types and associated displays with general applicability to STOVL operations. It has yielded numerous promising concepts for control augmentation systems and cockpit displays for decelerating transition to hover under IMC and landing in confined and austere sites and aboard small aviation-capable ships (refs. 1-5). During the past several years, selected concepts have been developed further, applied to STOVL fighter aircraft designs, and evaluated in moving-base simulations on the Ames Vertical Motion Simulator (refs. 6-8). Results of this body of ground-based simulation experiments indicate that a high degree of precision of operation for recovery aboard small ships in heavy seas and low visibility with acceptable levels of pilot effort can be achieved by integrating the aircraft flight and propulsion controls to significantly improve the basic aircraft response to pilot commands for attitude, height, and position control. The response types that elicited the most favorable ratings and comments were those that provided direct command of the aircraft responses associated with the task being performed. Thus for the decelerating approach to hover, the favored response type was decoupled flightpath and longitudinal-acceleration command with the ability to independently control pitch attitude without perturbing the longitudinal or vertical response. The preferred lateral-directional controls were the roll-rate command with bank-angle hold and yaw damping with turn coordination. In hover, decoupled control of the orthogonal translational velocities was most sought. The availability of digital $17 y$-by-wire control, precision inertial sensors for attitudes, rates, and position, and electronic displays makes it feasible to implement an integrated control and display design of this sophistication to achieve and demonstrate in flight the operational benefits promised by the simulation experience and to establish their value for advanced STOVL aircraft designs.

Flight experiments were conducted on Ames Research Center's V/STOL Systems Research Aircraft (VSRA) to assess the influence of these advanced control modes and head-up displays (HUDs) on flying qualities for precision approach and landing. This report describes the VSRA and its research systems, the elements of the flight experiment to evaluate control and display modes, the results of the pilots' evaluations, and modifications recommended for application to new STOVL aircraft.

\section{Description of the V/STOL Systems Research Aircraft}

The VSRA is the sole remaining aircraft from the YAV-8B Prototype Demonstration Program of the late 1970s. It has been highly modified for its role as a research aircraft. The basic aircraft, shown in hover in figure 1, is a single-seat, high-performance, transonic, light attack vertical/short takeoff and landing (V/STOL) aircraft. It is characterized by a shoulder-mounted, supercritical, swept wing and swept stabilator, both with marked anhedral. It has a single vertical fin and rudder, under-fuselage lift-improvement devices, and a large engine inlet with a double row of inlet doors. The aircraft is powered by a single Rolls-Royce Pegasus turbofan engine that provides lift thrust for takeoff and landing, cruise thrust for conventional wing-borne flight, deflected thrust for V/STOL and in-flight maneuvering, and compressor bleed air for the reaction control system (RCS). Four exhaust nozzles, two on each side of the fuselage, direct the engine thrust from fully aft to $98.5 \mathrm{deg}$ below the thrust line that is inclined 1.5 deg above the fuselage reference line.

The flight control system consists of conventional aerodynamic surfaces that are hydraulically powered. except for the rudder, which is completely mechanical, and reaction control jets at the extremities, which are pressurized by compressor bleed air when the exhaust nozzles are lowered. The reaction controls are mechanically linked to the respective acrodynamic control surfaces. Aircraft attitude is controlled by the reaction control jets in hovering flight and by conventional aerodynamic surfaces in wing-borne Might. Both systems contribute to control during transition between wing- and propulsion-borne flight. Longitudinal control is through downward-blowing front and rear fusclage reaction control jets and an all-moving stabilator; lateral control is through wing-tip-mounted reaction jets that thrust up and down and outboard ailerons; and directional control is through a sideways-blowing reaction jet located in the aft fuselage extension and through the rudder. Hydraulically powered control surface actuators are integrated with an electronically controlled, limited-authority stability augmentation system that provides pitch- and roll-rate damping below 250 knots and yaw-rate damping only through the yaw RCS. 

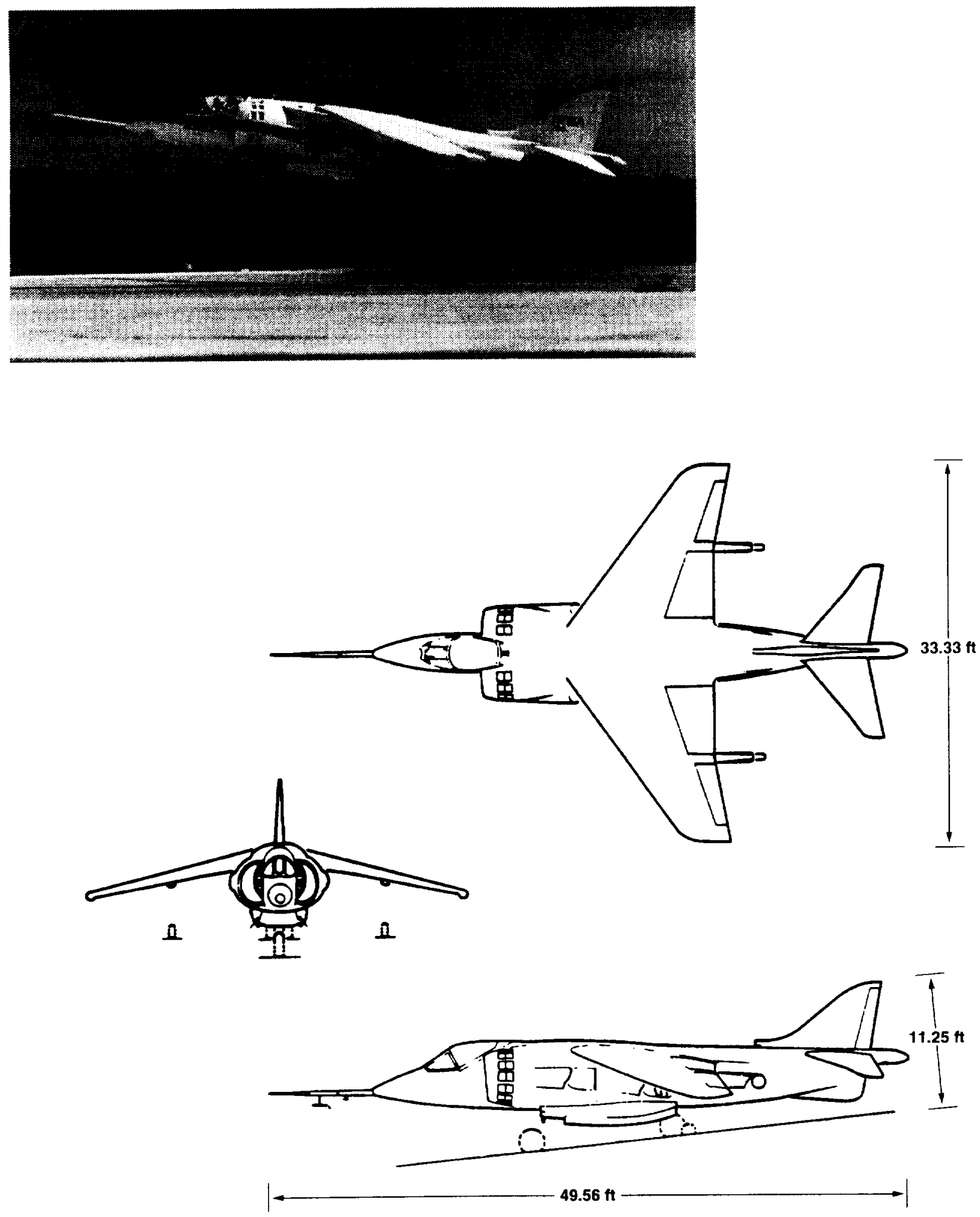

Figure 1. V/STOL Systems Research Aircraft (VSRA). 
The major components of the research system are indicated in the layout drawing and system architecture of figure 2. They consist of dual flight computers that contain sensor conditioning and state estimation, control, guidance, navigation, and display laws and response monitors; inertial navigation units (INUs) that are used to provide attitudes, body angular rates, linear velocities, and accelerations; radio altimeters; a differential Global Positioning System (GPS); a programmable symbol generator used to drive the HUD; a multipurpose display that provides for system command inputs as well as a moving map display; a servo control unit that provides monitoring and servo drive signals; production pitch, roll, and yaw series stability augmentation servos, pitch and roll trim servos, and limited-authority, high-rate series and full-authority, low-rate parallel servos to drive the throttle and nozzles. The HUD is a modified AV-8A production unit.

Control modes that were implemented in the Might computers for this experimental program are listed in table 1. The control laws are described in the appendix. The four configurations listed span control technologies that range from that of current generation operational V/STOL aircraft to the most advanced applications envisaged, based on the extensive simulation experience noted previously. As listed in table 1, their features are: Configuration 1-basic YAV-8B angular-rate damping; Configuration 2-pitch- and roll-attitude stabilization; Configuration 3-flightpath and longitudinal-acceleration command during transition combined with three-axis translational-rate command in hover; and Configuration 4-longitudinal-acceleration command during transition with translational-rate command in the horizontal plane and height-rate damping in hover. More specifically, in the first configuration, angular-rate damping is provided in pitch, roll, and yaw, with simple turn coordination and Dutch roll damping also available during transition. Thrust and thrust deflection are controlled manually through the aircraft's throttle and nozzle levers. For the second configuration, pitch-attitude command/attitude hold is available for transition and hover control modes. Roll-rate command/attitude hold is employed during transition, switching to attitude command/attitude hold in hover. The yaw axis provides turn coordination during transition and yaw-rate command in hover. Again, thrust and thrust deflection are controlled manually. For the third configuration, the pitch, roll, and yaw axes controls remain the same as for the second configuration during transition with the addition of flightpath and longitudinalacceleration command. In hover, pitch attitude can be adjusted through the pitch trim control. Otherwise, the translational-rate command provides for control of the longitudinal, lateral, and vertical axes. The fourth configuration is a variant of Configuration 3 , in which the vertical axis is simply direct thrust control during transition and incorporates a limited-authority series height-rate command in hover.

The cockpit layout of the aircraft is shown in figure 3 . The cockpit interface was dictated by the VSRA's singlecockpit configuration. For safe recovery from any research control system anomaly, the default configuration is the basic YAV-8B hydromechanical system. Therefore, it is necessary to retain the normal functioning of the stick, throttle, and nozzle lever, even when the research system is engaged. For this reason, in the case of Configuration 3, two thumbwheels were chosen as control inceptors for the longitudinal-acceleration and flightpath command response types and a proportional thumb controller was chosen for the translational-rate command response type. The longitudinal-acceleration command thumbwheel is mounted on the stick and has a zero detent but no centering; it is the inceptor of choice for this response type except that the preferred location would be on the throttle. The flightpath command thumbwheel with similar mechanical characteristics is mounted on the throttle and, when it is in use, the pilot must allow the throttle to be back driven as necessary by the flight control computers (FCCs). The use of a thumbwheel for flightpath command is a major compromise to accommodate the default constraints noted previously. Given design freedom, the inceptor of choice for flightpath command would be the throttle, since it best integrates the control of engine thrust in conventional flight with flightpath and vertical-velocity control in powered-lift operations. The proportional thumb controller functions like a joy stick in that it provides proportional control in two axes; it is mounted on the stick next to the trim button, has spring centering, and produces a velocity proportional to displacement in the direction of actuation. The use of this inceptor is also a compromise, as the preferred inceptor (indicated by considerable experience in simulation) would be the control stick itself. Configurations 1 and 2 were able to use the basic aircraft's stick, pedal, throttle, and nozzle inceptors for the attitude, thrust, and thrust-deflection control functions. Configuration 4 allowed for use of the throttle as the flightpath and vertical-velocity inceptor; the acceleration control thumbwheel was then relocated to the throttle handle. Thus these two inceptors were representative of an eventual operational configuration. A complete listing of the cockpit inceptor and response type pairings is presented in table 1 . 


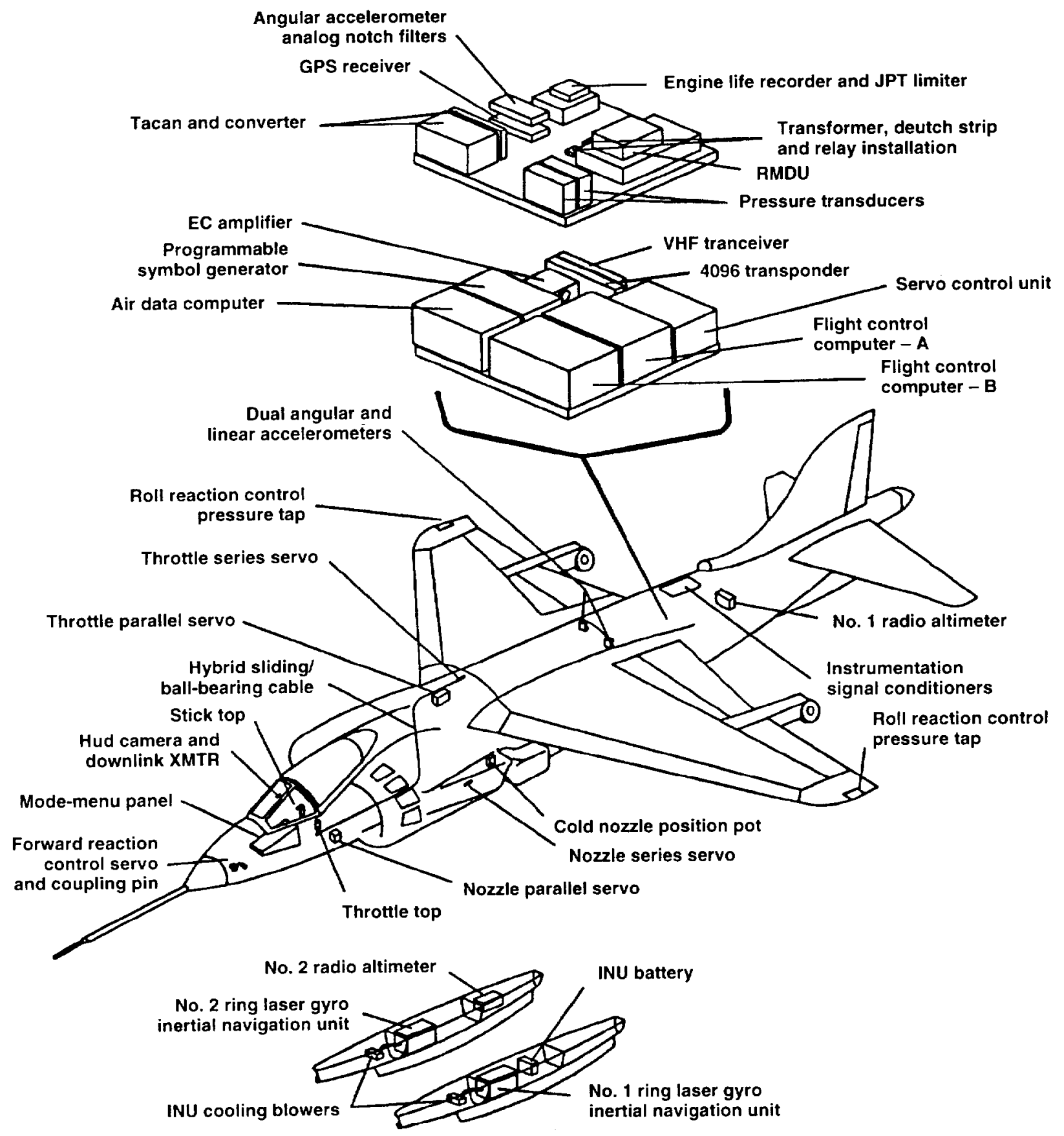

(a) System layout.

Figure 2. VSRA research system. 


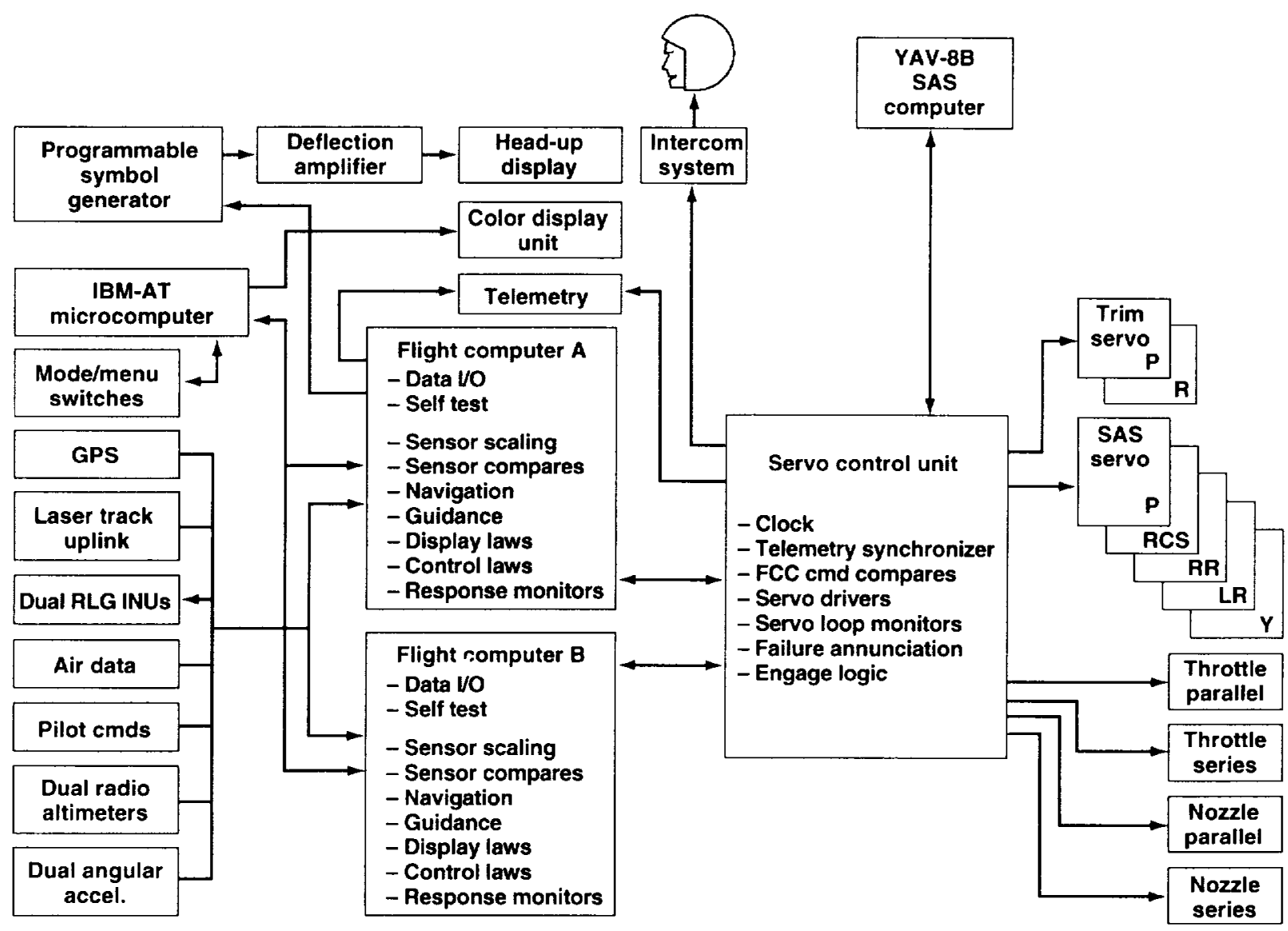

(b) System architecture.

Figure 2. Concluded. 
Table 1. Flight control modes

\begin{tabular}{|c|c|c|c|c|}
\hline \multirow[t]{2}{*}{ Inceptor } & \multicolumn{4}{|c|}{ Transition } \\
\hline & Configuration 1 & Configuration 2 & Configuration 3 & Configuration 4 \\
\hline Longitudinal stick & Pitch-rate damping & $\begin{array}{l}\text { Pitch-attitude } \\
\text { command/attitude } \\
\text { hold }\end{array}$ & N/A & $\begin{array}{l}\text { Pitch-attitude } \\
\text { command/attitude } \\
\text { hold }\end{array}$ \\
\hline Longitudinal trim & Trim rate & Pitch attitude & Pitch attitude & Pitch attitude \\
\hline Lateral stick & Roll-rate damping & $\begin{array}{l}\text { Roll-rate command/ } \\
\text { attitude hold }\end{array}$ & $\begin{array}{l}\text { Roll-rate command/ } \\
\text { attitude hold }\end{array}$ & $\begin{array}{l}\text { Roll-rate command/ } \\
\text { attitude hold }\end{array}$ \\
\hline Lateral trim & Trim rate & Roll attitude & Roll attitude & Roll attitude \\
\hline Pedals & Yaw damper & Yaw damper & Yaw damper & Yaw damper \\
\hline Throttle lever & Thrust magnitude & Thrust magnitude & N/A & Thrust magnitude \\
\hline Nozzle lever & Thrust deflection & Thrust deflection & $\mathrm{N} / \mathrm{A}$ & N/A \\
\hline Throttle thumbwheel & N/A & N/A & $\begin{array}{c}\text { Flightpath command } \\
\text { (vertical velocity } \\
\text { for } \mathrm{V}<60 \text { knots) }\end{array}$ & $\begin{array}{l}\text { Longitudinal- } \\
\text { acceleration } \\
\text { command/ } \\
\text { velocity hold }\end{array}$ \\
\hline Stick thumbwheel & N/A & N/A & $\begin{array}{l}\text { Longitudinal } \\
\text { acceleration } \\
\text { command/ } \\
\text { velocity hold }\end{array}$ & N/A \\
\hline $\begin{array}{l}\text { Proportional thumb } \\
\text { controller }\end{array}$ & N/A & N/A & N/A & N/A \\
\hline \multirow[t]{2}{*}{ Inceptor } & \multicolumn{4}{|c|}{ Hover } \\
\hline & Configuration 1 & Configuration 2 & Configuration 3 & Configuration 4 \\
\hline Longitudinal stick & Pitch-rate damping & $\begin{array}{l}\text { Pitch-attitude } \\
\text { command/attitude } \\
\text { hold }\end{array}$ & N/A & N/A \\
\hline Longitudinal trim & Trim rate & Pitch attitude & Pitch attitude & Pitch attitude \\
\hline Lateral stick & Roll-rate damping & $\begin{array}{l}\text { Roll-attitude } \\
\text { command/attitude } \\
\text { hold }\end{array}$ & $\begin{array}{l}\text { Roll-attitude } \\
\text { command/attitude } \\
\text { hold }\end{array}$ & $\begin{array}{l}\text { Roll-attitude } \\
\text { command/attitude } \\
\text { hold }\end{array}$ \\
\hline Lateral trim & Trim rate & Roll attitude & Roll attitude & Roll attitude \\
\hline Pedals & Yaw damper & Yaw-rate command & Yaw-rate command & Yaw-rate command \\
\hline Throttle lever & Thrust magnitude & Thrust magnitude & N/A & $\begin{array}{l}\text { Thrust with height- } \\
\text { rate damper }\end{array}$ \\
\hline Nozzle lever & Thrust deflection & Thrust deflection & $N / A$ & N/A \\
\hline Throttle thumbwheel & $\mathrm{N} / \mathrm{A}$ & N/A & $\begin{array}{l}\text { Vertical velocity } \\
\text { command/altitude } \\
\text { hold }\end{array}$ & $\mathrm{N} / \mathrm{A}$ \\
\hline Stick thumbwheel & N/A & N/A & $\mathrm{N} / \mathrm{A}$ & N/A \\
\hline $\begin{array}{l}\text { Proportional thumb } \\
\text { controller }\end{array}$ & $\mathrm{N} / \mathrm{A}$ & N/A & $\begin{array}{l}\text { Longitudinal-and } \\
\text { lateral-velocity } \\
\text { command }\end{array}$ & $\begin{array}{l}\text { Longitudinal-and } \\
\text { lateral-velocity } \\
\text { command }\end{array}$ \\
\hline
\end{tabular}




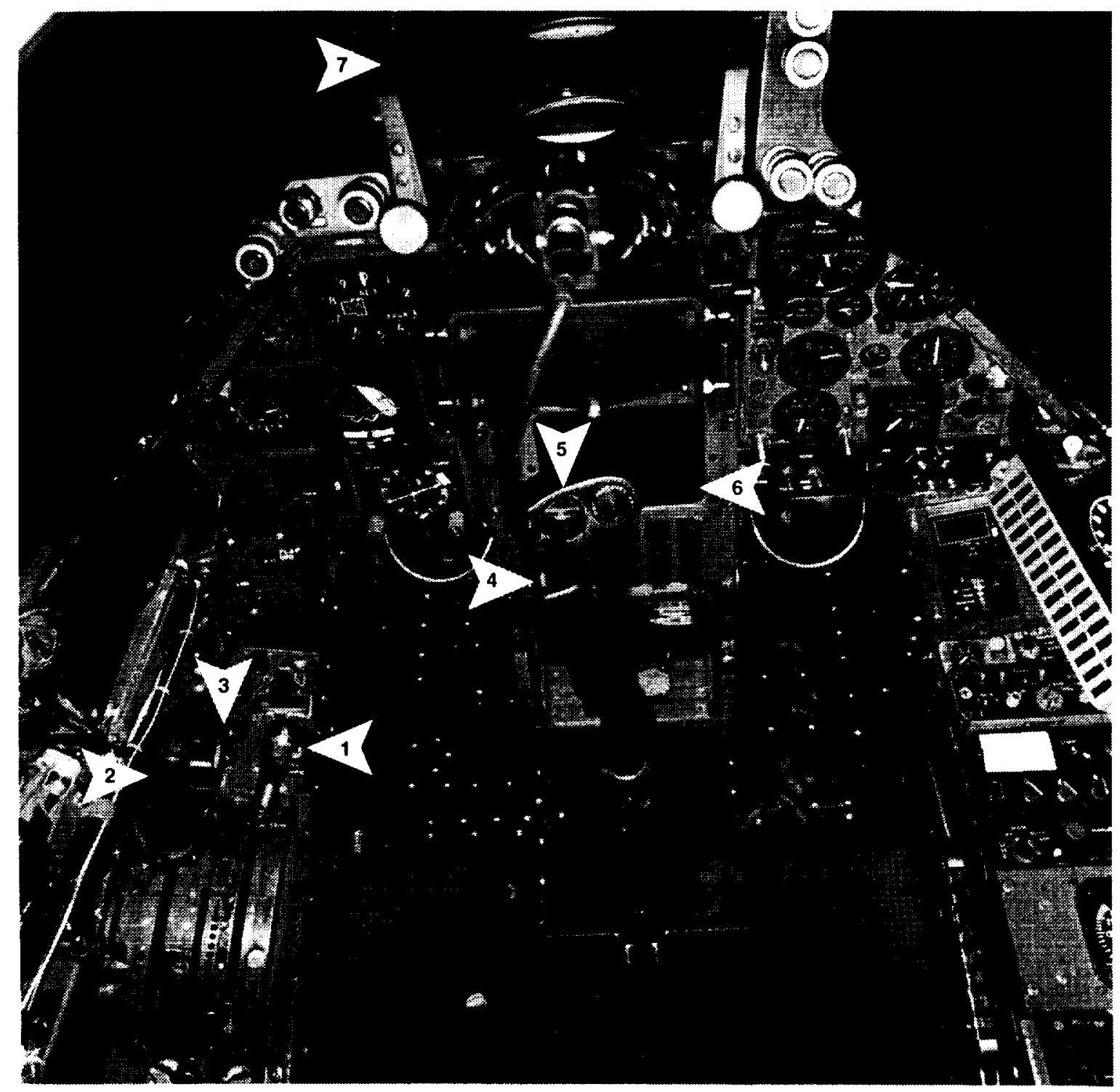

1. Nozzle handle

2. Throttle handle

3. Throttle thumbwheel

4. Stick thumbwheel

5. Proportional thumb controller

6. Control display unit

7. Head-up display

Figure 3. Cockpit layout. 
HUD modes are associated with the transition from conventional flight to hover and with the precision hover and vertical landing. They are tailored to the characteristics of the control mode selected by the pilot. References 9-12 present details of the design of the display formats and content. The two HUD modes are depicted in figure 4. For the transition phase (fig. 4(a)), the display is flightpath centered and presents the pilot with a pursuit tracking task for following the intended transition and approach guidance to a final hover point. Course and glideslope guidance are provided in the form of a leader (ghost) aircraft that follows the desired flight profile at a specified distance ahead of the VSRA. The pilot's task is to maneuver the VSRA's flightpath vertically and laterally to track the ghost aircraft, a task similar to a gunsight tracking task. Deceleration guidance is presented by an acceleration error ribbon on the left side of the flightpath symbol, which the pilot nulls to achieve the deceleration required to bring the aircraft to a hover at the initial hover station-keeping point. Situation information that accompanies the flightpath and ghost aircraft symbology includes aircraft attitude, barometric altitude (radar altitude below $400 \mathrm{ft}$ ), airspeed, reference angle of attack and angle-of-attack warning, engine rpm, jet pipe temperature (JPT), thrust vector angle, flap deflection, longitudinal acceleration, heading, distance to the hover point, and flight control mode annunciation.

During the latter stages of the deceleration, as the aircraft approaches the intended point of hover, selective changes are made to the approach display to provide guidance for the hover-point capture. Specifically, the longitudinalvelocity vector, predicted longitudinal velocity, and station-keeping cross appear referenced to the flightpath symbol (fig. 4(a)). The pilot controls the predicted velocity toward the position of the station-keeping cross and adjusts velocity to bring the cross to rest at the reference hover point (the point at which the cross is adjacent to the flightpath symbol). Once the aircraft is stabilized in this condition, the pilot is ready to perform the vertical landing.

For the vertical landing, the HUD format superimposes horizontal (plan) and vertical views and provides command and situation information in a pursuit tracking presentation (fig. 4(b)). The aircraft symbol, centrally located and fixed in the display, presents the relative locations of the landing gear and nose boom in plan view. Also in the plan view is the landing-pad symbol, representing a $40-\times 64-\mathrm{ft}$ landing area scaled in proportion to the landing gear of the aircraft symbol. The aircraft's horizontal-velocity vector is represented by a line emanating from the aircraft symbol. A horizontal-velocity predictor symbol indicates the magnitude and direction of the pilot's velocity commands. The pilot's task is to place the predicted velocity symbol over the intended hover position, typically the landing pad, and keep it there as the aircraft and pad symbols converge. The height of the aircraft above the landing pad is represented by the landing surface bar, which is displaced at a scaled vertical distance below the aircraft symbol. Predicted vertical velocity is displayed by a diamond, which is referenced to the right leg of the aircraft symbol and to a ribbon that represents the allowable range of sink rate. To maintain altitude, the pilot keeps the vertical-velocity diamond adjacent to the right leg of the aircraft symbol, indicating zero sink. To initiate the vertical landing and to maintain the desired closure rate to the pad, the pilot commands the diamond to the desired sink rate within the allowable limits. Attitude, radar altitude, airspeed, ground speed, distance to the hover point, engine rpm and JPT, thrust vector angle and flap deflection, heading, and verticalvelocity limits are provided as situation information.

\section{Flight Experiment}

The operational task for evaluation was a curved decelerating approach to hover, followed by a vertical landing on the landing pad (fig. 5) or by a slow landing on the runway. For evaluation purposes, the decelerating approaches were divided into two phases that reflect the principal aspects of the decelerating transition to hover as well as the precision instrument approach to decision height. The first phase was initiated on the downwind leg in level flight at pattern altitudes from 1000 to $1500 \mathrm{ft}$ at approximately $120 \mathrm{knots}$ in the powered approach configuration. This phase entailed capture of a 3-deg glideslope, initiation of a $0.1 \mathrm{~g}$ nominal deceleration, a left turn to base leg and then to align with the final approach course, and, on short final at a range of $1000 \mathrm{ft}$, a change in the nominal deceleration rate to $0.05 \mathrm{~g}$. Desired performance was defined as keeping the center of the ghost aircraft within the circular element of the flightpath symbol, with only momentary excursions permitted. Adequate performance was achieved when tracking excursions were significant, but not divergent. The initial phase of the approach was considered complete at the change in deceleration rate corresponding to the final closure to the hover point.

The second and final phase of the approach involved completion of the deceleration and acquisition of the hover point $50 \mathrm{ft}$ above the landing surface. This phase included an initial station-keeping hover $100 \mathrm{ft}$ to the right and $100 \mathrm{ft}$ aft of the landing spot. Desired performance was defined as acquisition of the hover with minimal overshoot and altitude control within $\pm 5 \mathrm{ft}$. Adequate performance was achieved when overshoot did not result in loss of the landing-pad symbol from the display field of 


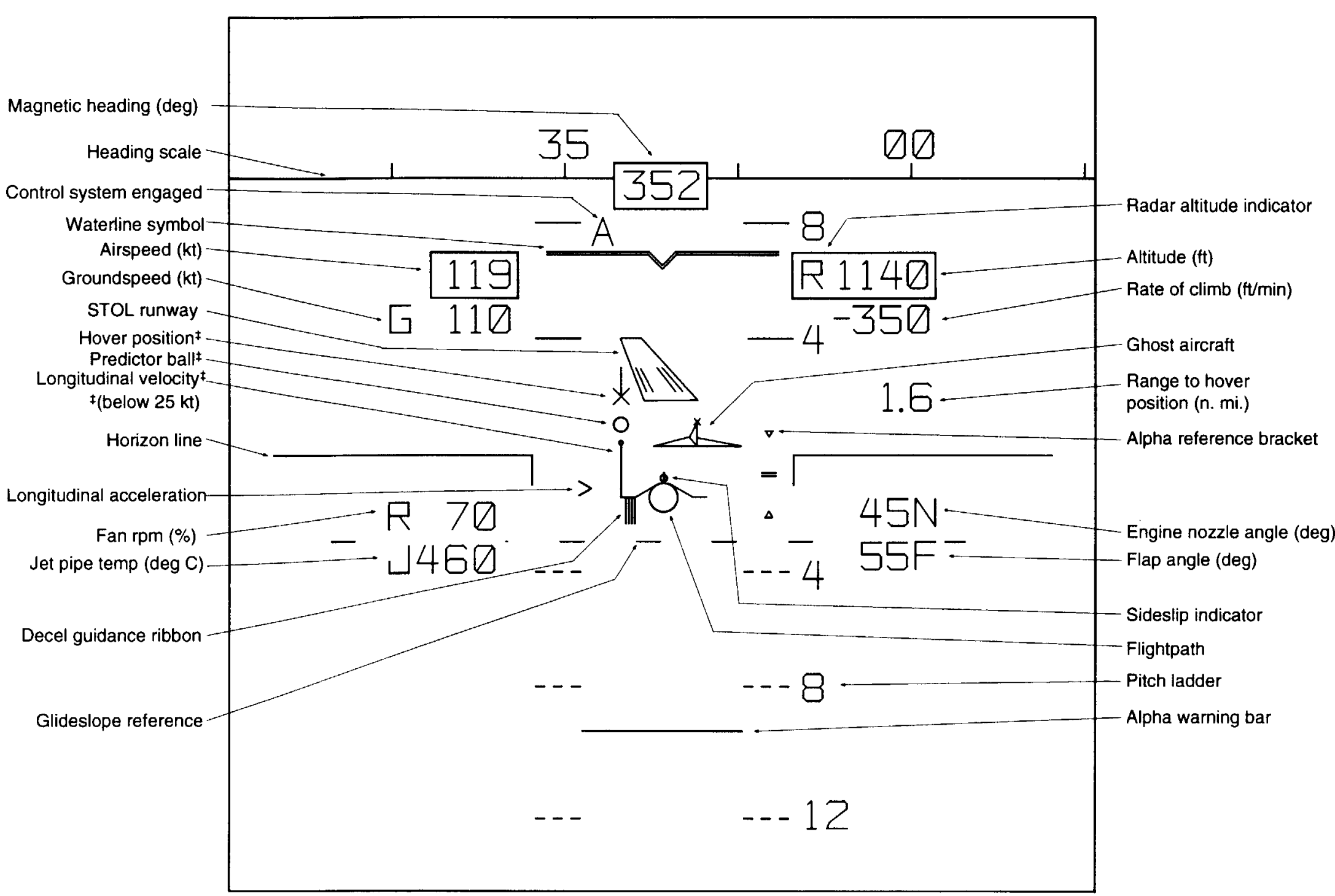

(a) Transition.

Figure 4. Head-up display formats. 


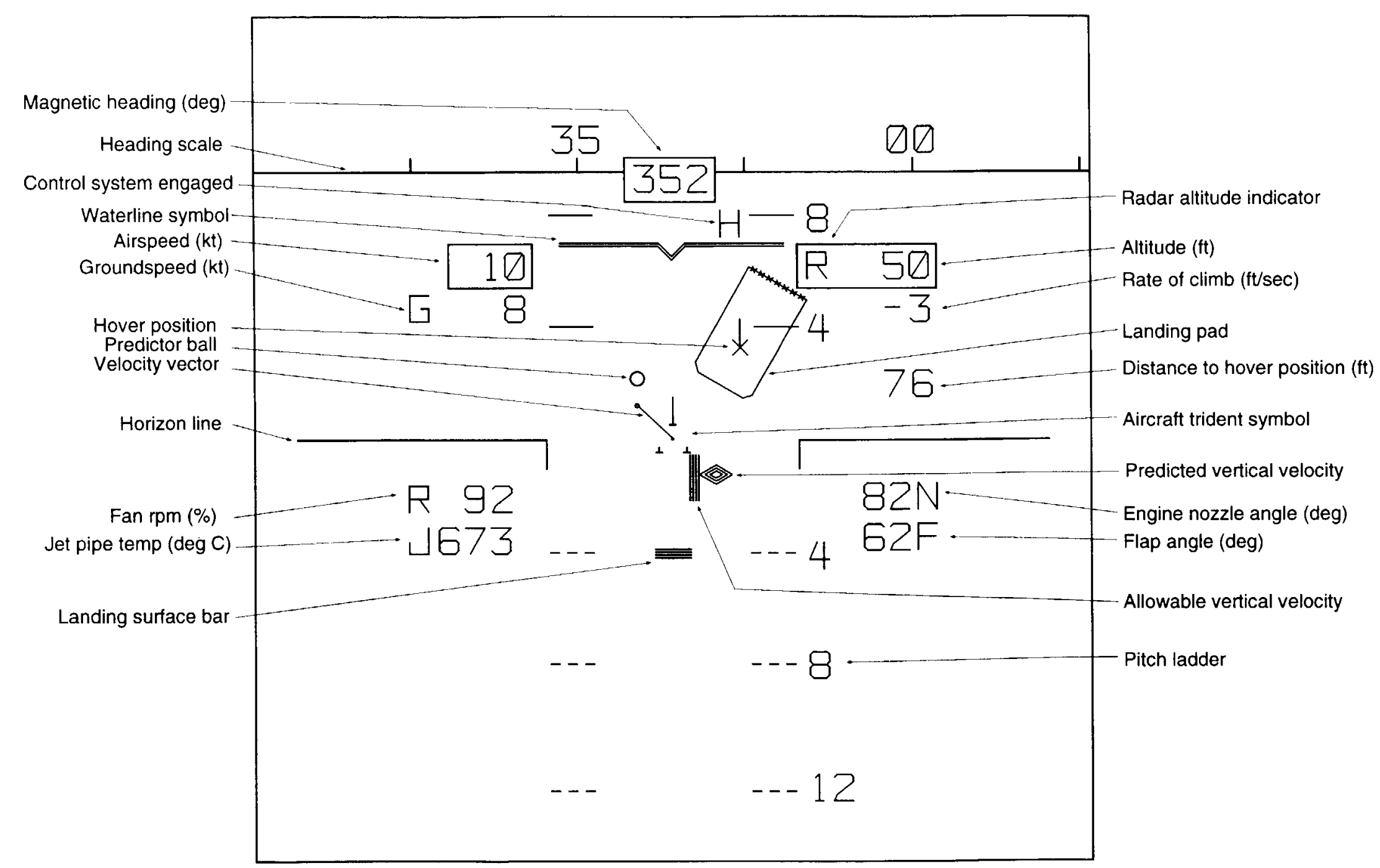

(b) Hover. 


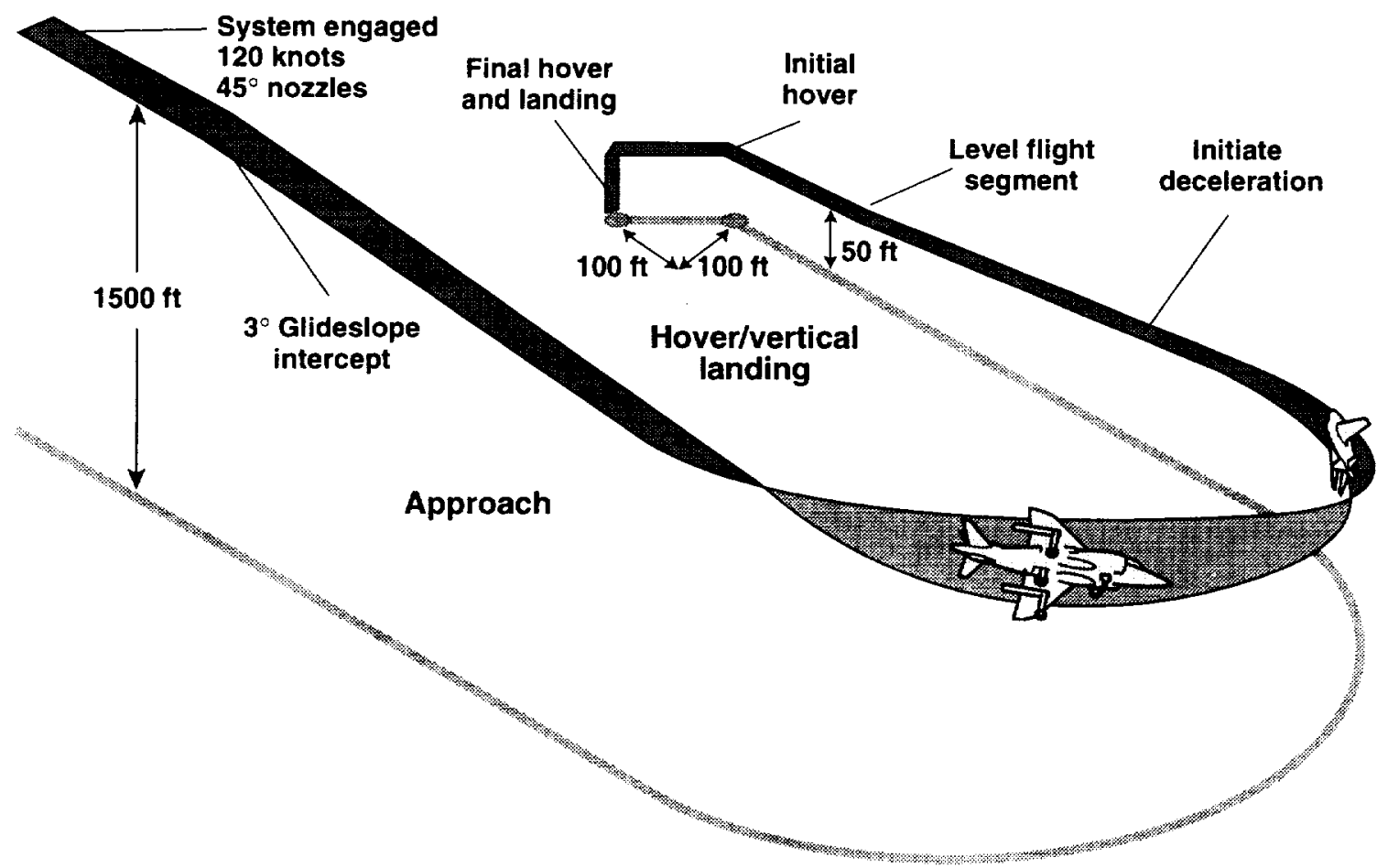

Figure 5. Approach profile.

view and the altitude control was safe. This segment was complete when a stable hover was established at the initial station-keeping point.

The vertical landing was initiated at the initial stationkeeping point with a constant altitude translation to a hover over a $40-\times 64-\mathrm{ft}$ landing pad marked on the taxiway, followed by a descent to touchdown on the pad. Desired landing performance was defined as touchdown within a 5-ft radius of the center of the pad with a sink rate of 3-5 ft/sec. Adequate performance was a touchdown within the confines of the pad at a sink rate less than $12 \mathrm{ft} / \mathrm{sec}$ and with minimal lateral drift.

Slow landings were performed under VMC to the main runway. Runs were initiated downwind in level flight in the landing pattern, as for the decelerating approach, and were flown to a visual aim point displaced approximately $1000 \mathrm{ft}$ from the runway threshold. Deceleration to the pilot's selected approach speed was performed in sufficient time to be stabilized on speed during the final straight-in segment of the approach. No guidance was provided by the ghost airplane on the HUD during the final segment; instead, the pilot aimed the flightpath symbol at the desired touchdown spot. This procedure presented a repeatable task from which touchdown precision could be determined. Desired performance was considered to be landing within $100 \mathrm{ft}$ of the aim point with a sink rate of 3-5 ft/sec. Adequate performance was defined as landing within $500 \mathrm{ft}$ at a sink rate no greater than $8 \mathrm{ft} / \mathrm{sec}$.

Five pilots with V/STOL and powered-lift aircraft experience performed as evaluation pilots in this experiment. Pilot ratings and comments were obtained, based on the Cooper-Harper scale (ref. 13). Detailed commentarics are provided in table 2 (p. 104). Time histories of data were processed in real time or post run to document the behavior of the aircraft and pilot performance.

The four configurations described in table 1 were used in the evaluations. These configurations were chosen to represent control and display technologies ranging from those of the AV-8B Harriers to response types providing direct command of aircraft response most directly associated with the task at hand. They can be generally defined as the basic YAV-8B SAS, the attitude command, the flightpath/acceleration and translational-rate command, and the acceleration command with height-rate damper and translational-rate command. Each configuration had a specific combination of transition and hover control modes. All operations were conducted under VMC in the winds and turbulence of the day. For the translational-rate command system, variations were made in the bandwidth of the longitudinal-, lateral-, and vertical-velocity controls by changing their individual forward-loop gains. Each of these system variants was evaluated for the hover positioning and vertical landing 
task to determine the boundary between satisfactory and adequate flying qualities for this task.

\section{Results}

Sixty-five flights were flown during the evaluation for the four configurations, including 120 decelerating approaches and 158 vertical landings. Operations generally occurred in light and variable winds with no significant turbulence component. On one occasion, noted in the following discussion, moderate winds and turbulence prevailed, providing an opportunity to assess the effects of significant disturbances on performance of the flightpath and acceleration command control mode.

Results of the flight experiments are presented first as pilot assessments of llying qualities in the form of Cooper-Harper pilot ratings and qualitative commentary supporting these ratings. Time historics of selected phases of the operation are used to illustrate task performance and activity of the individual controls. Implications of these results for control system and display design are covered in following subsections.

\section{Flying Qualities Assessment}

A discussion of results is presented for the individual segments of the approach and landing that were explained previously in the evaluation criteria, that is, the transition, hover-point acquisition, and vertical landing.

Transition- Results of the pilots' evaluations for the decelerating approach are presented in figure 6. Flying qualities for the basic YAV-8B with stability augmentation (Configuration 1) are only adequate, principally because of the workload associated with control of pitch attitude in the presence of trim changes with thrust and thrust deflection and with poor directional control. Workload during the initial stages of the approach was low, but it increased steadily as the aircraft decelerated and approached the initial hover point. With three control inceptors in the longitudinal axis (stick, throttle, and nozzle lever) and two hands available to operate them, the general strategy was to set the nozzle position open loop and then regulate pitch and throttle. This technique helped reduce the workload that would otherwise have been associated with continuous manipulation of thrust vector angle during the deceleration. Flightpath control was accomplished during the initial stages of the approach by changes in pitch attitude. When the aircraft is configured with the thrust deflected to the hover setting and the aircraft decelerates to speeds at which flightpath is not responsive to changes in pitch attitude, the throttle (thrust magnitude) becomes the primary flightpath or verticalvelocity controller. Pitch attitude was adjusted to follow the deceleration profile as presented to the pilot by the deceleration guidance ribbon on the HUD. Results of earlier simulation evaluations on the Ames Research Center's Vertical Motion Simulator (VMS; see refs. 2 and 11 ) of the basic YAV-8B for the transition task, shown by the vertical brackets on the figure, indicate an assessment of adequate flying qualities for the task similar to that obtained in the flight program.

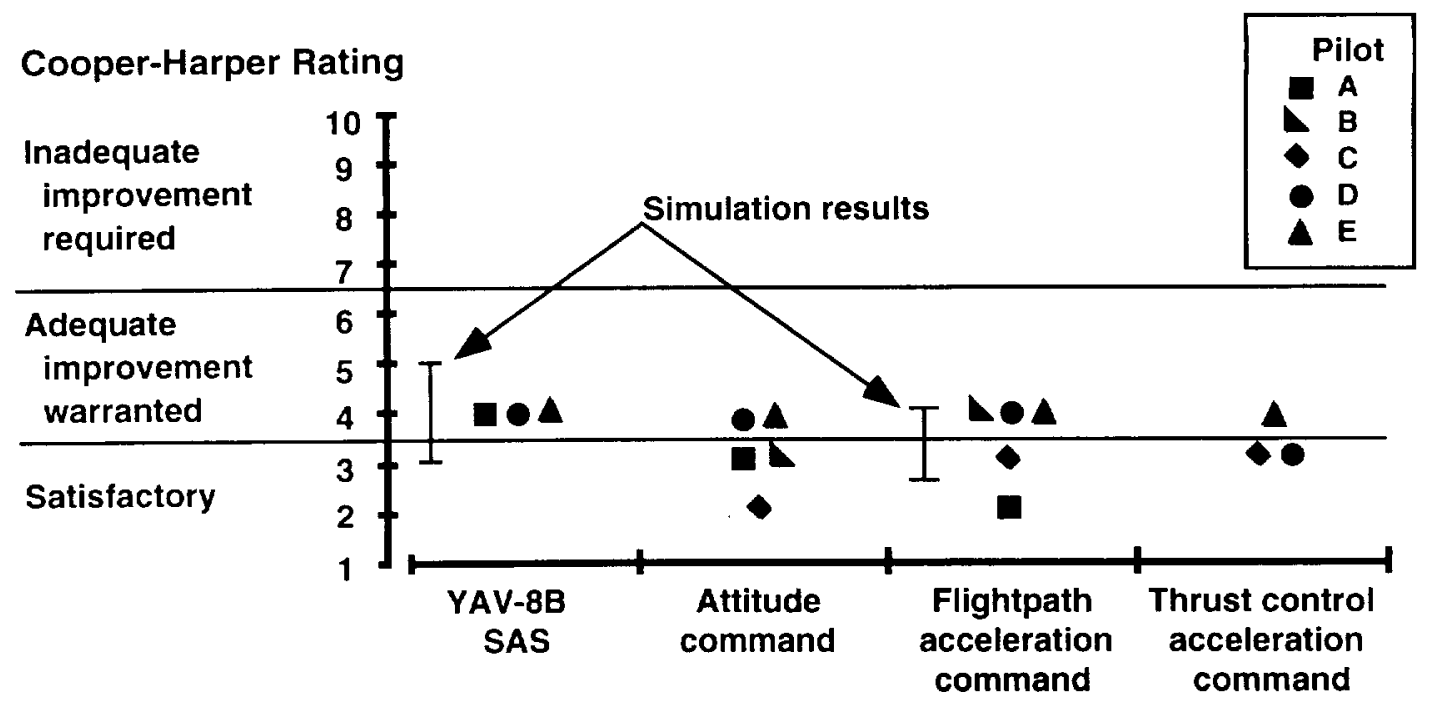

Figure 6. Pilot evaluations of the decelerating transition. 
Example time histories in figure 7 show the aircraft response and control effector behavior during the transition. The basic YAV-8B is typified by continuous throttle and stick inputs, oscillatory flightpath response, and frequent pitch-attitude perturbations. At the point the nozzle lever is moved to the hover stop, a large and continuous throttle advance to the hover setting is required as the aircraft decelerates. A large trim change accompanying the nozzle deflection and thrust increase is evident in the stick trace. Bank-angle control during the turn to final approach required continuous stick inputs with few rudder inputs until the latter stage of the approach, when the rudder was required for heading control at low speed.

When pitch and roll attitudes are stabilized (Configuration 2) by the attitude command system, flying qualities show some improvement. Favorable pilot comments reflected the improved stability of pitch attitude as a consequence of decoupling the pitch axis from the controls used for flightpath and deceleration. Other comments indicated an improved ability to follow the deceleration profile. Otherwise, control of flightpath with pitch or throttle and deceleration with thrust deflection and pitch attitude were similar to Configuration 1. For both the YAV-8B SAS and the attitude command system, significant attention to flightpath control and compensatory throttle inputs was required to compensate for heave disturbances when the thrust vector was deflected initially, and for the lift loss that occurs during the final phase of deceleration. Consistent with current AV-8 operational limitations, these characteristics would not permit decelerating approaches to be made in IMC.

As can be seen in figure 8 , Configuration 2 required less continuous stick activity other than occasional trimming when the nozzle was deflected or thrust was increased. Commanded changes in pitch attitude are evident toward the end of the approach to control the deceleration to hover. Throttle activity is similar to that for the YAV-8B SAS, including large continuous thrust changes throughout the deceleration. Pitch attitude and flightpath are noticeably more steady than for the YAV-8B SAS shown in figure 7. Control of the lateral-directional axes was comparable to that for the YAV-8B SAS.

When flightpath and longitudinal-acceleration command were employed (Configuration 3), the pilots' ratings were still borderline satisfactory/adequate as a consequence of objectionable wandering in the flightpath response early in the approach (100-120 knots) and deficiencies in the thumbwheel inceptors. This flightpath wandering is attributed to hysteresis in the nozzle control system $( \pm 4.5 \mathrm{deg})$. Nozzle variations within the hysteresis band, accompanied by variations in flap position through the nozzle-flap interconnect, were sufficient to induce coupling with the thrust control. This coupling introduced perturbations in flightpath that prevented achievement of the desired tracking performance. Pitch trim was also continuously active to counter the trim changes due to variations in thrust and thrust deflection. Ratings for approach-path tracking at constant speed prior to the deceleration were only adequate. Some pilots chose to ignore this behavior, once its cause was understood, and instead concentrated on achieving the most precise tracking during the latter stage of the approach. This stage consisted of the deceleration and descent to the nominal decision height of $100 \mathrm{ft}$, followed by capture of the hover altitude and the final deceleration to the hover. By this point, nozzle deflection had increased such that the hysteresis diminished significantly and the flaps reached their final setting of $62 \mathrm{deg}$. It was possible to achieve the desired tracking performance with minimal workload. Flightpath control was considered satisfactory for this final stage. Flightpath control was considered satisfactory also for the case of moderate wind and turbulence (15-knot winds with 3-ft/sec root mean square (rms) gusts). Decoupling of flightpath control from control of the deceleration was a major factor in workload reduction. Further, the HUD offered excellent path guidance for the curved approach through the ghost aircraft and also provided effective commands for the deceleration to hover. Pilots consistently noted the ease of tracking the ghost aircraft throughout the approach and the essentially open-loop nature of the deceleration.

The mechanical characteristics and the sensitivities of both of the thumbwheels were issues for most of the pilots. The stick thumbwheel appeared to be too sensitive in the airspeed range of 110-120 knots and then very noticeably undersensitive as the aircraft decelerated below 110 knots. The throttle thumbwheel was flush in its mounting, providing poor feel, which made small, precise inputs difficult. The throttle thumbwheel was also too sensitive in the 110-120-knots range, adequate below 110 knots, and far too low at hover. Were it not for these mechanical deficiencies and the opinion that the throttle thumbwheel was not the desired choice for flightpath control, the decelerating transition would have been raled satisfactory by the pilots. Results from the earlier simulations also reflect the borderline satisfactory' adequate ratings observed in these flight tests.

Representative time histories for Configuration 3 are presented in figure 9. They are characterized by an initial oscillatory flightpath response, then by precise tracking of the ghost aircraft and a smooth and continuous deceleration. Corrections with the throttle and stick thumbwheels for control of flightpath and deceleration were small and infrequent. The low workload is evident in the infrequent 

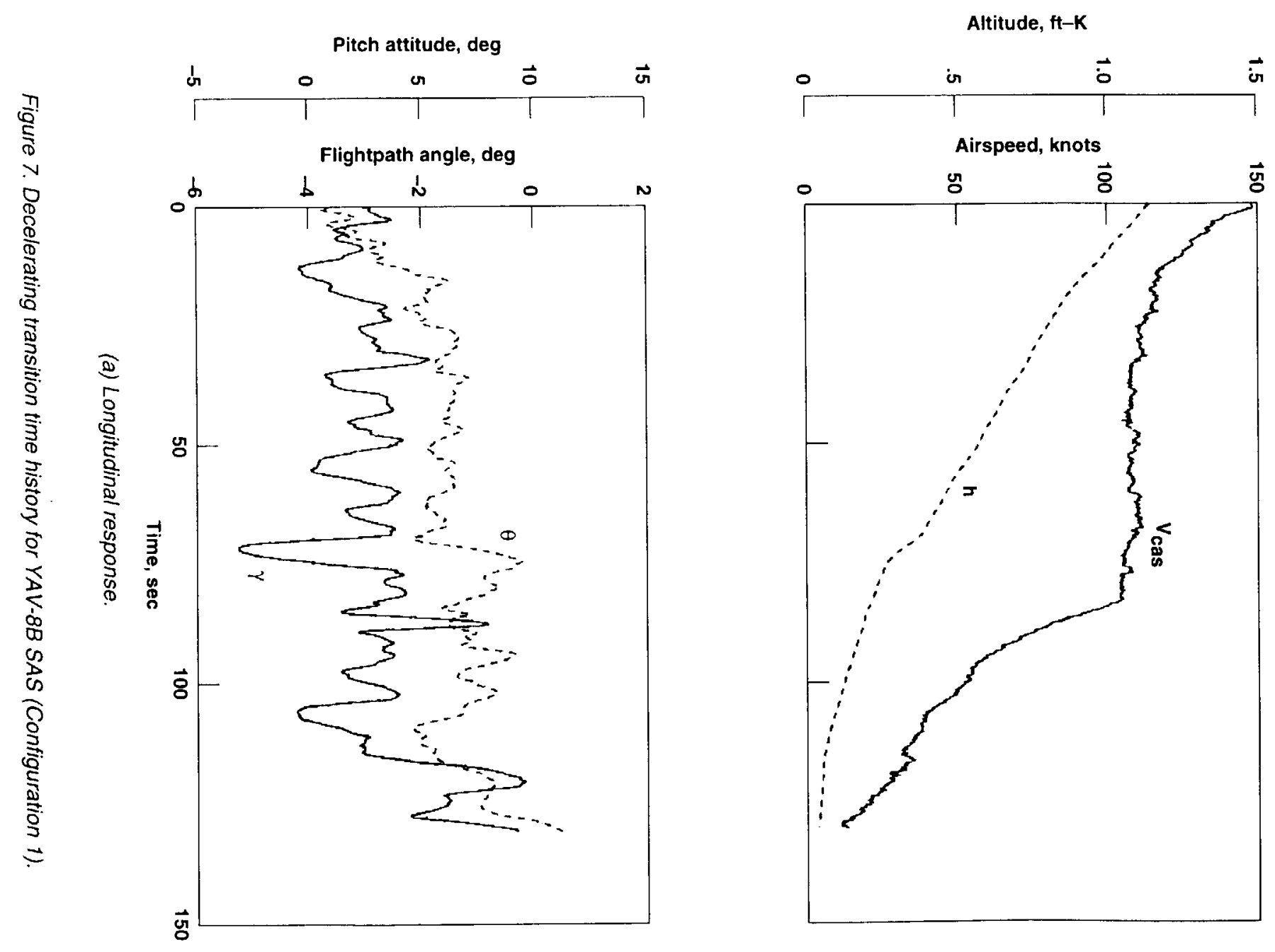

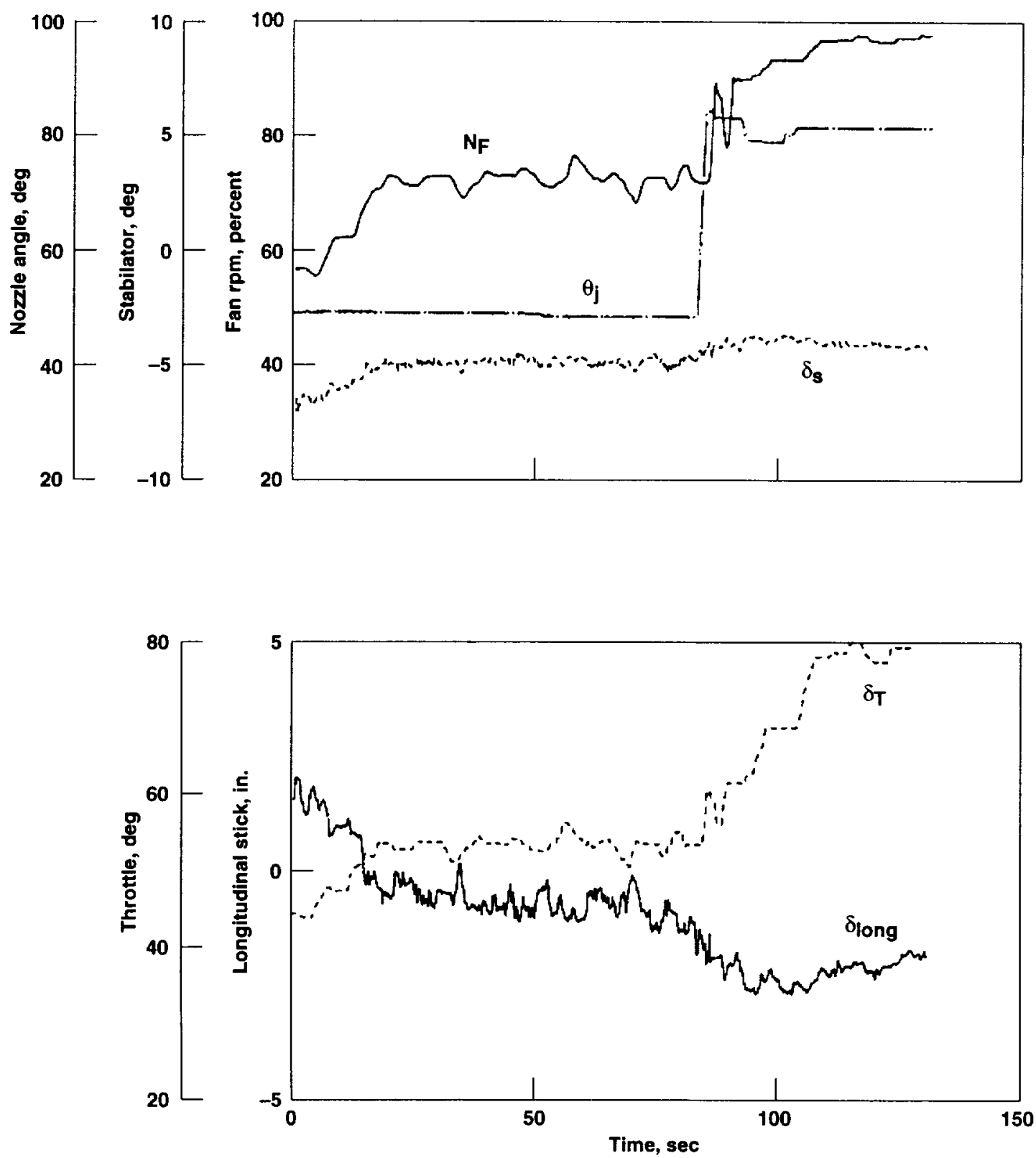

(b) Longitudinal inceptors and control effectors.

Figure 7. Continued. 

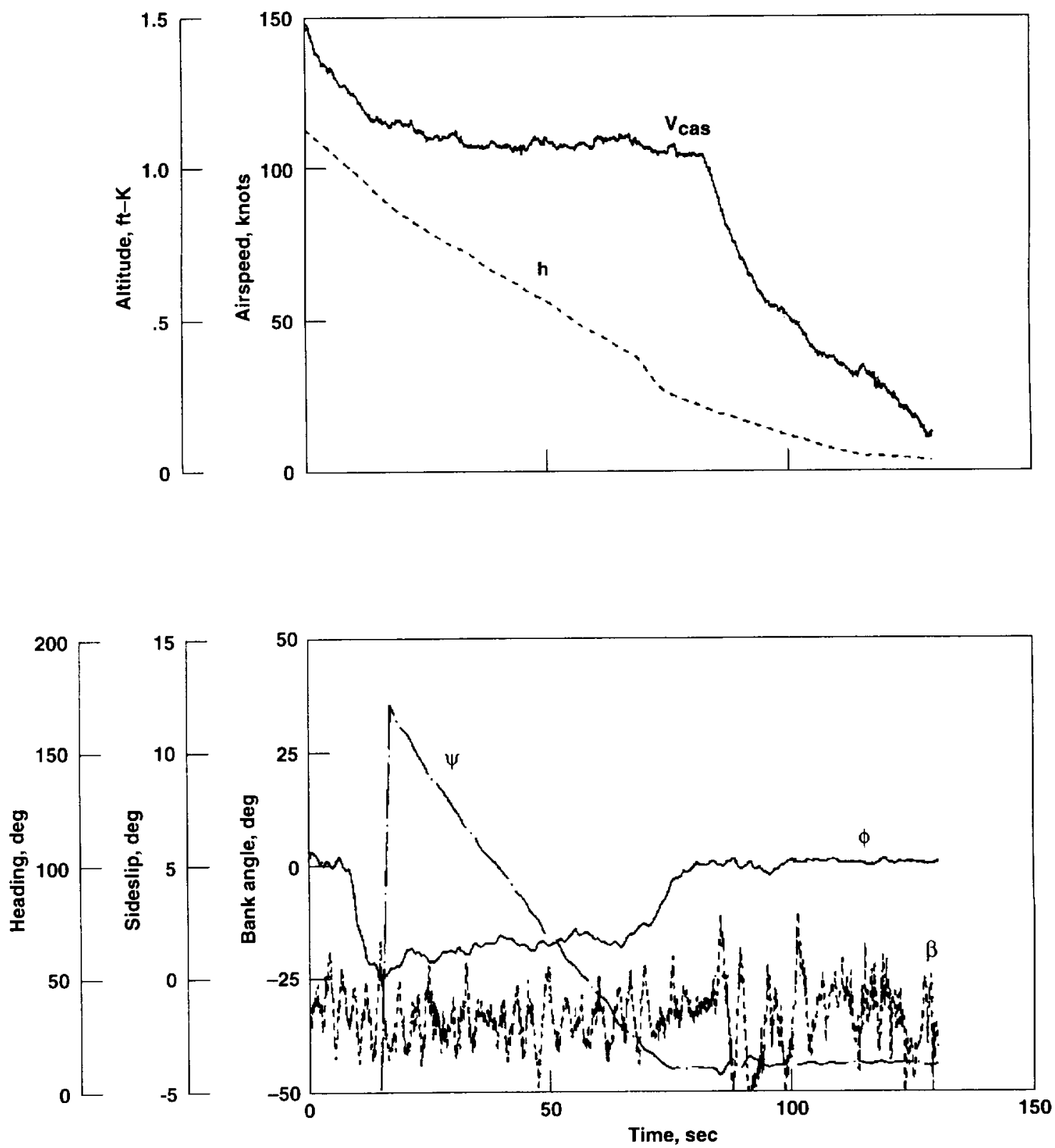

(c) Lateral-directional response.

Figure 7. Continued. 

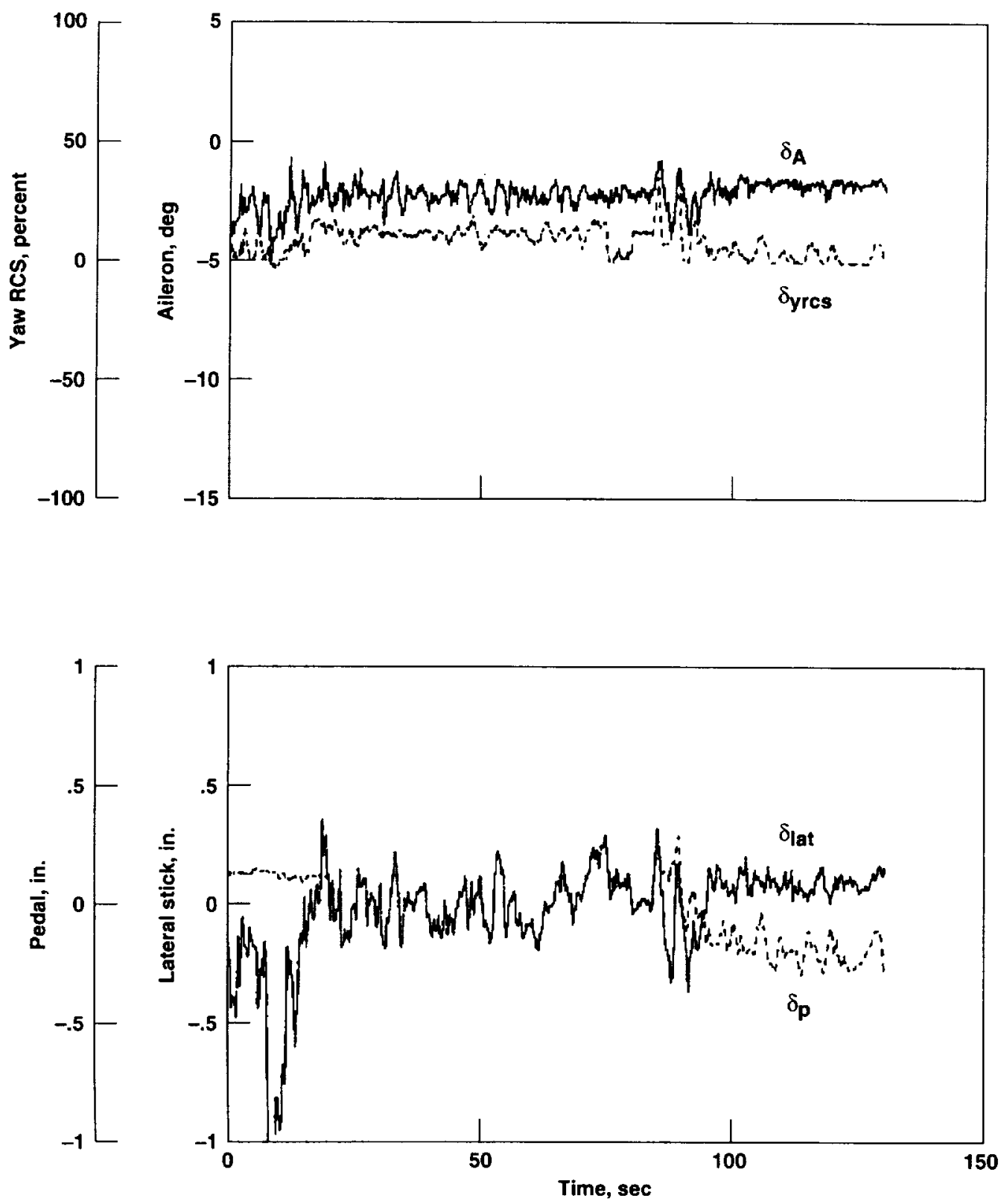

(d) Lateral-directional inceptors and control effectors.

Figure 7. Concluded. 

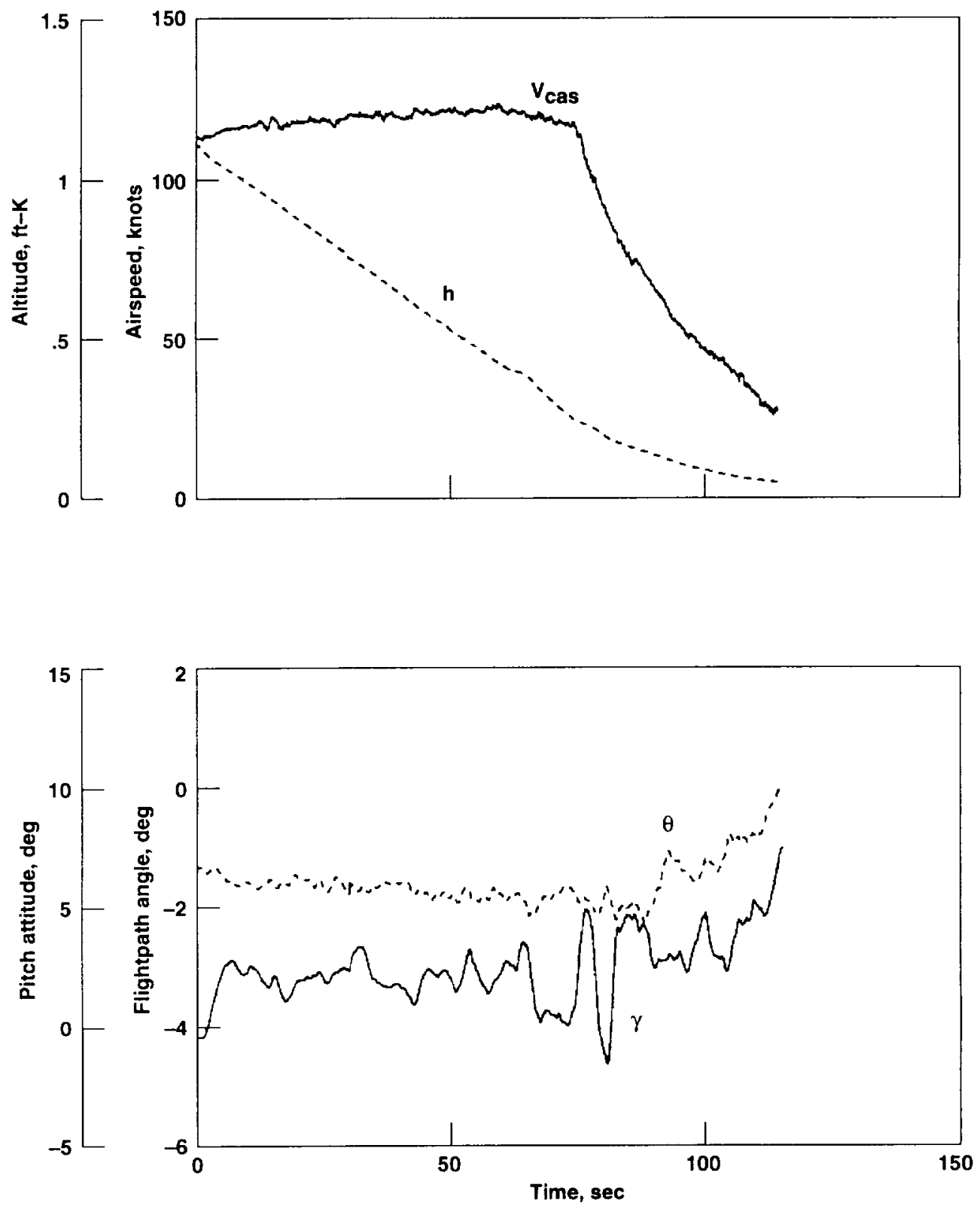

(a) Longitudinal response.

Figure 8. Decelerating transition time history for attitude command (Configuration 2). 

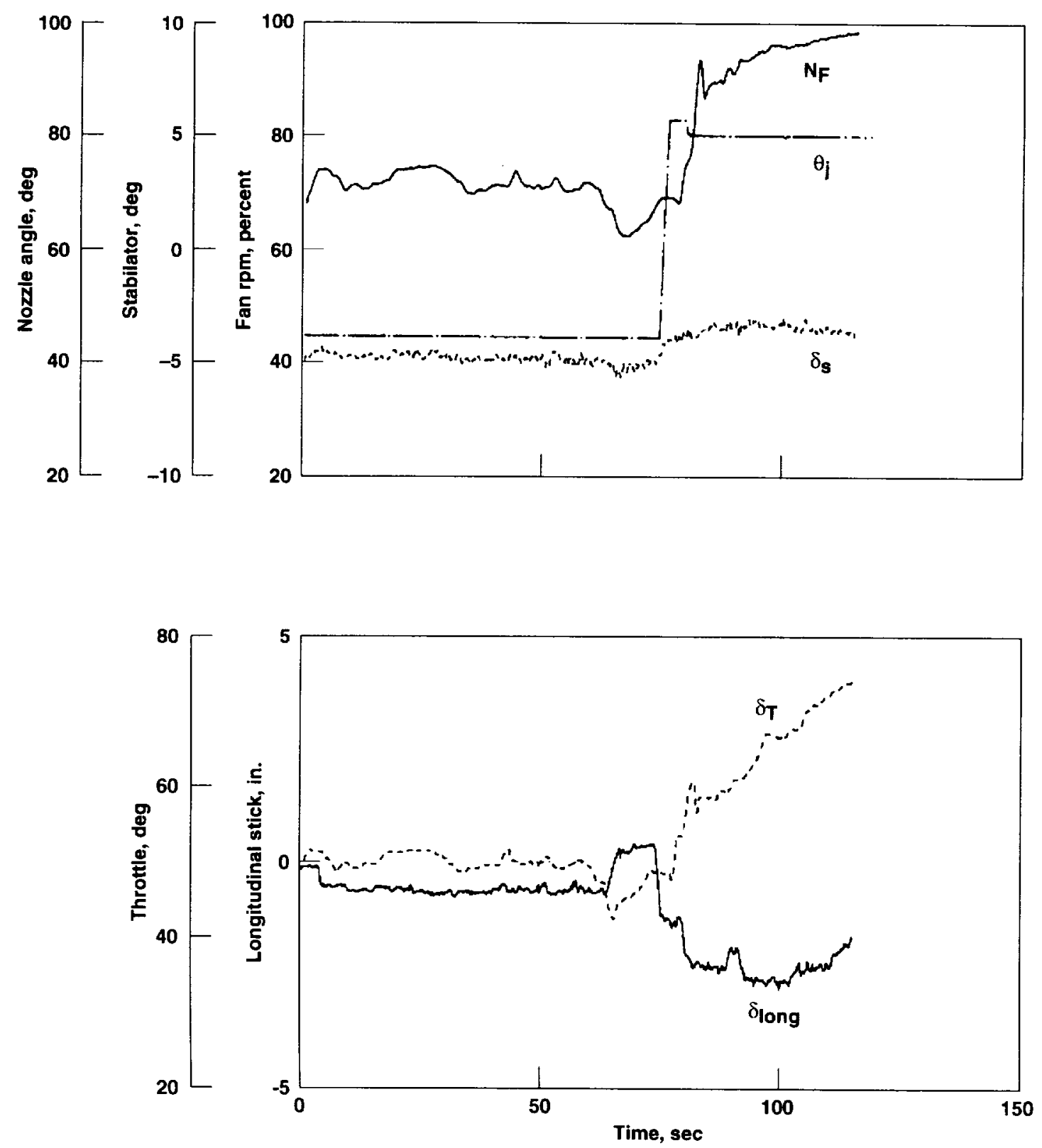

(b) Longitudinal inceptors and control effectors.

Figure 8. Continued. 

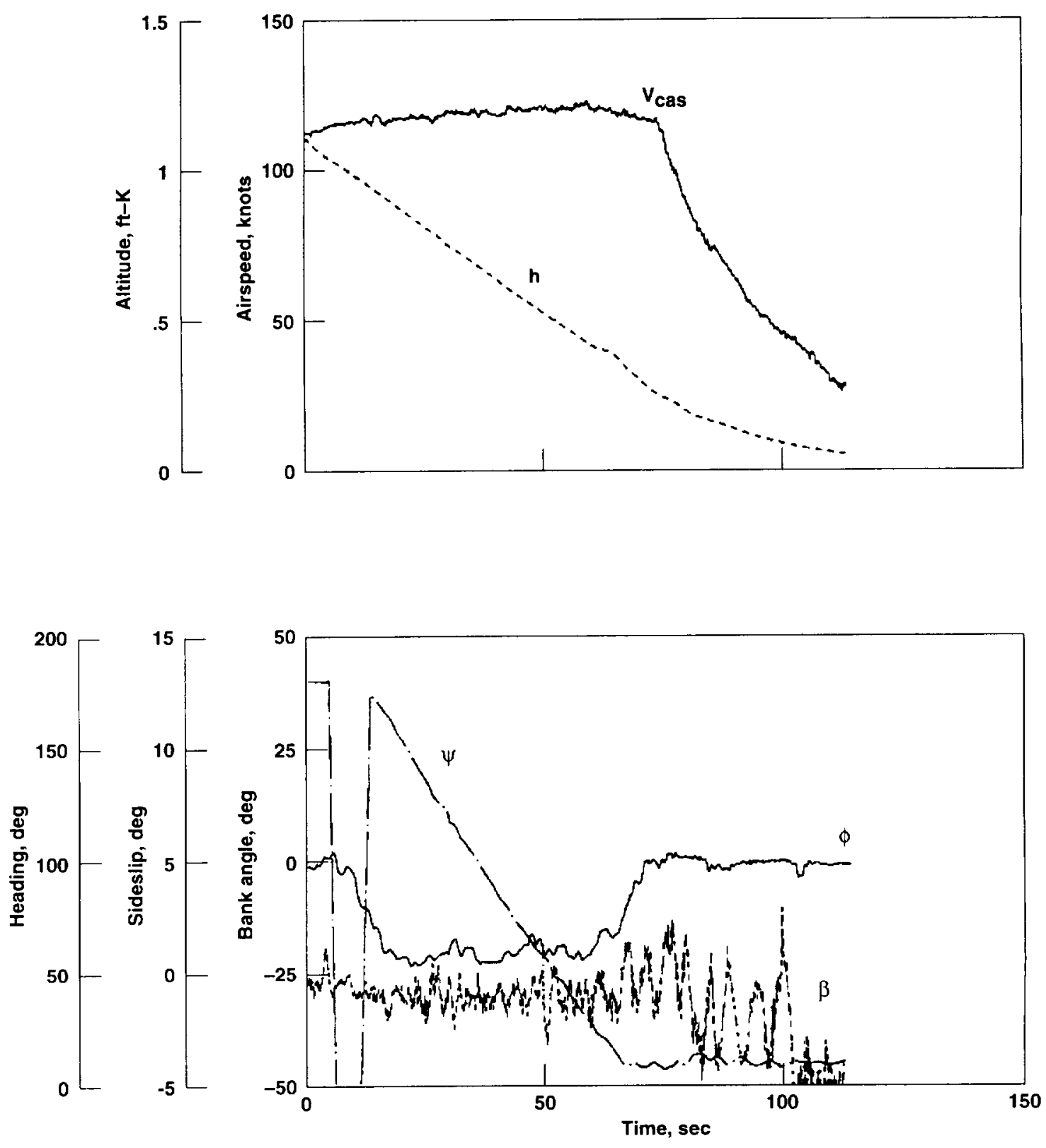

(c) Lateral-directional response.

Figure 8. Continued. 

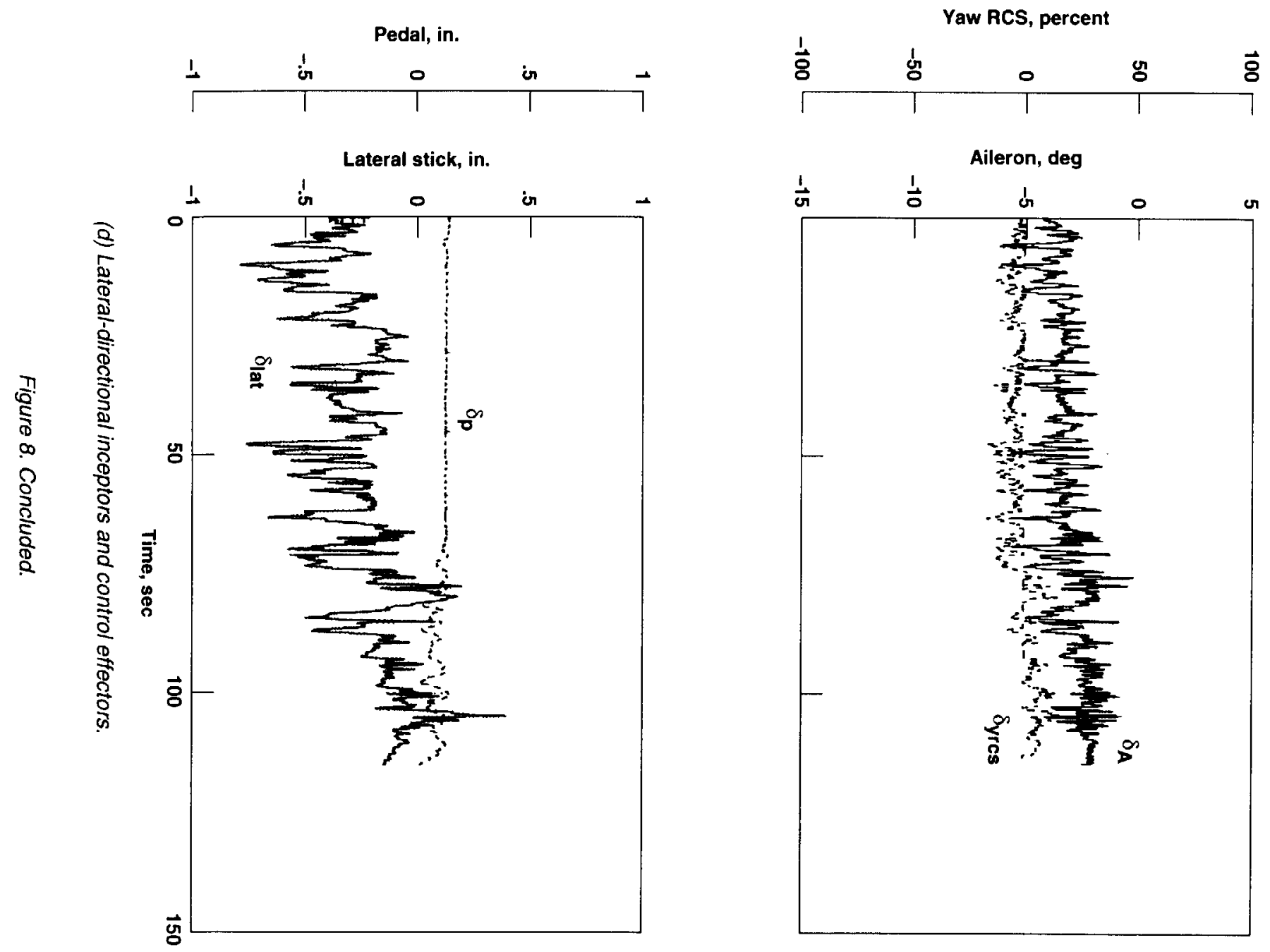

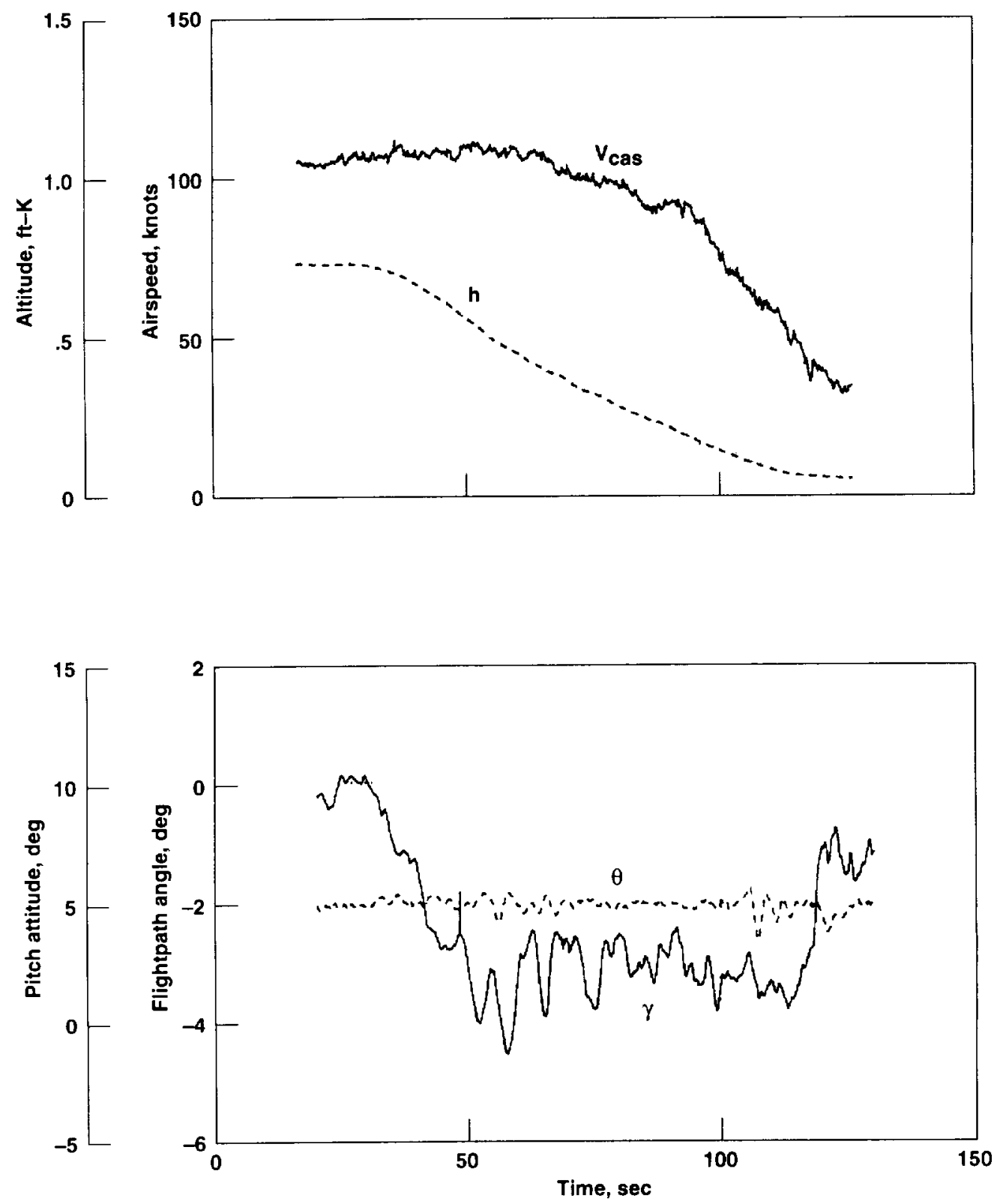

(a) Longitudinal response.

Figure 9. Decelerating transition time history for flightpath/acceleration command (Configuration 3). 

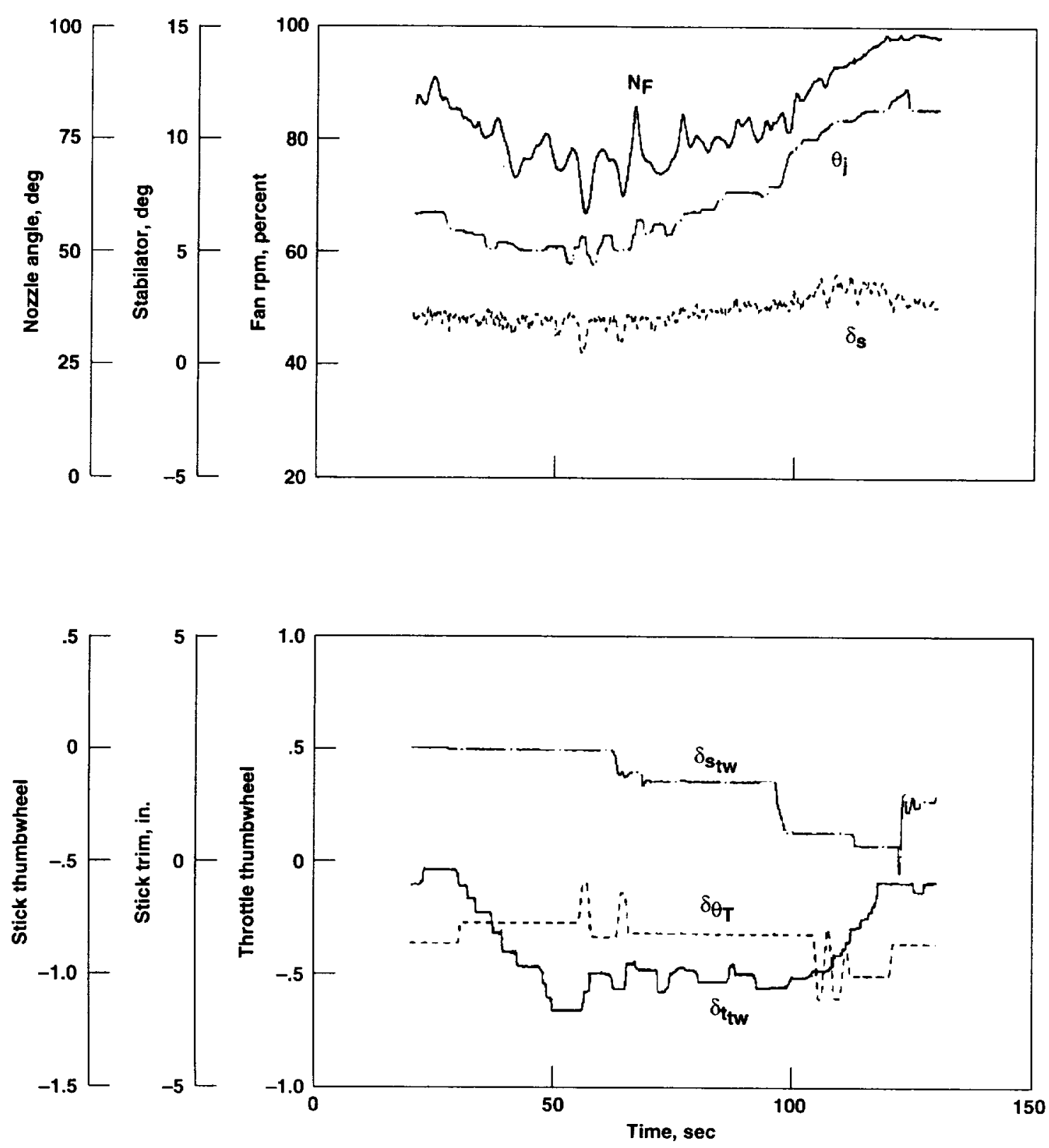

(b) Longitudinal inceptors and control effectors.

Figure 9. Continued. 

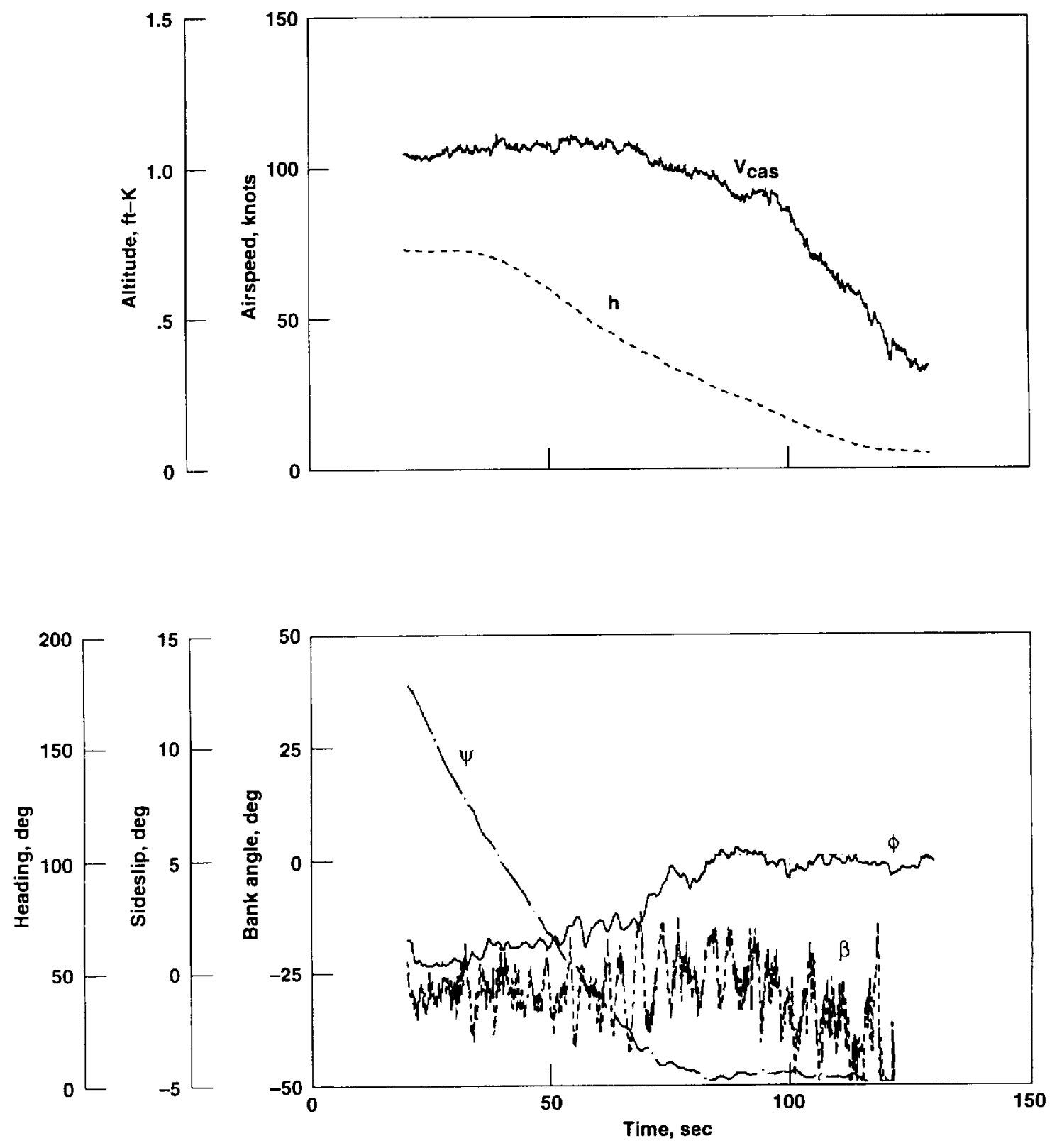

(c) Lateral-directional response.

Figure 9. Continued. 

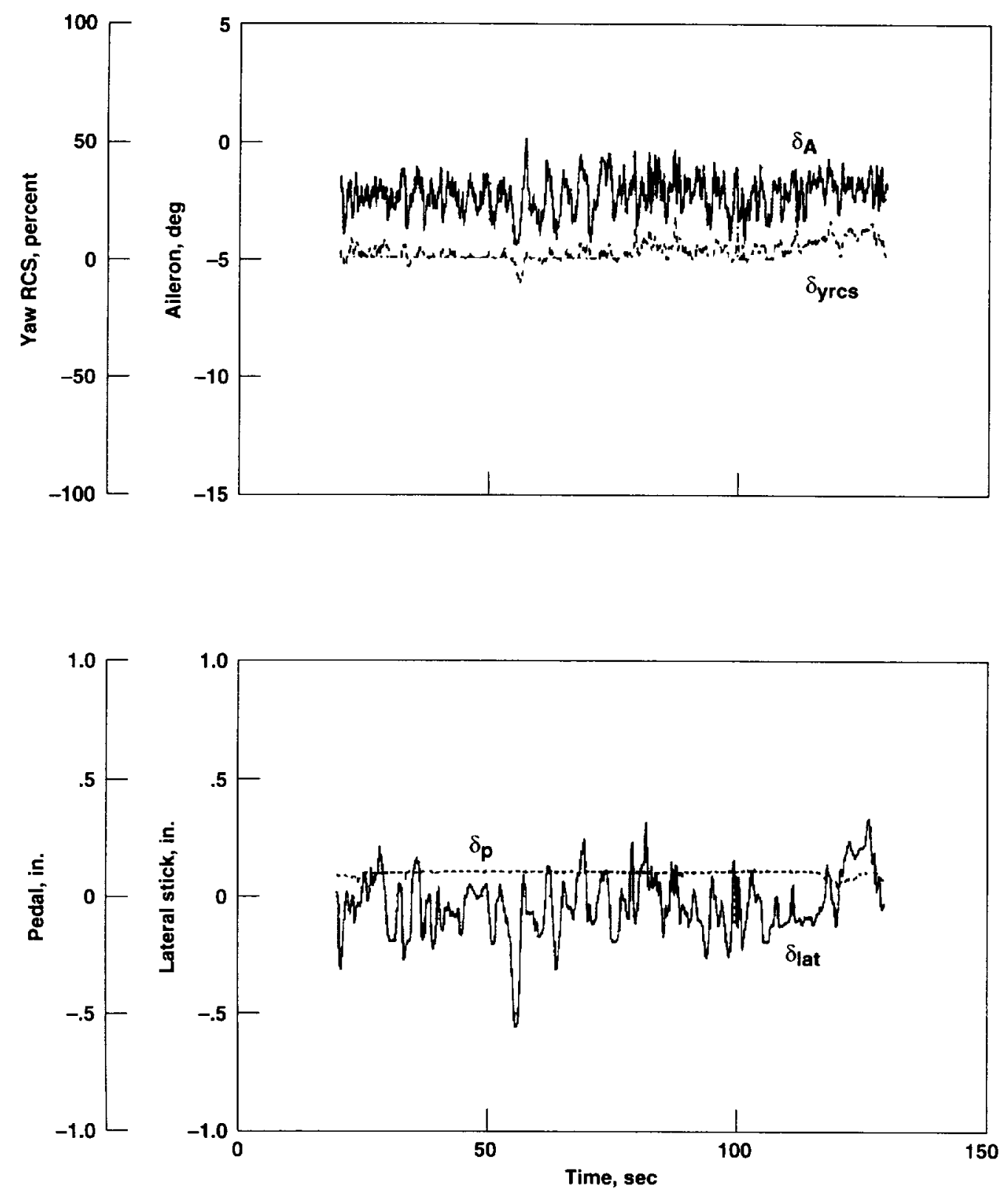

(d) Lateral-directional inceptors and control effectors.

Figure 9. Continued. 


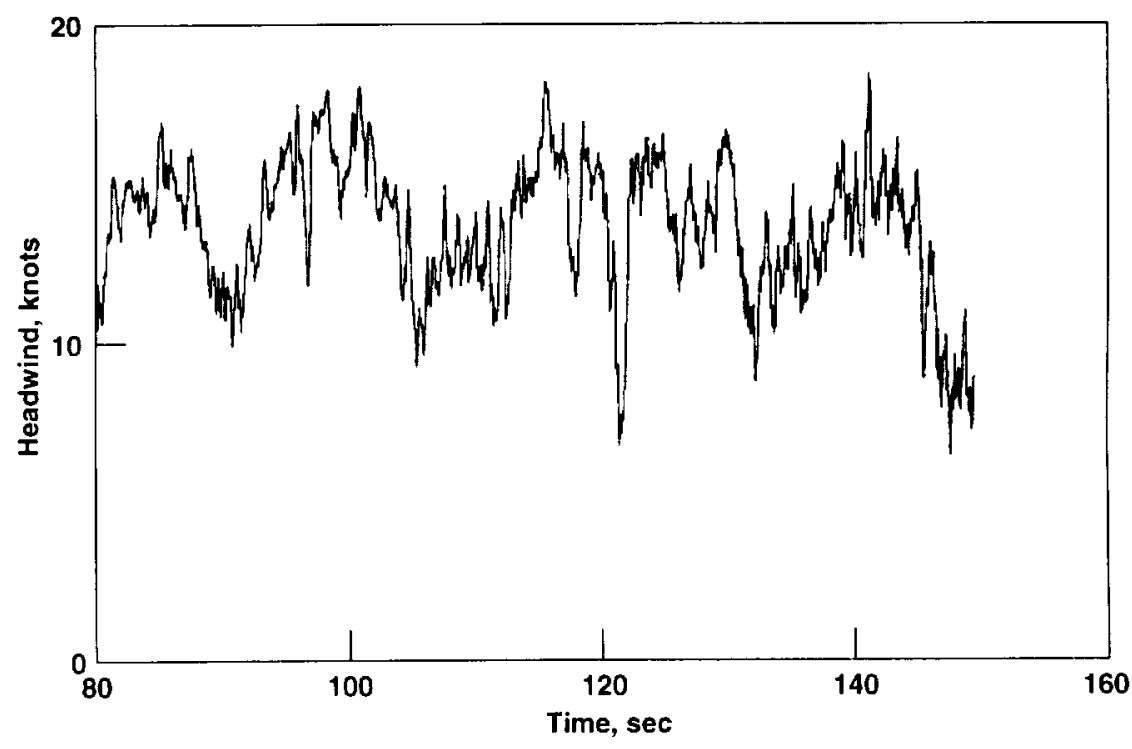

(e) Head-wind component.

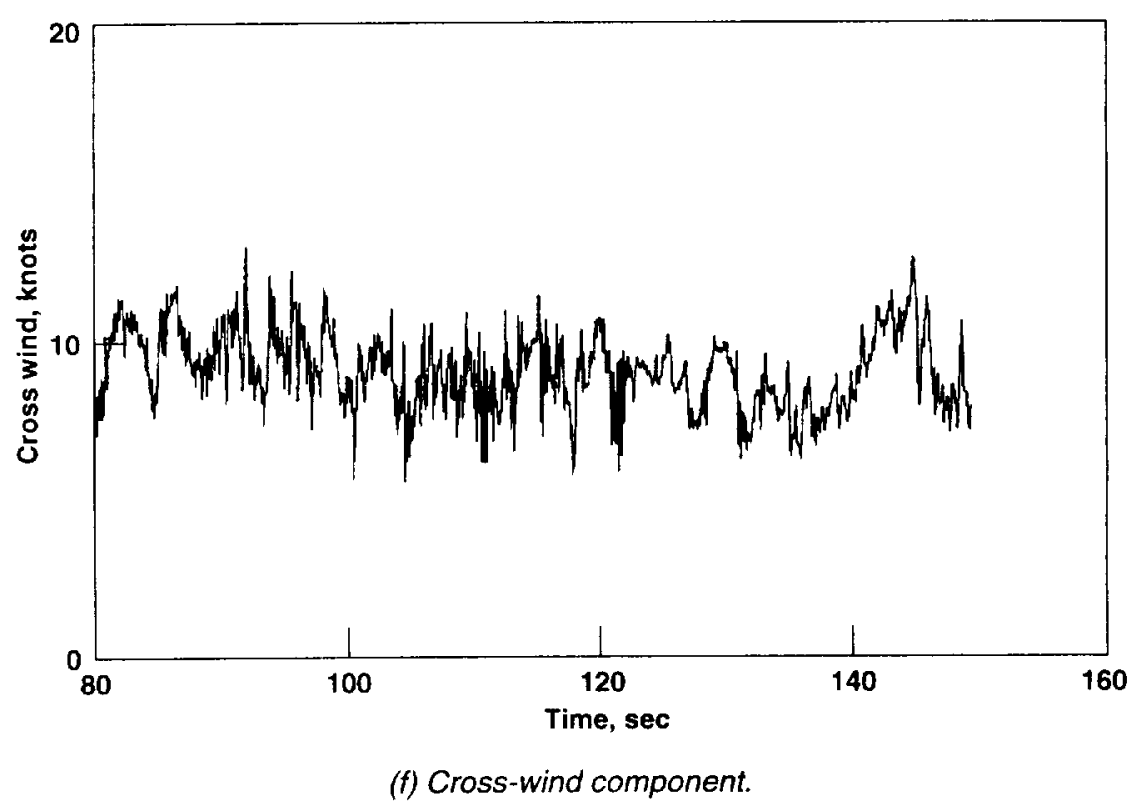

Figure 9. Continued. 


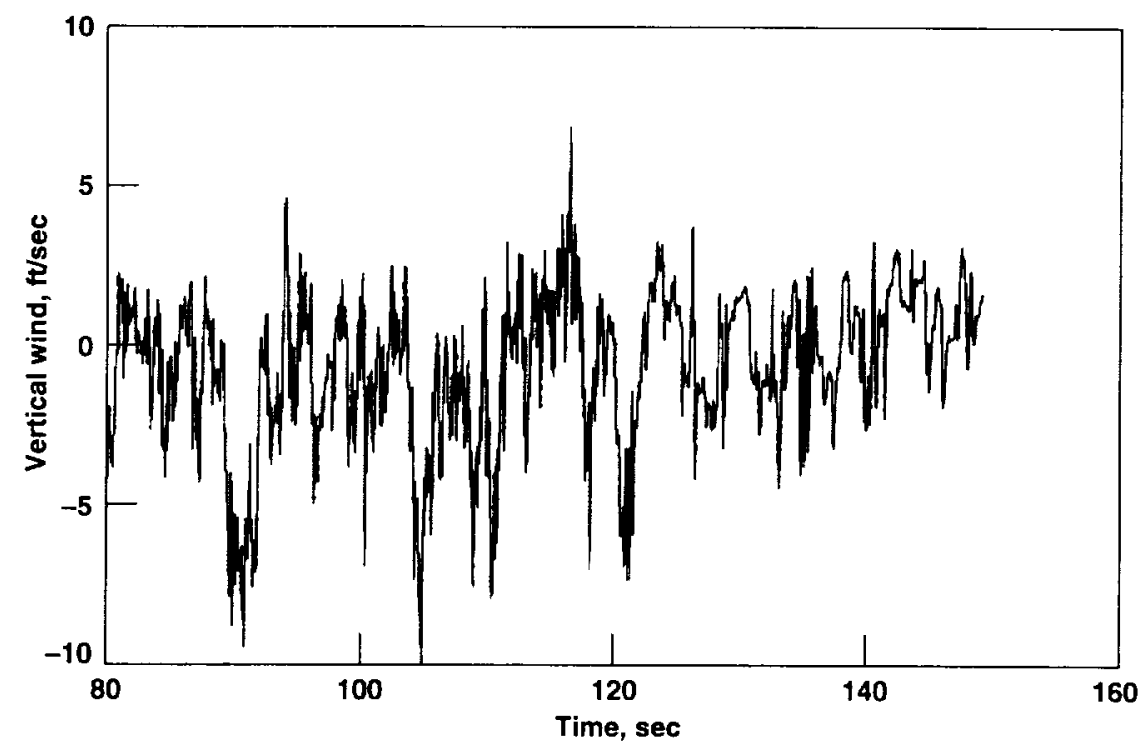

(g) Vertical-wind component.

Figure 9. Concluded.

command inputs and the stable pitch attitude. The smooth decrease in speed and altitude support the pilot commentary regarding high precision. This combination of low workload and high precision would enable instrument approaches to achieve very low minimums with a high degree of confidence. Lateral-path tracking was also precise and required only minor bank-angle changes to correct small lateral errors with respect to the ghost. The data shown in figure 9 are from an approach flown in a 10-15-knot head wind with an 8-10-knot cross-wind component and turbulence of $2-3 \mathrm{ft} / \mathrm{sec} \mathrm{rms}$.

The objectionable effects of nozzle hysteresis are shown in figure 10 , where the \pm 4.5 -deg band is apparent at nominal nozzle deflections of approximately $45 \mathrm{deg}$. For the thrust levels associated with this stage of the approach, $4.5 \mathrm{deg}$ of hysteresis translates into about $0.1 \mathrm{~g}$ of normal acceleration. This acceleration acts as a disturbance to the vertical axis and couples into the throttle control laws to cause an oscillatory response in engine thrust, as illustrated in figure 11. Once the nozzles are deflected below $50 \mathrm{deg}$, restoring torque from the deflected thrust acts as a preload on the nozzles, reducing the hysteresis to more tolerable levels $(1-1.5 \mathrm{deg})$. For example, it can be seen in figure 10 that, once the nozzles have deflected beyond $50 \mathrm{deg}$, the oscillatory nozzle and throttle response, and hence the oscillatory flightpath response, diminish significantly.

With the throttle employed as the thrust magnitude controller and with direct control of longitudinal accelera- tion with the thumbwheel (Configuration 4), the throttle inceptor was considered to be a more favorable control. Even without flightpath command and stabilization, two of the pilots rated the control of the decelerating approach as satisfactory. It should be noted that these data were obtained under calm wind conditions, and the lack of flightpath stabilization in disturbances could have caused these ratings to degrade. One pilot rated the approach adequate because the HUD flightpath symbol quickening was not optimized and the thumbwheel controller on the throttle did not have favorable mechanical characteristics. Except for these unfavorable characteristics, he would have rated the system satisfactory.

The longitudinal time histories of figure 12 show a smooth deceleration to near hover comparable to that of the flightpath and acceleration command system. Flightpath control was accomplished using both pitch attitude and thrust, depending on which was the most effective. Early in the approach, attitude was used while wing lift was effective. Then, as the aircraft slowed to jetborne speeds, a large throttle advance was required to replace wing lift. Thumbwheel usage for the deceleration was nearly open loop since the system controls precisely to the deceleration profile.

Hover-Point Acquisition- As shown in figure 13, control of the closure to hover at the initial station-kecping point was rated adequate for the basic YAV-8B configuration. With the low level of pitch augmentation, it was difficult to control closure rates to establish hover at the desired 

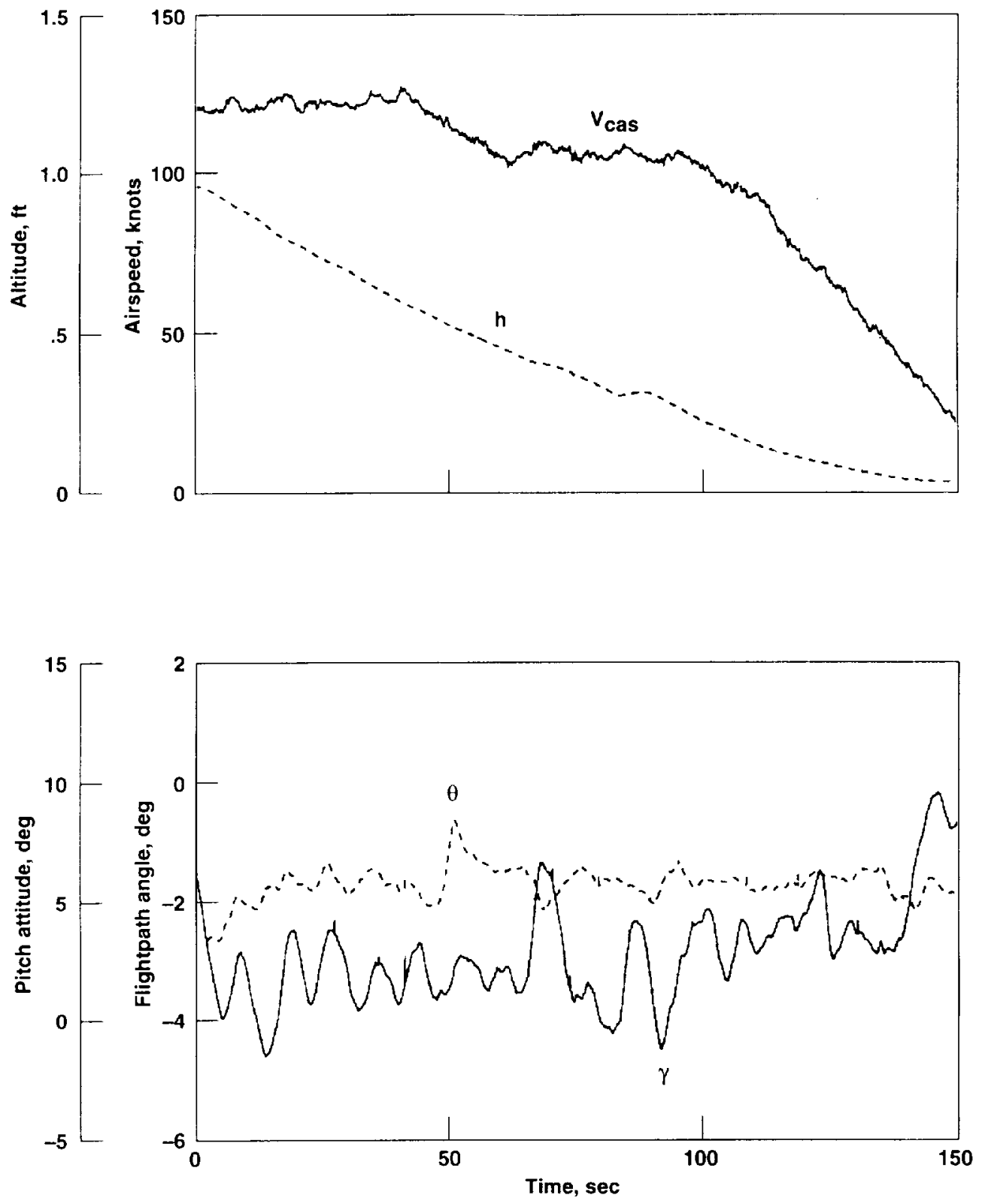

(a) Longitudinal response.

Figure 10. Example of nozzle hysteresis for Configuration 3. 
penu!nuos 01 anti!t

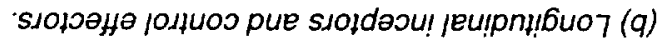
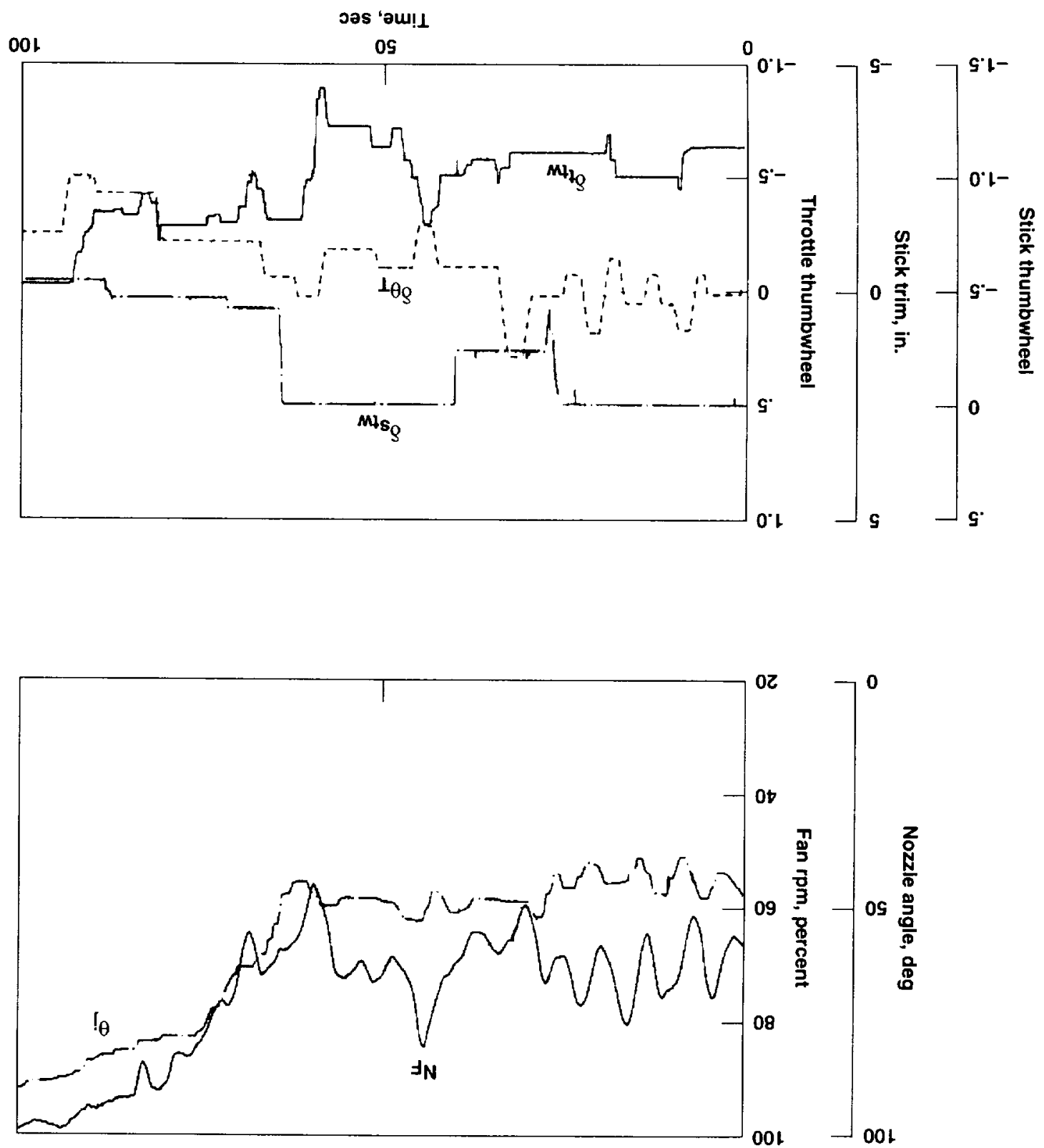


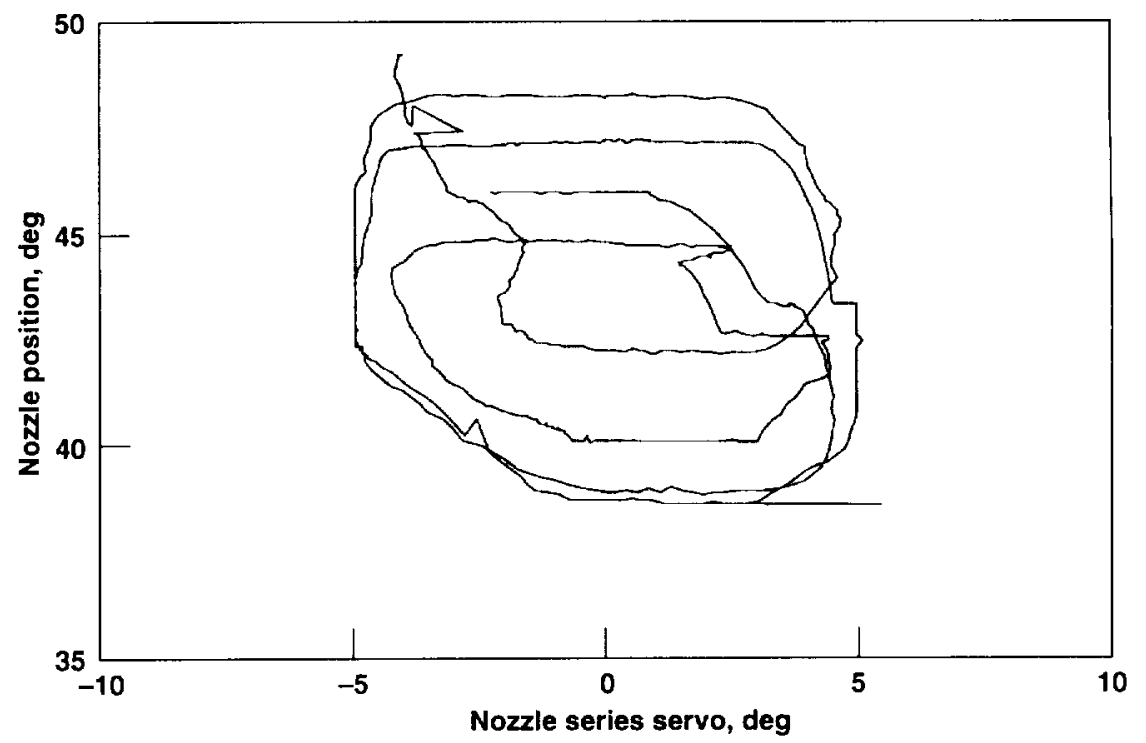

(c) Nozzle hysteresis loop.

Figure 10. Concluded. 
W
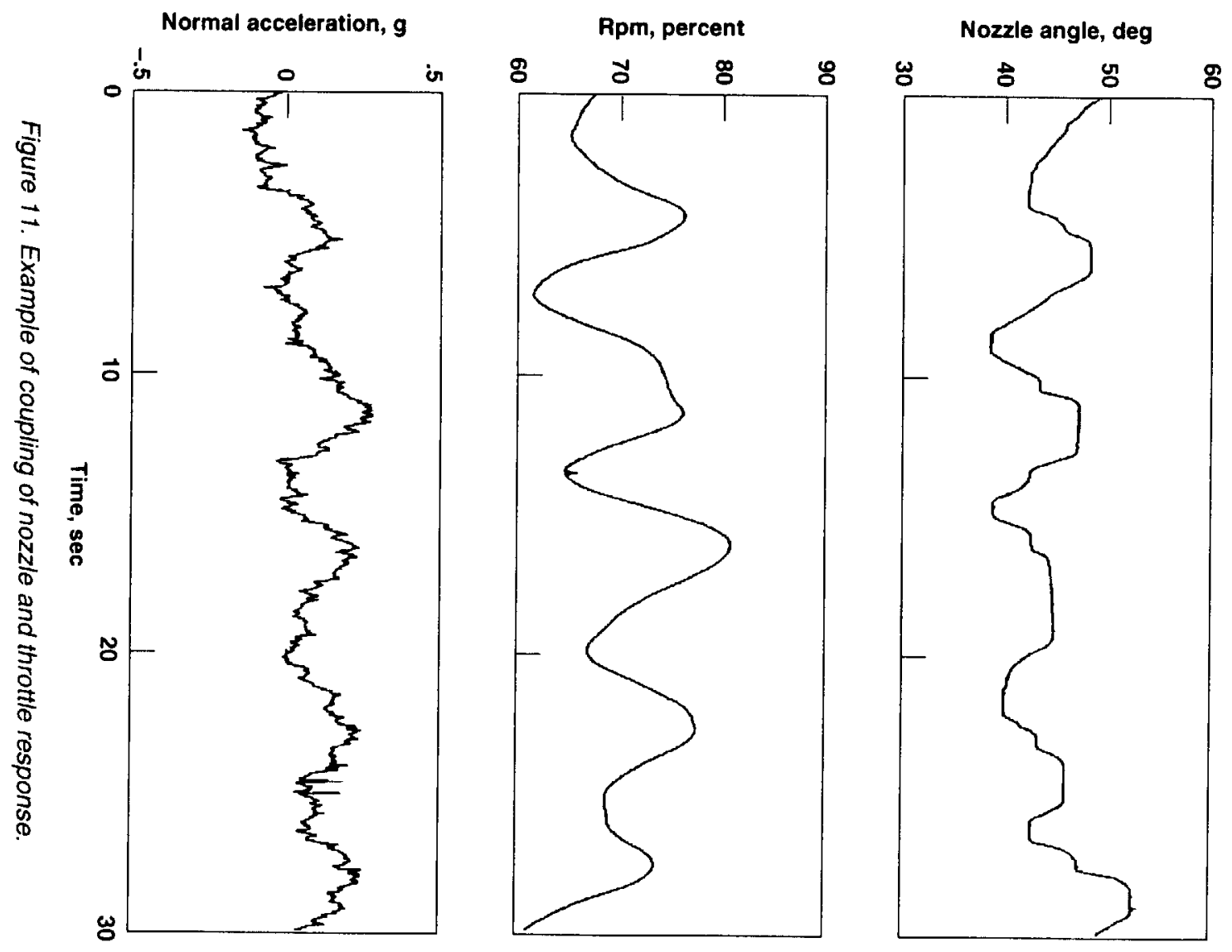

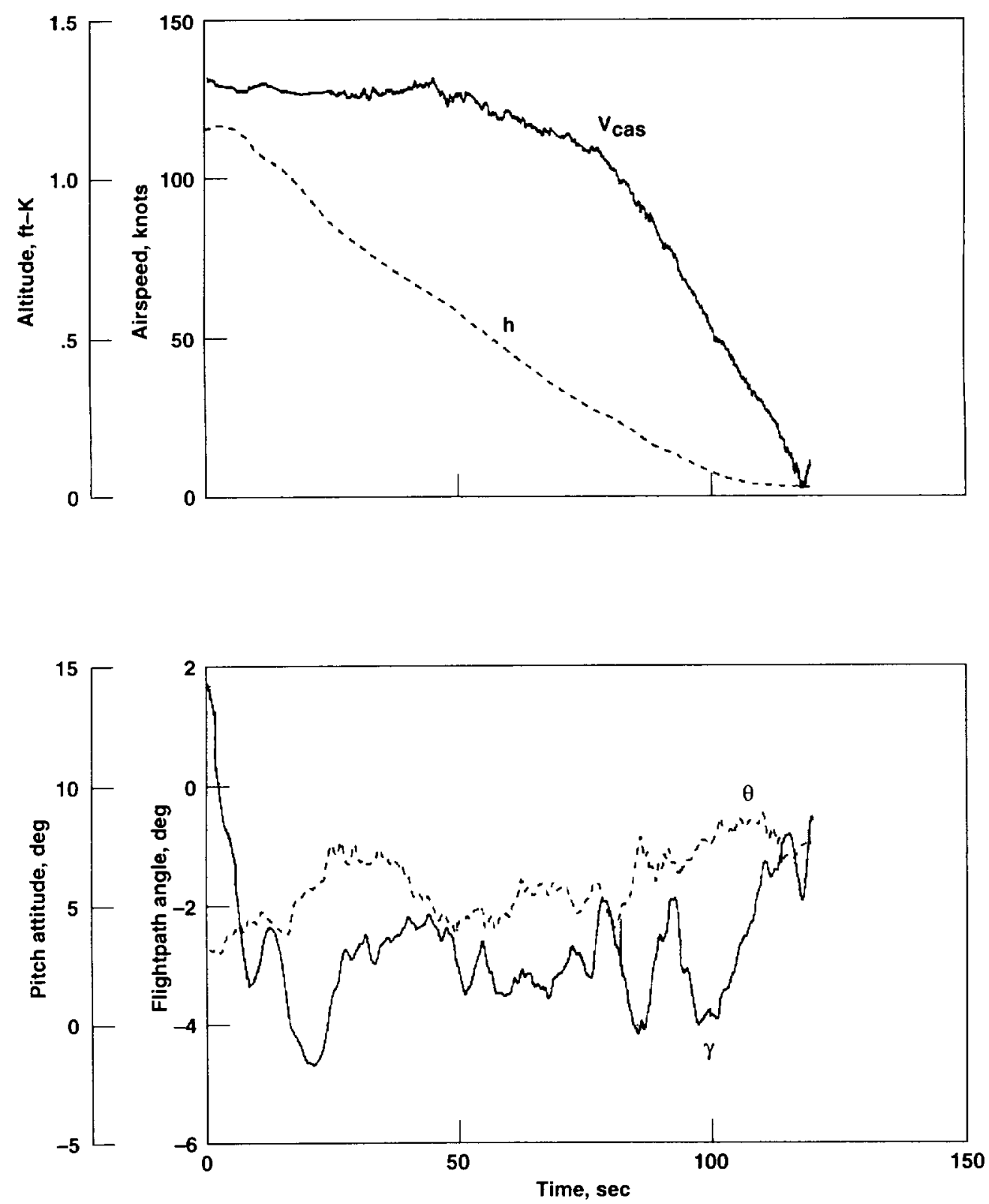

(a) Longitudinal response.

Figure 12. Decelerating transition time history for thrust control/acceleration command (Configuration 4). 

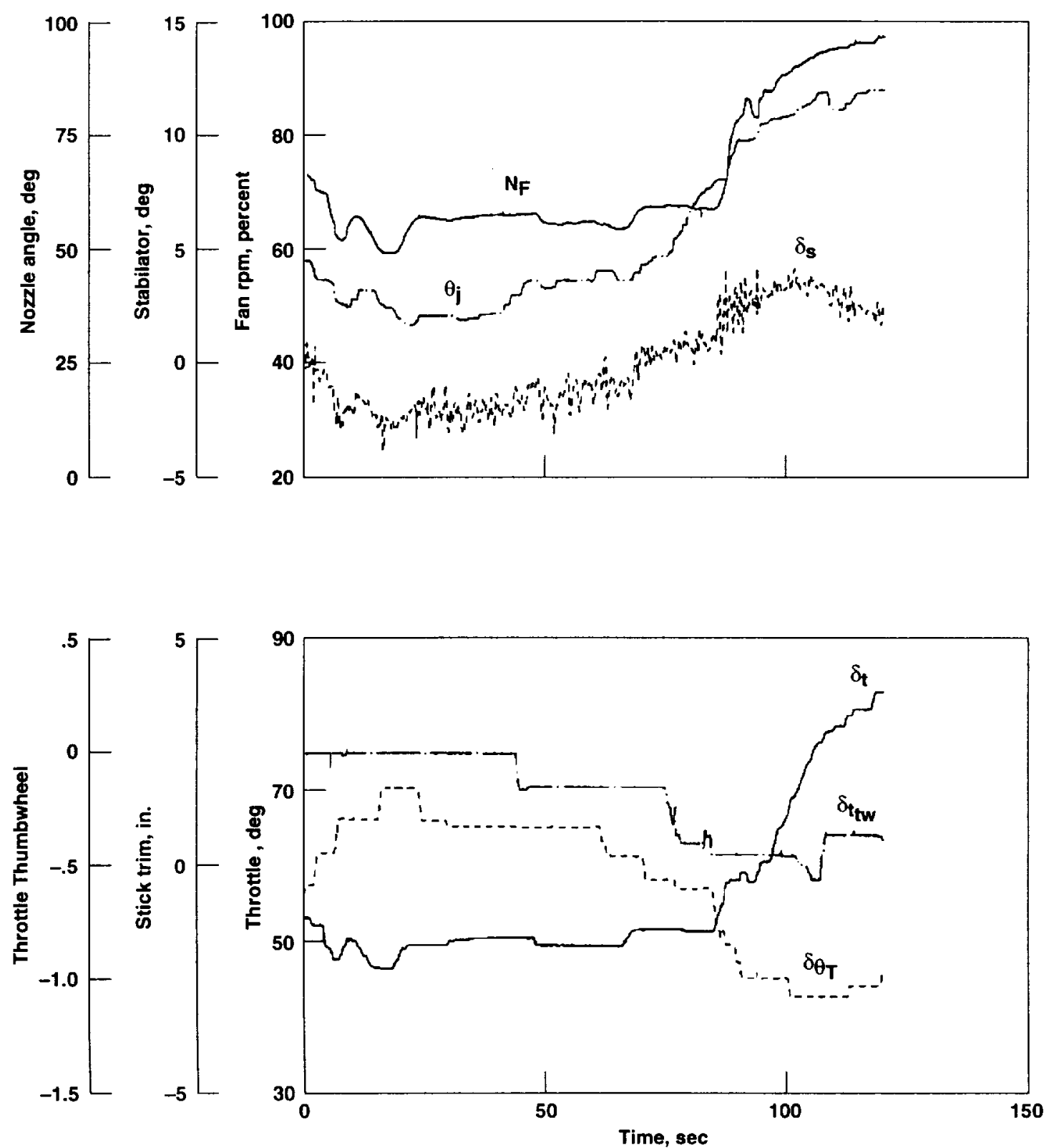

(b) Longitudinal inceptors and control effectors.

Figure 12. Concluded. 


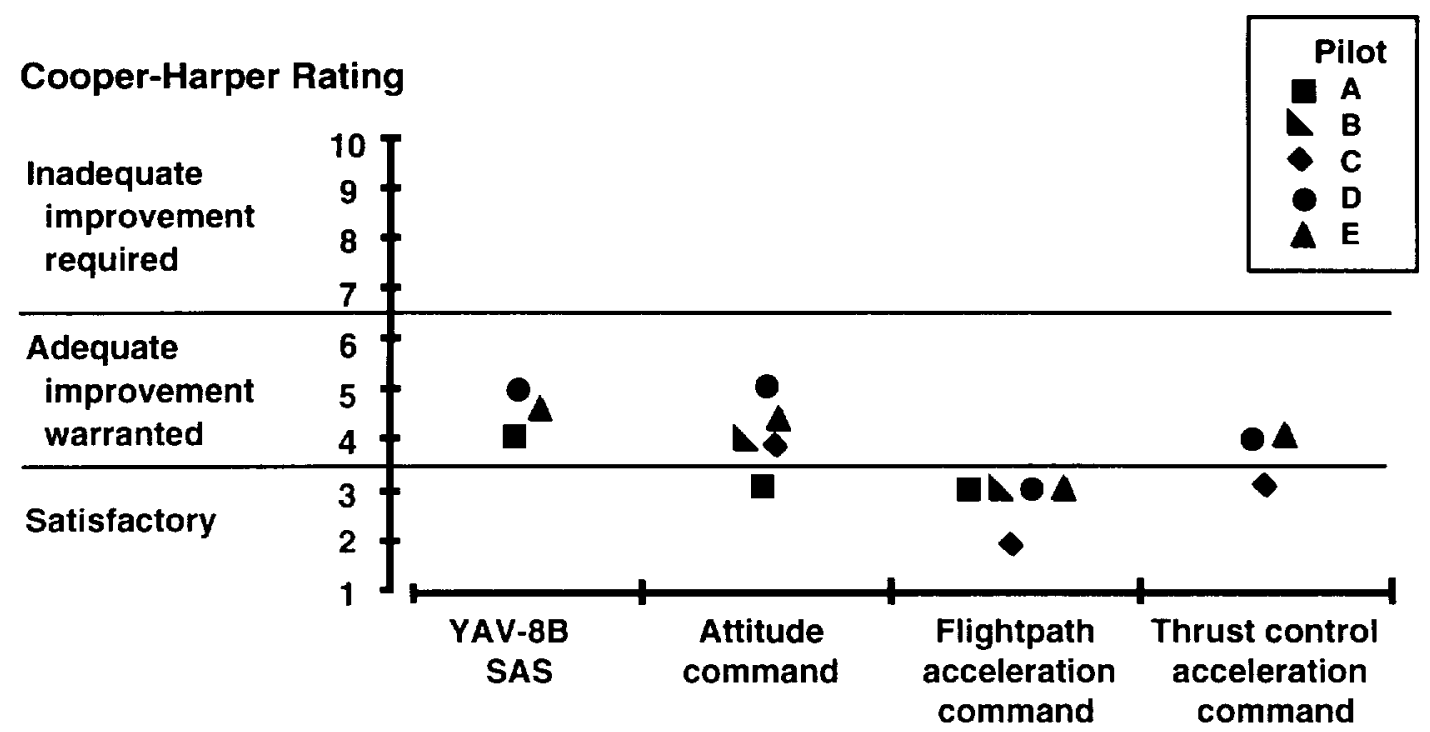

Figure 13. Pilot evaluations of hover-point acquisition.

point. Concentration on any single task element usually resulted in the deterioration of another element. Use of the closure guidance (controlling the predictor ball to the station-keeping-point cross) was difficult for some pilots, and they would resort to external visual references to complete the deceleration to hover at the station-keeping point. Height control was also difficult with thrust control alone because of low vertical damping and a tendency to wander away from an established hover height. Coordination of throttle and pitch-control inputs was required when making attitude changes to adjust the deceleration.

Representative time histories of hover-point acquisition are shown in figure 14. The YAV-8B was typified by oscillatory vertical-velocity control and frequent throttle manipulations. Several attitude adjustments were made to control closure to the hover point during the final stage of the deceleration. The pedals were active to maintain heading.

With the inclusion of attitude stabilization (Configuration 2), flying qualities improved slightly to horderline adequate/satisfactory. The closure symbology was still difficult for some pilots to use, and the difficulty with height control remained. Some pilots used a technique of making gross changes in deceleration with thrust vector angle while making minor adjustments with pitch attitude. Height control remained the predominant contributor to workload for the same reasons noted previously. The time histories in figure 15 exhibit large transients in vertical velocity and a particularly large throttle input in conjunction with a large pitch-attitude excursion as the aircraft reaches hover. This hehavior reflects the strong coupling between attitude and height control when large attitude changes are used for deceleration. An oscillatory bank angle and roll-control response appear during an abrupt lateral correction approaching hover. A residual smallamplitude oscillation in the lateral control persists during the initial hover, rellecting the high roll-loop gain for the attitude command control. The pilot's control of bank angle was not impacted by this oscillation. Its absence in the lateral stick indicates that it was not induced by the pilot. Simulator experience indicates that the roll gain could be reduced to eliminate the oscillation without degrading bank-angle control for the pilot.

Flightpath and deceleration command (Configuration 3) made the task fully satisfactory for most pilots because of the improvement in height control. Some pilots found it difficult to use the longitudinal-velocity vector and horizontal-position symbology in conjunction with the stick thumbwheel to control the final deceleration to the hover point; other pilots found the task easy to acconplish. Vertical-velocity control was precise and height hold was open loop. Desired performance was generally achieved with minimal workload. Time histories in figure 16 are characterized by a smooth capture of the hover altitude and a gradual deceleration to the hover station-keeping point. Control activity with the thumbwheels was minor, and lateral precision was good with little lateral-control activity evident.

For manual control of thrust with the deceleration command (Configuration 4 ), the ratings were borderline satisfactory/adequate with the principal deficiencies being the control of the final closure to the hover point and the 

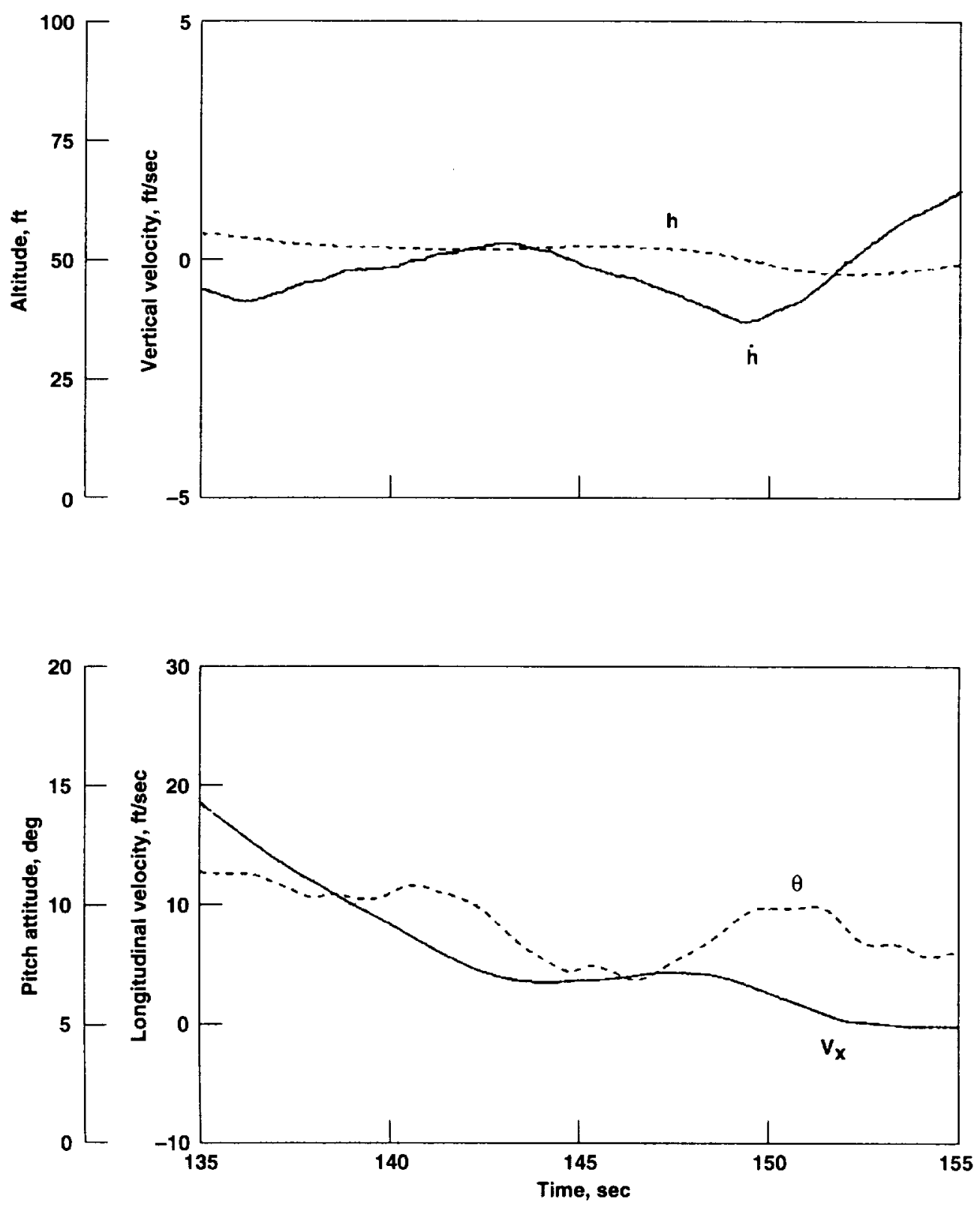

(a) Longitudinal response.

Figure 14. Station-keeping point acquisition time histories for YAV-8B SAS (Configuration 1). 

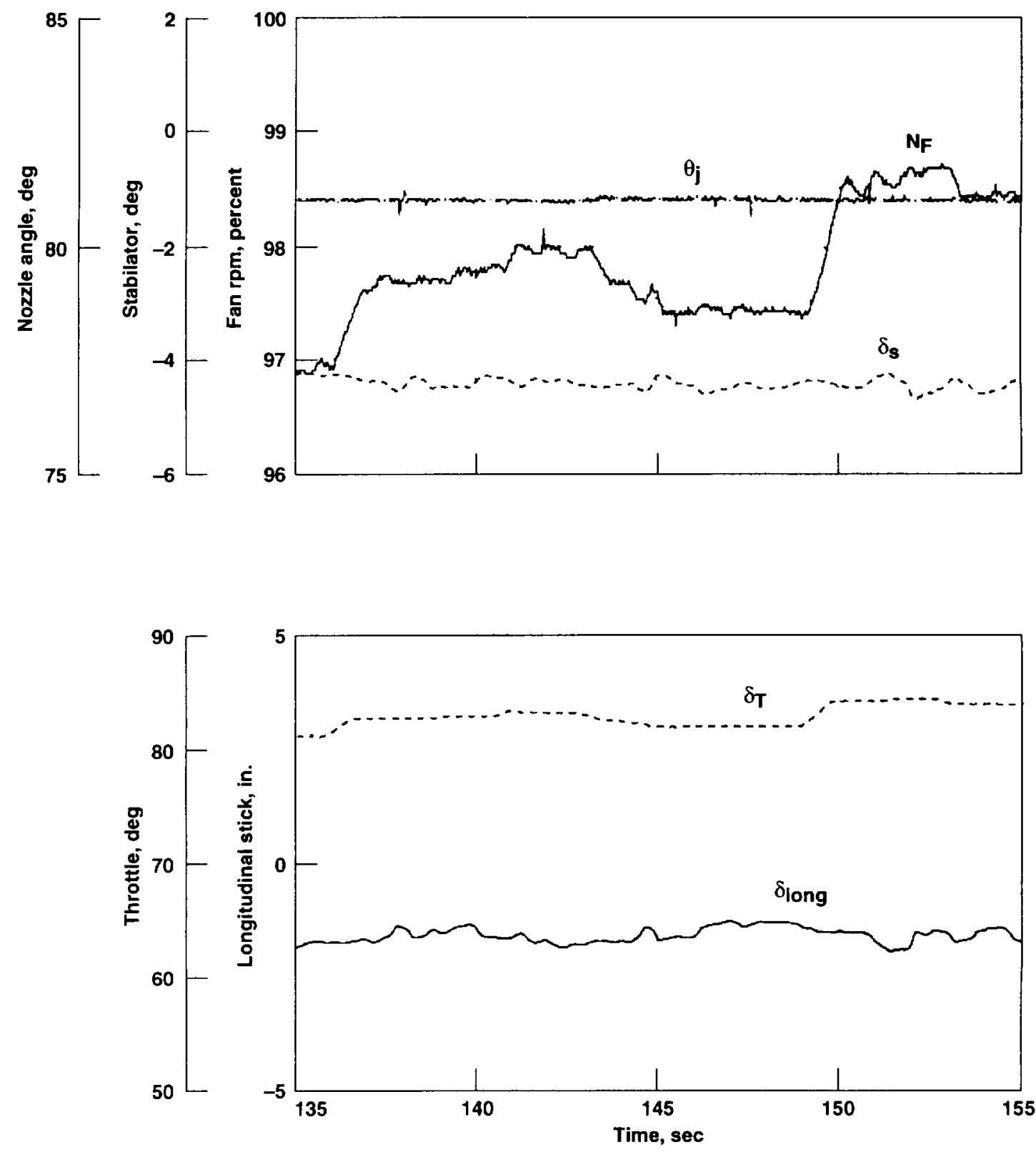

(b) Longitudinal inceptors and control effectors

Figure 14. Continued. 

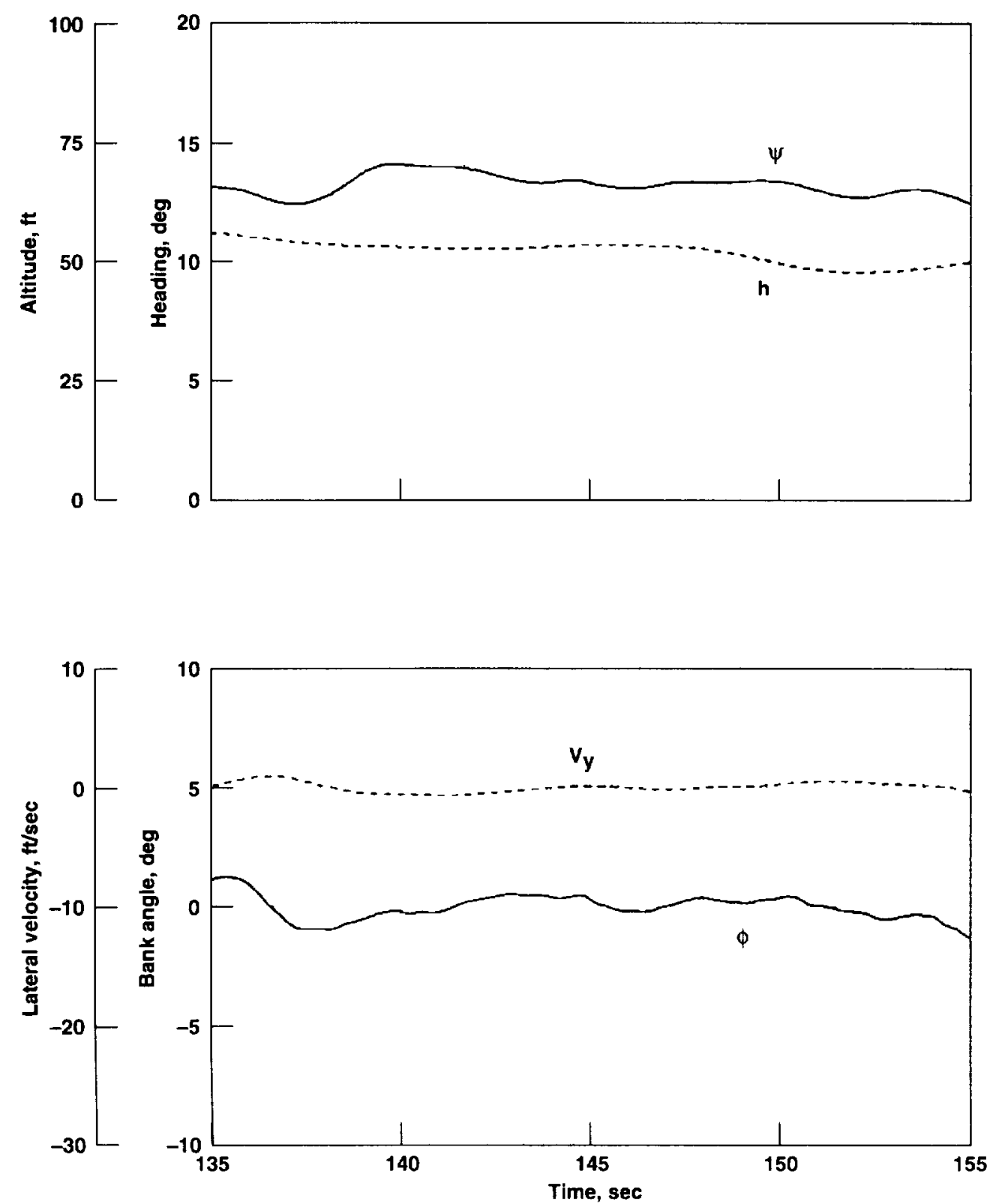

(c) Lateral-directional response.

Figure 14. Continued. 

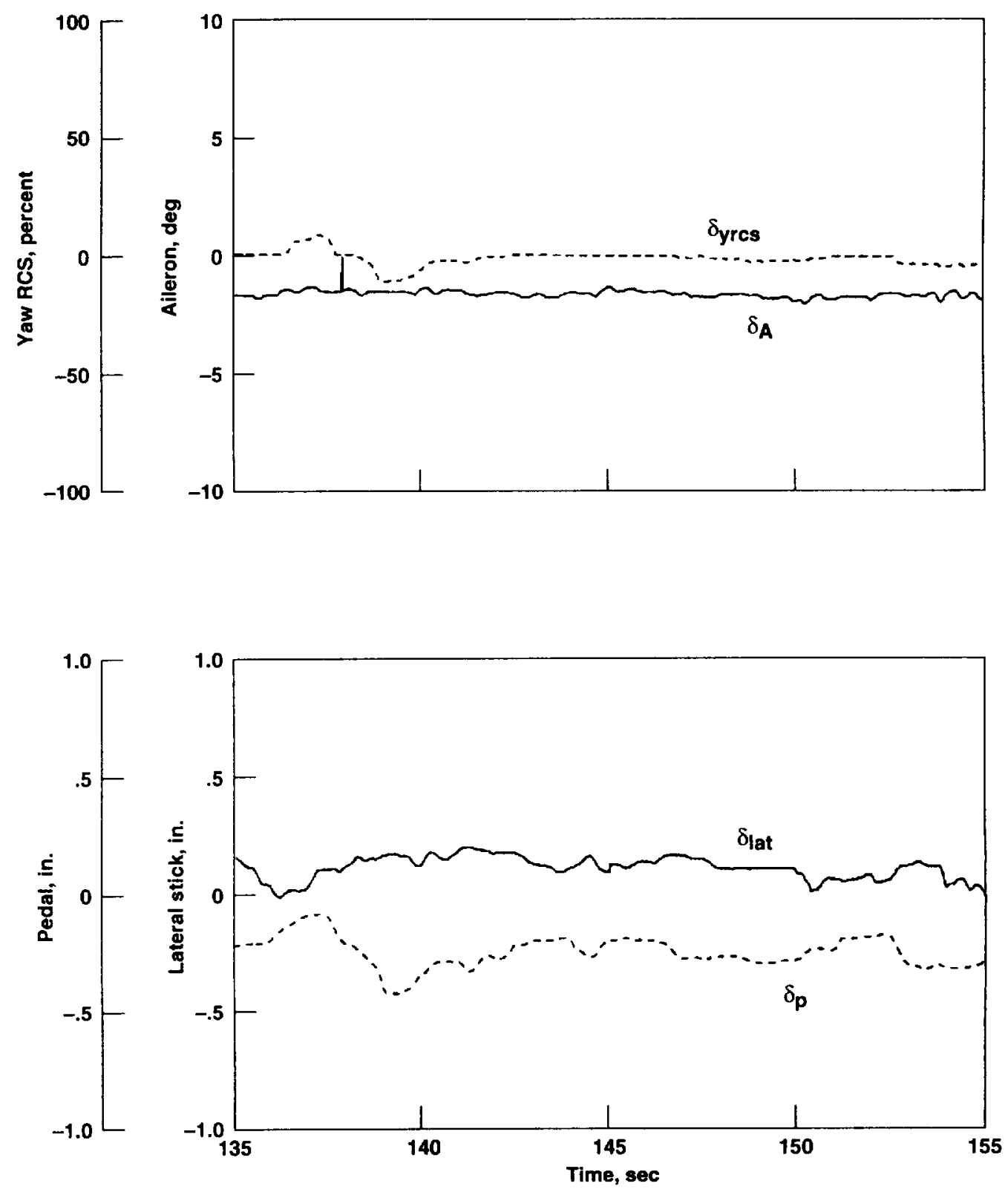

(d) Lateral-directional inceptors and control effectors.

Figure 14. Concluded. 

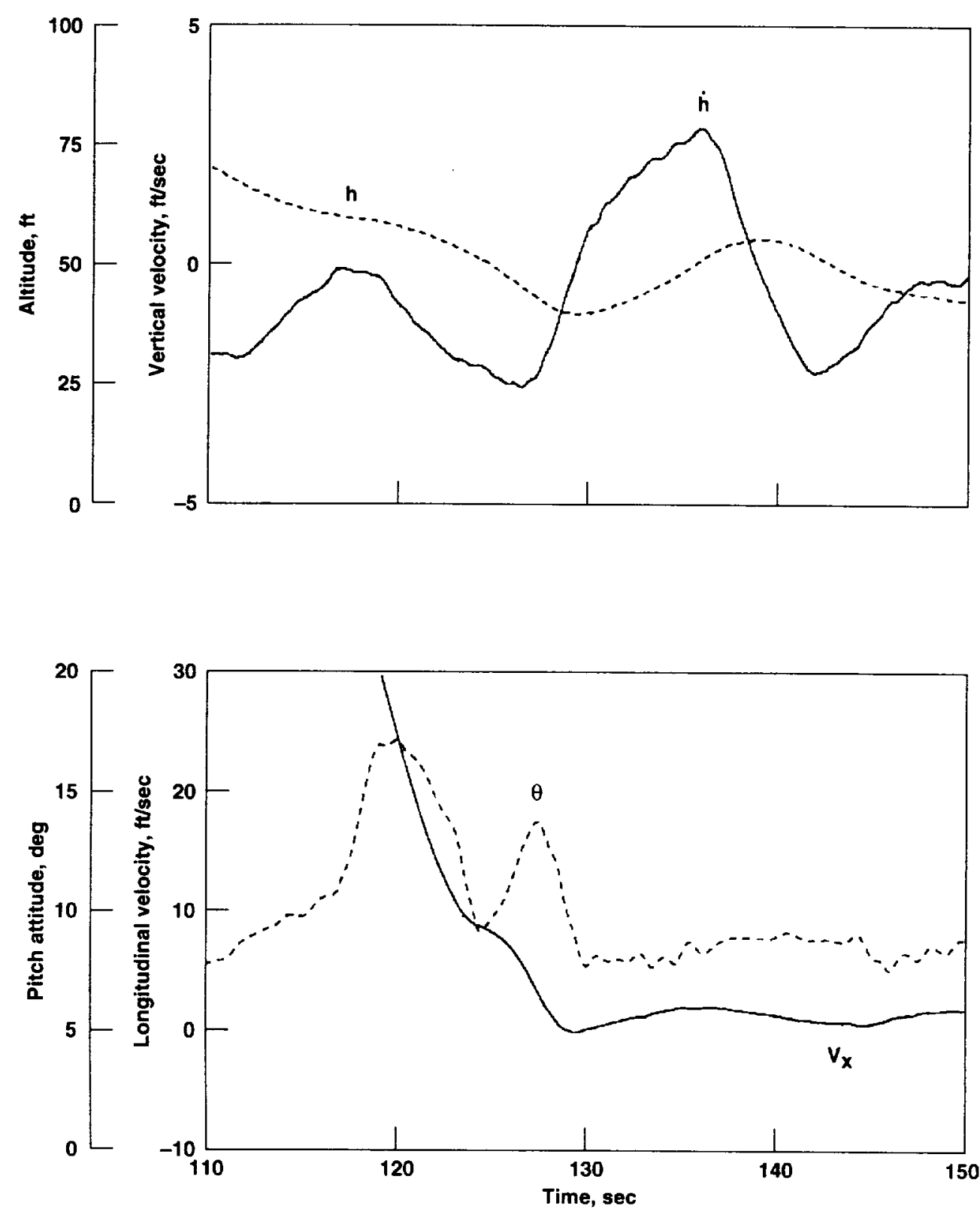

(a) Longitudinal response.

Figure 15. Station-keeping point acquisition time histories for attitude command (Configuration 2). 
penu!!

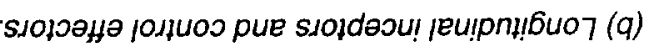
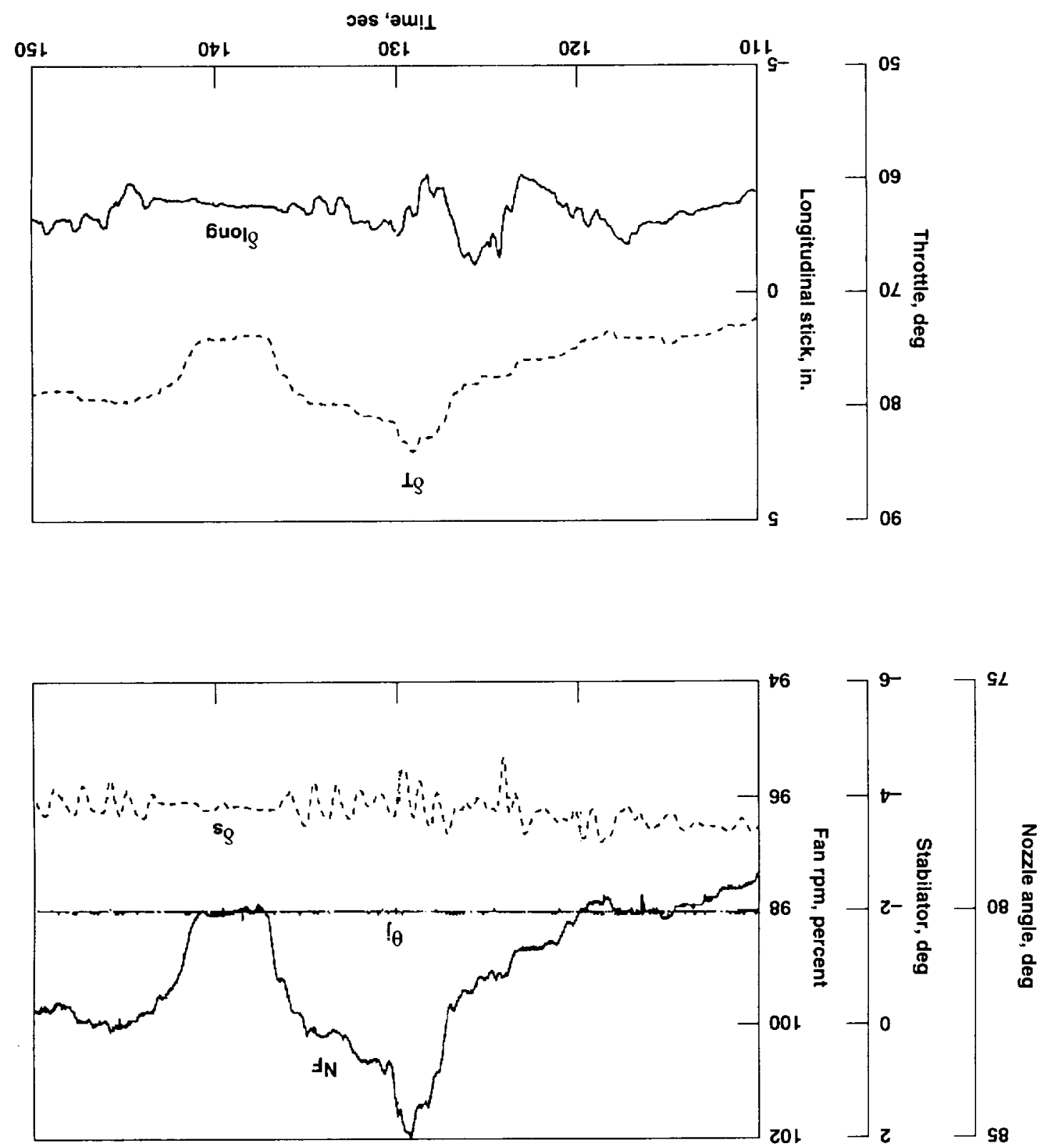

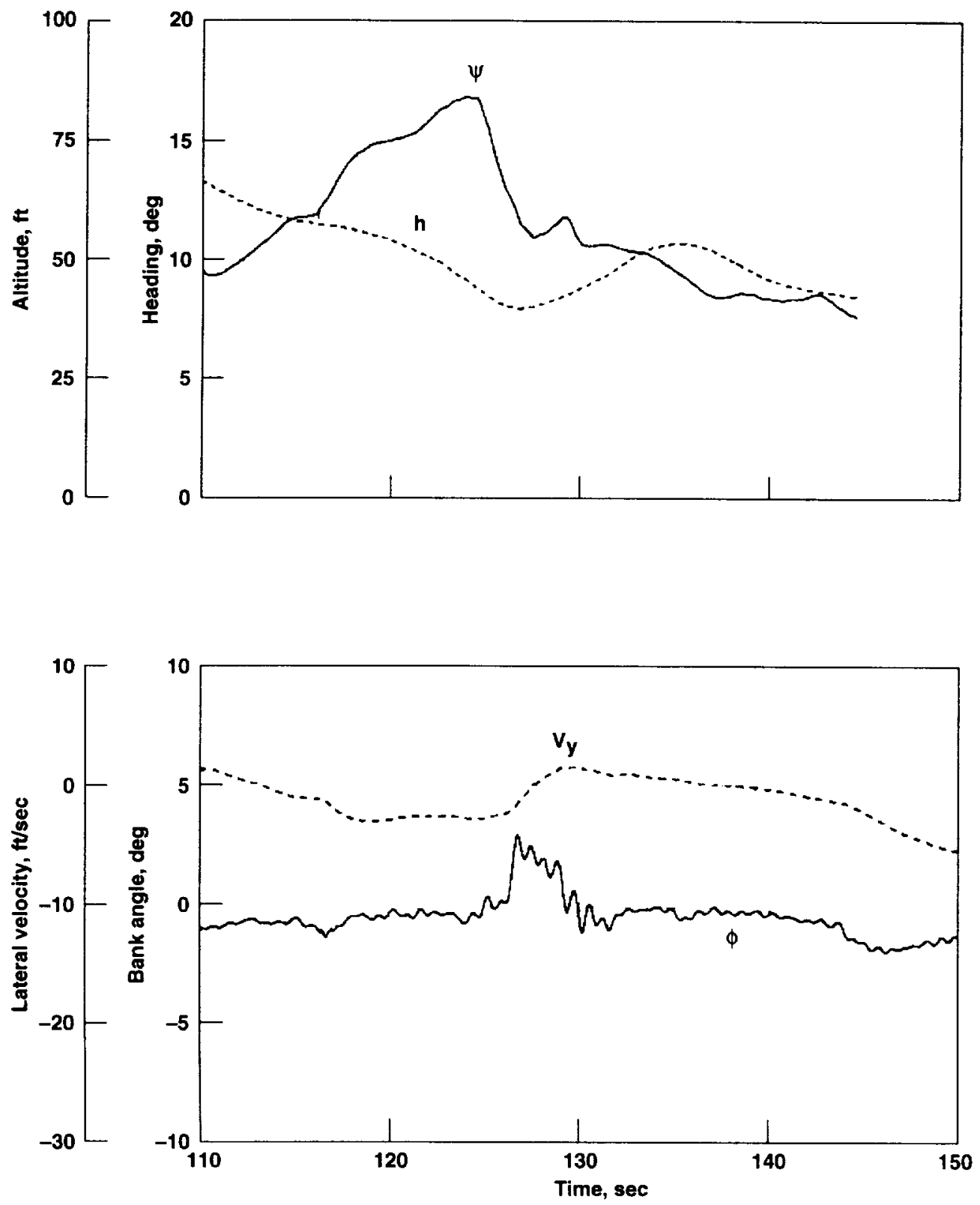

(c) Lateral-directional response.

Figure 15. Continued. 

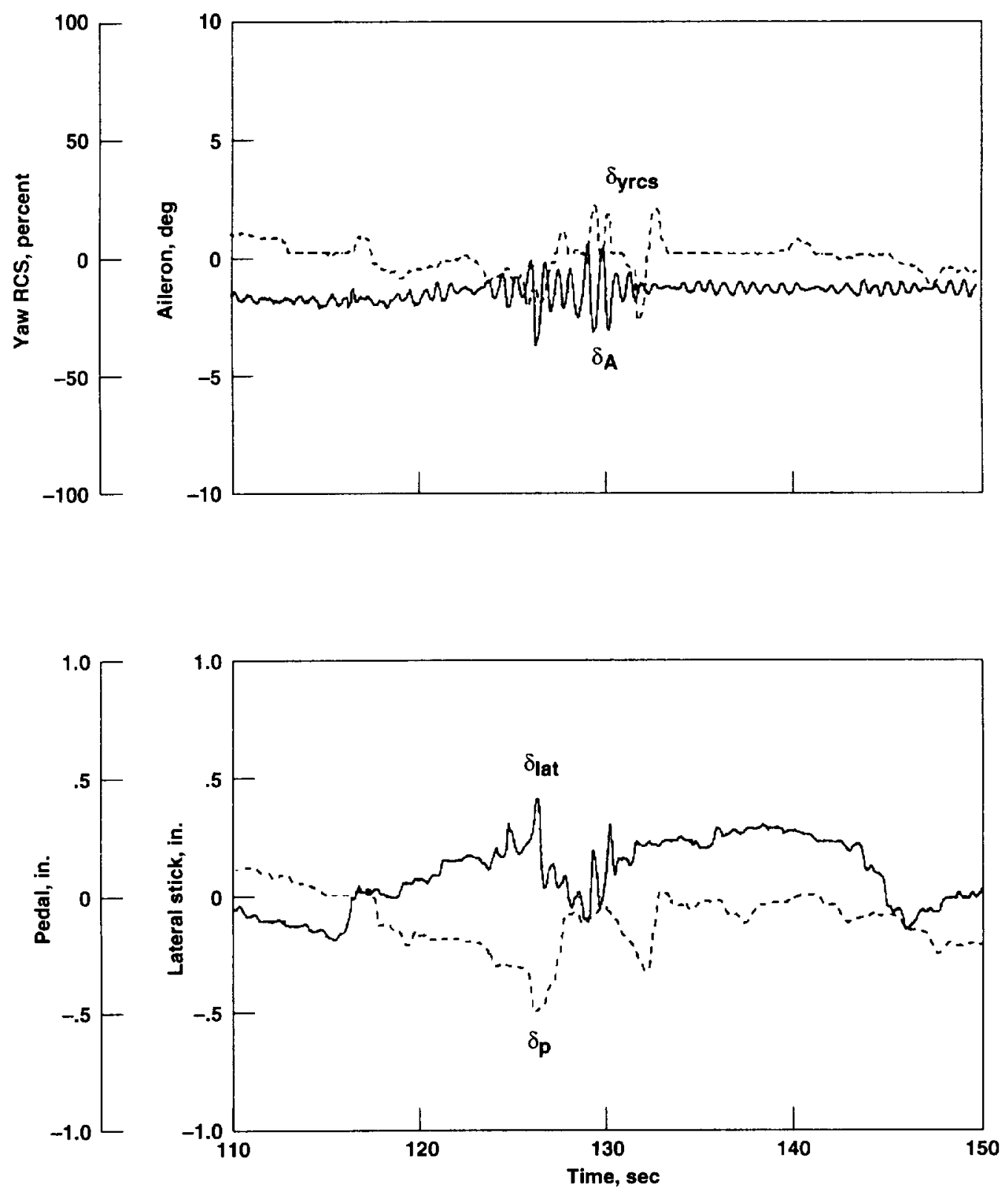

(d) Lateral-directional inceptors and control effectors.

Figure 15. Concluded. 

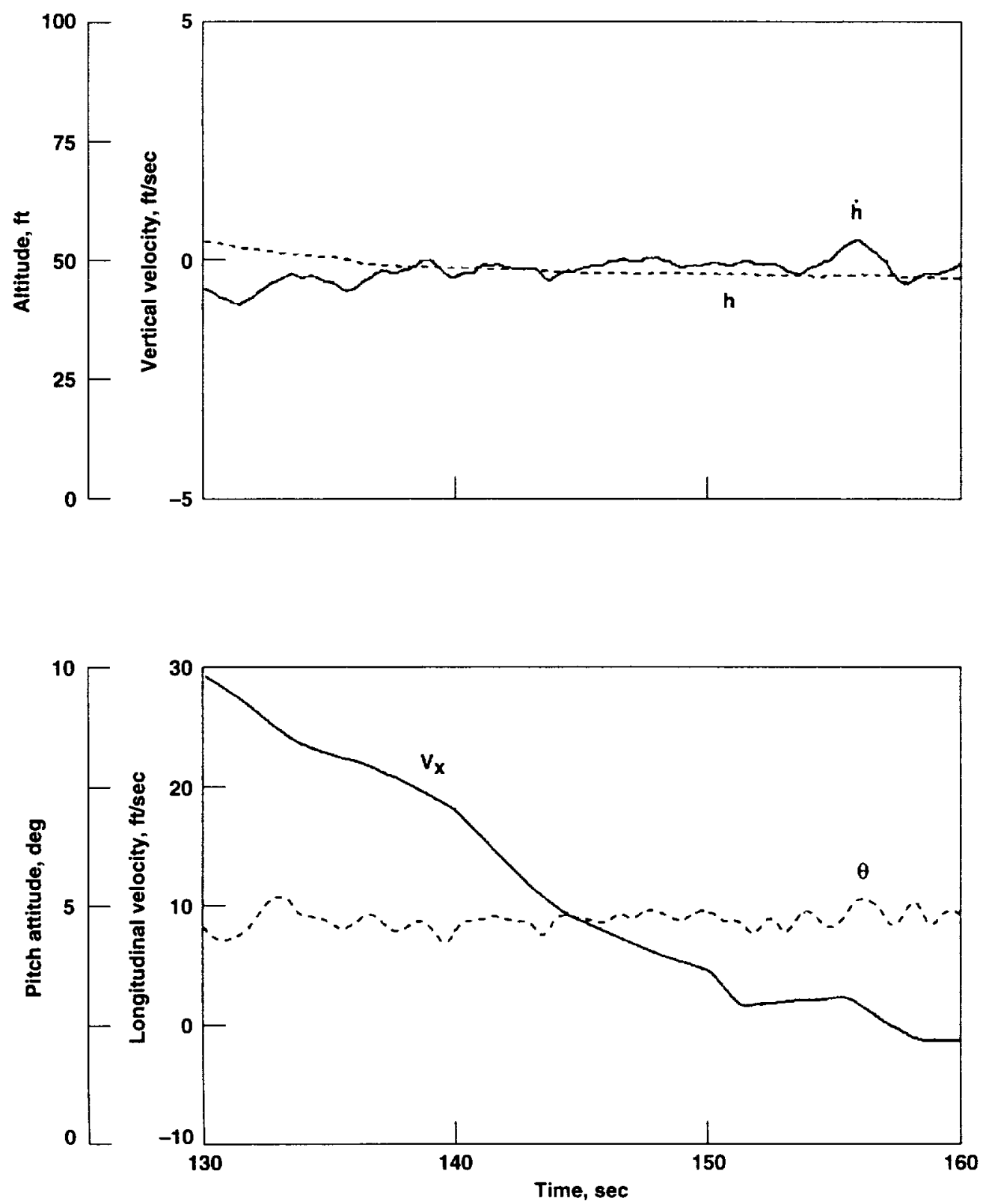

(a) Longitudinal response.

Figure 16. Station-keeping point acquisition time histories for flightpath/acceleration command (Configuration 3). 

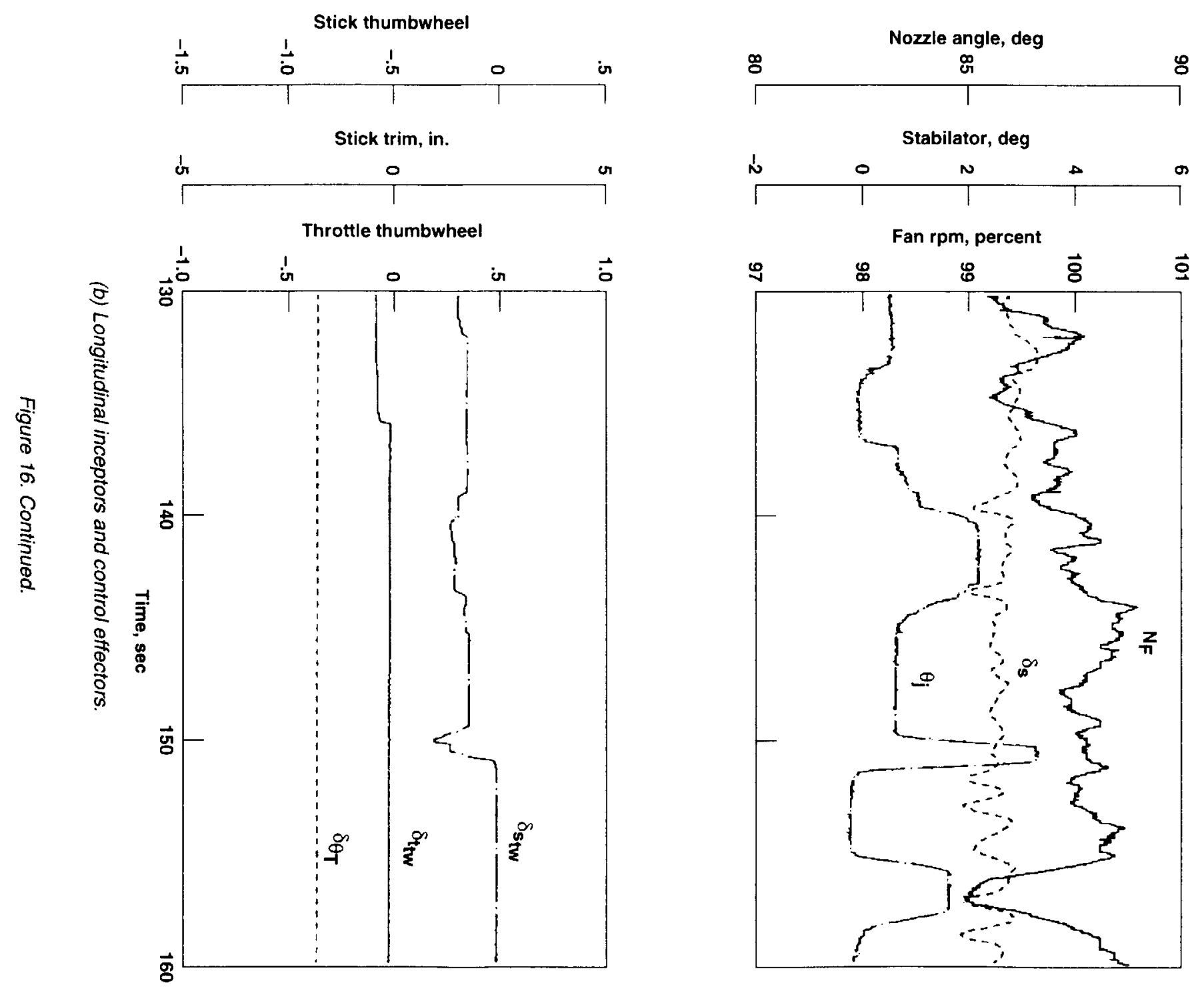

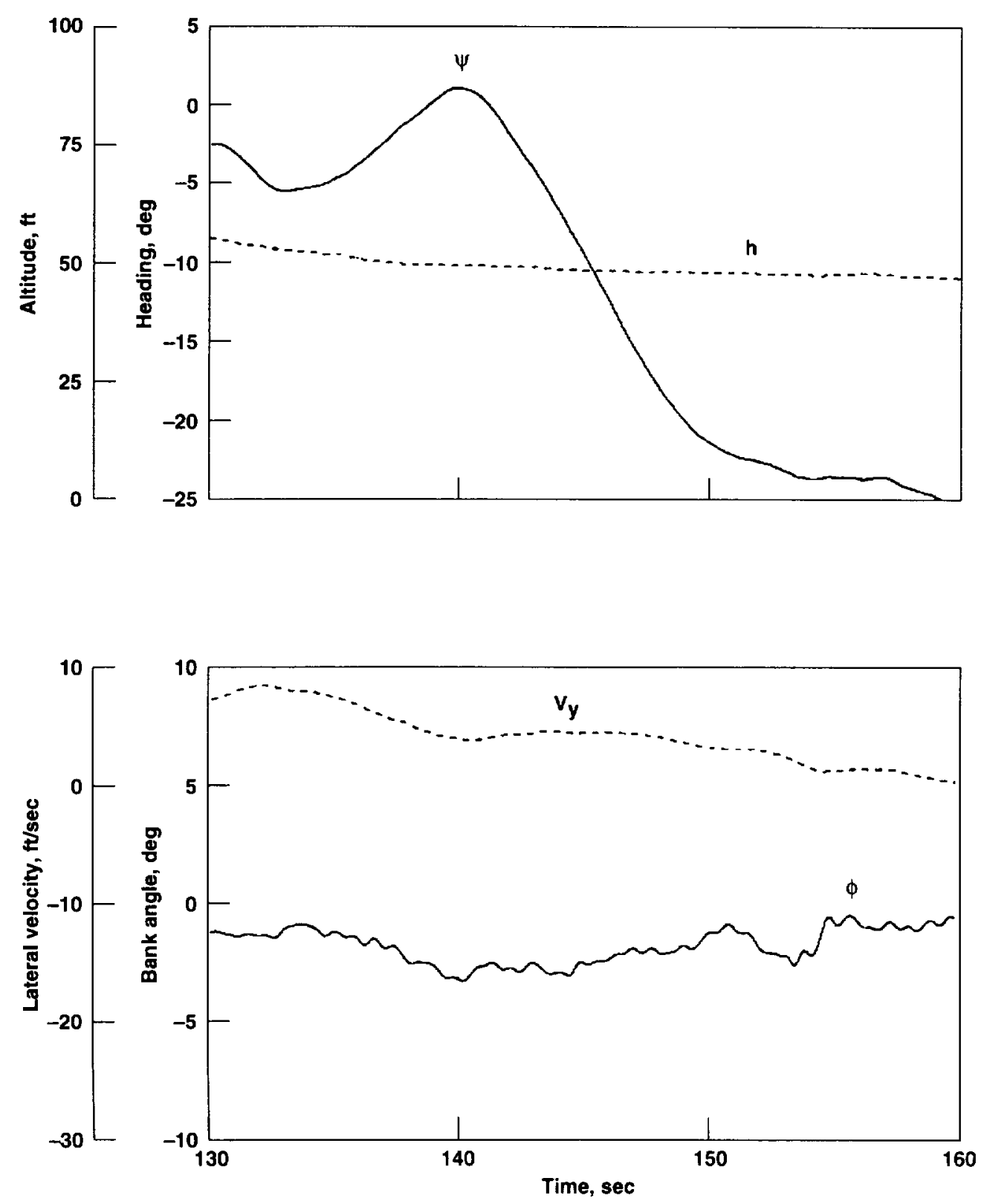

(c) Lateral-directional response.

Figure 16. Continued. 

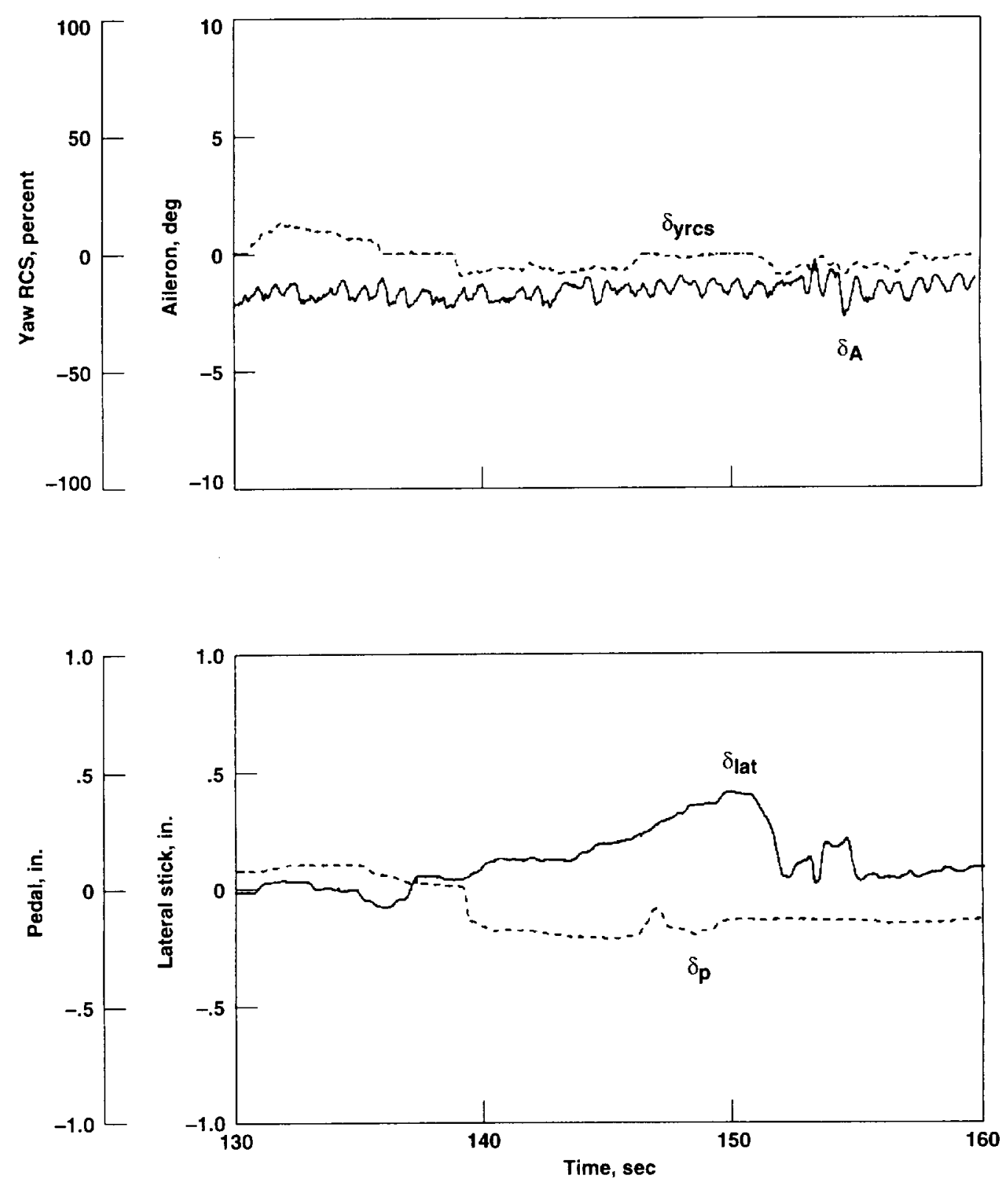

(d) Lateral-directional inceptors and control effectors.

Figure 16. Concluded. 
throttle thumbwheel mechanical characteristics. One pilot sought more deceleration authority with the thumbwheel. Otherwise, the transition from the approach to hover control was easy. As can be seen in figure 17, the final deceleration is smooth and the hover point is captured with a final adjustment with the thumbwheel. No throttle manipulation was required for altitude control.

Vertical Landing- Figure 18 shows that the pilot ratings of the vertical landing with the basic YAV-8B system fall in the adequate range. Pilots considered the principal deficiency to be the considerable attention and compensation required to control sink rate during the descent in the presence of ground effect. Stabilization of pitch and roll attitude during translational maneuvers and in the presence of thrust changes also made the task difficult with the basic aircraft. As can be seen from the brackets in figure 18 , the range of previous simulation ratings compare reasonably well with these flight results.

Representative time histories of the vertical landing, shown in figure 19 , are typified by wandering height control, with frequent throttle corrections made in an attempt to establish a steady hover altitude. Numerous pitch-attitude adjustments were necessary during the translation to the hover point and during the descent to landing. Roll and yaw controls were also very active for controlling the lateral translation and maintaining a steady heading.

No significant improvement was provided by the attitude command system (Configuration 2) because of annoying features associated with the limited range of authority afforded by the pitch and roll series servos. Specifically, when the servos reached their limits, the aircraft reverted from an attitude-stabilized response to an acceleration response. At that point, the attitude response to the stick became too sensitive. Furthermore, height and sink-rate control remained difficult tasks. Assessments of position holding during the descent varied from easy to accomplish to having an annoying tendency to drift off the point.

Figure 20 illustrates the same difficulty with hover-height control that was evident for the basic YAV-8B. Pitch excursions and stick activity were similar to those of the YAV-8B. Lateral-stick activity for the lateral of fset correction to the hover point was reduced somewhat from that for the YAV-8B, as was pedal activity for heading control. Again, the oscillatory control response is reflective of the high-gain attitude control system performance.

When vertical-velocity command was introduced with the translational-rate system (Configuration 3), the landing ratings improved to satisfactory. Height and sink-rate control became very precise and were performed with little effort. The resulting decoupling of height response from translational control in the horizontal plane was considered to be the principal source of the reduction in workload. Position control was accomplished with desired precision and generally with minimal compensation by using the proportional thumb controller. One pilot experienced a tendency to drift off the hover point rearward and to the left, requiring moderate effort to compensate. Aggressive longitudinal maneuvers could lead to objectionable discrepancies between the longitudinalvelocity vector and predictor ball because of a lag in the aircraft's response to the translational-rate command. Bank-angle excursions to provide lateral translational control were generally considered to be reasonable and comfortable. On one occasion during hover in a steady wind, the lack of integral control to provide trim into the wind caused the pilot to hold a steady command on the proportional thumb controller to maintain position. This situation points to the need to include integral control to relieve the pilot of this demand. With the exception of concerns about longitudinal drift, the translational-rate control was also a significant source of reduced workload since horizontal positioning could be accomplished with fewer control inputs and lower pilot concentration. Finally, the hover display, in combination with the translational-rate command control, gave the pilot the ability to achieve excellent hover and landing precision, with touchdowns consistently inside a 5 -ft-radius circle. The hover display format did not pose a problem for the pilots; they accommodated readily to the mixed presentation of horizontal and vertical information. Simulation data represented by the brackets show the same fully satisfactory ratings as were obtained in flight.

Vertical velocity is set precisely and maintained during the descent to landing (fig. 21). Only minor adjustments show on the throttle thumbwheel. Minor adjustments are evident with the proportional thumb controller for longitudinal and lateral position, with corrections made smoothly and precisely.

With the height-rate damper and translational-rate command (Configuration 4), the hover positioning and landing task was also fully satisfactory. Height control was easy and essentially the same as with vertical-velocity command. Minor compensation was required with the throttle during aggressive longitudinal or lateral maneuvers when the thrust vector was displaced significantly from the vertical. The throttle was considered to be the natural control for the vertical axis. As shown in figure 22 , hover positioning with the height-rate damper and translational-rate command was smooth and height hold and vertical-velocity control were accomplished with minimal throttle adjustment. 


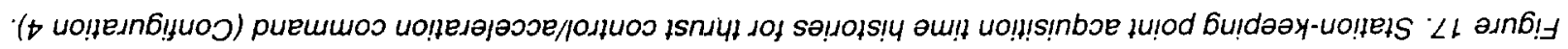
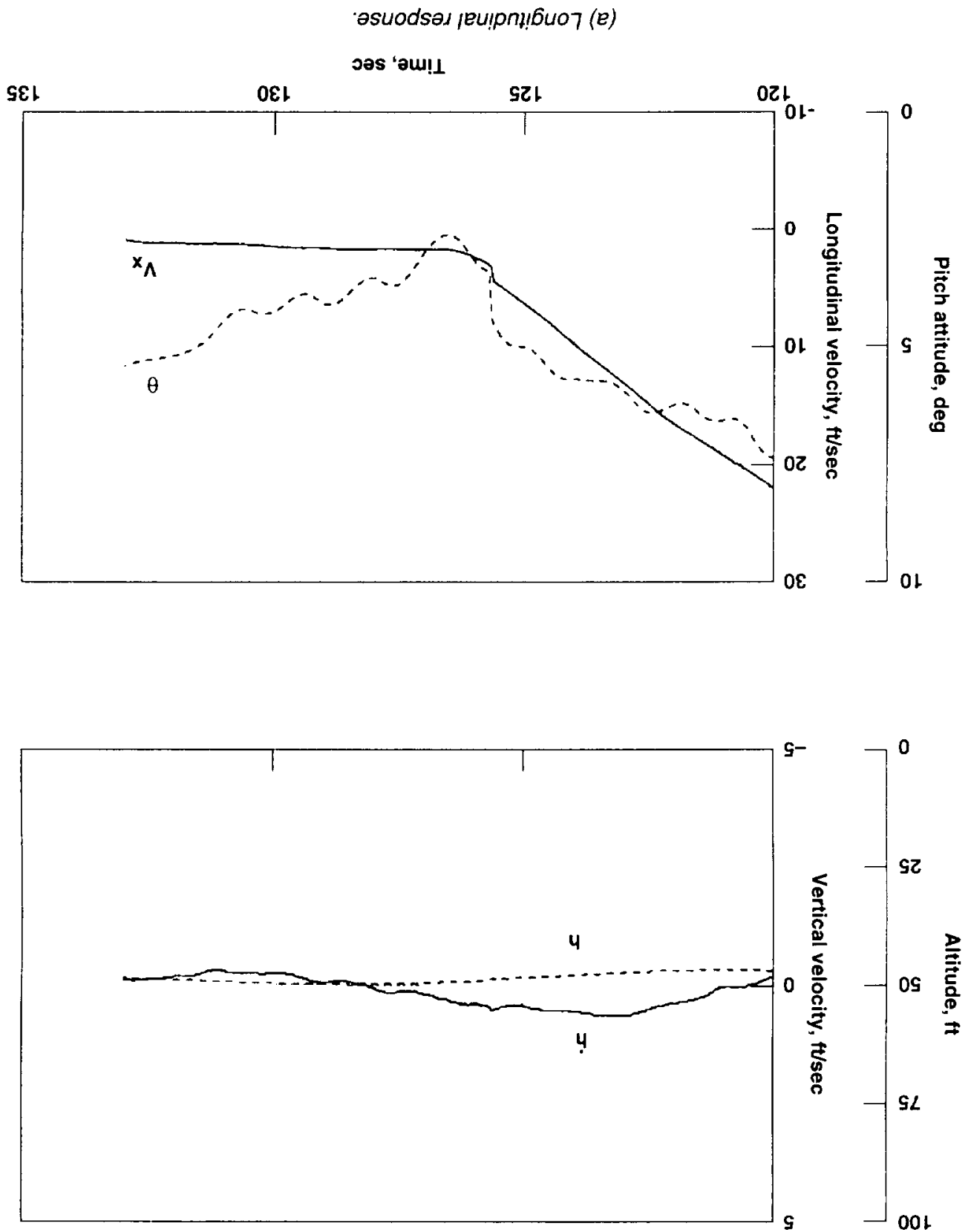

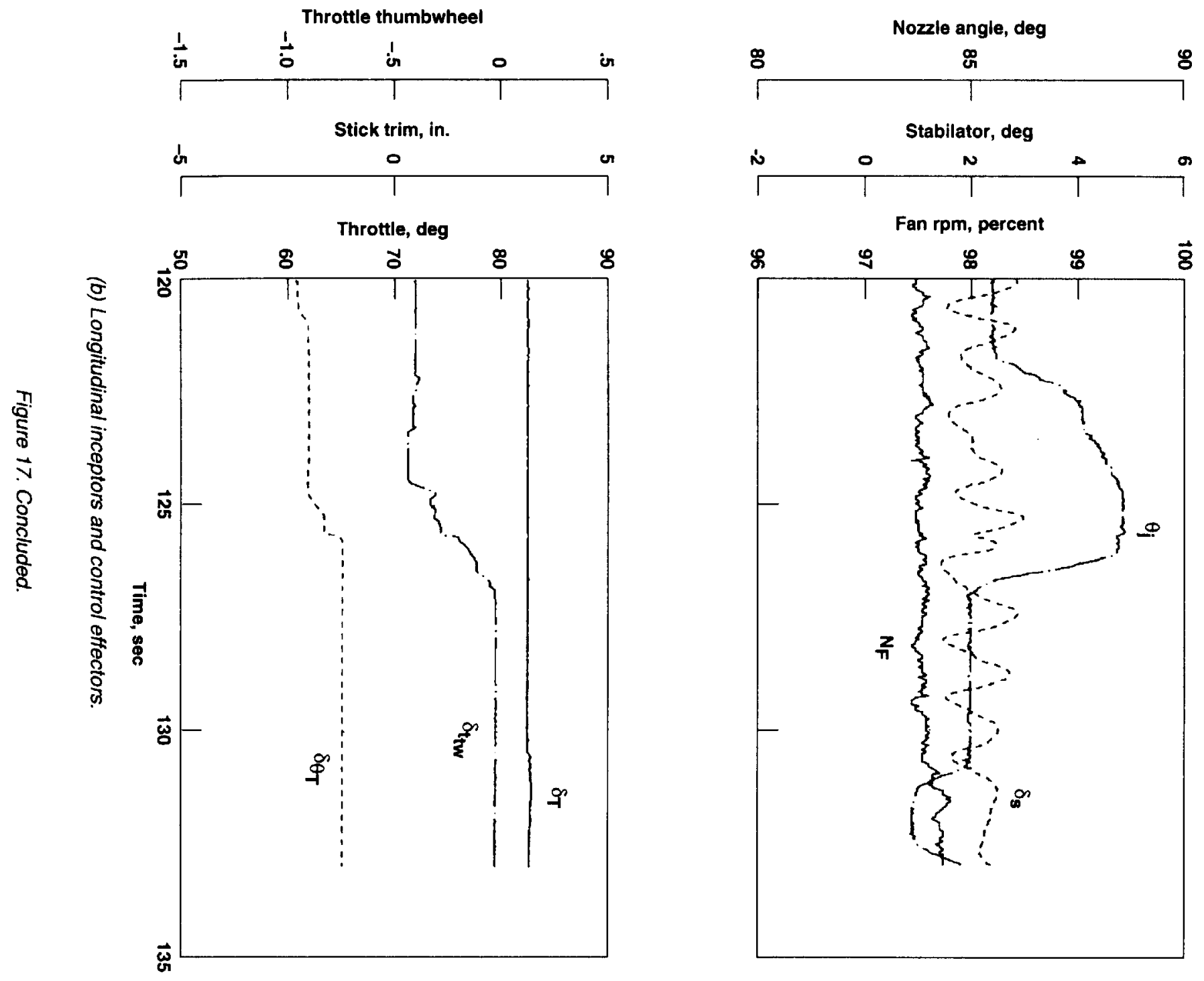


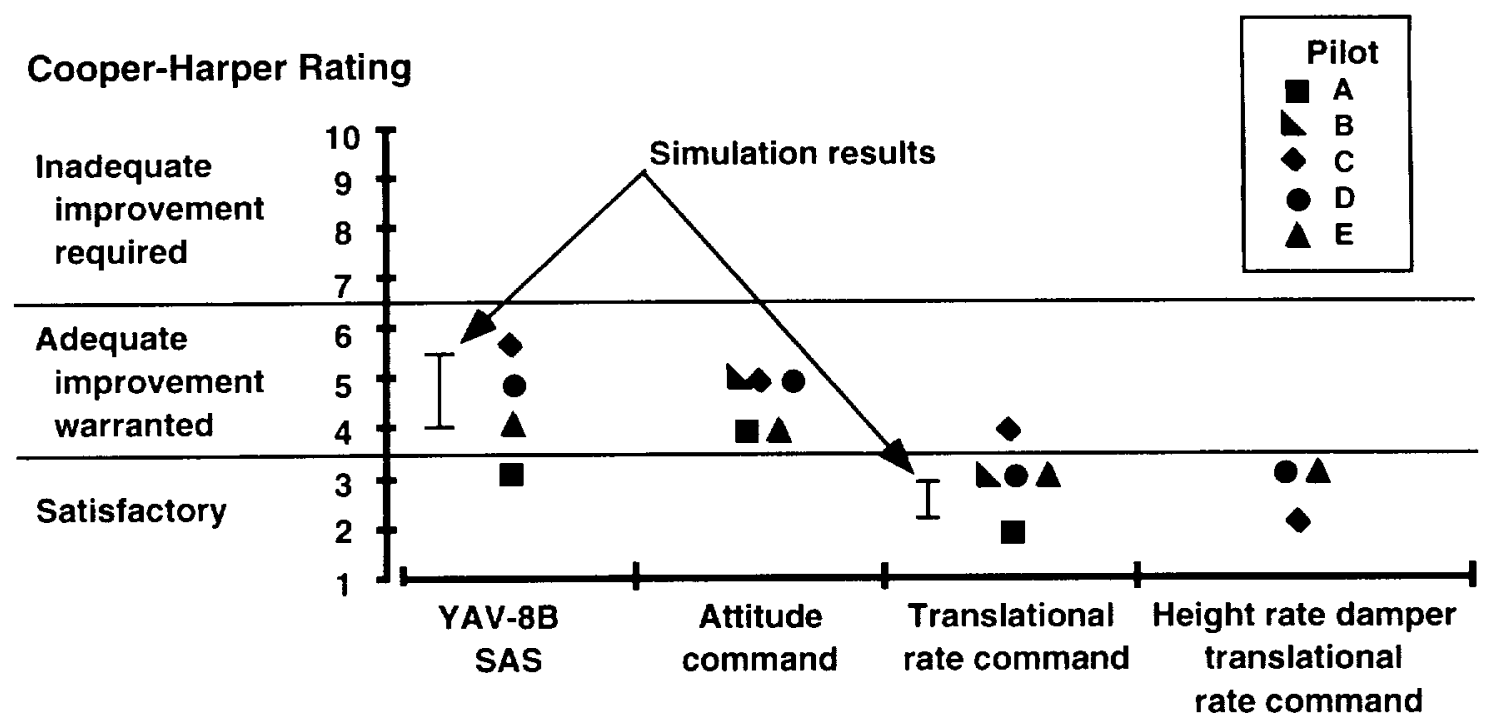

Figure 18. Pilot evaluations of vertical landing. 

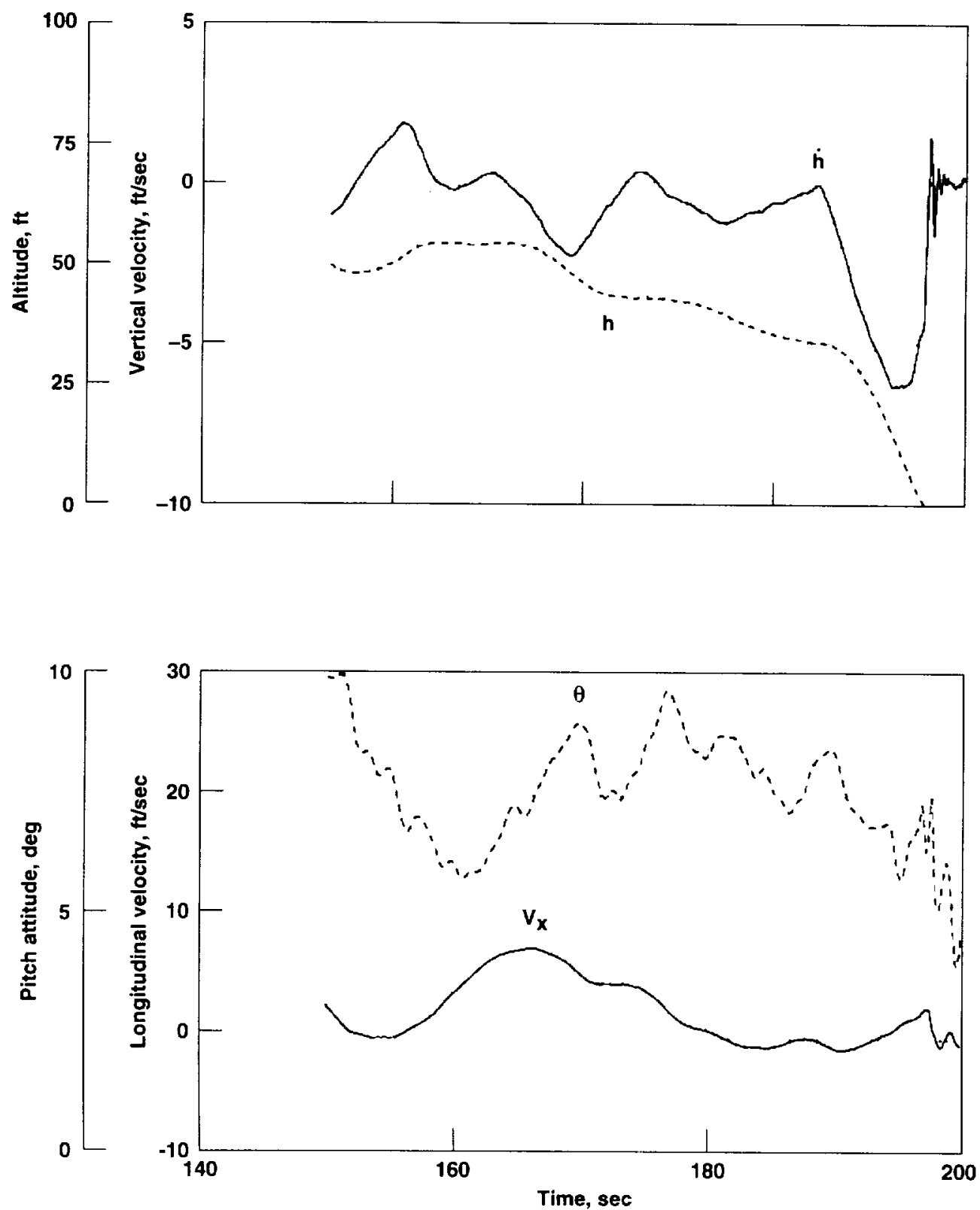

(a) Longitudinal response.

Figure 19. Hover and vertical-landing time histories for YAV-8B SAS (Configuration 1). 

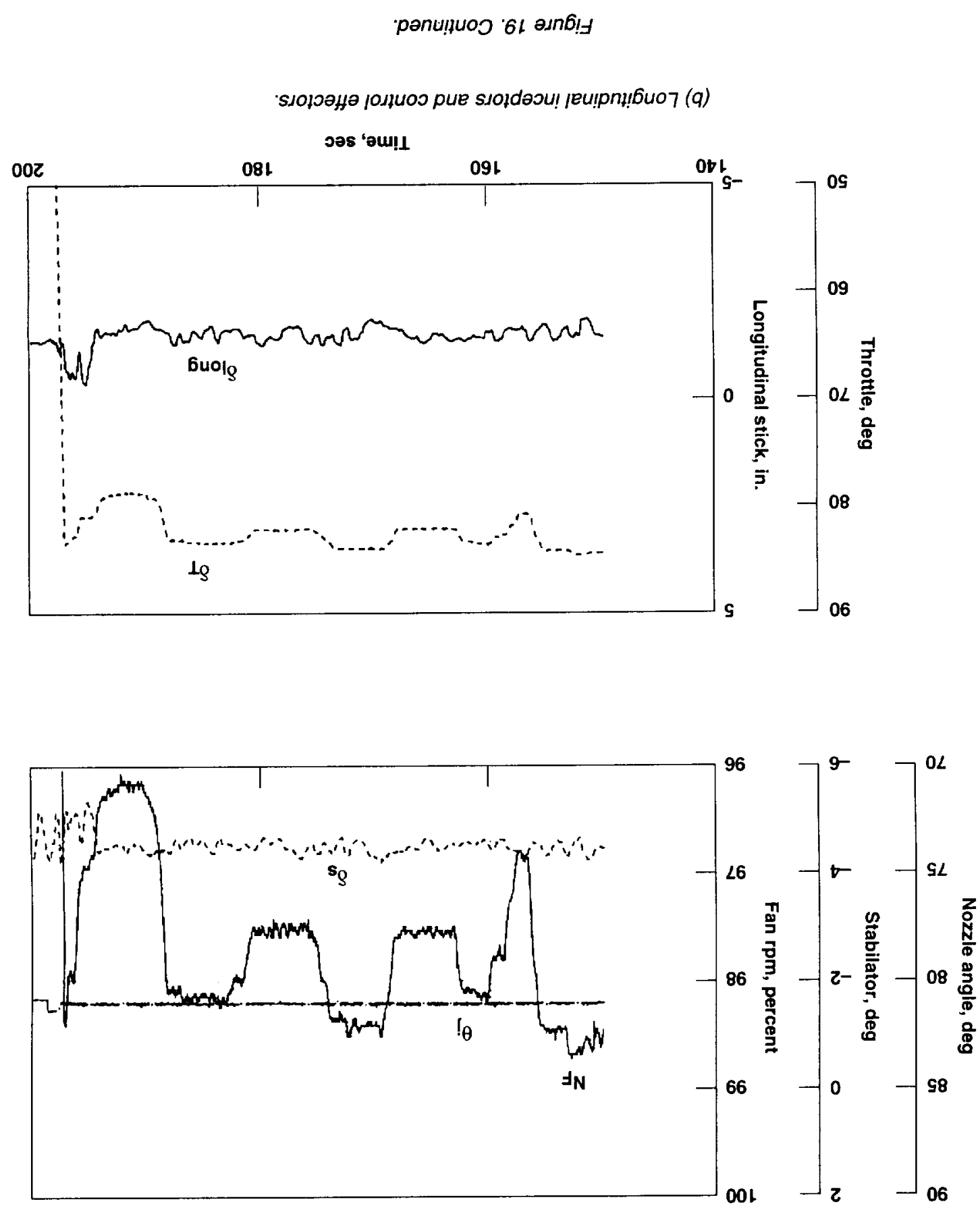

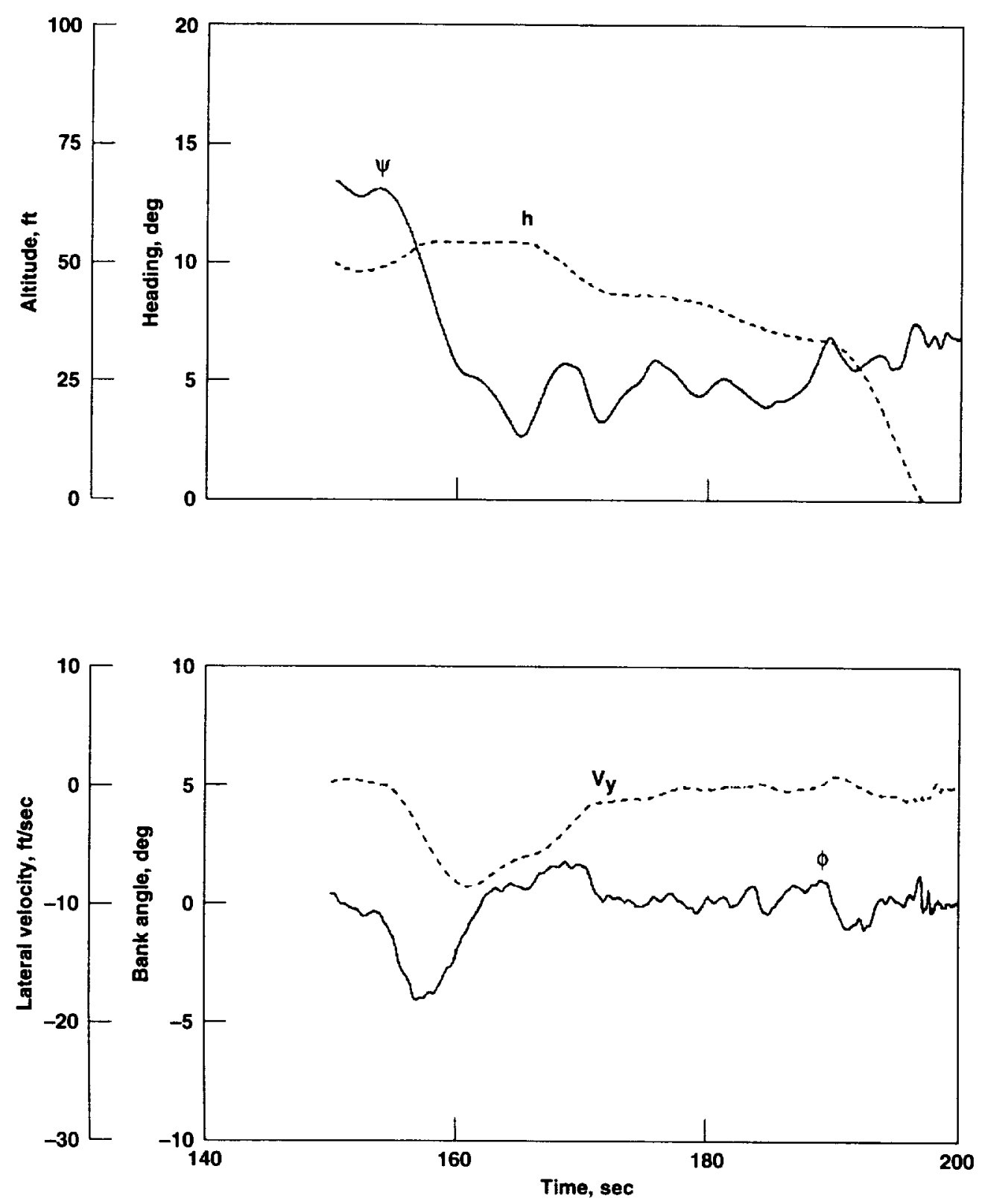

(c) Lateral-directional response.

Figure 19. Continued. 

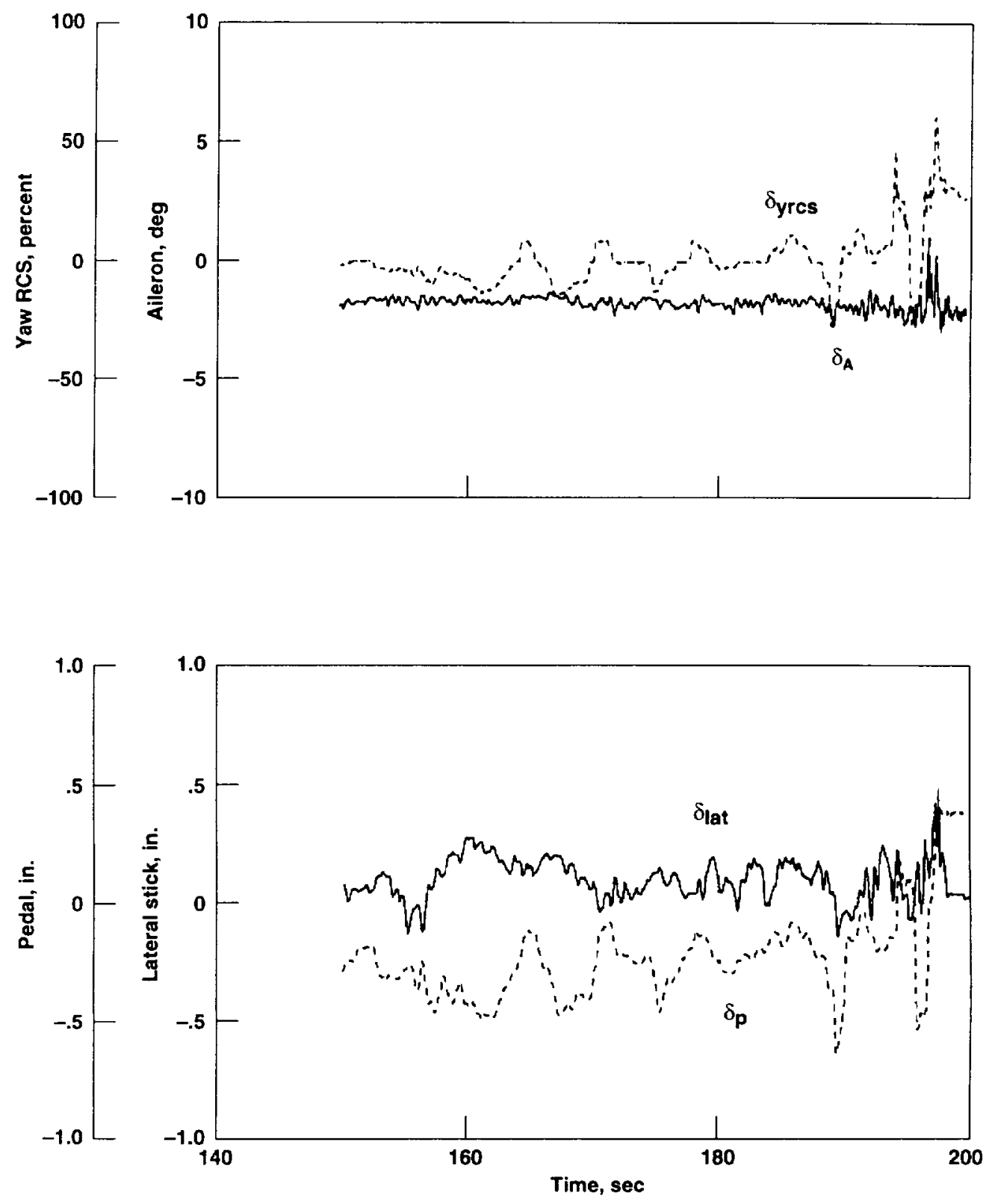

(d) Lateral-directional inceptors and control effectors.

Figure 19. Concluded. 

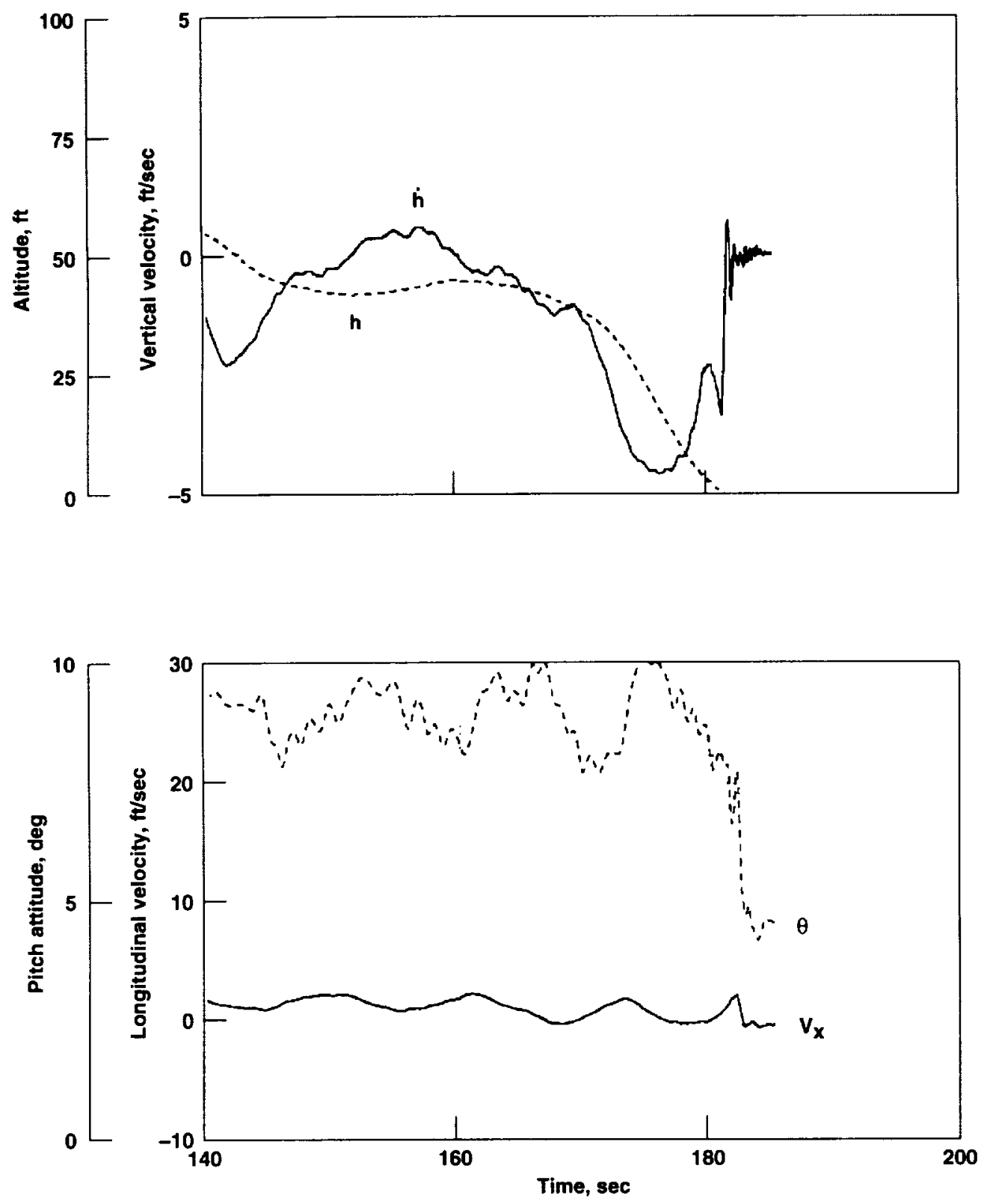

(a) Longitudinal response.

Figure 20. Hover and vertical-landing time histories for attitude command (Configuration 2). 


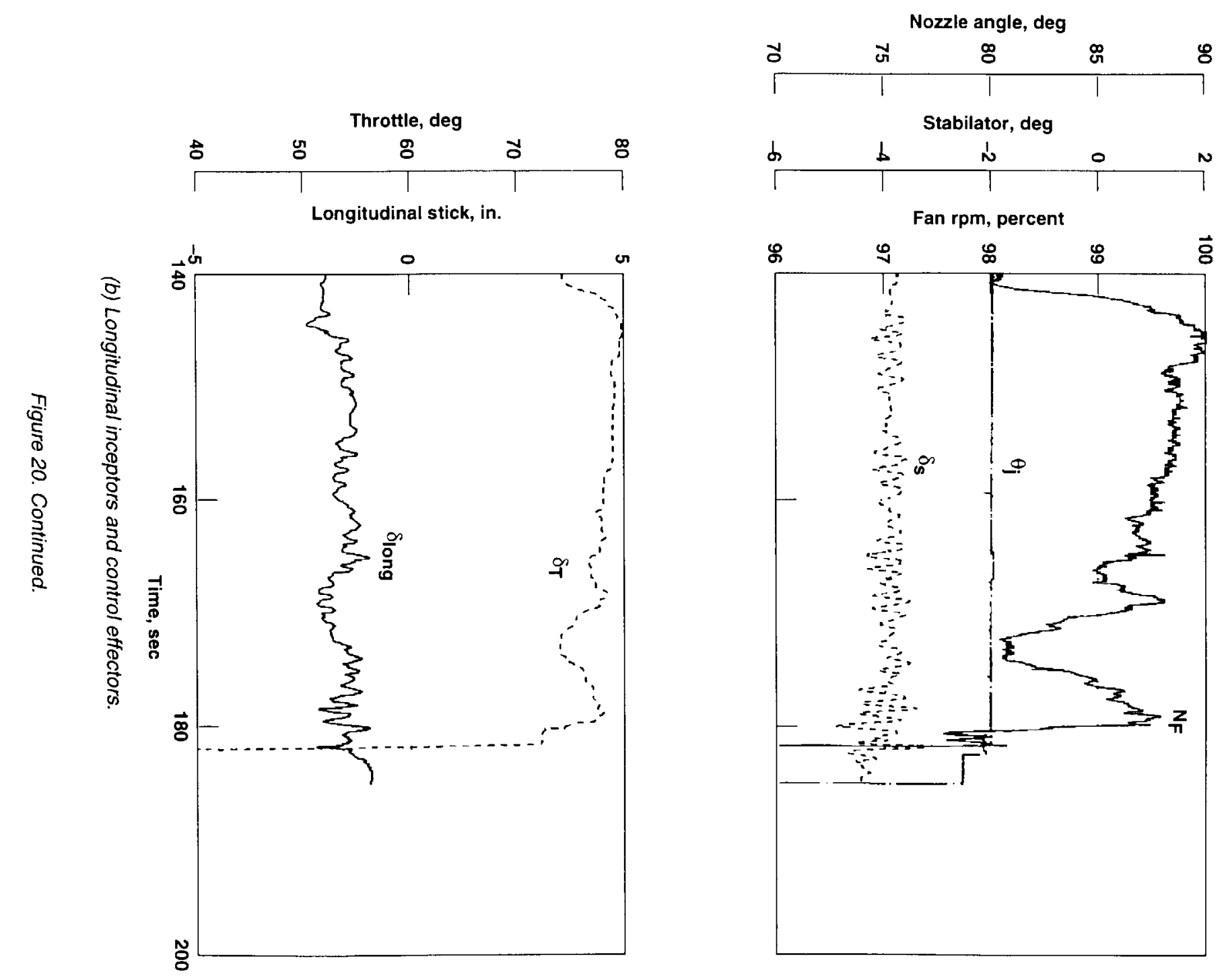



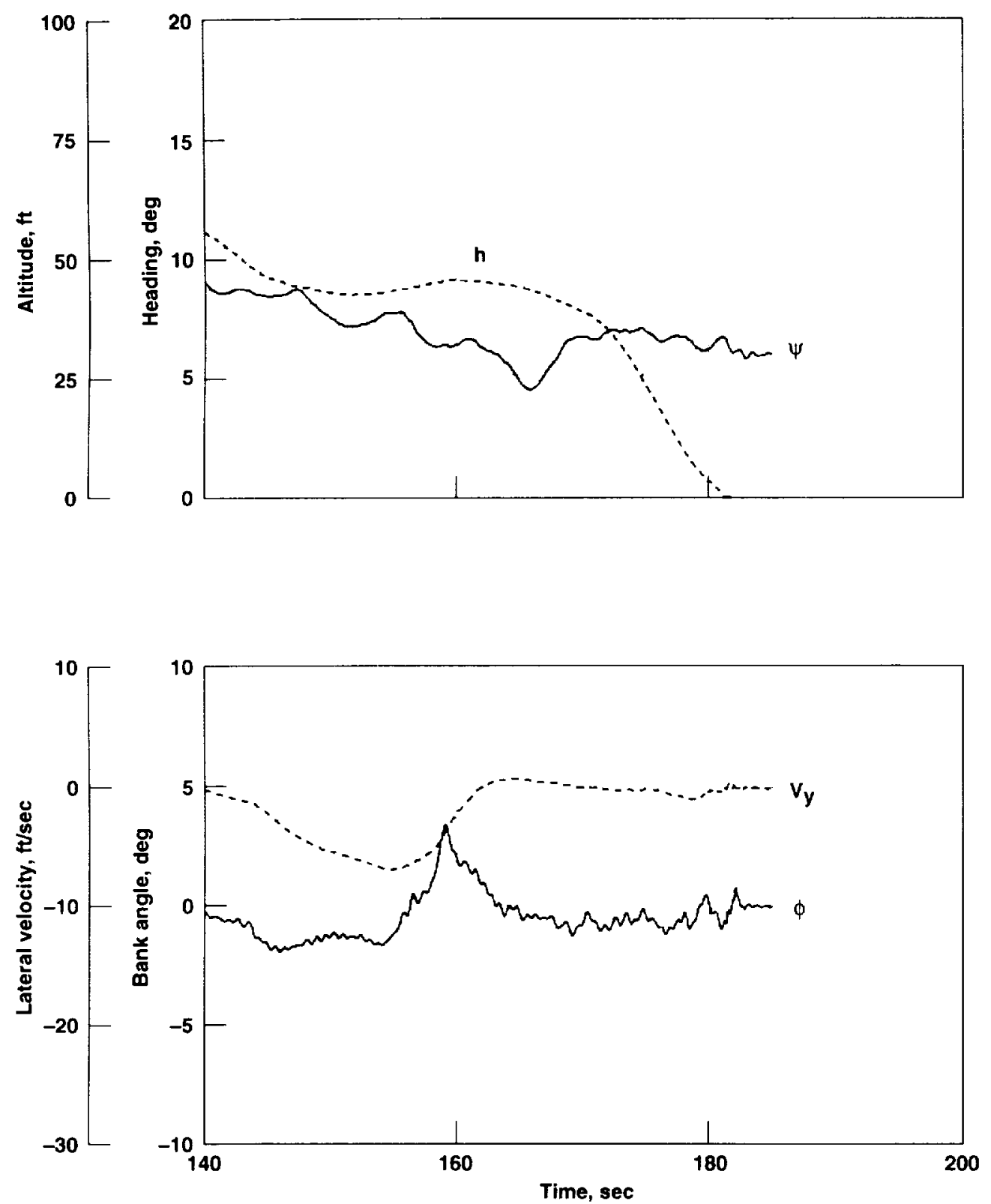

(c) Lateral-directional response.

Figure 20. Continued. 

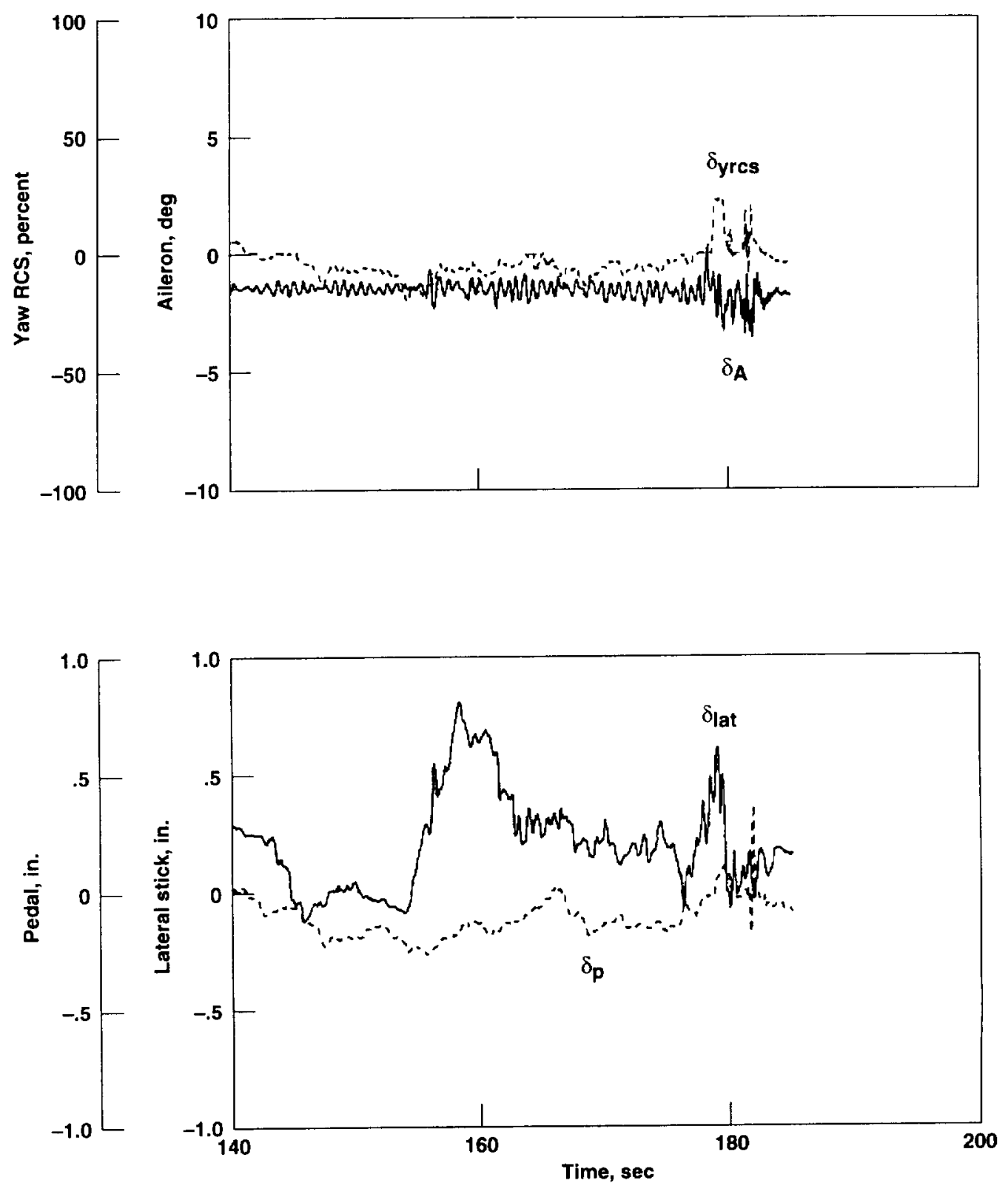

(d) Lateral-directional inceptors and control effectors.

Figure 20. Concluded. 
8
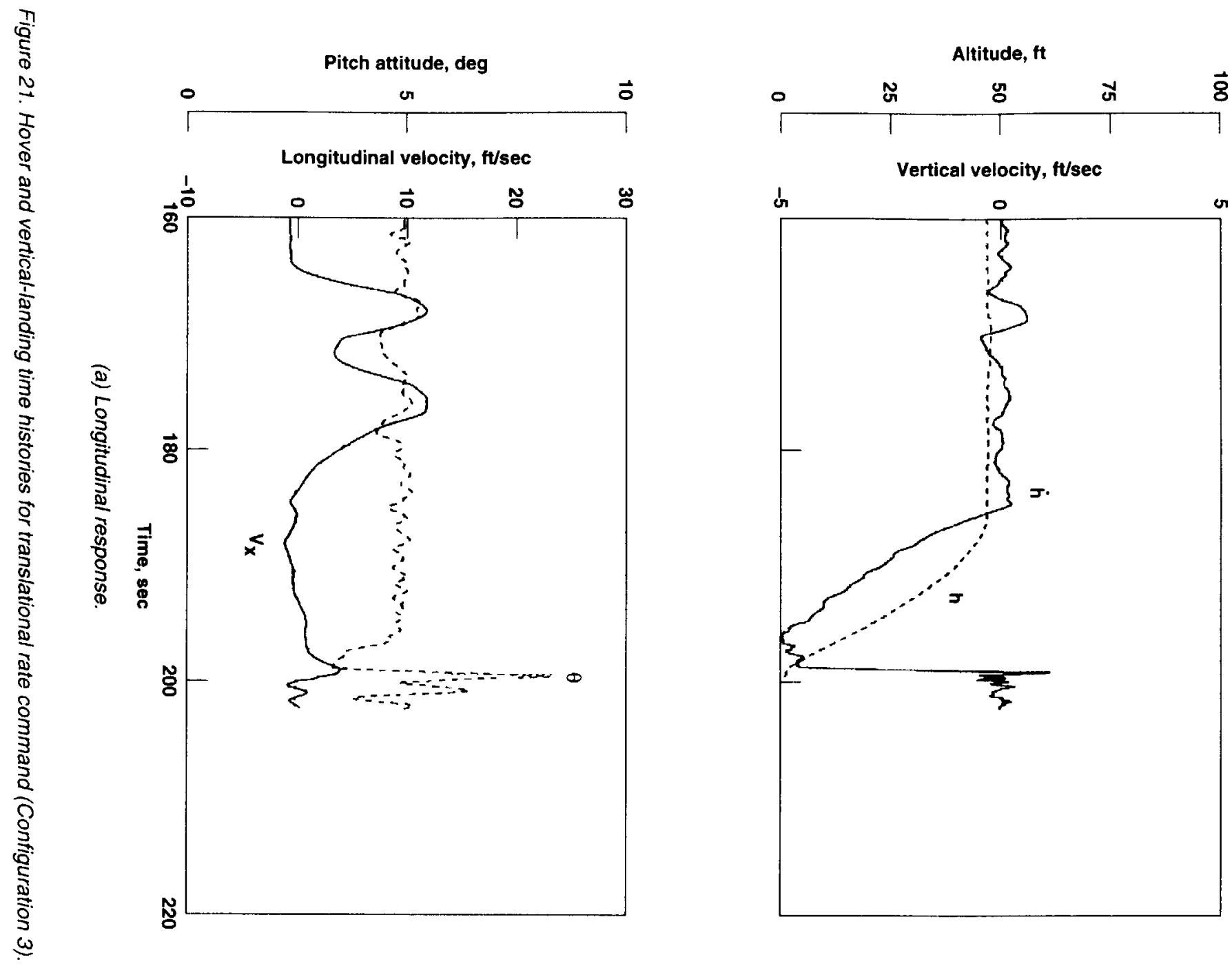

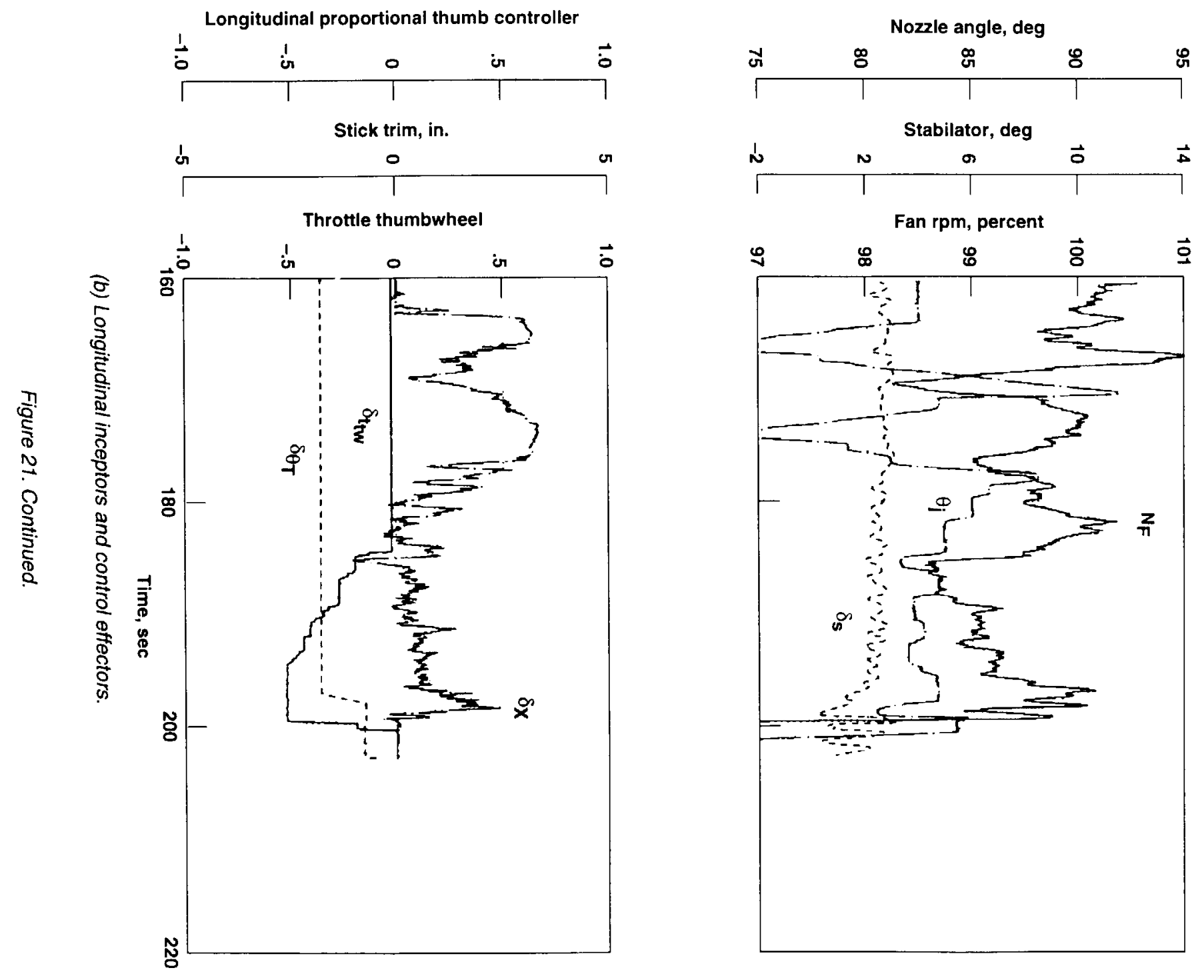

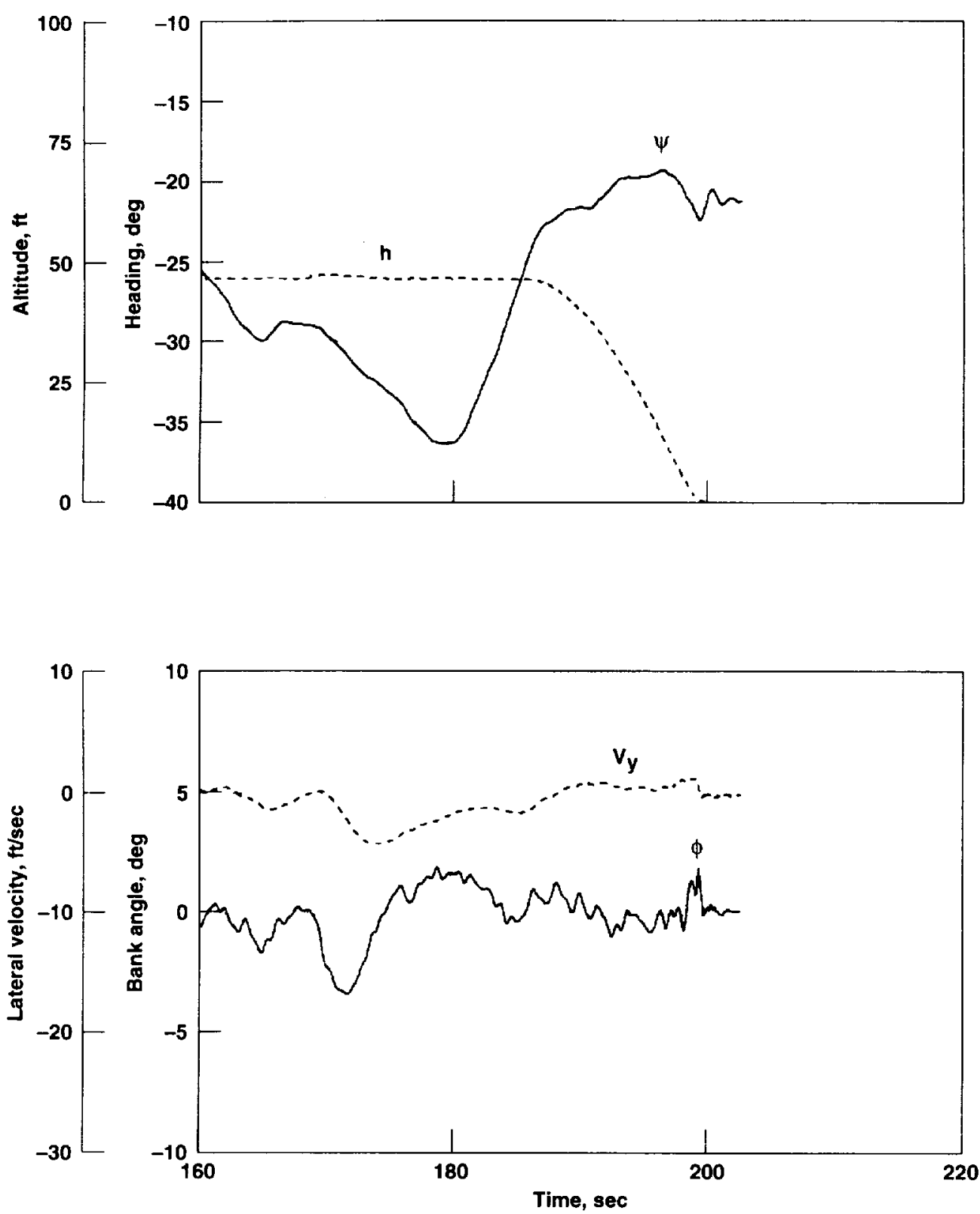

(c) Lateral-directional response.

Figure 21. Continued. 

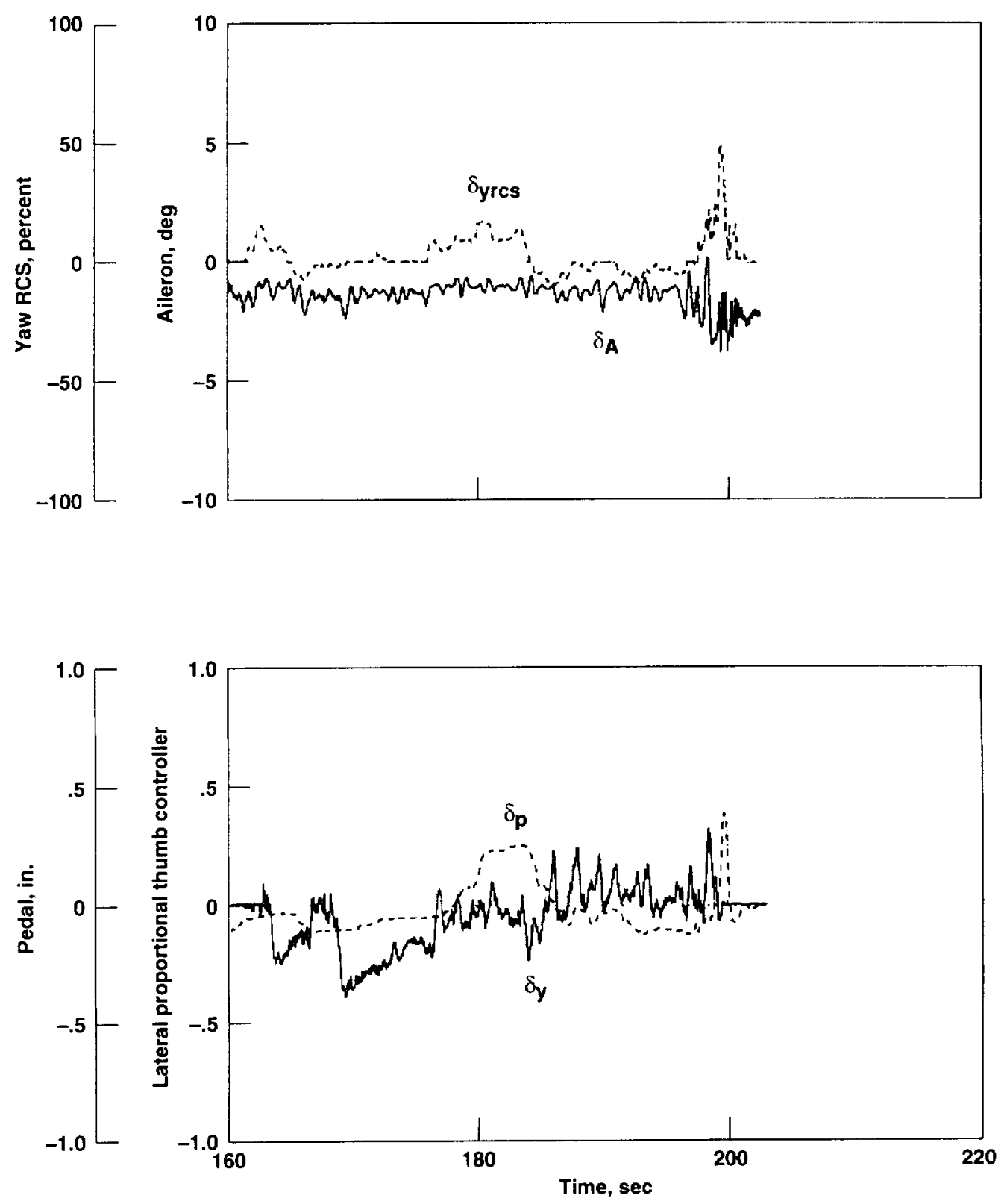

(d) Lateral-directional inceptors and control effectors.

Figure 21. Concluded. 

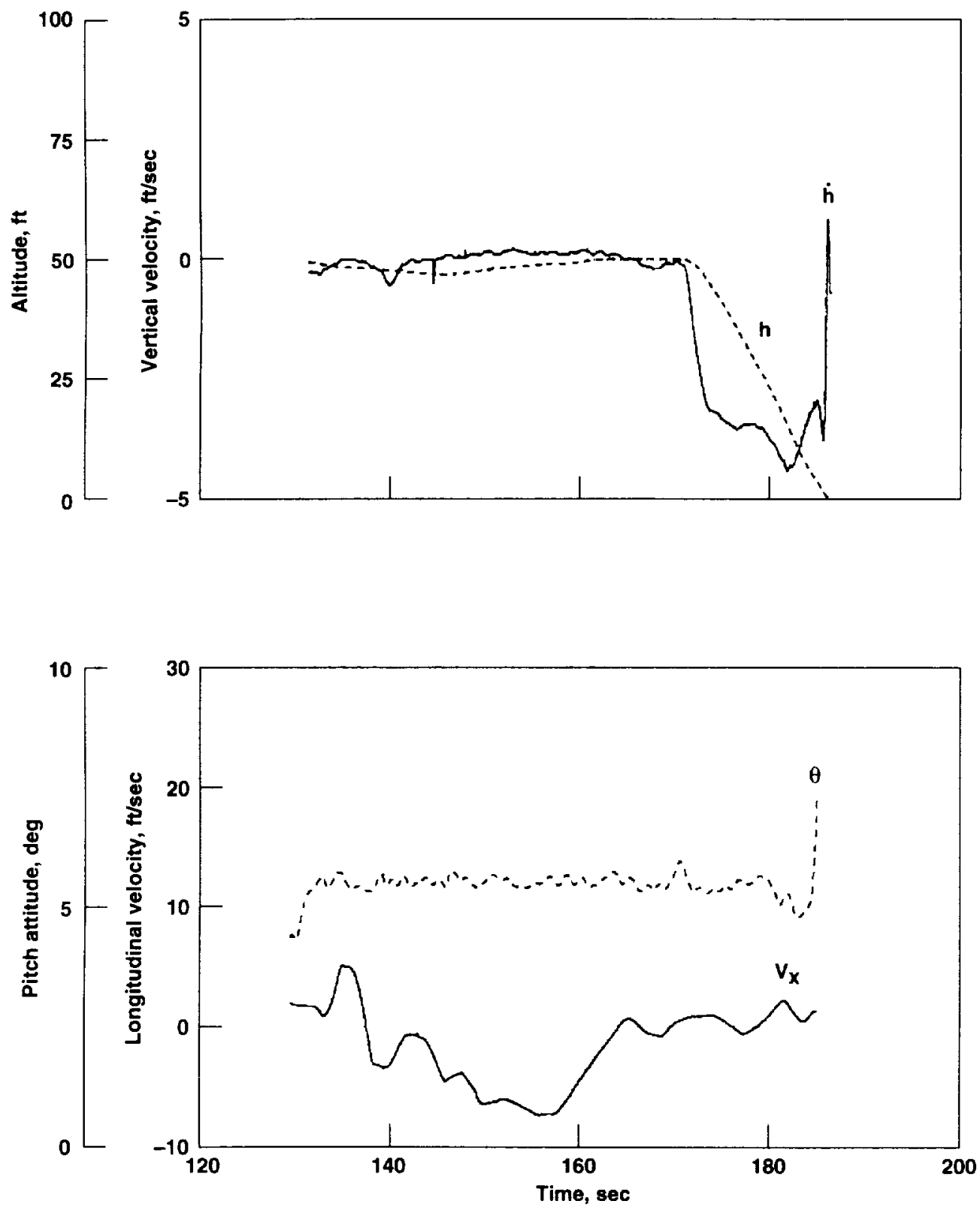

(a) Longitudinal response.

Figure 22. Hover and vertical-landing time histories for height-rate damper/translational-rate command (Configuration 4). 

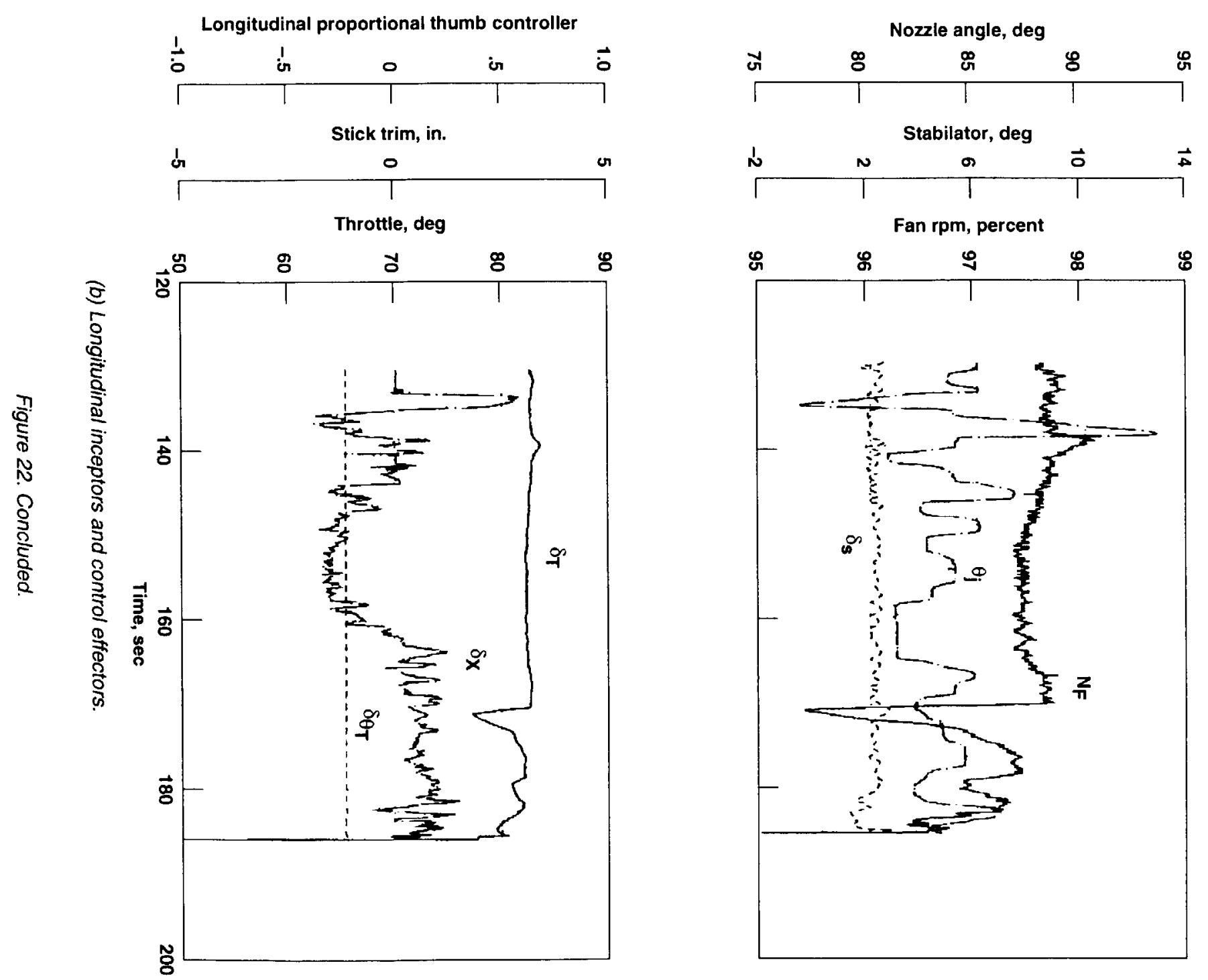
Effects of control bandwidth: Variations in translational-rate control system bandwidth produced the results shown in figures 23-25. The value of the bandwidth of the control system is defined as the frequency for a 45-deg phase margin for longitudinal-, lateral-, or vertical-position response to the respective cockpit controller. It was determined from frequency response data obtained using the method described in reference 14 . Examples of these frequency responses for the baseline translational-rate command configurations are presented in the appendix.

Longitudinal-velocity control results, presented in figure 23 , indicate that a borderline satisfactory/adequate bandwidth is $0.33 \mathrm{rad} / \mathrm{sec}$. The baseline longitudinal translational-rate control evaluated in the program had a bandwidth of $0.36 \mathrm{rad} / \mathrm{sec}$ and was considered to be fully satisfactory, as noted previously. For the lateral controller, the borderline bandwidth is $0.25 \mathrm{rad} / \mathrm{sec}$, as shown in figure 24 . The baseline lateral translational-rate control with a bandwidth of $0.29 \mathrm{rad} / \mathrm{sec}$ was rated satisfactory. For both longitudinal- and lateral-position control, at the lower bandwidths the pilots complained about a sluggish response to their commands through the proportional thumb controller and poor predictability in translating to, and establishing a precise hover over, the intended point. The satisfactory/adequate boundary for vertical-position control bandwidth is $0.6 \mathrm{rad} / \mathrm{sec}$, as shown in figure 25 . In comparison, the baseline height-rate command bandwidth was determined to be $0.64 \mathrm{rad} / \mathrm{sec}$ and was rated solidly satisfactory. Complaints about height control for the lower bandwidths concerned a sluggish response to verticalvelocity commands and poor holding of a steady vertical velocity as the aircraft entered ground effect, causing the pilot to adjust the sink-rate command to complete the landing. At the lowest bandwidth tested, positive ground cushion upon entering ground effect caused sufficient fluctuations in sink rate to arrest the descent momentarily. For all three axes, the basic aircraft with no translationalrate augmentation was rated only adequate (handlingqualities rating (HQR) 4 to 5) for the hover-position control task.

Slow Landing- Pilots' evaluations for the attitude command system revealed some improvement over the basic YAV-8B; the improvement was achieved by decoupling the attitude response in the presence of thrust modulation for path control. Control of flightpath was precise during the approach. The flightpath command system was rated satisfactory during the approach as a consequence of the precise path control and the ability to easily set and hold speed. However, one pilot rated the flare to touchdown borderline satisfactory/adequate because of the need to compensate for a tendency to pitch down when entering ground effect. The pitch series servo was of insufficient authority to counter the nose-down moment, thus forcing the pilot to intervene to avoid a nose-gear strike at touchdown. Another pilot complained of a sluggish flightpath response in the landing flare; he desired additional descending flightpath authority. However, the flightpath command system was considered to be a superior mode for performing slow landings where precise control to an austere landing area, such as a narrow road, is demanded.

Example time histories for the flightpath/acceleration command system, shown in figure 26 , illustrate a slow landing from a visual approach along a descending turn to the runway. The turn was completed to line up with the runway at an altitude of about $150 \mathrm{ft}$. After the initial stick thumbwheel input to decelerate to the target approach speed of 100 knots, no further action was required of the pilot for speed control. Speed held steady in the presence of flightpath corrections about a nominal 4-deg path throughout the approach and during the flare to touchdown. Nearly full aft throttle thumbwheel was required for a descent of $5 \mathrm{deg}$. The initial action to reduce sink rate prior to touchdown was performed with the throttle thumbwheel.

\section{Control System Performance}

Control Utilization- Figures 27 through 40 show minimum, maximum, and mean control activity for the VSRA during approach, station-keeping-point acquisition, hover, vertical landing, and slow landing, collected over the course of more than 100 flights. The data are categorized by the control mode used for each flight and arranged from left to right in order of increasing mean control activity. The variation in mean control activity is associated with variations in aircraft trim due to changes in loading and winds among the individual runs. Maximum and minimum excursions about the mean reflect control authority used for maneuvering. It should be noted that most data were obtained for light winds and turbulence.

Pitch control: Figures 27-30 illustrate pitch-control activity for the different tasks and response types. During the decelerating approach (fig. 27), there is no apparent influence of control response type on peak control excursions about the mean. The excursions are on the order of \pm 2.5 to 4 deg out of a total stabilator authority of -10.25 to $11.25 \mathrm{deg}$, and they represent 23 to 37 percent of total authority. Variations in the mean stabilator deflection reflect changing longitudinal trim associated with variations in center of gravity with fuel remaining for different approaches. For the task of capturing the stationkeeping point, response type impacts control usage to some degree. As noted previously, for the YAV-8B SAS 


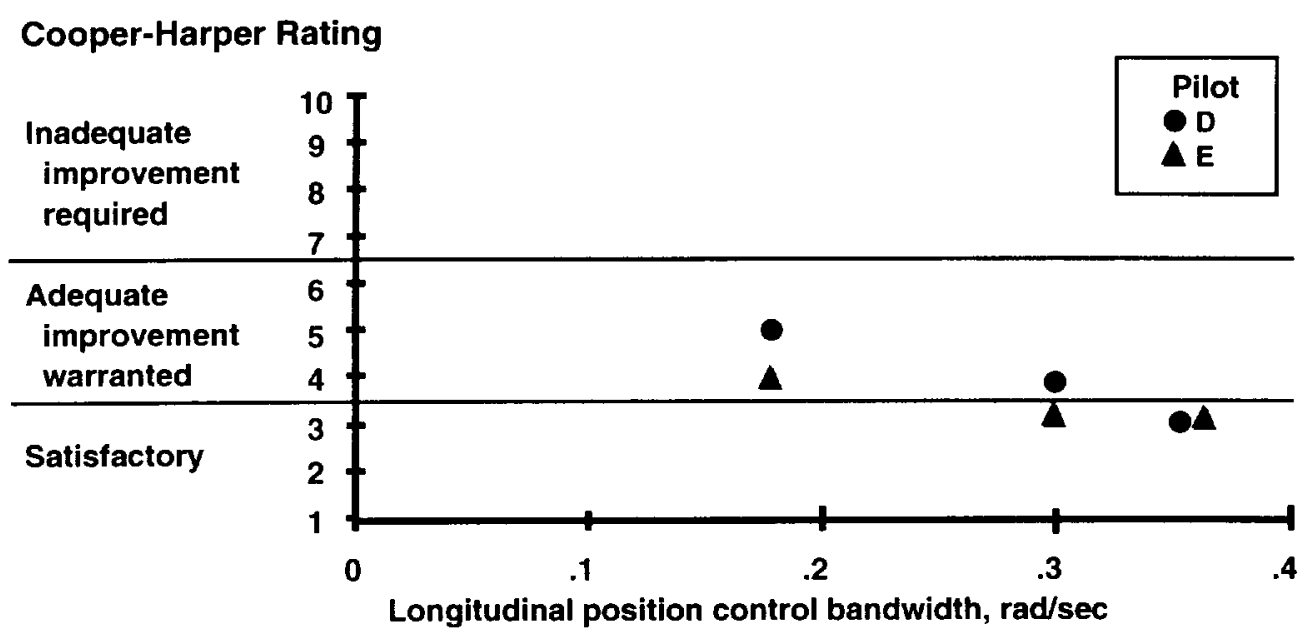

Figure 23. Pilot evaluations of longitudinal-position control bandwidth.

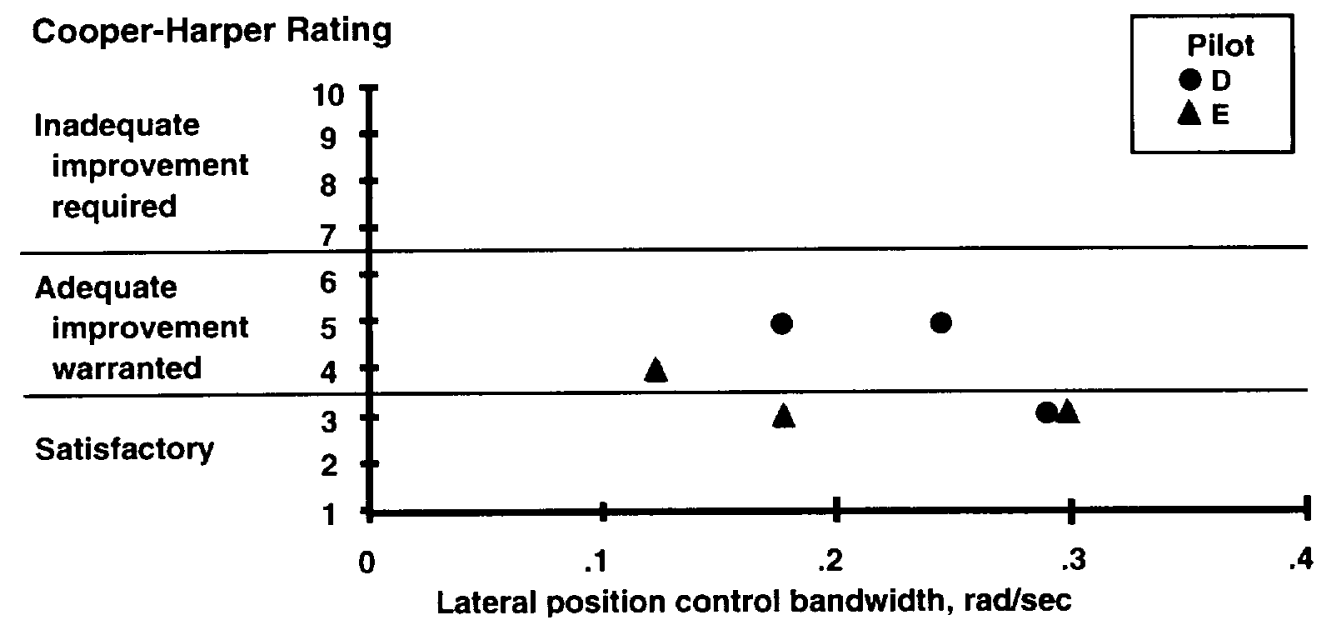

Figure 24. Pilot evaluations of lateral-position control bandwidth.

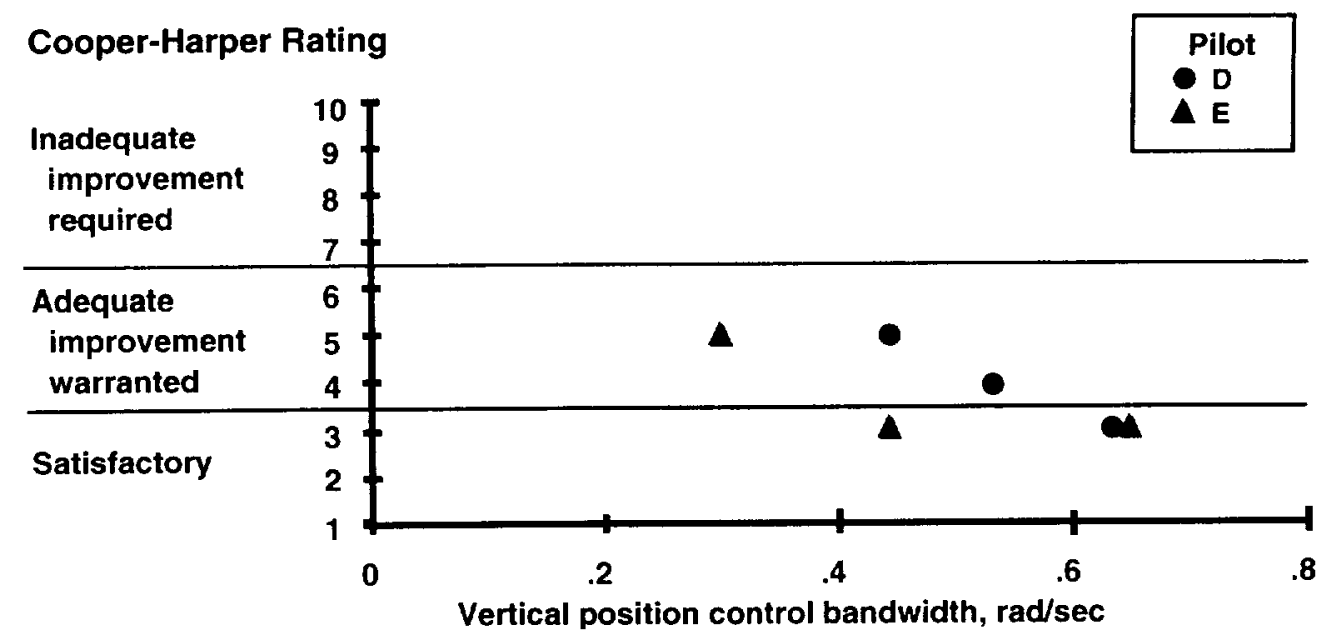

Figure 25. Pilot evaluations of vertical-position control bandwidth. 

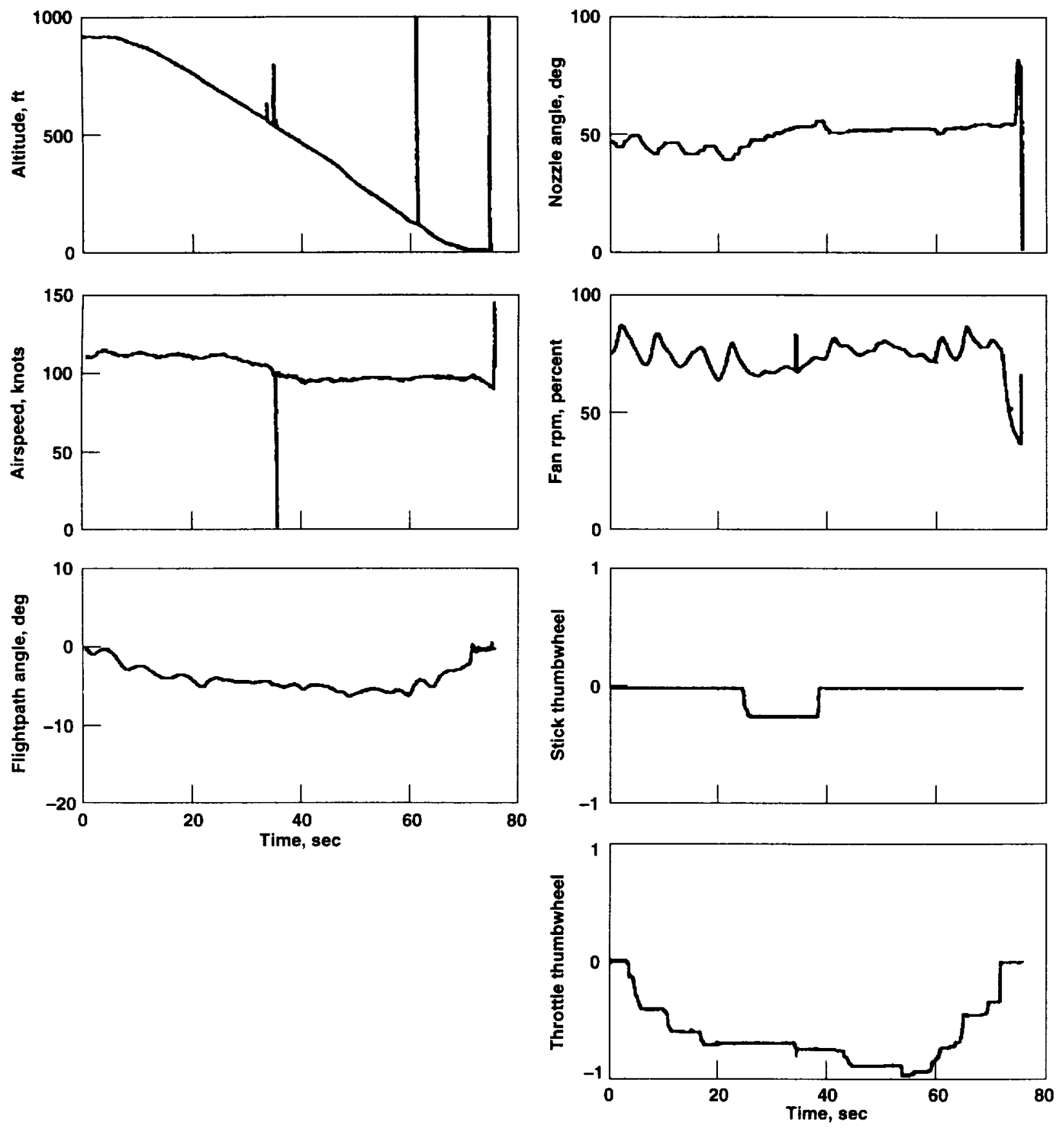

(a) Longitudinal response.

Figure 26. Time histories for Configuration 3 in a slow landing. 

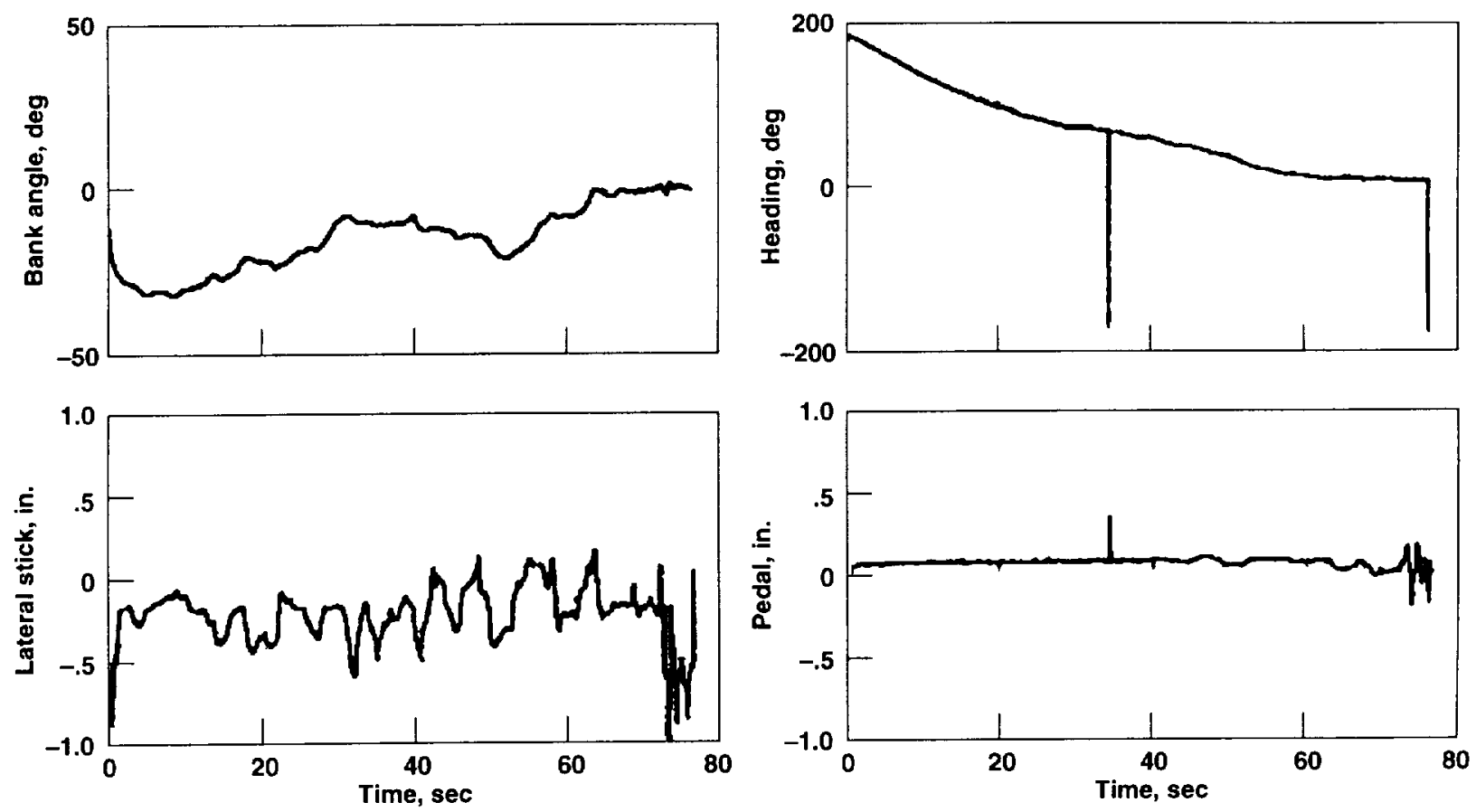

(b) Lateral response.

Figure 26. Concluded.

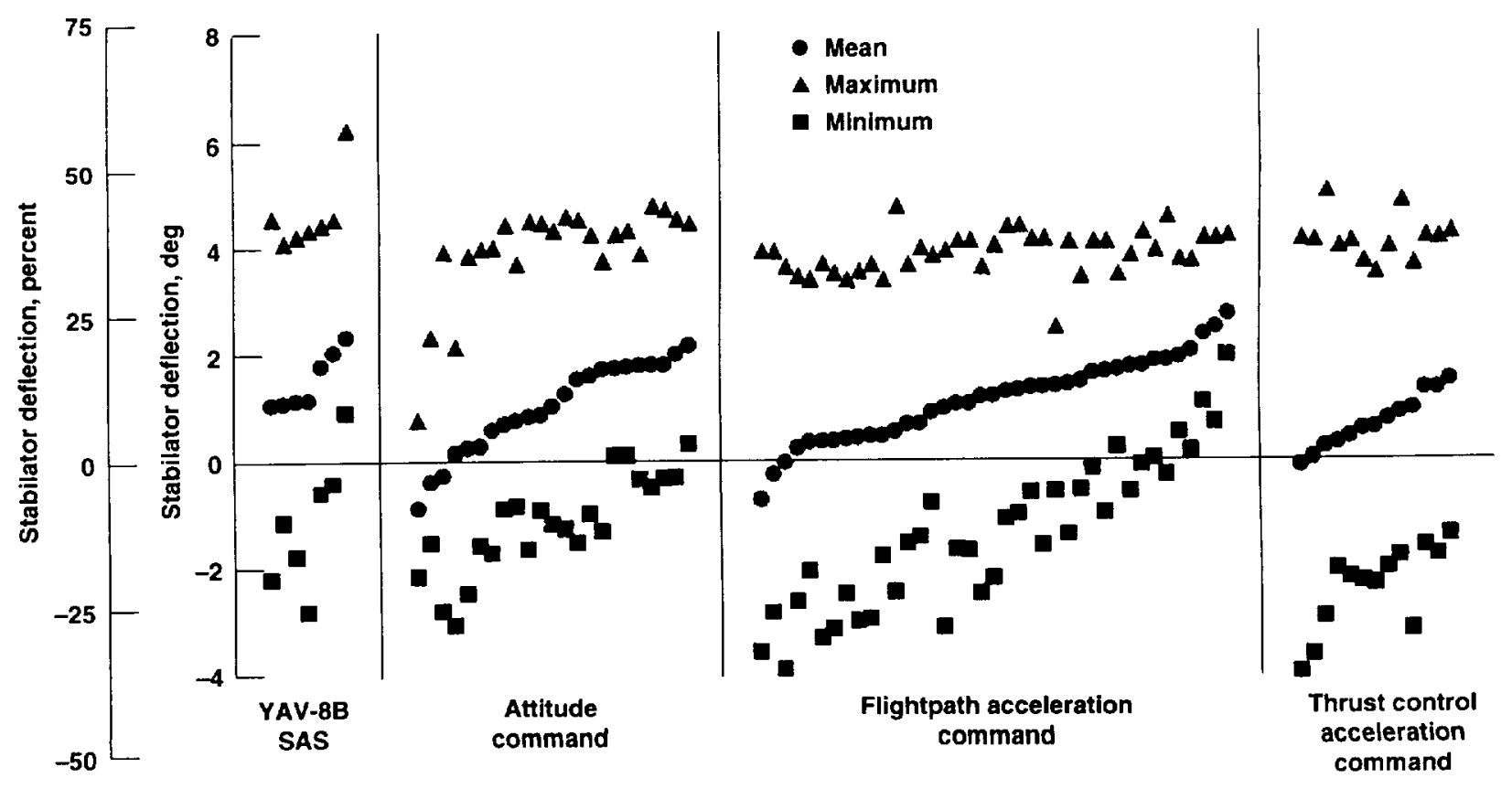

Figure 27. Pitch-axis control activity during approach. 


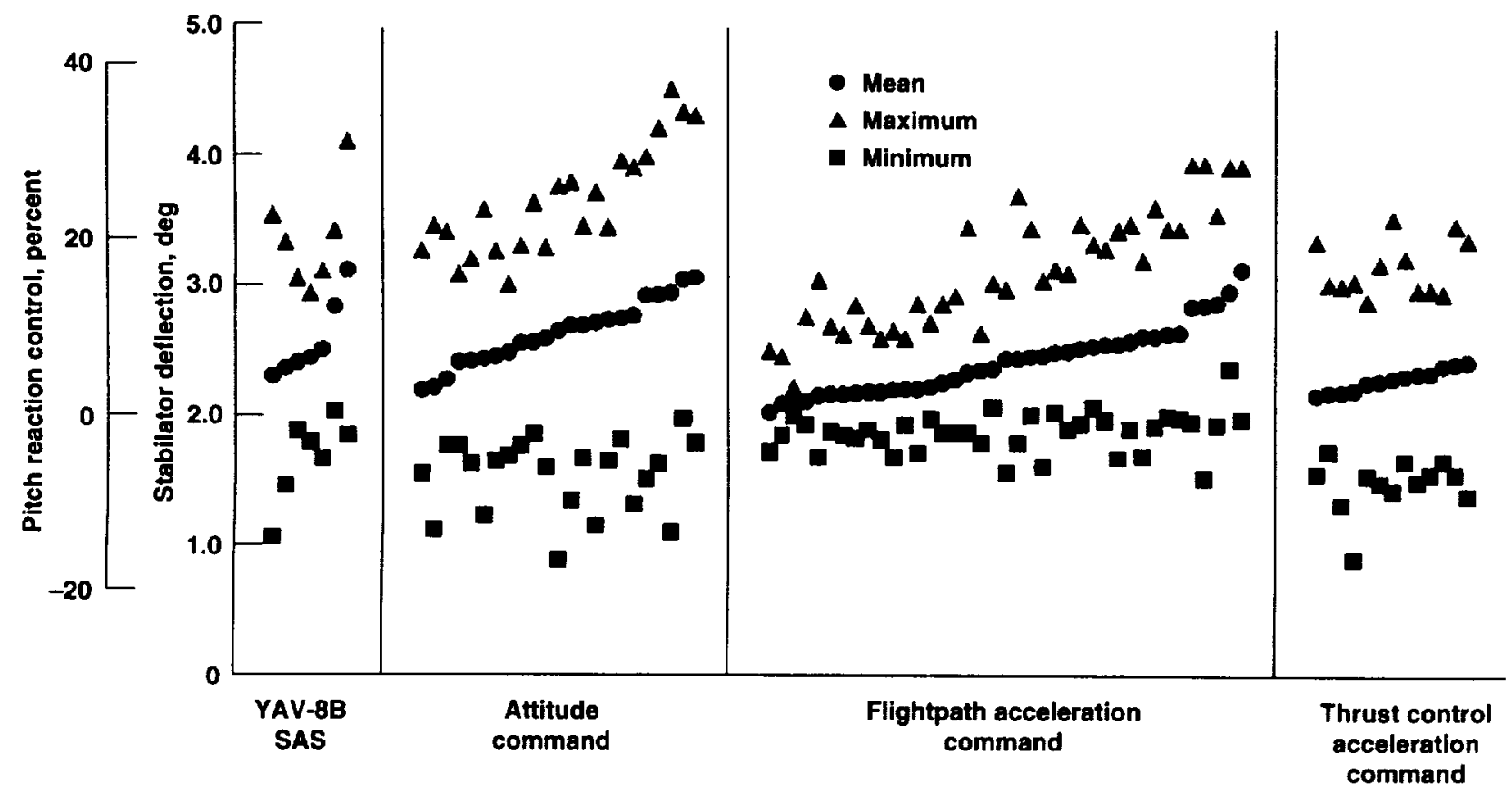

Figure 28. Pitch-axis control activity during hover-point acquisition.

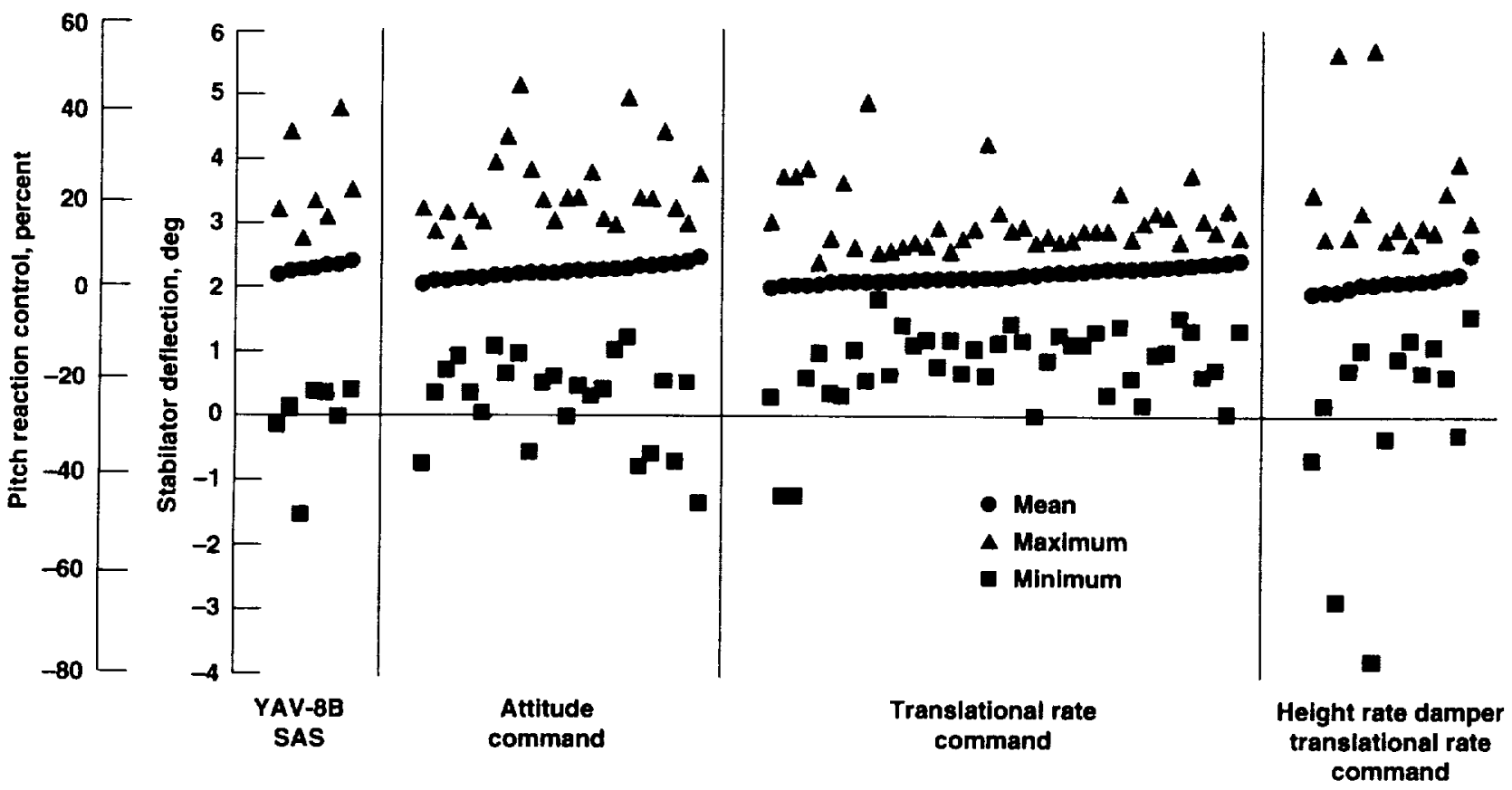

Figure 29. Pitch-axis control activity during hover and vertical landing. 


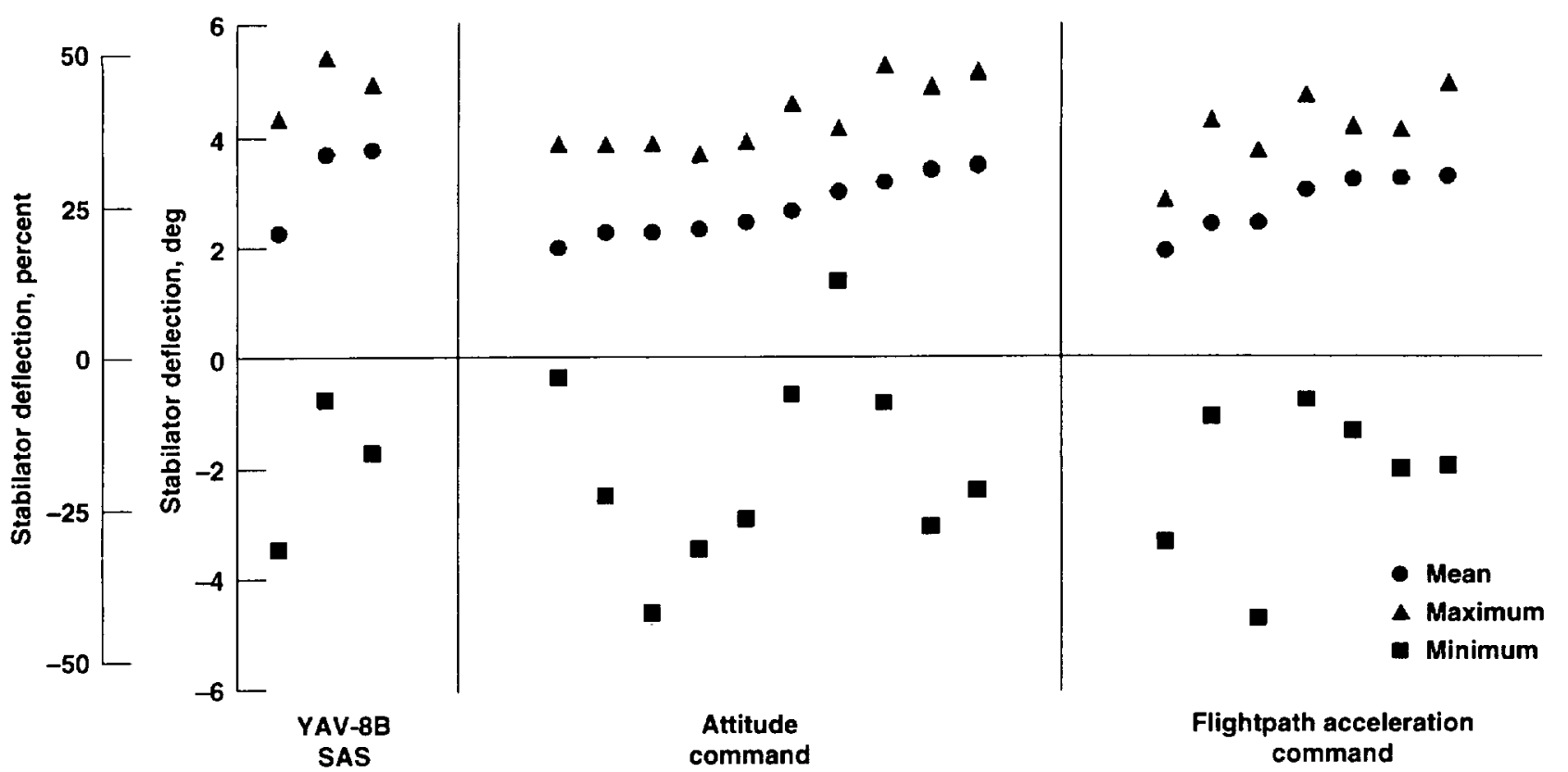

Figure 30. Pitch-axis control activity during slow landing.

and the attitude command system, the pilot adjusts pitch attitude to decelerate to the hover, whereas for the two systems with longitudinal-acceleration command working through thrust deflection, the pitch attitude is held constant. The data in figure 28 show that peak control excursions for the YAV-8B SAS and the attitude command system exceed those for the flightpath/ acceleration command and thrust control with acceleration command systems. For the former two response types, excursions range from 0.7 to $1.7 \mathrm{deg}$. It should be noted that, for hover or near-hover conditions, reaction controls rather than the stabilator supply the control moments, and the RCS authority (in terms of equivalent stabilator position) ranges from -3.3 to $10 \mathrm{deg}$. Thus the excursions noted represent 10 to 25 percent of total pitch reaction control authority. For the latter two response types, excursions range from 0.4 to $1 \mathrm{deg}$ of the equivalent stabilator and represent 6 to 16 percent authority. This contrast between response types holds for the hover and vertical landing task as well. In figure 29, peak excursions for the YAV-8B SAS and attitude command range from 1 to $3 \mathrm{deg}$ (up to 45 -percent authority), whereas those for the two longitudinal-acceleration command systems range from 0.4 to $2 \mathrm{deg}$ (up to 30 -percent authority). Rather sparse data exist for slow landings and do not reveal any influence of response type. Figure 30 indicates excursions from 1.5 to $3 \mathrm{deg}$, or about 28 percent of total stabilator authority for this task for all the systems.
Roll control: Control activity for the roll axis is presented in figures 31-34 for the various tasks. Response types do not influence the level of roll-control activity for any of the tasks, even though attitude stabilization is provided for all except the YAV-8B SAS and the lateralvelocity command is available for two of the modes in hover. In figure 31 , data for the approach show peak excursions about the mean from $0.5 \mathrm{deg}$ right wing down to 1 deg left wing down, with many cases of substantially lower magnitude. Of a total aileron authority of $\pm 16.8 \mathrm{deg}$, these larger excursions still reach only 6 percent of maximum aileron. The airplane shows a consistent left-wing-down trim requirement of $1 \mathrm{deg}$. During acquisition of the station-keeping point (fig. 32), occasional peaks in control utilization are as large as those for the approach, but the predominance of data show small excursions of about $0.2 \mathrm{deg}$. For hover or nearhover conditions, control authority is based on the maximum available reaction control, which in this case is $\pm 11.5 \mathrm{deg}$ of equivalent aileron. Thus, the range of peak roll control excursions for this task is from 2 to 9 percent of the reaction control capability for all the response types. For hover and vertical landing (fig. 33), the magnitude of peak excursions is similar to those for the station-keeping-point acquisition. Again, the control usage is from 2 to 9 percent of maximum reaction control. Peak aileron excursions for the slow landing (fig. 34) are again from 0.2 to as large as $1 \mathrm{deg}$, and in this case they 

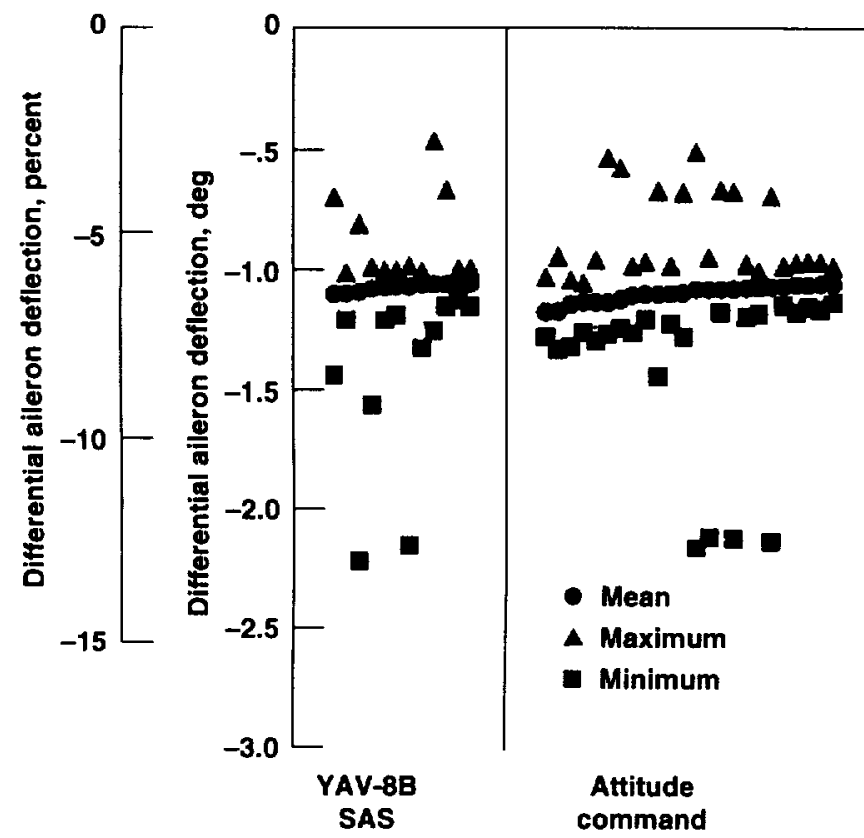

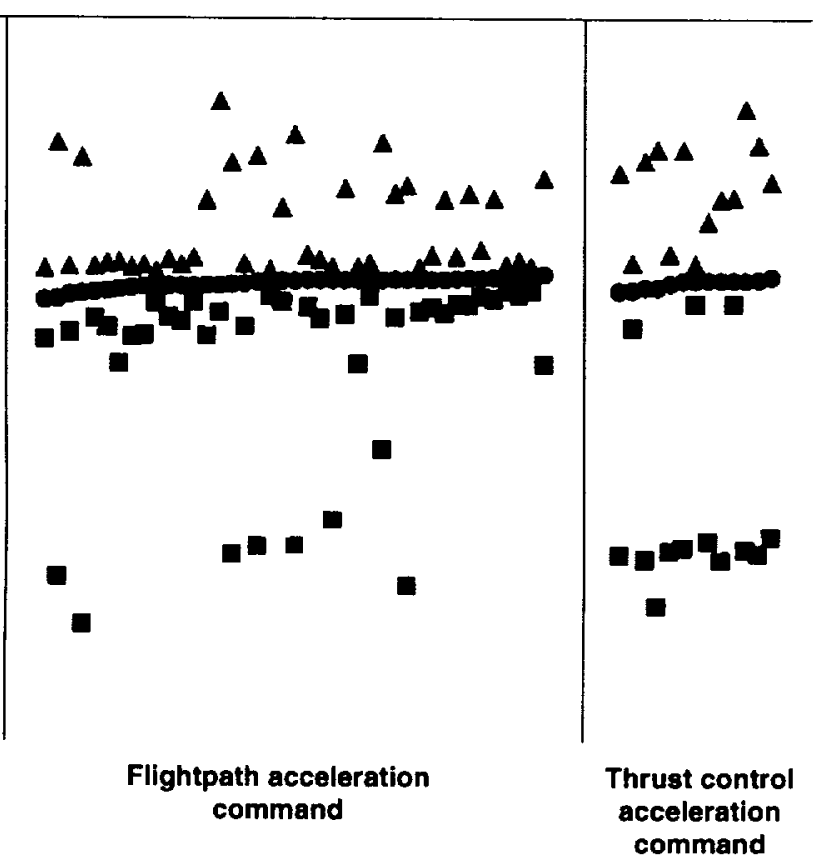

Figure 31. Roll-axis control activity during approach.
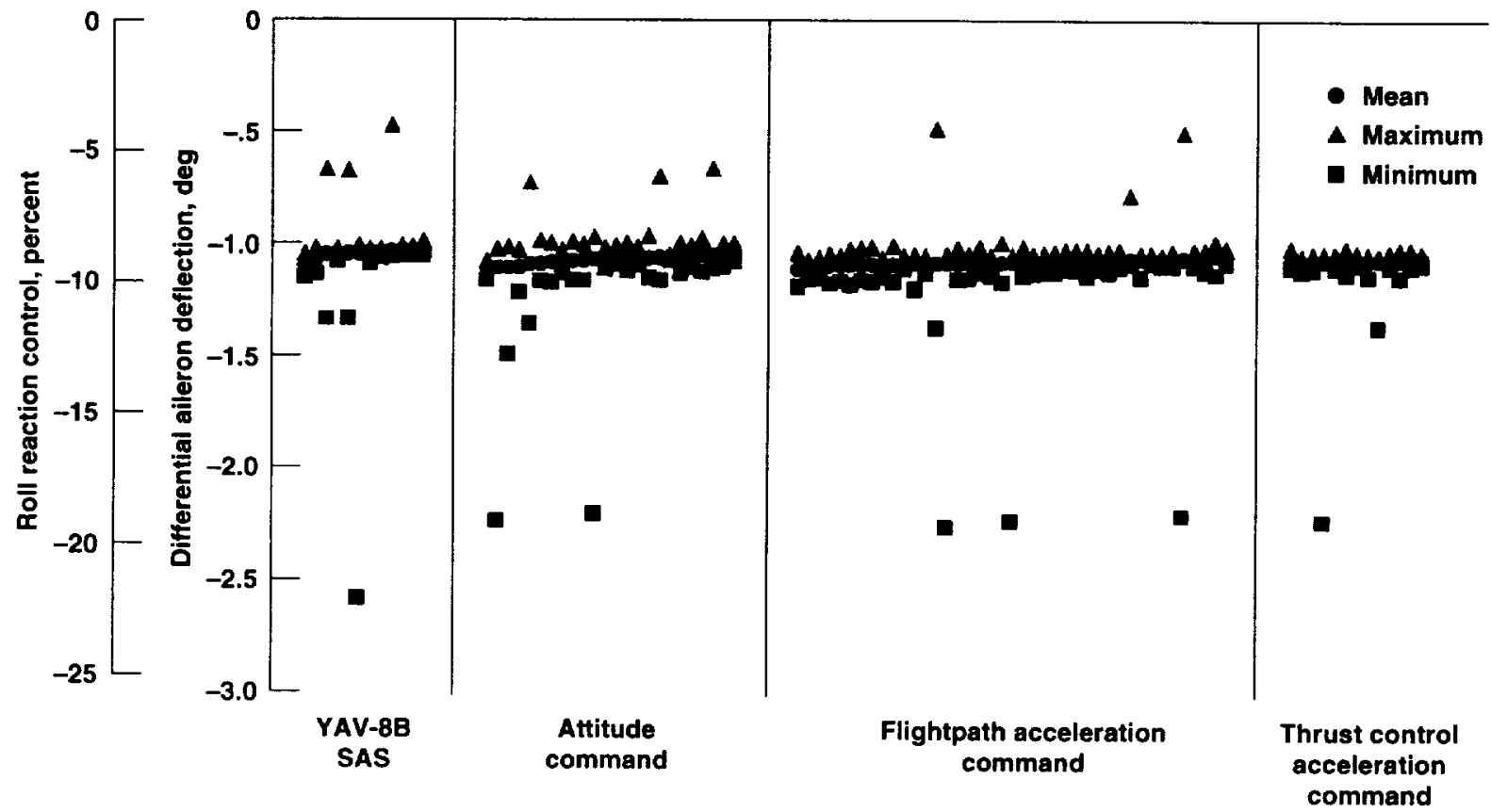

Figure 32. Roll-axis control activity during hover-point acquisition. 


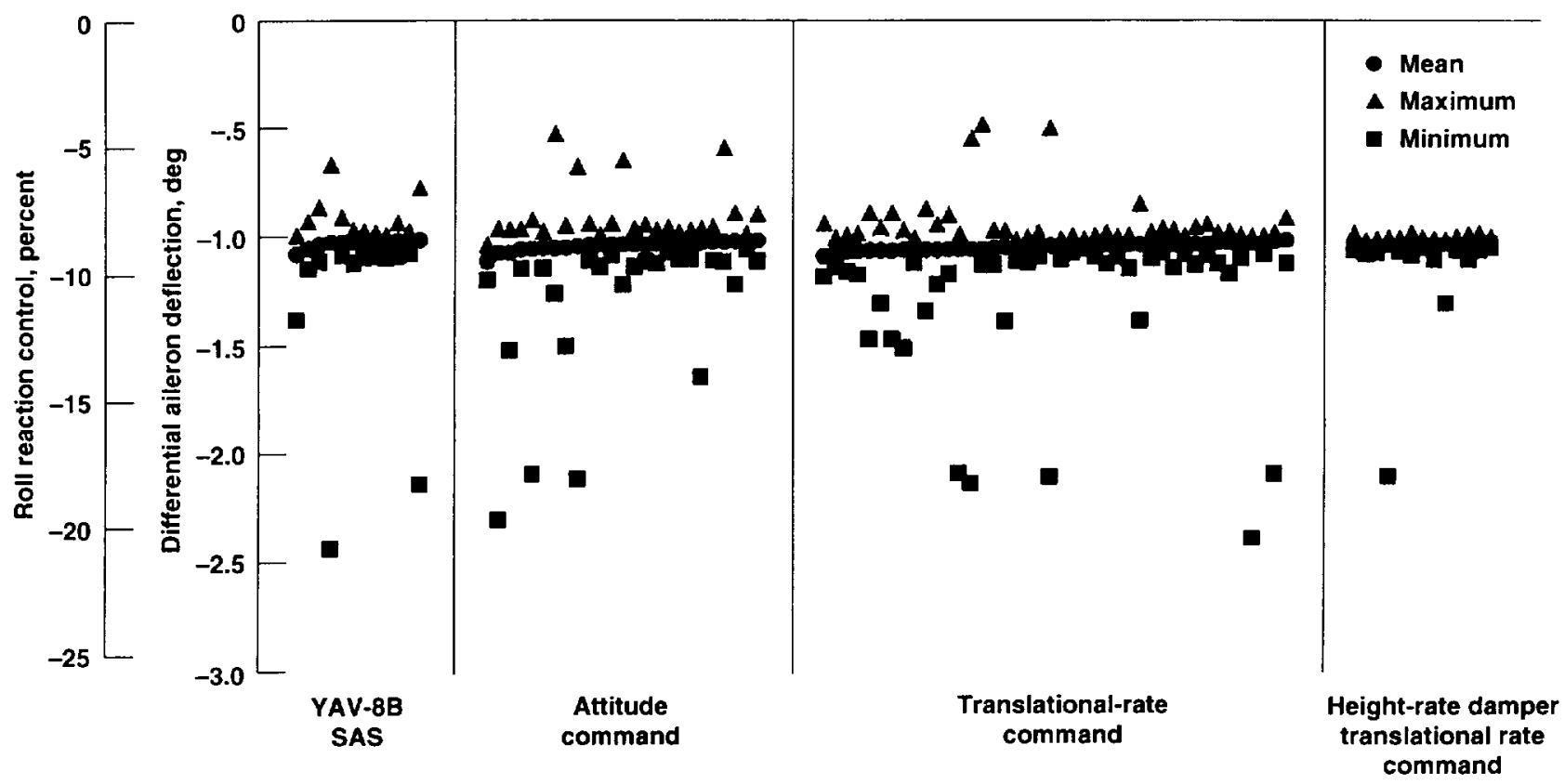

Figure 33. Roll-axis control activity during hover and vertical landing.

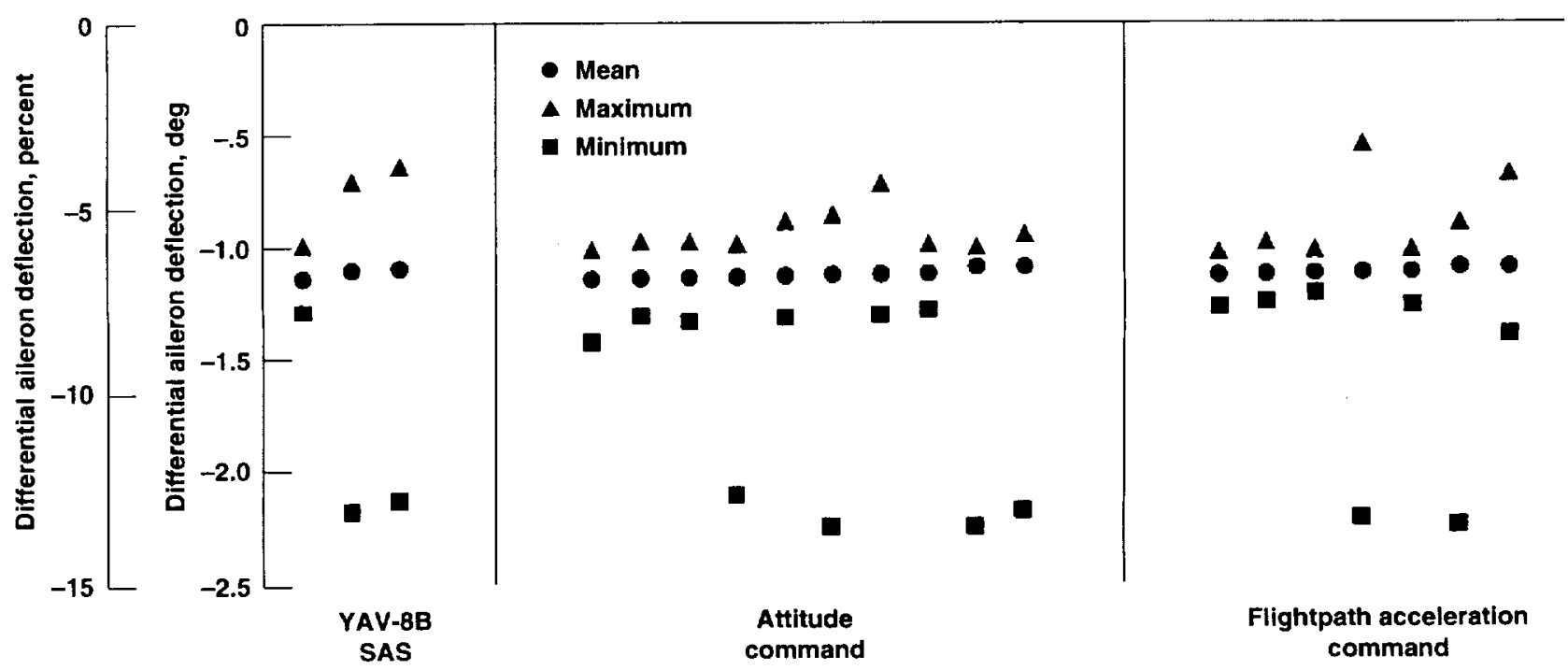

Figure 34. Roll-axis control activity during slow landing. 
reflect up to only 6 percent of the total lateral control available in forward flight.

Yaw control: Figures $35-38$ present yaw-control usage in the same format as for pitch and roll. As for the roll axis the response type has no effect on control activity. During the approach, for all system variants shown in figure 35 , nominal peak excursions are about 20 percent of yaw reaction control authority. Occasional peak occurrences up to 50-70 percent can be observed, but they are the exception. Control activity is shown as a percent of yaw reaction control since this is the only control that includes inputs from both the pilot's pedal and the series stability-augmentation system servo. Because virtually all the approaches were flown without pedal inputs during the approach, little or no rudder activity is present, and the reaction control reflects total yaw control used. During acquisition of the stationkeeping point, figure 36 shows that peak utilization was from 40 to as high as 60 percent, although many of the cases indicate only about \pm 20 -percent excursions from the mean. The 40- to 60-percent range also holds for the hover and vertical landing; however, some variations as large as 80 to 100 percent are observed in the data in figure 37. Slow landings (fig. 38) show excursions of about 30 percent, which are more on the order of those utilized during the approach.

Thrust control: In the case of thrust utilization, data are presented only for acquisition of the station-keeping point, hover, and vertical landing. During the approach, such large variations in thrust were required as the aircraft decelerated that meaningful data cannot he presented. Acquisition of the station-keeping point produced the results shown in figure 39 , revealing small differences between response types with manual thrust control and those with vertical-velocity command. In the case of the former, the YAV-8B SAS and attitude command, excursions in engine power setting about the mean are on the order of 1 to 1.5 percent rpm. At high thrust settings associated with hover, a 1-percent change in rpm equates to 3 percent of the maximum available vertical thrust for the Pegasus engine. Thus the rpm excursions noted are equivalent to 3 to 4.5 percent of maximum thrust. For the vertical-velocity command systems, somewhat lower peak rpm excursions of 0.6 to 1 percent are noted, amounting to 2 to 3 percent of maximum thrust. For the hover and vertical-landing tasks (fig. 40), only a slight difference in rpm excursions exists between the manual thrust and vertical-velocity command controls. Where the manualthrust-control types show nominal excursions of about 1.8-percent rpm (5.4-percent maximum thrust) during hover, the vertical-velocity command systems are only marginally lower (1.5- to 1.8 -percent $\mathrm{ppm}$ or 4.5- to 5.4-percent maximum thrust).
Control Frequency Content- Measures of the frequency content of the pitch, roll, and yaw control effectors were obtained in transition for the flightpath/acceleration command system and in hover for these three controls; engine rpm was also measured for the translational-rate command control. These results were obtained using the frequency analysis method described in reference 14, and they are presented in the power spectral plots of figures 41 to 43 . The ordinate of these figures is the square of normalized control magnitude plotted on a decibel scale. Frequency bandwidth is defined analytically in this case as the upper frequency that contains 0.707 of the energy of the entire control response. In computing this bandwidth, the frequency response data were truncated at low frequency so as to disregard energy in the response associated with trim control.

For the decelerating transition, figure 41 presents the pitch-, roll-, and yaw-control frequency content obtained from time histories from three approaches. Analytically defined bandwidths are 5.5,6.0, and $1.4 \mathrm{rad} / \mathrm{sec}$ for the stabilator, aileron, and yaw reaction control, respectively. A visual inspection of these plots indicates general agreement with the analytical measure except for the stabilator, which shows a rolloff above $3.5 \mathrm{rad} / \mathrm{sec}$. Given the notch in the stabilator frequency response just above $2 \mathrm{rad} / \mathrm{sec}$, the analytical measure of bandwidth may have been biased to a higher frequency than would have been the case if the frequency response were flat over the frequency band.

Results from four hover cases (fig. 42) show the bandwidths defined analytically for the data to be $5.3,8.5$, and $2.3 \mathrm{rad} / \mathrm{sec}$ for the pitch, roll, and yaw reaction controls, respectively. The well-defined peak in the roll response reflects the high-frequency oscillation in the roll control that is associated with the high forward-loop gain in this axis. Engine rpm response for the vertical-velocity command system and for manual control of thrust during hover are indicated in figure 43 . Whereas engine response to the pilot's manual control for height rolls off above $0.6 \mathrm{rad} / \mathrm{sec}$, the vertical-velocity command control does not begin to drop off until about $0.8 \mathrm{rad} / \mathrm{sec}$, and it still shows appreciable response out to $3 \mathrm{rad} / \mathrm{sec}$.

\section{Design Recommendations}

Numerous suggestions were made by the participating pilots regarding improvements that could be made in the system design that could resolve some of their concerns, as well as alternate design approaches that should be considered in contrast to those used in the VSRA. These comments, along with related experience of the VSRA design team, are separated into those related to the control 


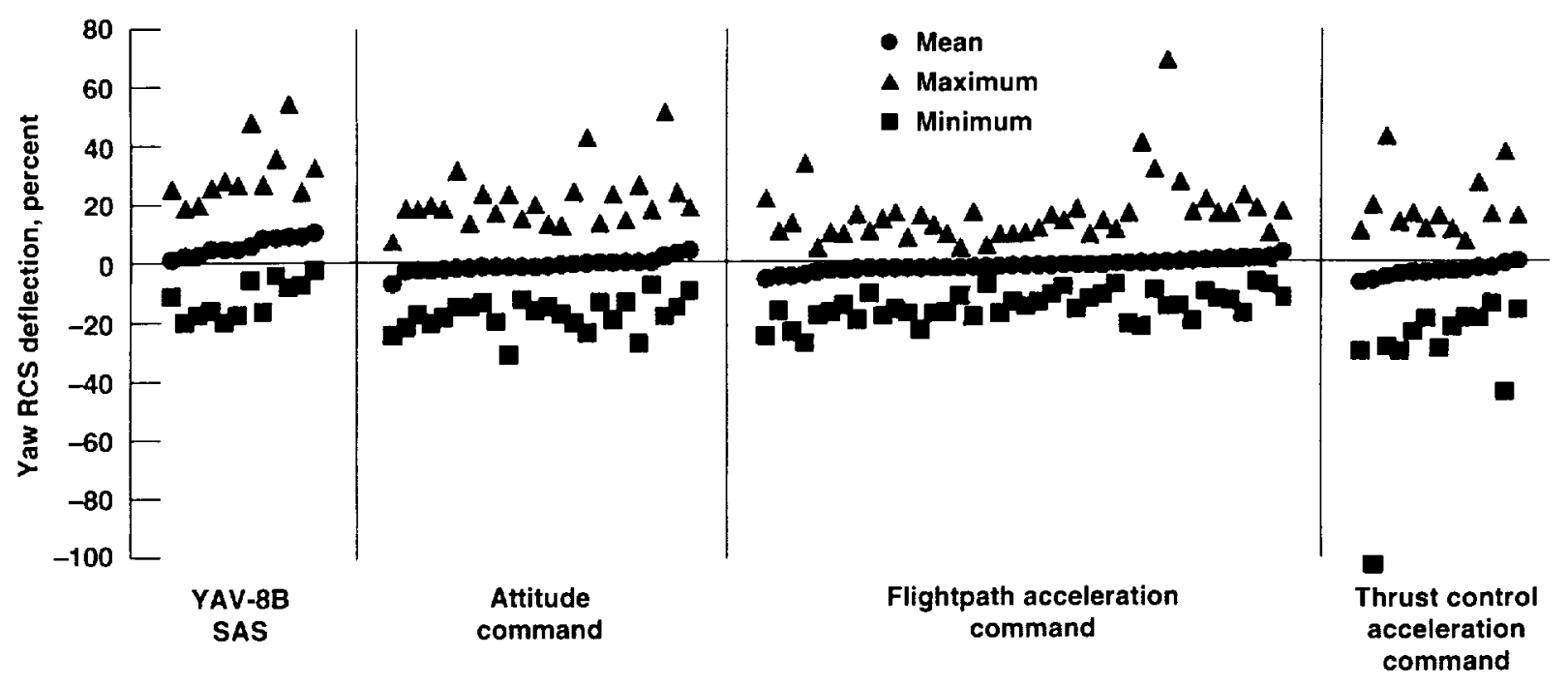

Figure 35. Yaw-axis control activity during approach.

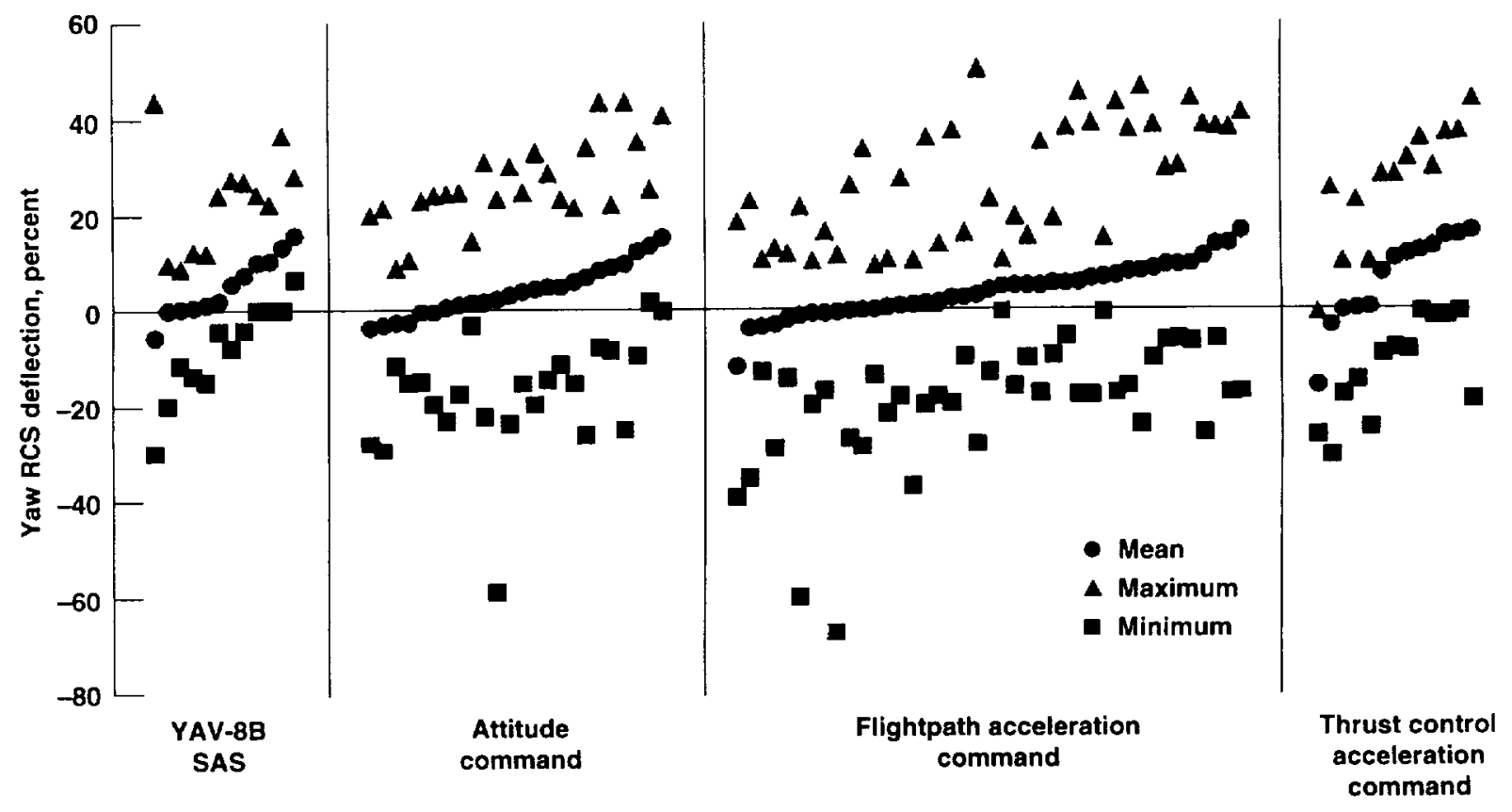

Figure 36. Yaw-axis control activity during hover-point acquisition. 


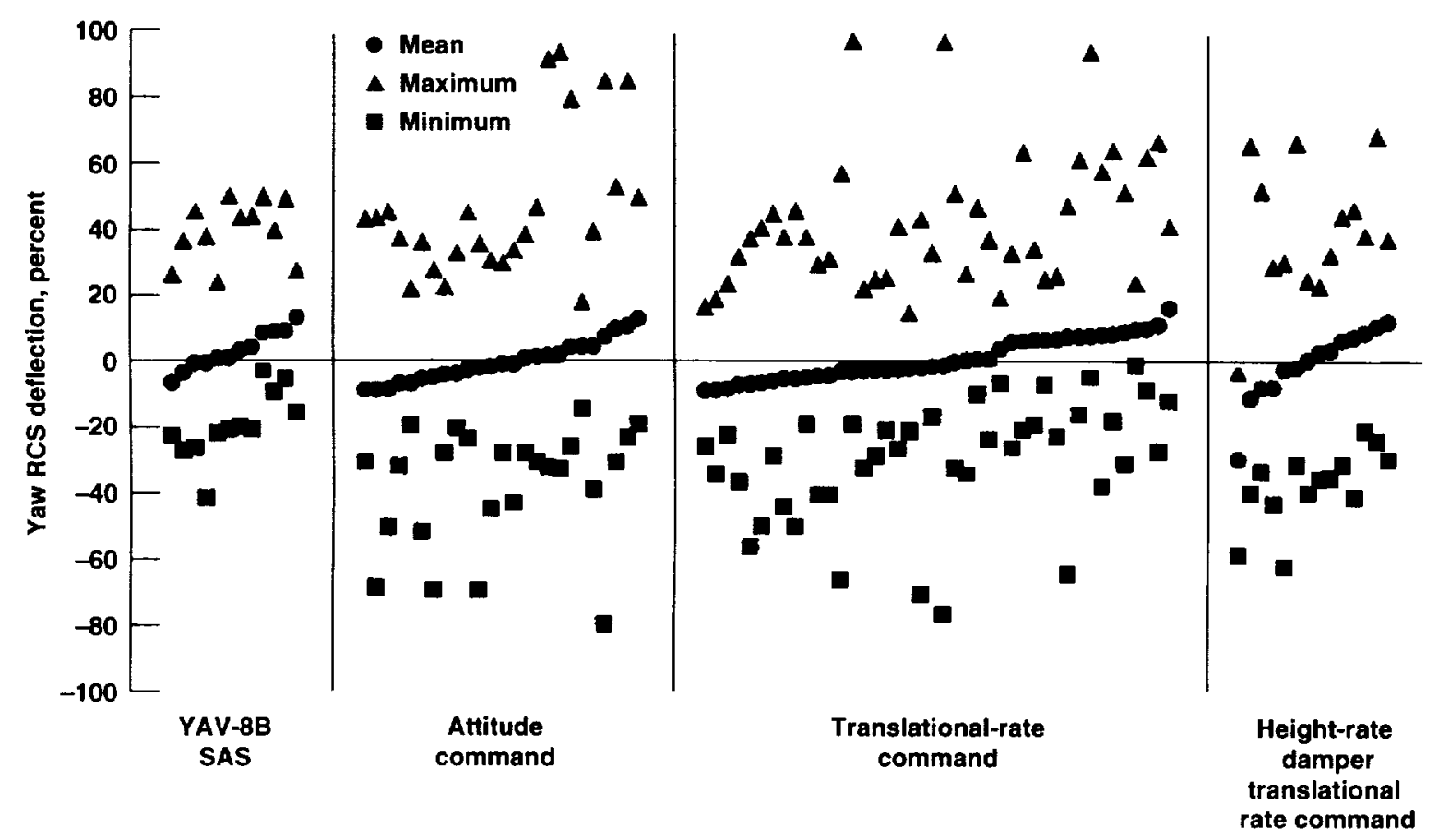

Figure 37. Yaw-axis control activity during hover and vertical landing.

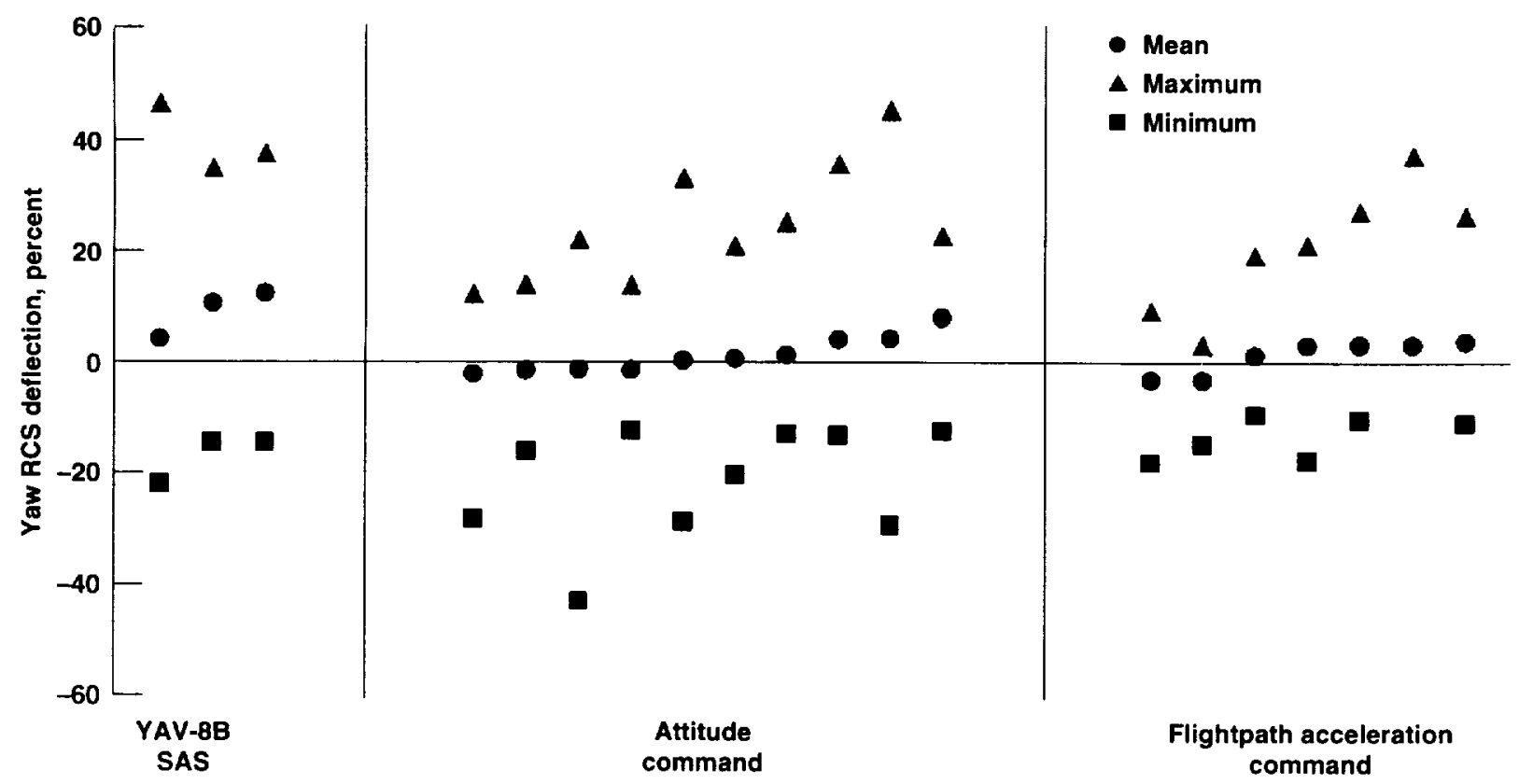

Figure 38. Yaw-axis control activity during slow landing. 


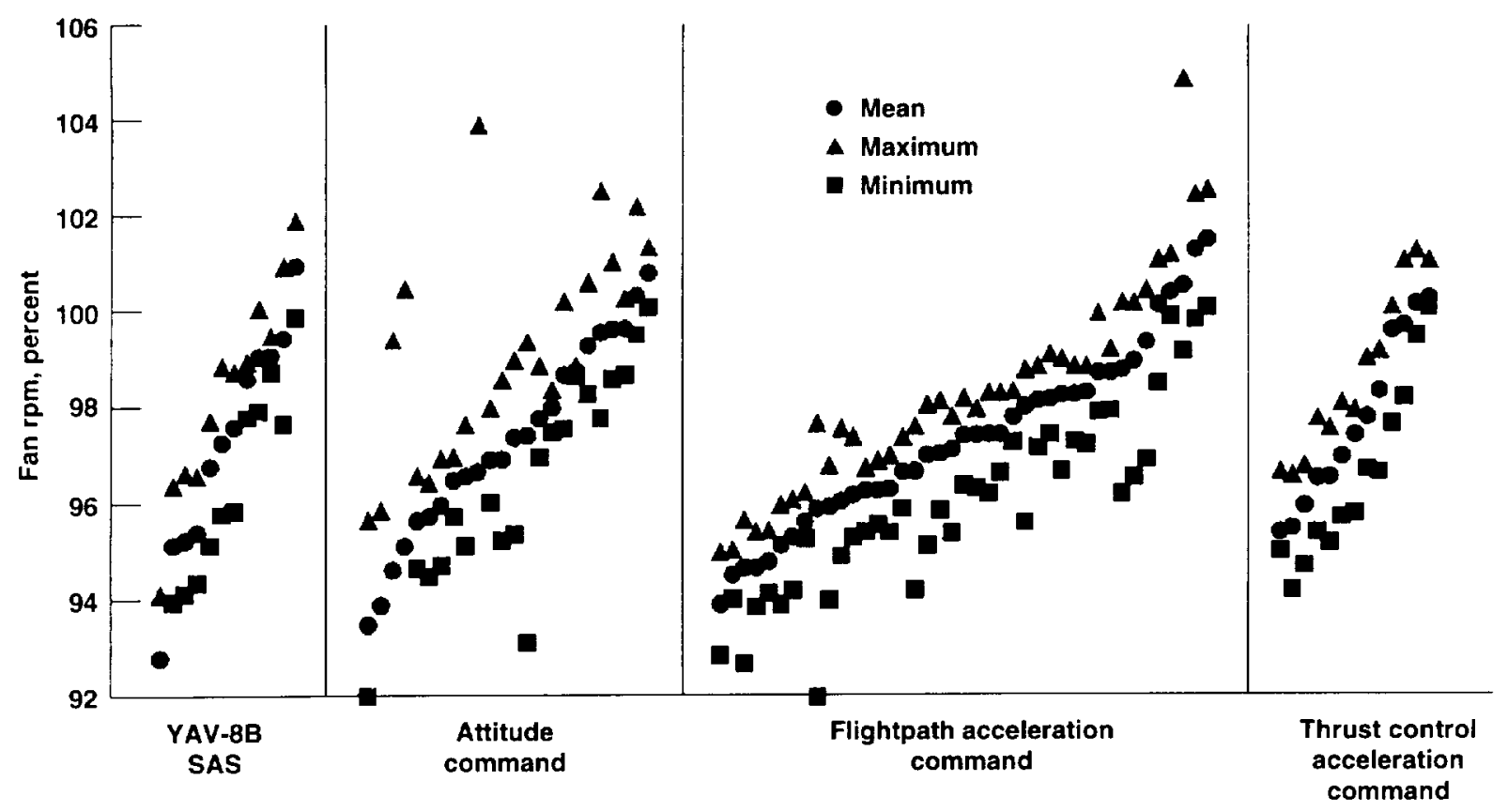

Figure 39. Vertical-axis control activity during hover-point acquisition.

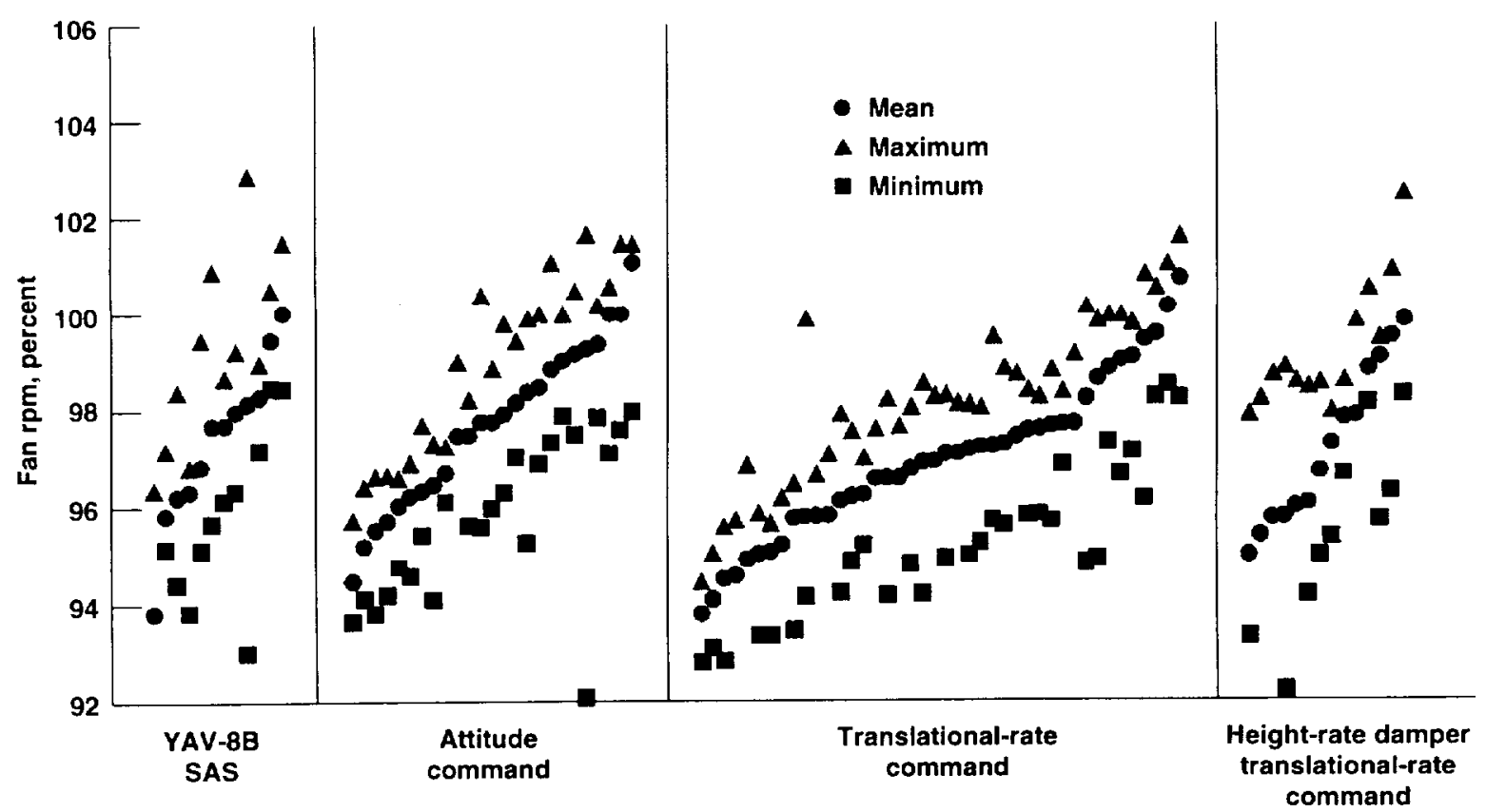

Figure 40. Vertical-axis control activity during hover and vertical landing. 


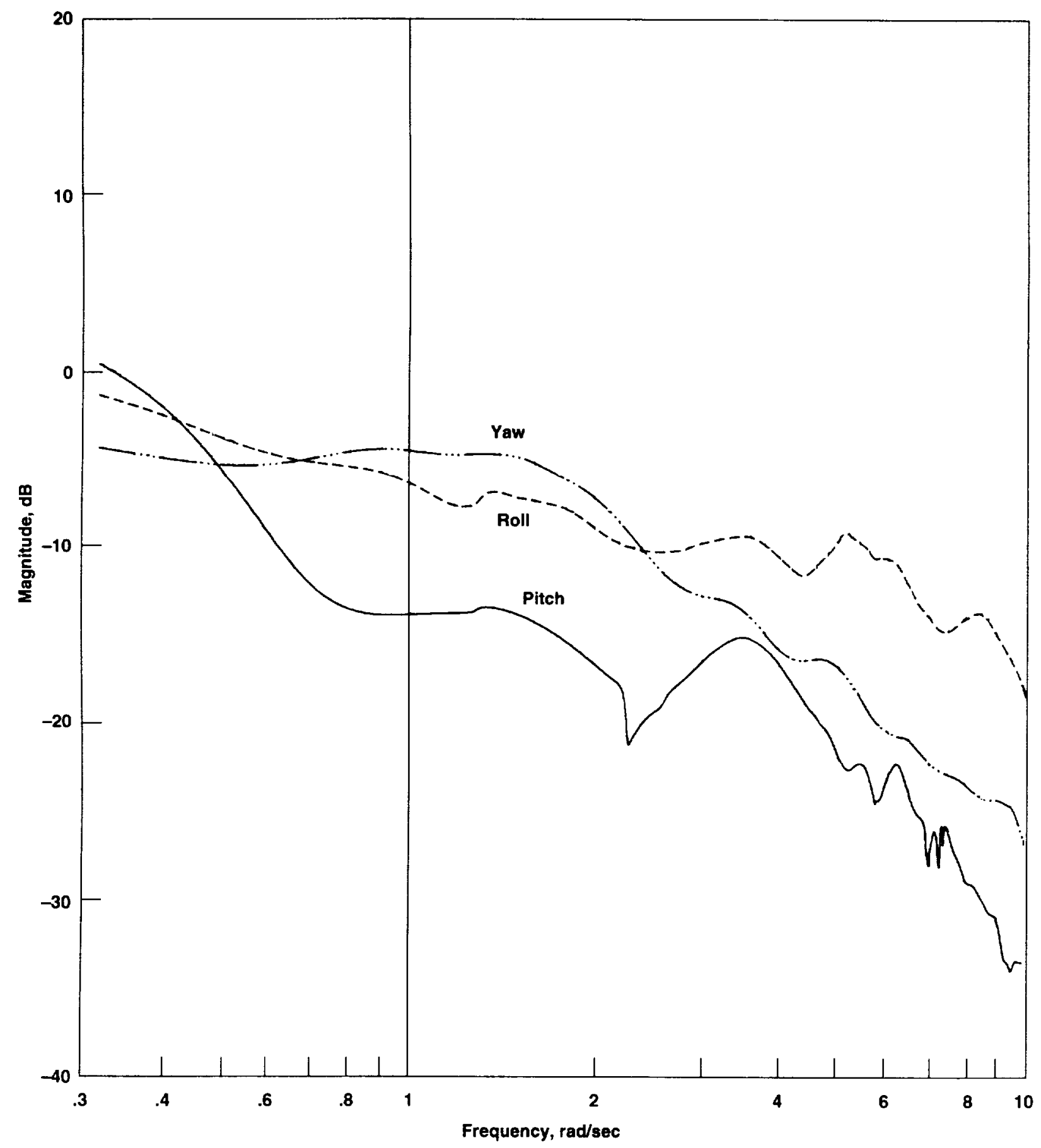

Figure 41. Control frequency content for the approach. 


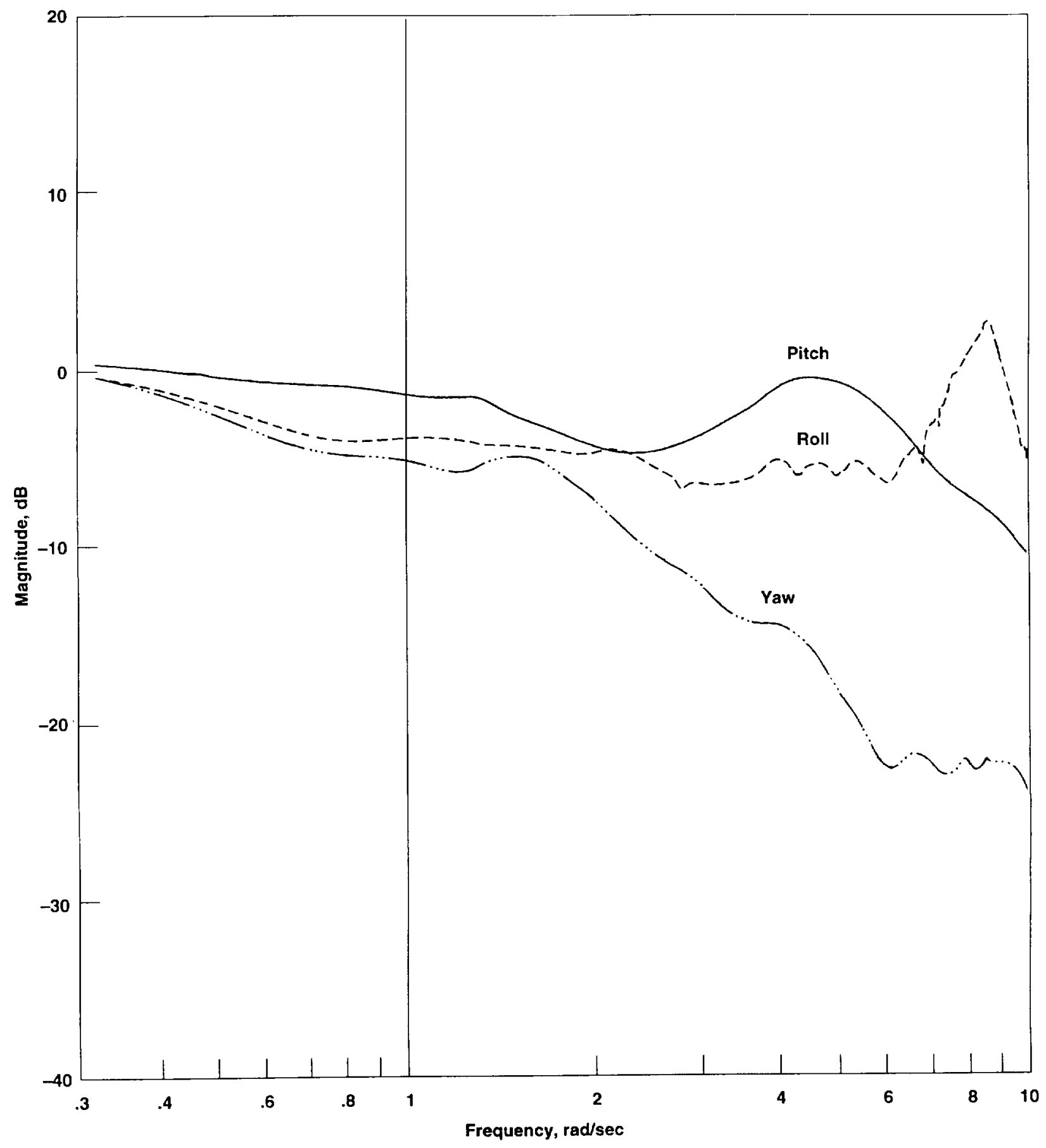

Figure 42. Control frequency content for hover. 


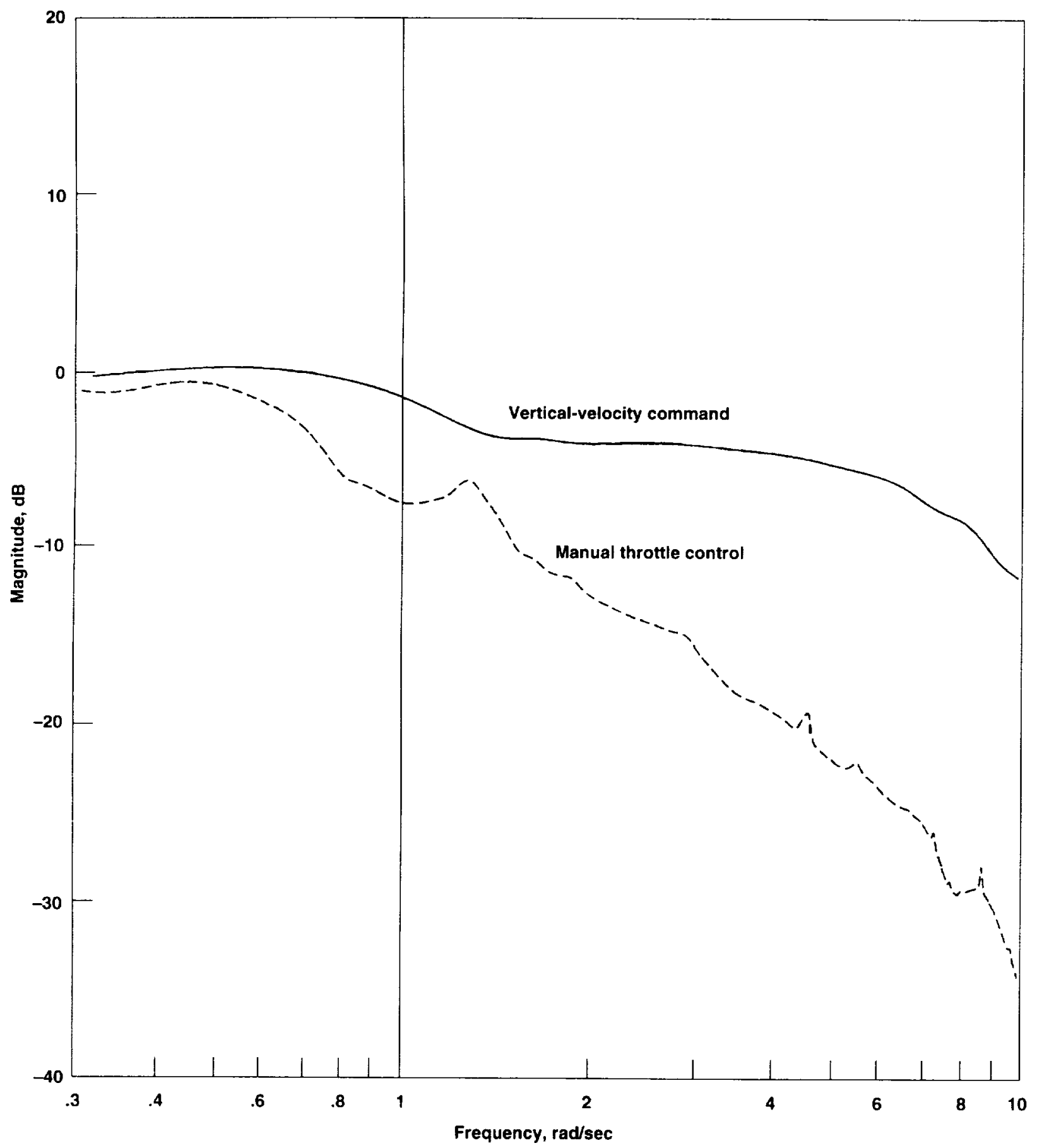

Figure 43. Engine rpm frequency content for hover. 
system and those related to the HUD; they are noted as follows.

Control System-Comments are presented with regard to the individual control axes; they deal with the control inceptor and the attendant aircraft response.

1. Location of the pitch trim button made its use awkward; a central location on the stick would be preferable.

2. A few pilots considered roll-control sensitivity to be high with the rate command/attitude-hold mode; others considered the sensitivity acceptable.

3. Directional control during the approach was poor, especially in turbulence. This characteristic is attributed to the fact that the low-authority series servo works solely through the yaw reaction control. Further, the directionalcontrol law was not sufficiently high in gain to make full use of the servo authority.

4. One pilot would have liked for the directional augmentation to point the aircraft's nose into the wind when turning during low-speed air taxi.

5. Several pilots stated a preference for using a throttle lever as the inceptor to control flightpath and vertical velocity as opposed to the thumbwheel located on the throttle. These comments were reinforced by three of the pilots in the evaluation of Configuration 4.

6. Some pilots found it easy to confuse the use of the thumbwheels, in terms of both function and sense of application. Instances of reverse control of flightpath with the throttle thumbwheel were noted for these pilots. A preferable set of inceptors, a throttle handle for flightpath as noted in item 5, and a thumbwheel mounted on the throttle for longitudinal acceleration were considered by these pilots to be a plausible solution to these objections.

7. A lag was noted in flightpath response to the thumbwheel during the approach and during slow landings. It would be desirable to reduce this lag somewhat, although the control response characteristics were rated satisfactory.

8. Nonlinear sensitivity for the thumbwheels would have been a better match for desired sensitivities over the low-speed range through approach to hover. For example, the stick thumbwheel was considered to be overly sensitive at high speeds and insensitive at low speeds.

9. Concern was raised about throttle reduction at fixedpitch attitude when controlling flightpath because of the increase in angle of attack occurring at low speeds and low altitudes. Preference was stated for coordinated use of attitude and thrust for flightpath control while semi-jetborne until the aircraft has decelerated to speeds where wing lift effectiveness is no longer adequate. From that point on into hover, throttle alone would be used for vertical-speed control and pitch attitude would be set as desired for hover and landing.

10. Excessive hysteresis in the nozzle control excited flightpath disturbances for the flightpath/acceleration command system. Hysteresis in the thrust-deflectioncontrol effectors needs to be minimized for both the transition and hover.

11. A few pilots found the proportional thumb controller to be too sensitive for control of longitudinal and lateral translational rates.

12. Several pilots expressed a preference for using the center stick instead of the proportional thumb controller for translational-rate command. One pilot preferred the proportional thumb controller for this inceptor because of a concern for a reverse sense of application of the center stick to control the horizontal display elements in the hover display.

13. Some pilots observed a lag in the longitudinalvelocity response in the translational-rate command.

14. One pilot preferred more lateral translational-rate command authority, particularly when translating into a cross-wind component. Quicker lateral-velocity response was also desired with the lateral system using bank angles up to $10 \mathrm{deg}$.

15. Several pilots preferred a discrete manual switch by the pilot between the transition and hover control modes.

16. The number of discrete selections of control mode, display mode, and guidance when switching from approach to hover was excessive, and the selections should be integrated.

17. Back-drive motion of the stick and throttle by the parallel actuators could cause inadvertent inputs to the thumbwheels and proportional thumb controller.

Head-up Display-Comments on the HUD format and drive laws are associated with either the approach or the hover display modes.

1. As noted previously, pitch-attitude cues were considered by some pilots to be poor and in need of a stronger pitch reference.

2. One pilot desired to see actual flightpath displayed along with the quickened flightpath symbol.

3. As reflected in earlier comments, some pilots had difficulty using the longitudinal-velocity predictor ball and the station-keeping-point symbols to control closure to the hover point. This comment applied to both the 
attitude command and the flightpath/acceleration command control modes. One pilot chose to use the approach display down to approximately a $100-\mathrm{ft}$ altitude, then switch to external visual cues to complete the deceleration to the hover point. Whether this difficulty was fundamental to the display concept or due to training procedures is not clear.

4. Symbol clutter in the hover display at the hover point was objectionable to most pilots.

5. Pilots preferred having the velocity-vector and predictor-ball symbols available on the approach display for speeds of 25 knots and below, instead of the speeds of 20 knots and below used in the initial display design.

6. Workload would be reduced by having the displaymode switch triggered by the switch of the control mode.

7. It would be desirable to maintain higher speed in the early part of the approach, then to make an acceptably aggressive deceleration down to the final closure deceleration to the station-keeping point.

\section{Conclusions}

Flight experiments were conducted on the Ames Research Center's V/STOL Systems Research Aircraft (VSRA) to assess the influence of advanced control modes and head-up displays on flying qualities for precision approach and landing operations. Evaluations were made for decelerating approaches to hover followed by a vertical landing and for slow landings for four control/ display mode combinations: the basic YAV-8B SAS; attitude command for pitch, roll, and yaw; flightpath acceleration command and translational-rate command; and height damper with translational-rate command. HUDs that could be used in conjunction with these control modes provided flightpath tracking/pursuit guidance for the decelerating approach and a mixed horizontal and vertical presentation for precision hover and landing.

Flying qualities were established for candidate control modes and displays for the approach and vertical landing. Results of the pilots' evaluations indicated that satisfactory flying qualities could be achieved for the decelerating transition to hover with flightpath/longitudinalacceleration command systems and for precision hover and vertical landing with translational-rate command systems. Attitude command systems and the basic YAV-8B stability-augmentation system provided only adequate flying qualities during hover and landing hecause they did not compensate for poor verticalvelocity control. The basic YAV-8B also was considered to be just adequate for the transition because of poor flightpath control and large trim changes with thrust and thrust deflection. The attitude command system improved on the basic YAV-8B for the transition. It was considered marginally satisfactory because it eliminated the pilot's need to counter trim changes. However, the demands of thrust control during the deceleration, as the loss of wing lift must be compensated by increasing thrust, were objectionable to the pilots. These findings, in conjunction with related ground-based simulation results, indicate that the flightpath/longitudinal-acceleration command response type would be an essential part of a system to permit operation to instrument minimums significantly lower than those achieved today for the AV-8B. It would also be a superior mode for performing slow landings where precise control to an austere landing area, such as a narrow road, is demanded. The translational-rate command system would reduce pilot workload for demanding vertical landing tasks aboard ship and in confined land-based sites.

The HUD was generally felt to offer excellent path guidance for the curved approach through the ghost aircraft as well as effective commands for the deceleration to hover. It would be expected to significantly reduce pilot workload and improve precision for night shipboard recovery for AV-8B operations or for operation to lower visibility minimums than permissible for the AV-8B. In combination with the translational-rate command control, the hover display gave the pilot the ability to achieve excellent hover and landing precision, with touchdowns consistently inside a 5-foot-radius circle. The hover display format did not pose a problem for the pilots; they accommodated readily to the mixed presentation of horizontal and vertical information.

Control utilization and frequency content were documented for the control effectors in all axes. The only significant effect of control response type on control activity was observed to be a reduction in pitch control used with the longitudinal-acceleration command during the approach to hover in comparison to that used for the basic YAV-8B or the attitude command system. This reduction is attributed to the absence of pitch maneuvering to control deceleration to the hover for the longitudinal-acceleration command. Similar results were observed for the translational-rate command system during hover and vertical landing; thrust deflection rather than pitch attitude was used to maneuver longitudinally. Otherwise, only minor differences in control activity or none at all were experienced for the different response types for pitch, roll, yaw, and thrust control for the various tasks. Borderline satisfactory/adequate flying qualities associated with bandwidth of the translationalrate control were established for the hover and landing task for longitudinal and lateral position and for height 
control. These bandwidths were $0.33,0.25$, and

$0.6 \mathrm{rad} / \mathrm{sec}$, respectively.

The use of a throttle-mounted thumbwheel for flightpath control in the approach and for vertical-velocity control in the hover was a significant limitation to the pilots and had an adverse effect on their ratings. Furthermore, the use of a stick-mounted proportional thumb controller for translational-rate command in hover was not ideal. Prominent suggestions for design modifications were to use the throttle for flightpath and vertical-velocity command; to use the center stick for translational-rate command; to allow flightpath control to blend in a natural fashion as speed decays from pitch attitude to thrust as the primary controller; to reduce hysteresis in the thrustdeflection-control effectors to a minimum; to improve directional control during transition with a higher authority yaw-augmentation system; and to switch both control and display modes from approach to hover simultaneously.

\section{References}

1. Foster, J. D.; Moralez, E.; Franklin, J. A.; and Schroeder, J. A.: Integrated Control and Display Research for Transition and Vertical Flight on the NASA V/STOL Research Aircraft (VSRA). NASA TM-100029, Oct. 1987.

2. Moralez, E.; Merrick, V. K.; and Schroeder, J. A.: Simulation Evaluation of an Advanced Control Concept for a V/STOL Aircraft. Journal of Guidance, Control, and Dynamics, vol. 12, no. 3, May-June 1989 , pp. 334-341.

3. Farris, G. G.; Merrick, V. K.; and Gerdes, R. M.: Simulation Evaluation of Flight Controls and Display Concepts for VTOL Shipboard Operations. AIAA Paper 83-2173, Aug. 1983.

4. Merrick, V. K.: Simulation Evaluation of Two VTOL Control/Display Systems in IMC Approach and Shipboard Landing. NASA TM-85996, Dec. 1984.
5. Merrick, V. K.: A Translational Velocity Command System for VTOL Low-Speed Flight. NASA TM-84215, Mar. 1982.

6. Franklin, J. A.; Stortz, M. W.; Engelland, S. A.; Hardy, G. H.; and Martin, J. L.: Moving Base Simulation Evaluation of Control System Concepts and Design Criteria for STOVL Aircraft. NASA TM-103843, June 1991.

7. Chung, W. W. Y.; Borchers, P. F.; and Franklin, J. A.: Moving Base Simulation of an ASTOVL Lift Fan Aircraft. NASA TM-1 10365. Sept. 1995.

8. Franklin, J. A.; Stortz, M. W.; Gerdes, R. M.; Hardy, Gordon H.; Martin, James L.; and Engelland, Shawn A.: Simulation Evaluation of Transition and Hover Flying Qualities of the E-7A STOVL Aircraft. NASA TM-101015, Aug. 1988.

9. Merrick, V. K.; Farris, G. G.; and Vanags, A.: A Head Up Display for Application to V/STOL Aircraft Approach and Landing. NASA TM-102216, Jan. 1990.

10. Merrick, V. K.: Some VTOL Head-Up Display Drive-Law Problems and Solutions. NASA TM-104027, Nov. 1993.

11. Dorr, D. W.; Moralez, E.; and Merrick, V. K.: Simulation and Flight Test Evaluation of HeadUp-Display Guidance for Harrier Approach Transitions. AIAA Paper 92-4233, Aug. 1992.

12. Merrick, V. K. and Jeske, J. A.: Flightpath Synthesis and HUD Scaling for V/STOL Terminal Area Operations. NASA TM-110348, Apr. 1995.

13. Cooper, G. E.; and Harper, R. P., Jr.: The Use of Pilot Rating in the Evaluation of Aircraft Handling Qualities. NASA TN D-5153, Apr. 1969.

14. Tischler, Mark B.: System Identification Methods for Aircraft Flight Control Development and Validation. NASA TM-110369, Oct. 1995. 


\section{Appendix}

\section{Control Laws}

VSRA control laws underwent extensive development in ground-based simulation followed by further refinement during the VSRA flight program. The final version of the pitch, roll, yaw, longitudinal-, lateral-, and vertical-axis control laws that were flown on the VSRA during the flying qualities evaluation program is described in the following paragraphs.

Frequency response characteristics of some of the baseline control modes that were obtained during the flight test program are noted in this discussion. These data were obtained from frequency sweeps generated by the pilot for the control axes and flight conditions of interest and analyzed using the frequency response method described in reference 14 . They are the basis for definition of control bandwidth for the baseline control modes. Variations in bandwidth for the translational-rate command modes that were made around the baseline configurations were documented using the nonlinear simulation model of the VSRA aircraft and system.

Pitch Control- For pitch control in transition or hover, an attitude-command/attitude-hold response type was implemented, as shown in figure A-1. The pilot's inputs were through the control stick and trim switch. Gain $\mathrm{K}_{\theta_{C}}$ established control sensitivity, while $\mathrm{K}_{\theta}$ and $\mathrm{K}_{\dot{\theta}}$ determined system bandwidth and phase margin. Gain $\mathrm{K}_{1} \mathrm{~g}_{\theta}$ was the coupling gain to the stabilizer and was scheduled in proportion to dynamic pressure. Scheduled cross feeds from engine rpm and nozzle position were used to reduce the associated trim changes. The positive feedback of servo command through the first-order filter was equivalent to proportional-plus-integral feed-forward compensation, and their relative proportion was established by the first-order filter time constant $\tau_{\theta}$. System gains and time constants are listed on the figure. In figure A-2, the pitchattitude frequency response from frequency sweeps with the longitudinal stick at 120 knots indicates a bandwidth for attitude control of $3.8 \mathrm{rad} / \mathrm{sec}$ for a $45-\mathrm{deg}$ phase margin. The basic YAV-8B SAS (Configuration 1) consisted simply of pitch-rate feedback.

Roll- and Lateral-Velocity Control- Roll control modes are presented in figure A-3; both rate-command/attitudehold (fig. A-3(a)) and attitude-command/attitude-hold (fig. A-3(b)) response types were available. The control stick and trim switch provided the pilot's inputs. Gain $\mathrm{K}_{\phi_{C}}$ established control sensitivity for attitude command mode; gain $K_{\phi_{\text {hold }}}$ served the same purpose for the rate command mode; and gain $K_{\phi_{\mathcal{G}}}$ was used to adjust overshoot in roll response. Gains $\mathrm{K}_{\phi}$ and $\mathrm{K}_{\phi}$ determined system bandwidth and phase margin, and gain $\mathrm{K}_{1 \mathrm{~g}_{\phi}}$ was the coupling gain to the ailerons. Proportional-plusintegral compensation was adjusted through the time constant $\tau_{\phi}$, similar to that for the pitch control. No frequency sweeps were performed for the roll-attitude control system. The basic YAV-8B SAS (Configuration 1) consisted simply of roll-rate feedback.

Lateral-velocity control laws are shown in figure A-4. Command inputs came through the lateral proportional thumb controller. Gain $\mathrm{KVy}_{\mathrm{y}_{\mathrm{c}}}$ set the control sensitivity, and gain $\mathrm{K}_{\mathrm{V}_{\mathrm{y}}}$ provided the desired control bandwidth and associated roll response to the pilot's velocity command inputs. The forward-loop gain $\mathrm{K}_{\mathrm{lg}_{\mathrm{y}}}$ coupled the velocity command to the roll-control laws. The lateral-velocity frequency response from frequency sweeps with the lateral proportional thumb controller for hover are shown in figure A-5. The bandwidth for lateral-position control is based on the frequency for a 45-deg phase margin for position response, which is equivalent to the frequency for a 45-deg phase lag for lateral velocity. The positioncontrol bandwidth noted on figure A-5 is $0.29 \mathrm{rad} / \mathrm{sec}$; for lateral-velocity control the bandwidth for a 45-deg phase margin is seen to be $0.73 \mathrm{rad} / \mathrm{sec}$.

Yaw Control- Yaw-control modes provided yaw damping during transition (fig. A-6(a)) and switched to yaw-rate command at low speed and in hover (fig. A-6(b)) for Configurations 2, 3, and 4. In transition, lead-lag filtered lateral acceleration and washed-out yaw-rate feedbacks along with lateral-stick-position cross feed were used to improve turn coordination and Dutch roll damping. In the hover control mode, yaw-rate feedback alone was used for yaw-rate command. No frequency response data were obtained for the yaw control.

\section{Longitudinal-Acceleration and Velocity Control-} The longitudinal-acceleration control is shown in figure A-7(a). During transition between forward flight and hover, the pilot commanded longitudinal acceleration using a thumbwheel on the control stick for Configurations 1,2 , and 3 . For Configuration 4 , the input came from the thumbwheel on the throttle handle. Complementary filtered calibrated airspeed feedback was used for speeds in excess of 80 knots; longitudinal inertial velocity was fed back at lower speeds. Gain $K_{\dot{V}} x_{c}$ set control sensitivity, and the feedback gain $K_{205}$ determined phase margin. The forward-loop gain $\mathrm{K}_{\lg _{\mathrm{x}}}$ determined the bandwidth and coupled the acceleration command to the nozzle control.

For precision hover (fig. A-7(b)), the thumbwheel was switched out and the proportional thumb controller provided longitudinal-velocity commands. In this mode, the stick was disconnected from the pitch-attitude command system. Although most of the hover maneuvering 


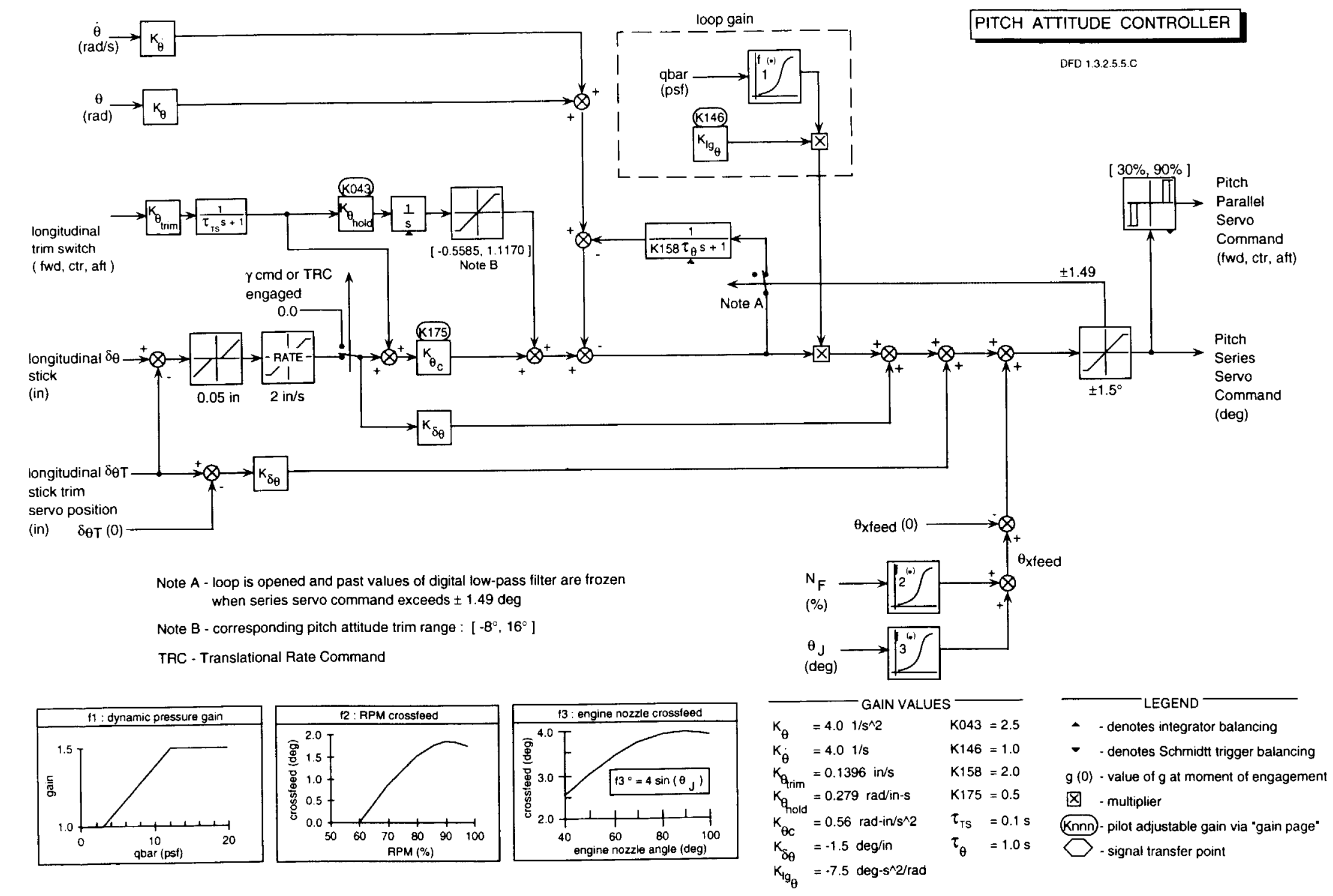

Figure A-1. Pitch-attitude command control law. 

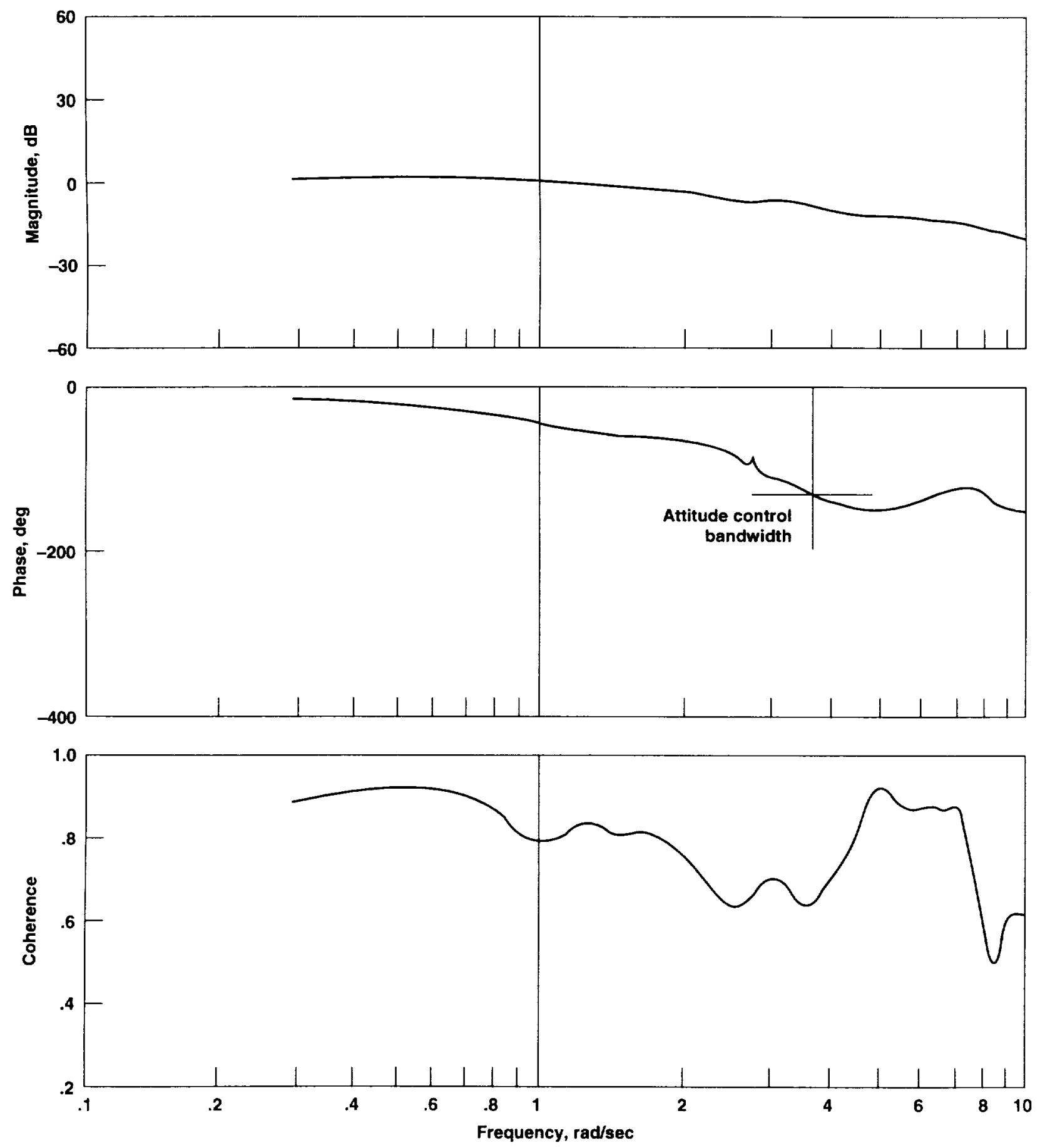

Figure A-2. Frequency response for baseline attitude command; 120 knots. 


\section{ROLL RATE CONTROLLER}

DFD 1.3.2.5.5.F

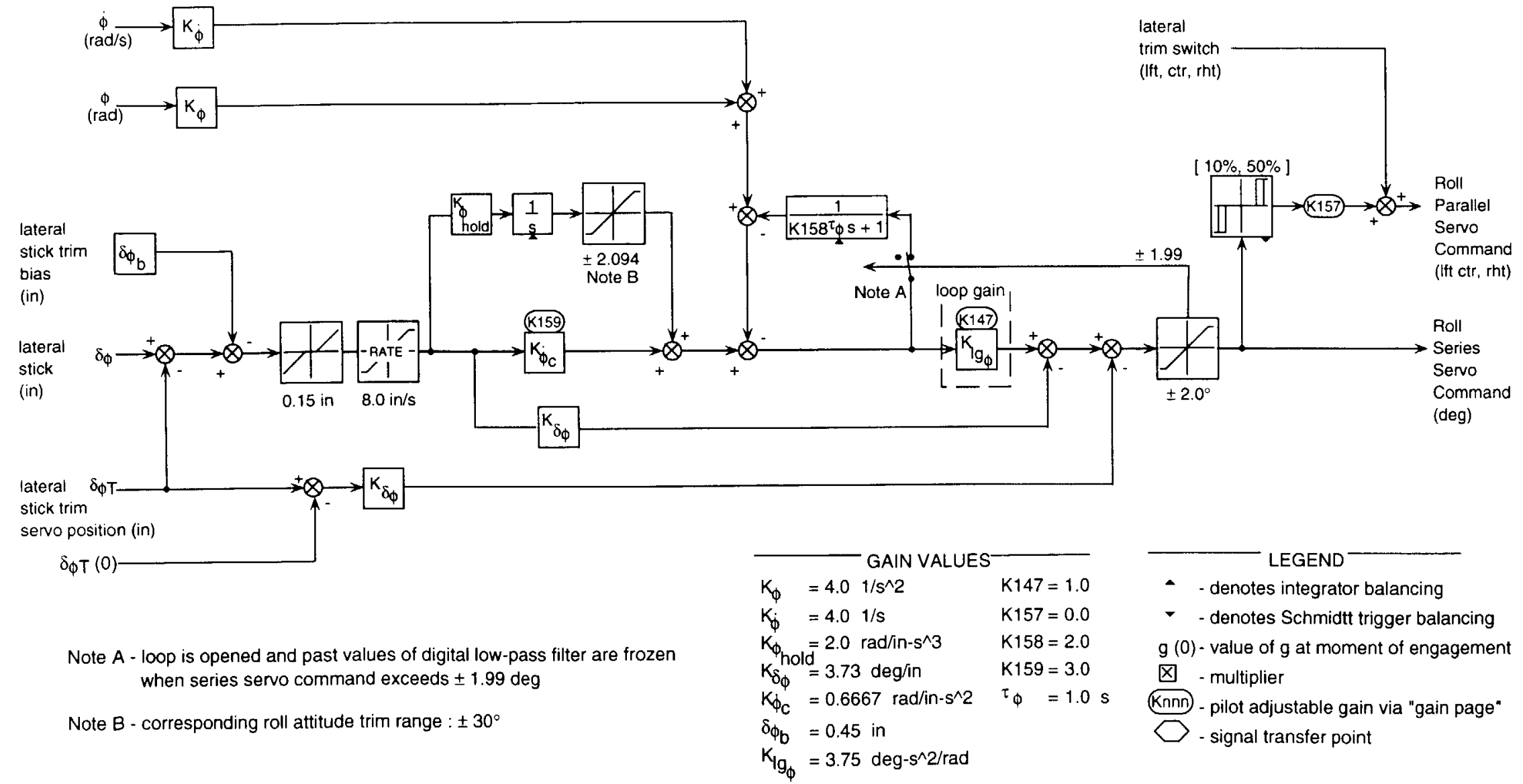

(a) Roll-rate command.

Figure A-3. Roll-axis control laws. 


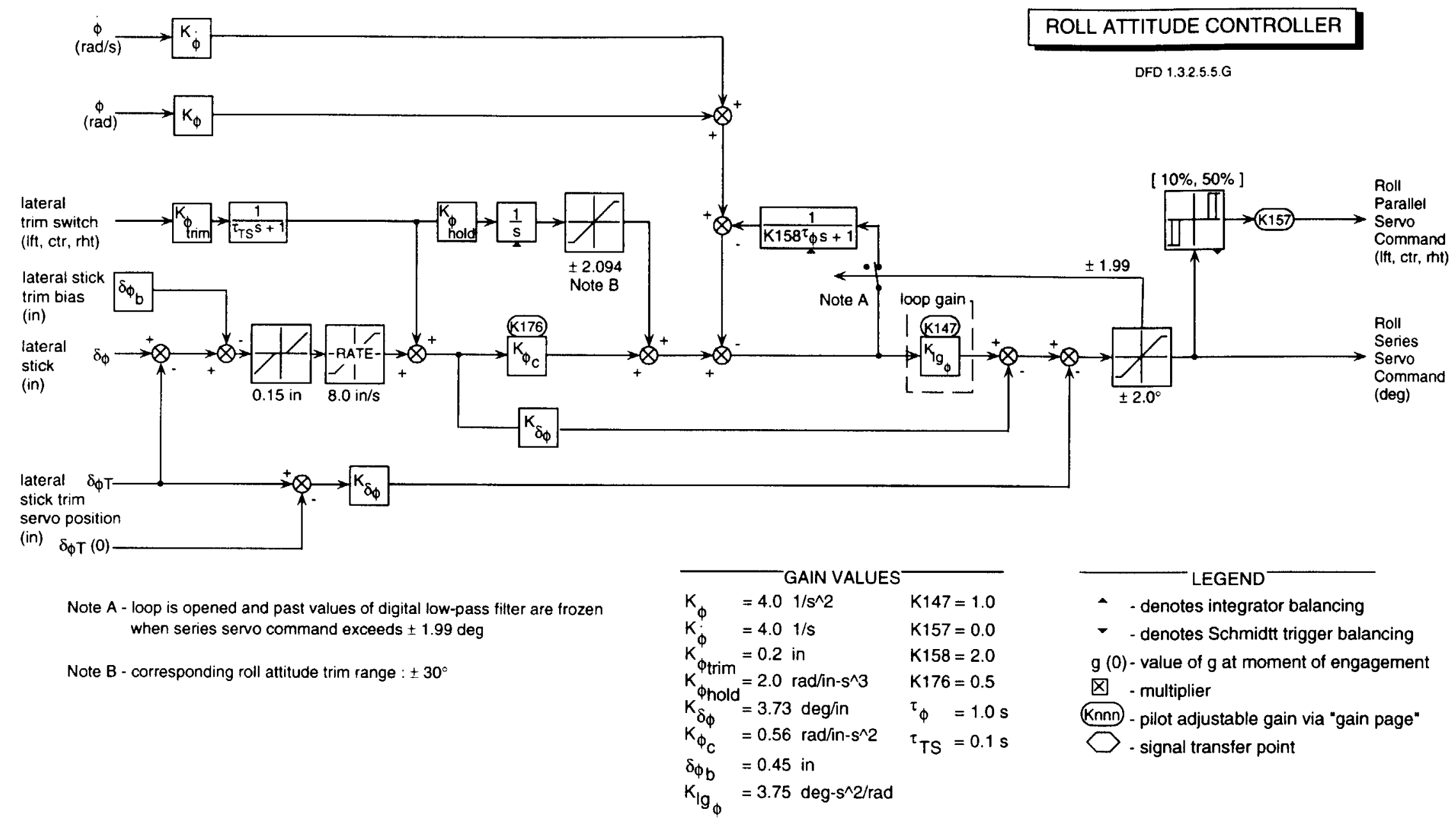

(b) Roll-attitude command.

Figure A-3. Concluded. 
DFD 1.3.2.5.5. H

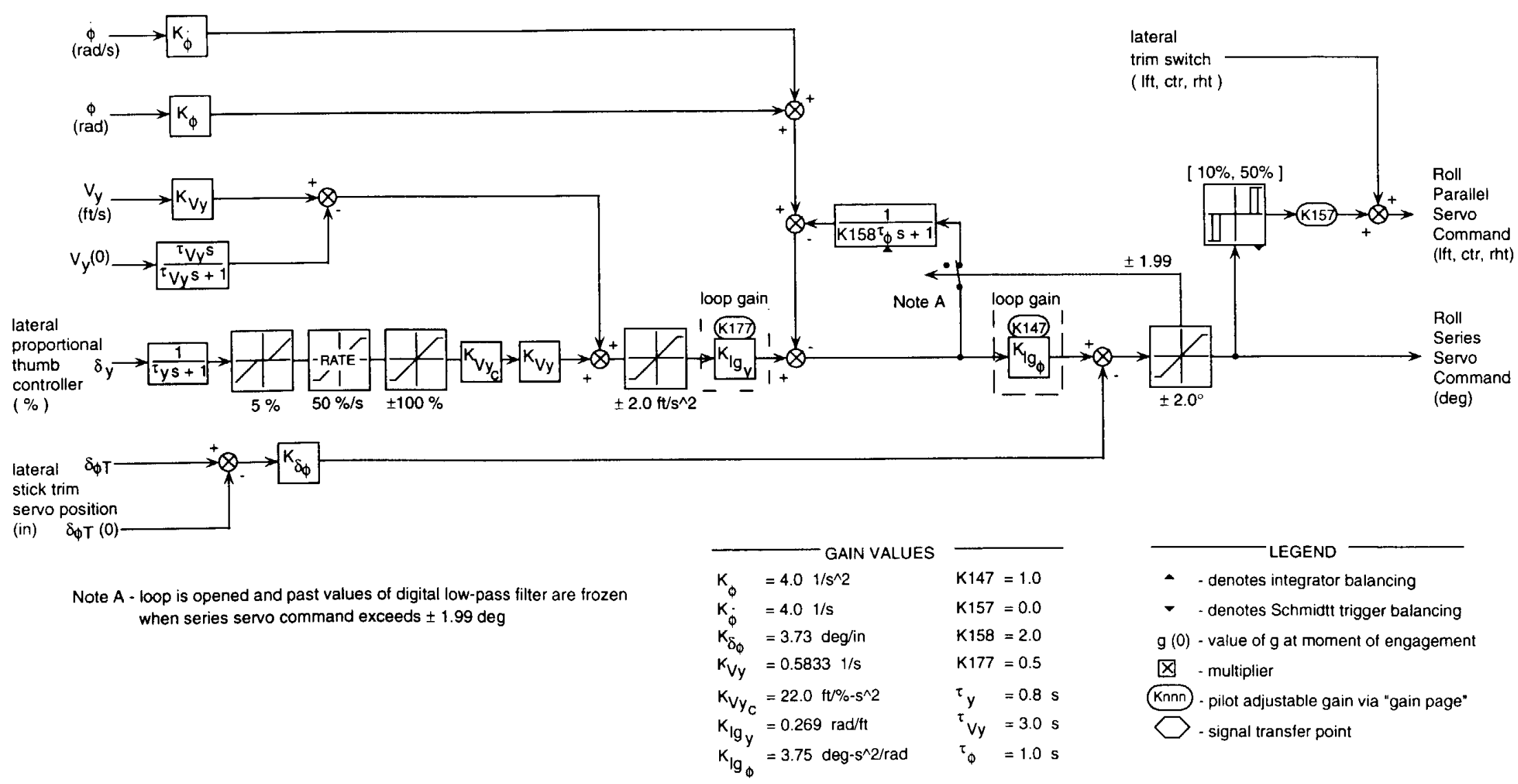

Figure A-4. Lateral-velocity command control law. 

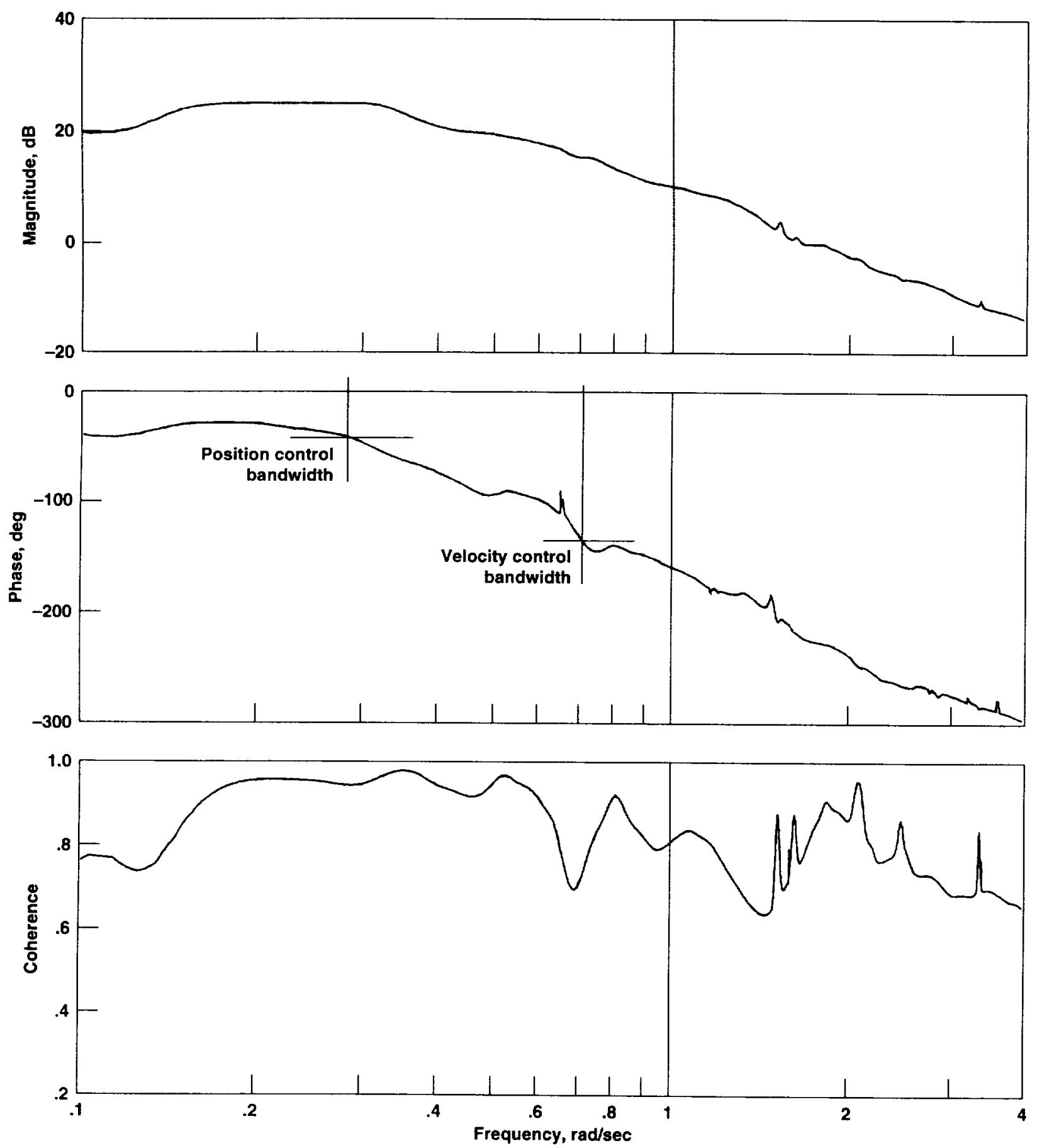

Figure A-5. Frequency response for baseline lateral translational-rate command in hover. 


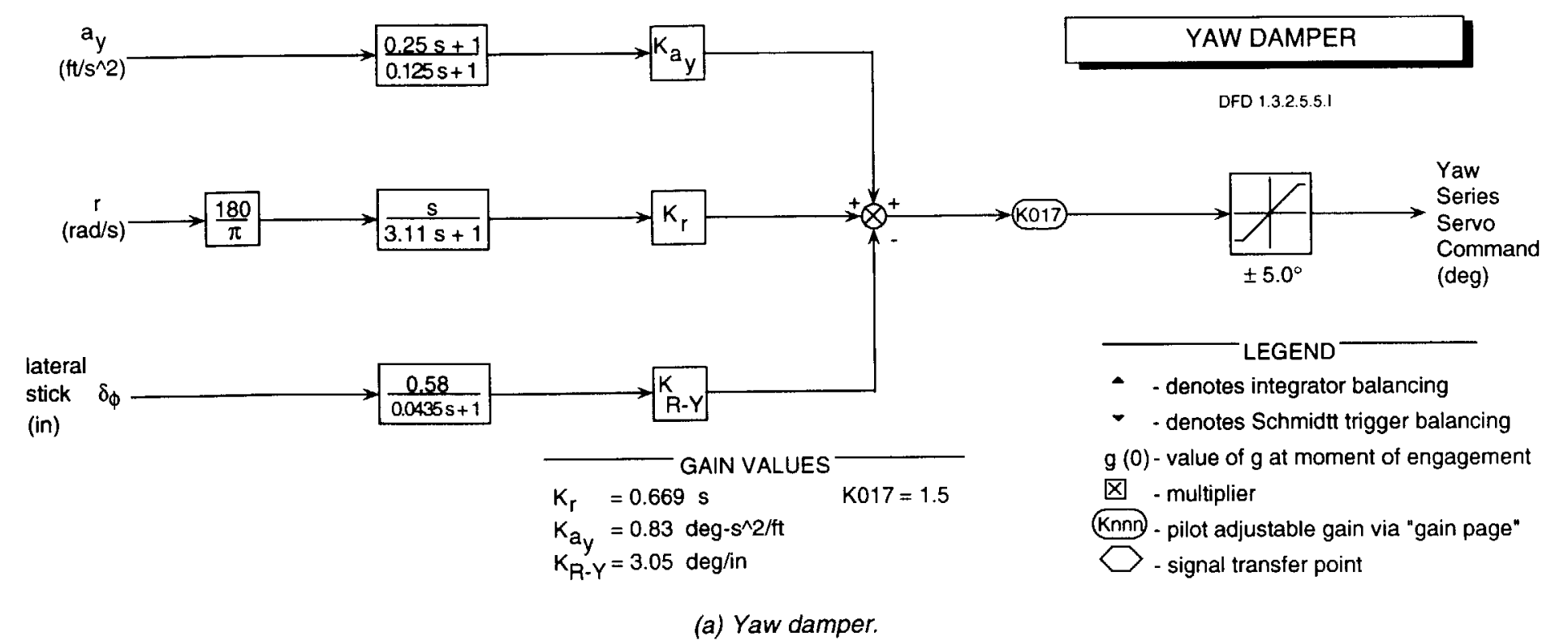

Figure A-6. Yaw-axis control laws. 


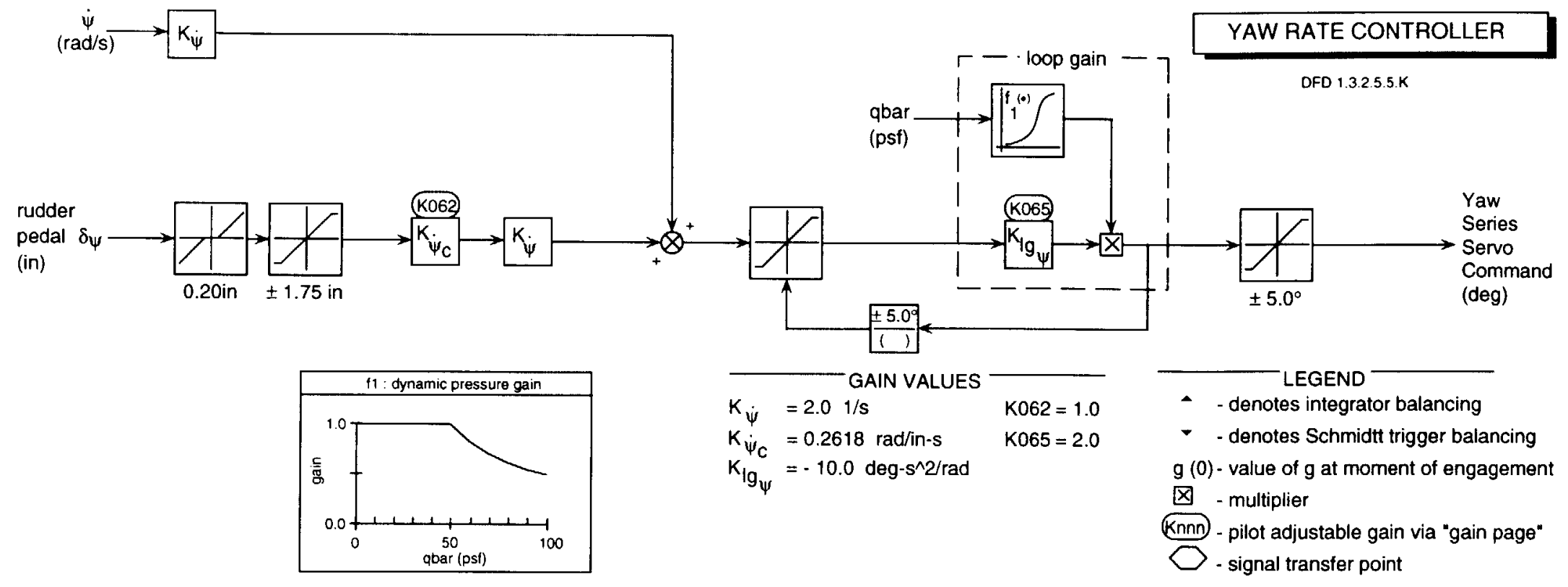

(b) Yaw-rate command.

Figure A-6. Concluded. 


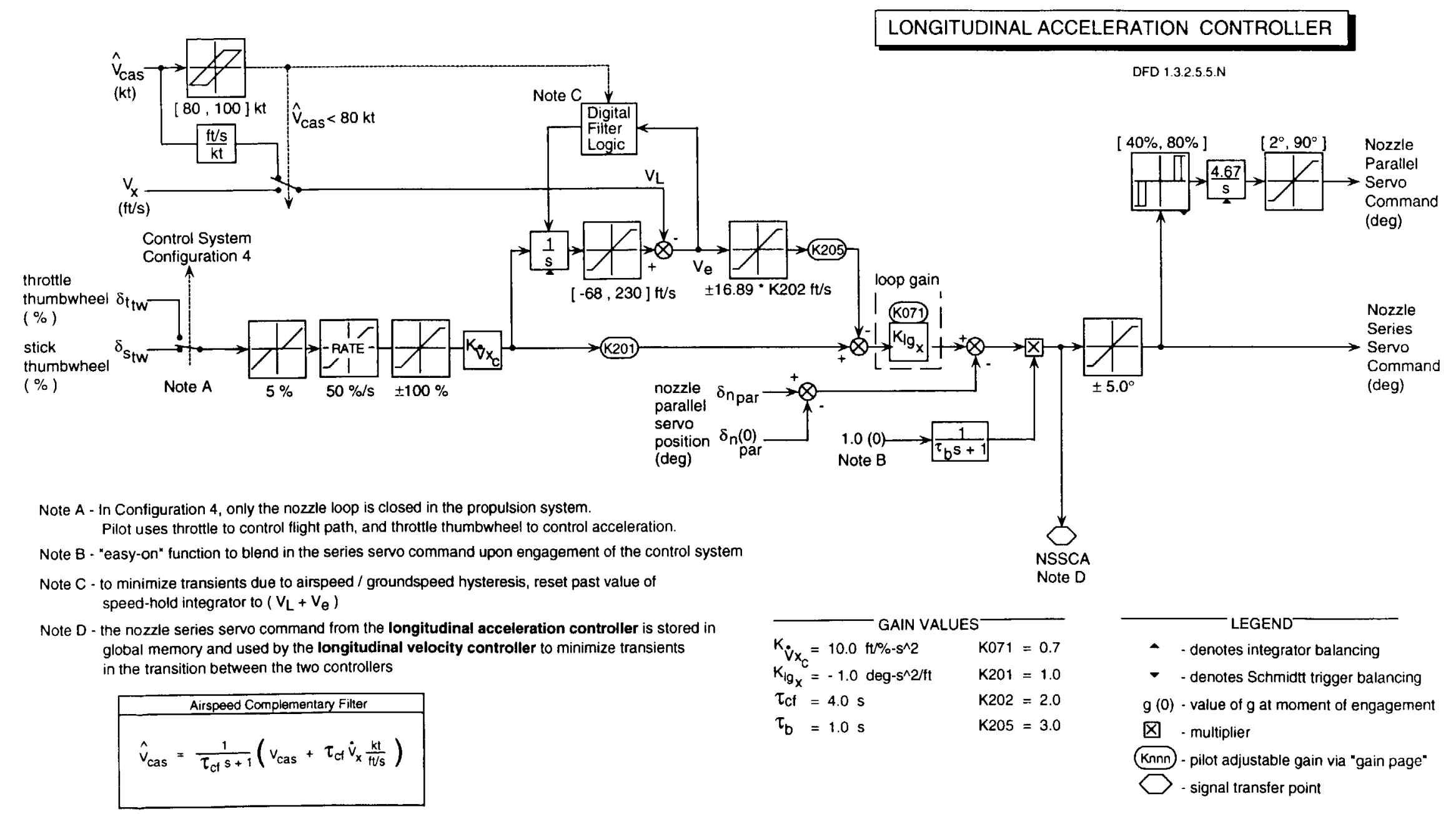

(a) Acceleration command.

Figure A-7. Longitudinal-axis control laws. 
DFD 1.3.2.5.5.0
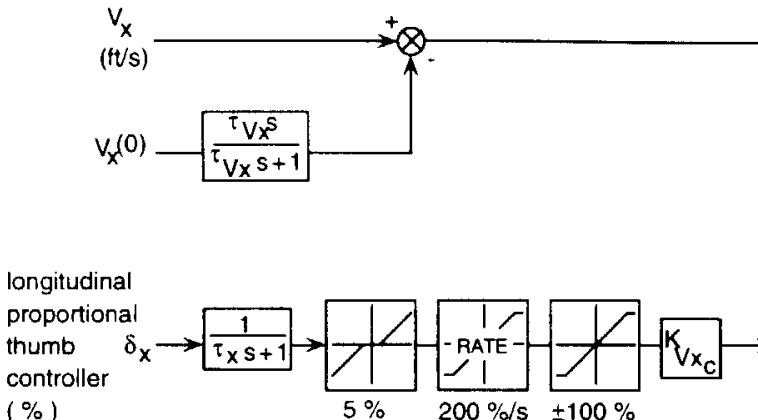

$(\%)$ $5 \% \quad 200 \% / \mathrm{s} \pm 100 \%$

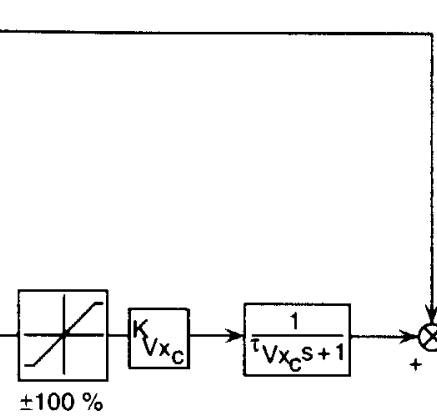

nozzle parallel

servo

position $\delta n_{\mathrm{par}}^{(0)}$

(deg) (deg)

par
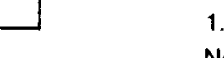

Note A

Note A - "easy-on" function to blend in the series servo command upon engagement of the control system

Note B - the nozzle series servo command from the longitudinal acceleration controller is stored in global memory and used by the longitudinal velocity controller to minimize transients in the transition between the two controllers

Note C - one-shot switch ICNOZCMD is momentarily closed at instant the longitudinal velocity controller is engaged; also, the nozzle series servo command from the longitudinal acceleration controller, NSSCA, is set to 0.0 to allow re-engagements of the longitudinal velocity controller

$$
\begin{aligned}
& \text { GAIN VALUES } \\
& K_{V_{X_{C}}}=-22.0 \mathrm{H} / \%-\mathrm{s}^{\wedge} 2 \quad K 082=0.75 \\
& \mathrm{~K}_{\lg _{\mathrm{x}}}=-1.0 \mathrm{deg}-\mathrm{s}^{\wedge} 2 / \mathrm{ft} \quad \mathrm{K} 202=2.0 \\
& \tau_{\mathrm{x}}=0.8 \mathrm{~s} \quad \mathrm{~K} 205=3.0 \\
& \tau_{\mathrm{Vx}}=3.0 \mathrm{~s} \\
& \tau_{b}=1.0 \mathrm{~s} \\
& \tau_{\text {wo }}=2.0 \mathrm{~s} \\
& \tau_{v_{x_{c}}}=0.5714 \mathrm{~s}
\end{aligned}
$$

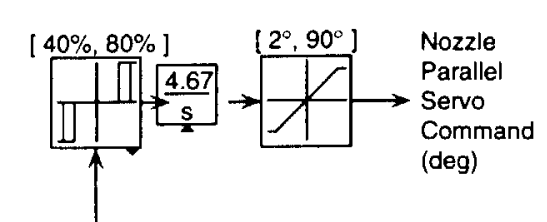

Command Nozzle Series Servo Command (deg)

(b) Longitudinal-velocity command. 
was performed at a constant pitch attitude, attitude changes could be made by using the trim switch. The functions of the control gains were similar to those for the acceleration command. As shown in the longitudinalvelocity frequency response to the longitudinal proportional thumb controller in figure A-8, the bandwidth for a 45-deg phase margin for longitudinal-position control in hover was $0.36 \mathrm{rad} / \mathrm{sec}$; for longitudinal-velocity control the bandwidth for a 45-deg phase margin was $1.1 \mathrm{rad} / \mathrm{sec}$.

Flightpath and Vertical-Velocity Control - The flightpath angle or vertical-velocity command originated with the throttle thumbwheel. This command input, in combination with the normal acceleration and verticalvelocity feedbacks, was the essence of the flightpath control law for transition (fig. A-9). The velocity $V_{x}$ was ground speed along track and was used to convert the pilot's flightpath-angle command to an equivalent vertical-velocity command. For ground speeds below $100 \mathrm{ft} / \mathrm{sec}$, this velocity was frozen at the $100-\mathrm{ft} / \mathrm{sec}$ value to convert the pilot's command from flightpath angle to vertical velocity as appropriate for hover and low-speed flight. The gain $\mathbf{K}_{\gamma}$ determined control sensitivity, gain $\mathrm{K}_{\mathrm{V}_{Z}}$, the phase margin, and gain $\mathrm{K}_{1 \mathrm{~g}_{\mathrm{Z}}}$, the system bandwidth. Positive feedback of the lagged servo command provided proportional-plus-integral compensation in the forward loop. The time constant $\tau_{\mathrm{Z}}$ was scheduled with engine rpm to provide first-order compensation for the engine thrust lag. The flightpath frequency response to frequency sweeps with the throttle thumbwheel is presented in figure A-10(a) for the flight condition of a 3-deg descent at 80 knots. These data show a bandwidth for altitude control of $0.38 \mathrm{rad} / \mathrm{sec}$ for a 45 -deg phase margin. The bandwidth of flightpath control was obtained from a frequency response plot of the integral of normal acceleration, shown in figure A-10(b). The integral of normal acceleration was used instead of flightpath response since it showed higher coherence with respect to the control input at frequencies defining flightpath bandwidth. From this figure, the flightpath bandwidth is $1.6 \mathrm{rad} / \mathrm{sec}$.

The hover vertical-velocity control law, shown in figure A-11, had a similar form to that for flightpath control, with the addition of altitude feedback to provide a height-hold function in hover. The reference altitude $h_{H}$ was synchronized with the measured radar altitude until the pilot's vertical-velocity command was centered and the vertical velocity was less than I f $/ \mathrm{sec}$, at which time the reference altitude was held at its past value. Also, for this condition, the vertical-velocity feedback and command gains were doubled to increase handwidth for the attitude-hold loop. Control sensitivity was established by the gain $\mathrm{K}_{\mathrm{V}_{\mathrm{c}}}$. The vertical-velocity frequency response for frequency sweeps with the thumbwheel controller in hover is presented in figure A-12. Vertical-position control showed a bandwidth for a 45-deg phase margin of $0.64 \mathrm{rad} / \mathrm{sec}$. The bandwidth for vertical-velocity control was $3.6 \mathrm{rad} / \mathrm{sec}$.

A height-rate damper, shown in figure A-13, was implemented as an alternative to the vertical-velocity command system and was the basis of Configuration 4 . This control law consisted simply of a command input through the throttle handle along with vertical-velocity feedback. It was designed to produce a bandwidth similar to that of the vertical-velocity command.

\section{Head-Up Display Laws}

Drive laws for the flightpath symbol, horizontal-velocity predictor ball, and vertical-velocity diamond are described in general in references 9-12. Specific characteristics for these laws as currently used on the VSRA are noted in the discussion that follows.

As indicated in reference 9 , the flightpath symbol was quickened to compensate for lags in the airframe and propulsion-system response. For Configurations 1, 2 , and 4 , where thrust was controlled manually using the throttle, the flightpath compensation included lagged pitch rate and washed-out throtte commands in combination with the true flightpath in accordance with the equation

$$
\begin{aligned}
\gamma_{\mathrm{q}}= & \frac{\mathrm{K}_{\mathrm{q}} \dot{\theta}}{\mathrm{s}+\sigma_{\mathrm{w}}} \\
& +57.3\left[\tan ^{-1}\left(\frac{\mathrm{K}_{\delta_{\mathrm{T}}} \delta_{\mathrm{T}}}{\mathrm{V}_{\mathrm{tl}}}\right)\left(\frac{\mathrm{s}}{\mathrm{s}+\sigma_{\mathrm{w}}}\right)+\tan ^{-1}\left(\frac{\dot{\mathrm{h}}}{\mathrm{V}_{\mathrm{tl}}}\right)\right]
\end{aligned}
$$

where

$$
\begin{aligned}
\sigma_{\mathrm{w}} & =\mathrm{Z}_{\mathrm{w}_{\text {hover }}}+\mathrm{V}_{\mathrm{af}} \mathrm{Z}_{\mathrm{W}}^{\prime}+\mathrm{Z}_{\mathrm{w}_{\text {damper }}} \\
\mathrm{Z}_{\mathrm{w}_{\text {hover }}} & =0.02 \mathrm{sec}^{-1} \\
\mathrm{Z}_{\mathrm{w}}^{\prime} & =0.00164 \mathrm{rad} / \mathrm{ft} \\
\mathrm{Z}_{\mathrm{w}_{\text {damper }}} & =0.77 \mathrm{sec}^{-1} \\
\mathrm{~K}_{\mathrm{q}} & =0.25 \mathrm{ft} / \mathrm{sec} / \mathrm{deg} \\
\mathrm{K}_{\delta_{\mathrm{T}}} & =\mathrm{A}_{\delta_{\mathrm{T}}} \sin \theta_{\mathrm{j}} / \sigma_{\mathrm{w}} \\
\mathrm{A}_{\delta_{\mathrm{T}}} & =1.09 \mathrm{ft} / \mathrm{sec}^{2} / \mathrm{deg}
\end{aligned}
$$

The pitch-rate term was blended out for speeds below $55 \mathrm{knots}$ and the ground speed was frozen at $100 \mathrm{ft} / \mathrm{sec}$ for speeds less than $100 \mathrm{ft} / \mathrm{sec}$. For Conliguration 3, the flightpath was complemented with its commanded value in the short term according to 

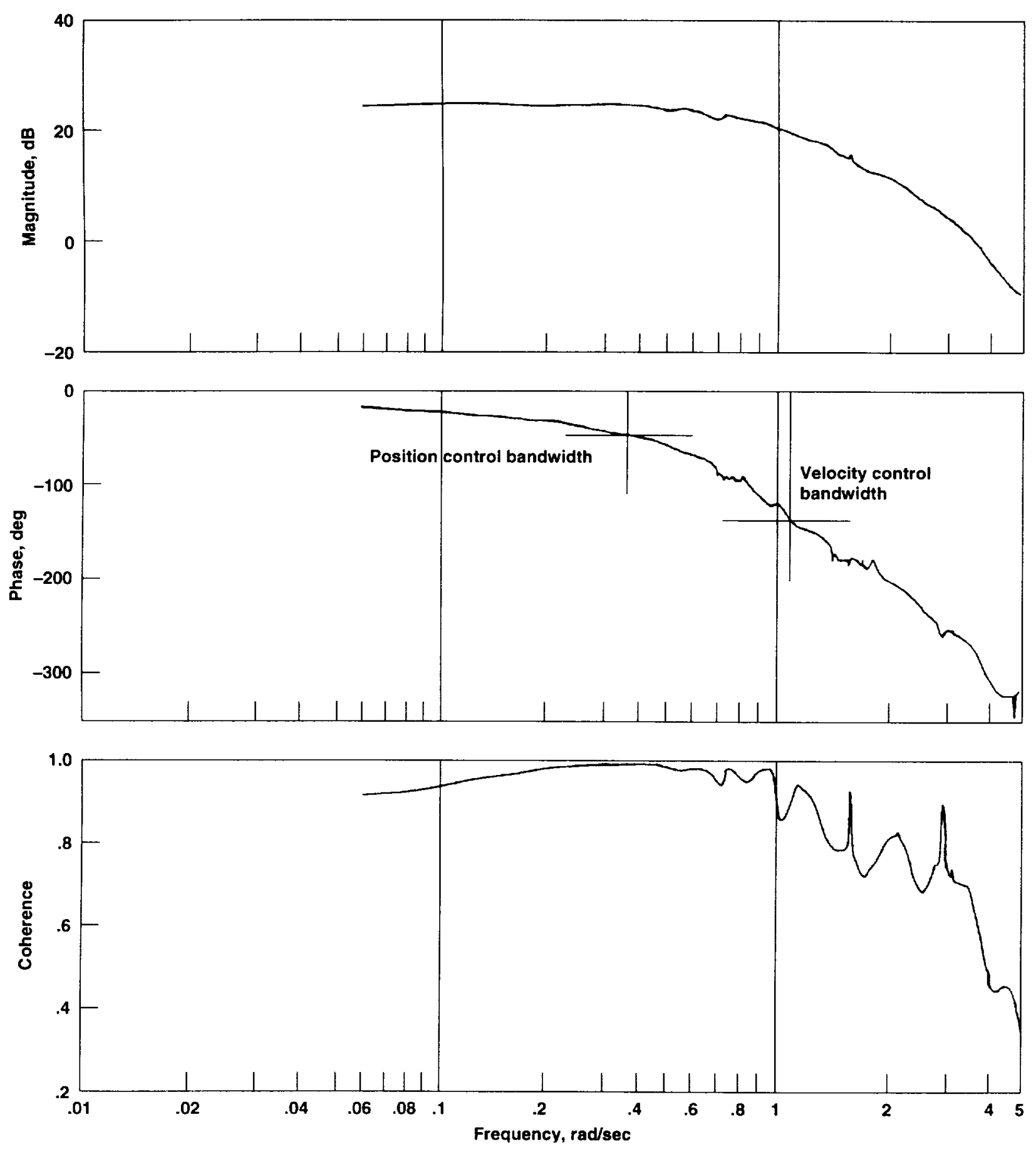

Figure A-8. Frequency response for baseline longitudinal translational-rate command in hover. 


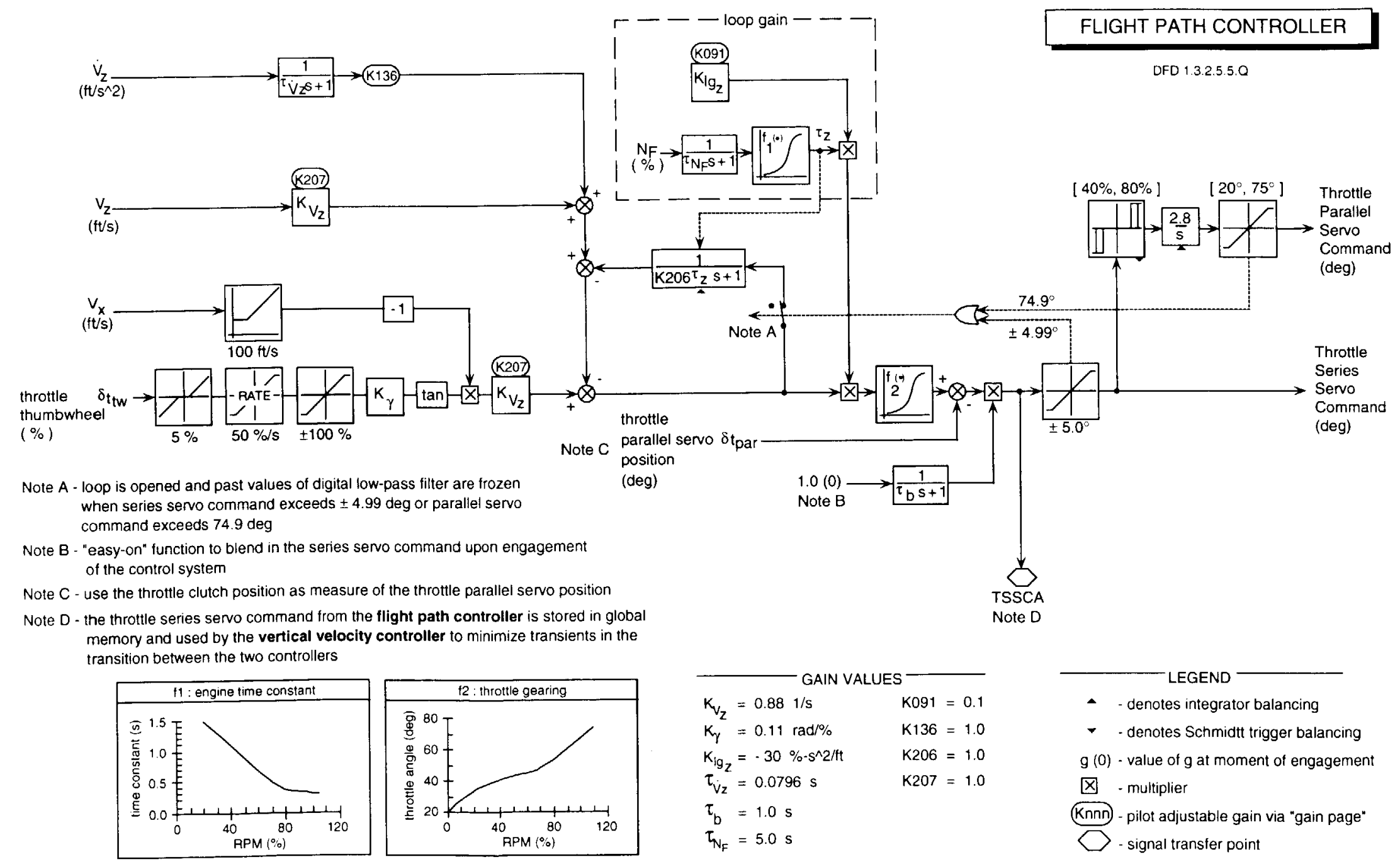

Figure A-9. Flightpath command control law. 

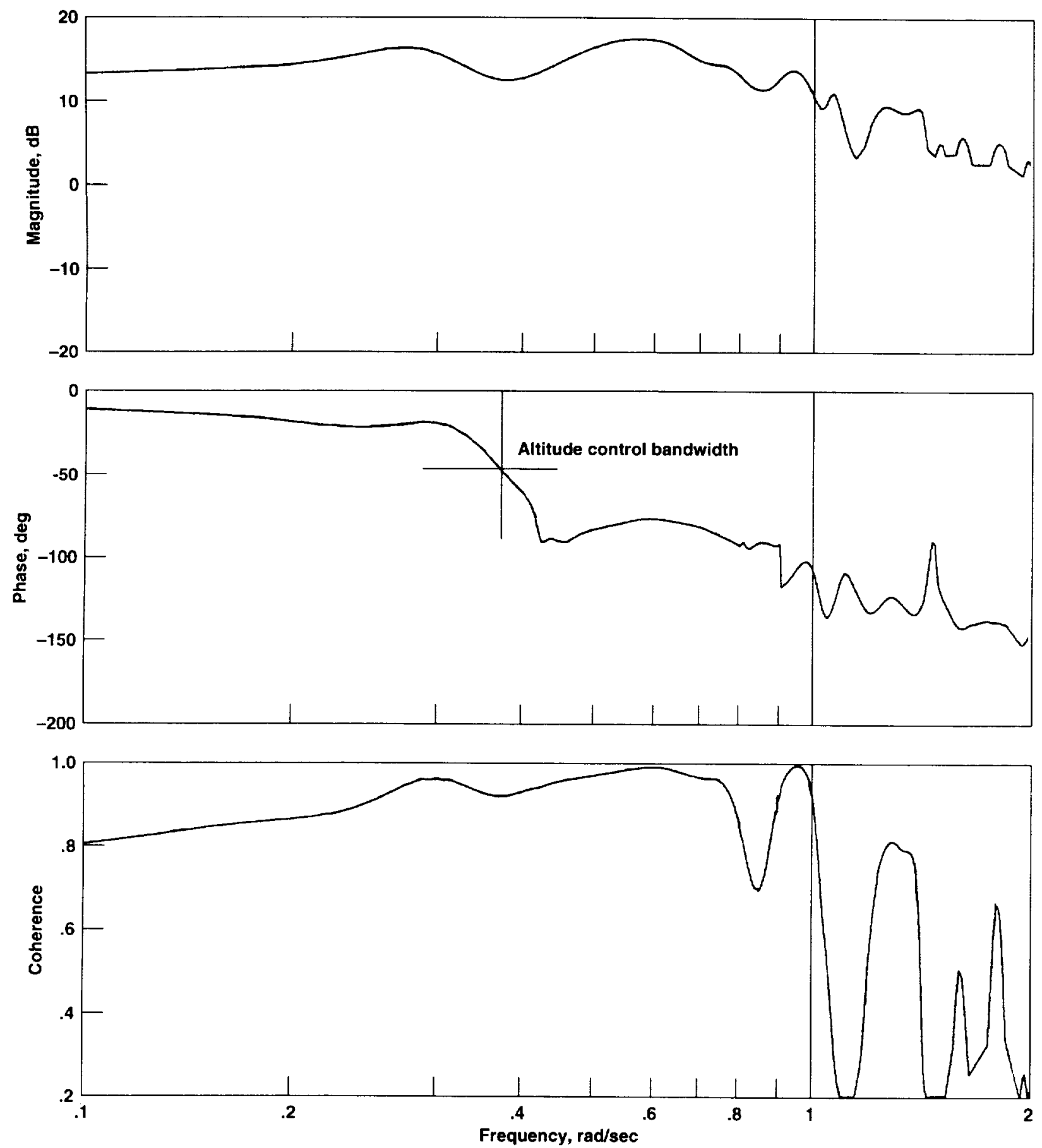

(a) Flightpath response.

Figure A-10. Frequency response baseline flightpath command system; 80 knots. 

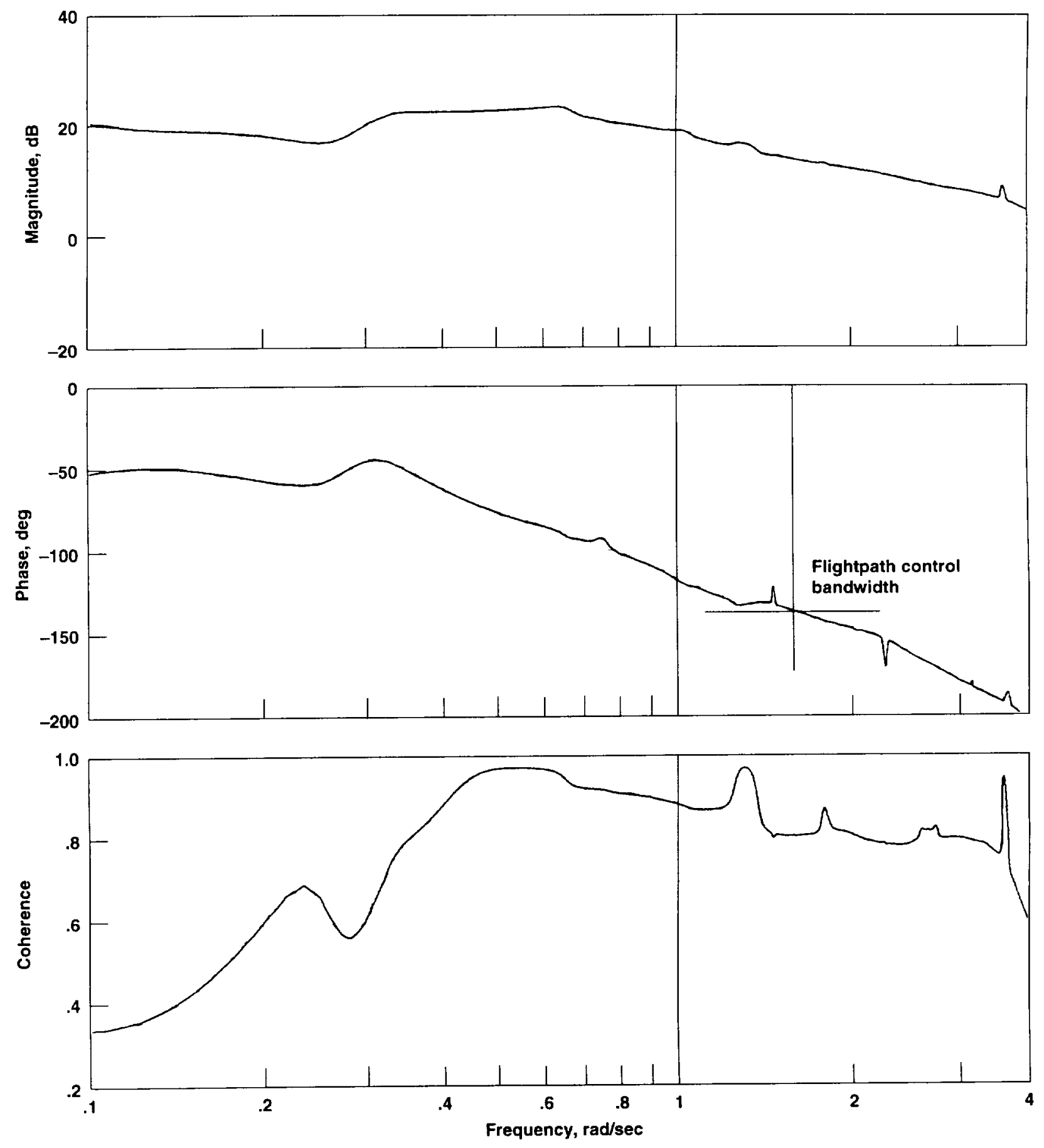

(b) Integral of normal acceleration response.

Figure A-10. Concluded. 


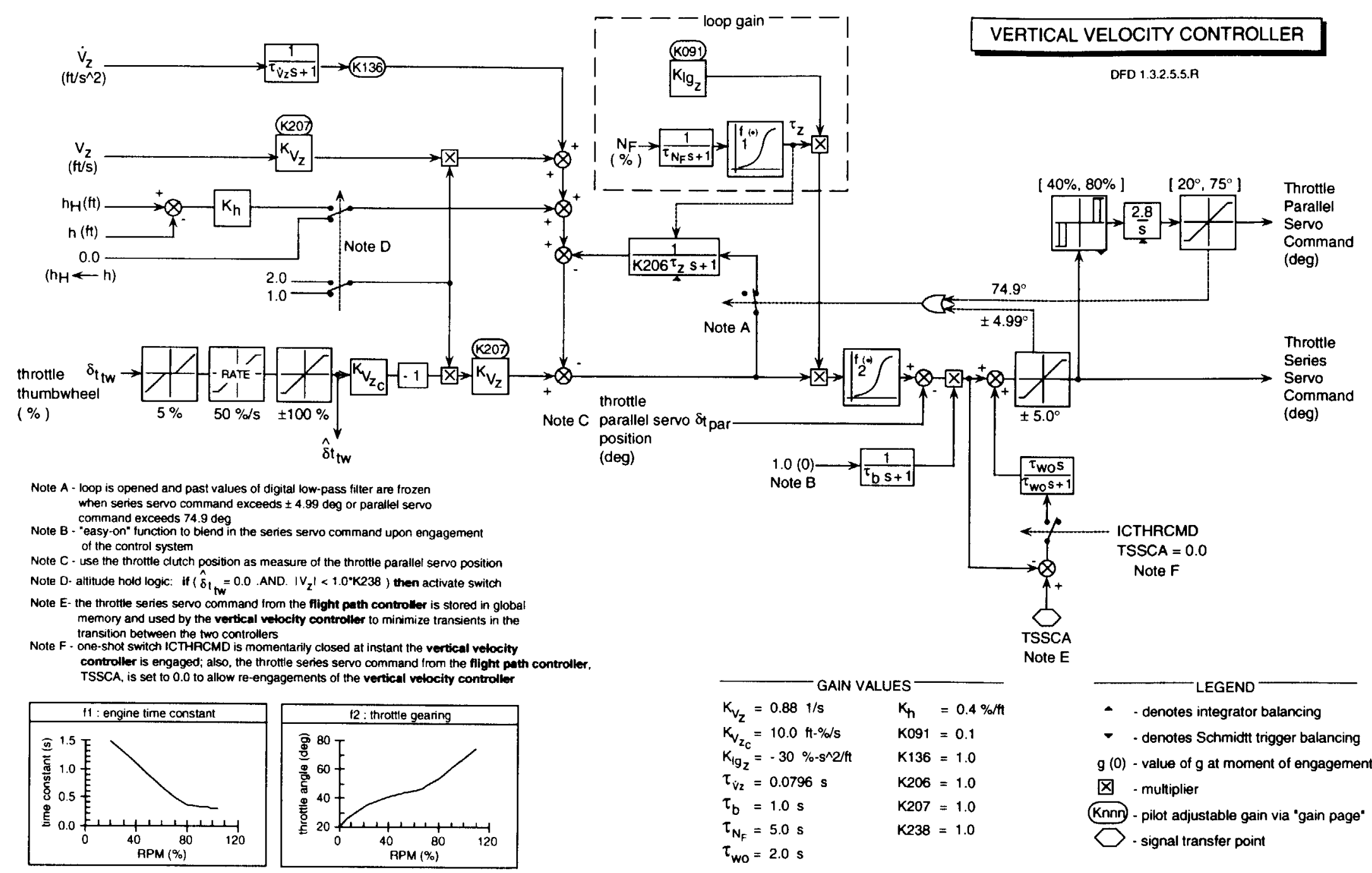

Figure A-11. Vertical-velocity command control law. 

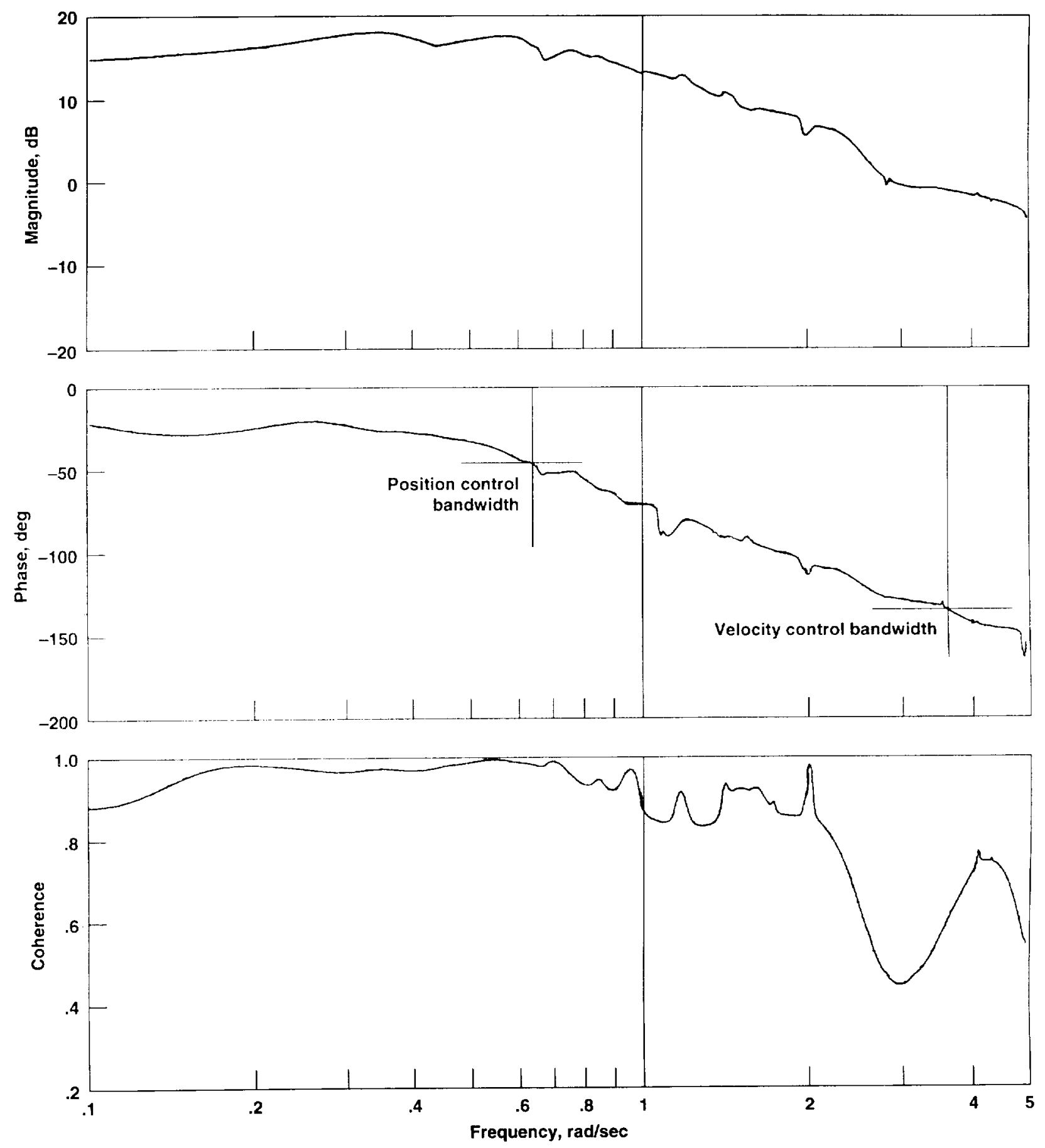

Figure A-12. Frequency response for baseline vertical-velocity command in hover. 


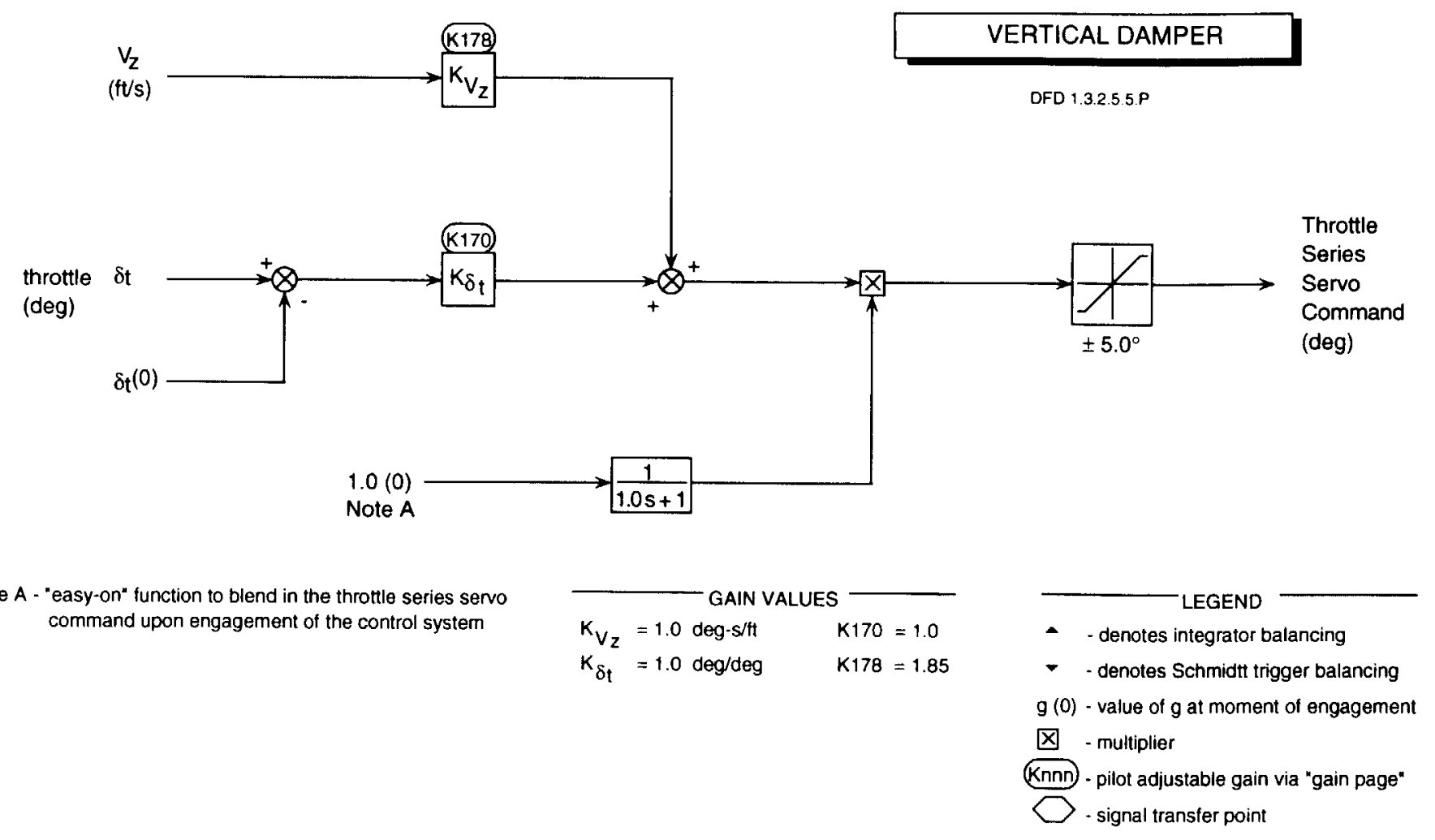

Figure A-13. Height-rate damper control law. 


$$
\gamma_{\mathrm{q}}=57.3\left[\tan ^{-1}\left(\mathrm{~K}_{\mathrm{h}_{\mathrm{c}}} \frac{\dot{\mathrm{h}}_{\mathrm{c}}}{\mathrm{V}_{\mathrm{tl}}}\left(\frac{\mathrm{s}}{\mathrm{s}+\omega_{\gamma}}\right)\right) \tan ^{-1}\left(\frac{\dot{\mathrm{h}}}{\mathrm{V}_{\mathrm{tl}}}\right)\right]
$$

where the gain $K_{h_{c}}=1.1$ and the washout frequency $\omega_{\gamma}=0.44 \mathrm{sec}^{-1}$.

During the latter stages of the deceleration as the aircraft approached the intended point of hover, selective changes were made to the approach display to provide guidance for the hover-point capture. Specifically, the longitudinalvelocity vector, predicted longitudinal velocity, and station-keeping cross appeared referenced to the verticalvelocity diamond symbol, as shown in figure 4(a). The drive law for predicted longitudinal velocity is shown in the following discussion of the hover display.

For the vertical landing, drive laws for the horizontalvelocity predictor ball and vertical-velocity diamond included compensation for aircraft and propulsion-system lags. In this case, for Configurations 1 and 2, true horizontal velocities were complemented with translational accelerations and washed-out control commands according to the relationships:

$$
\begin{aligned}
\mathrm{v}_{\mathrm{x}_{\mathrm{c}}}= & \mathrm{V}_{\mathrm{x}}+\frac{\mathrm{T}_{\dot{\mathrm{v}}}}{\mathrm{s}+1 / \mathrm{T}_{6}}\left[\dot{\mathrm{V}}_{\mathrm{x}}-\mathrm{g}\left(\dot{\theta}+\dot{\theta}_{\mathrm{j}}\right)\left(\frac{\mathrm{s}}{\mathrm{s}+\sigma_{\mathrm{u}}}\right)\right] \\
& -\mathrm{K}_{\theta_{\mathrm{c}}}\left[\frac{\mathrm{s}\left(\mathrm{s}+4 \Omega_{\mathrm{o}}\right)}{\left(\mathrm{s}+\sigma_{\mathrm{u}}\right)\left(\mathrm{s}+\mathrm{D}_{\mathrm{x}}\right)}\right] \delta_{\text {long }} \\
\mathrm{V}_{\mathrm{y}_{\mathrm{c}}}= & \mathrm{V}_{\mathrm{y}}+\frac{\mathrm{T} \dot{\mathrm{v}}}{\mathrm{s}+1 / \mathrm{T}_{6}}\left[\dot{\mathrm{V}}_{\mathrm{y}}-\mathrm{g}(\dot{\phi})\left(\frac{\mathrm{s}}{\mathrm{s}+\sigma_{\mathrm{v}}}\right)\right] \\
& +\mathrm{K}_{\phi_{\mathrm{c}}}\left[\frac{\mathrm{s}\left(\mathrm{s}+4 \Omega_{\mathrm{o}}\right)}{\left(\mathrm{s}+\sigma_{\mathrm{v}}\right)\left(\mathrm{s}+\mathrm{D}_{\mathrm{y}}\right)}\right] \delta_{\mathrm{lat}}
\end{aligned}
$$

where

$$
\begin{aligned}
& \sigma_{u}=0.05 \mathrm{sec}^{-1} \\
& \sigma_{\mathrm{v}}=0.05 \mathrm{sec}^{-1} \\
& \mathrm{~T}_{\dot{\mathrm{v}}}=2
\end{aligned}
$$

$$
\begin{aligned}
\mathrm{T}_{6} & =10 \mathrm{sec} \\
\mathrm{K}_{\theta_{\mathrm{c}}} & =0.247 \\
\mathrm{~K}_{\phi_{\mathrm{c}}} & =1.287 \\
\Omega_{\mathrm{o}} & =1.75 \mathrm{rad} / \mathrm{sec} \\
\mathrm{D}_{\mathrm{x}} & =1.38 \mathrm{rad} / \mathrm{sec} \\
\mathrm{D}_{\mathrm{y}} & =4.23 \mathrm{rad} / \mathrm{sec}
\end{aligned}
$$

For Configurations 3 and 4, the commanded horizontal velocities from the proportional thumb controller were displayed directly.

The vertical-velocity diamond's displacement, $t_{w_{c}}$, was proportional to complemented vertical speed. For Configurations 1 and 2, vertical velocity is complemented with vertical acceleration so that

$$
\mathrm{t}_{\mathrm{w}_{\mathrm{c}}}=\mathrm{K}_{\mathrm{w}}\left[\dot{\mathrm{h}}+\frac{\mathrm{T}_{\mathrm{h}}}{\mathrm{T}_{6} \mathrm{~s}+1}\left(\ddot{\mathrm{h}}+\mathrm{K}_{\delta_{\mathrm{T}}} \delta_{\mathrm{T}} \mathrm{T}_{6} \frac{\mathrm{s}^{2}}{\mathrm{~s}+\sigma_{\mathrm{w}}}\right)\right]
$$

where

$$
\begin{aligned}
\mathrm{K}_{\mathrm{W}} & =0.2 \mathrm{deg} / \mathrm{f} \mathrm{vec} \\
\mathrm{T}_{6} & =10 \mathrm{sec} \\
\mathrm{K}_{\delta_{\mathrm{T}}} & =1.45 \mathrm{ft} / \mathrm{sec}^{2} / \mathrm{deg} \\
\sigma_{\mathrm{W}} & =0.02 \mathrm{sec}^{-1}
\end{aligned}
$$

When translational-rate command or the height damper were engaged, vertical velocity was complemented with washed-out vertical-velocity command from the thumbwheel or throttle, so that

$$
\mathrm{t}_{\mathrm{w}_{\mathrm{c}}}=\mathrm{K}_{\mathrm{w}}\left[\dot{\mathrm{h}}+\dot{\mathrm{h}}_{\mathrm{c}}\left(\frac{\mathrm{s}}{\mathrm{s}+\omega_{\gamma}}\right)\right]
$$

and $\omega_{y}=0.44 \mathrm{sec}^{-1}$. A horizontal bar indicated the altitude remaining to touchdown. Attitude, air velocity, engine rpm, thrust vector angle, heading, vertical-velocity limits, and wind direction were provided as situation information. 
Table 2. Handling quality ratings and comments

\begin{tabular}{|c|c|c|c|c|c|}
\hline Config & Pilot & Dates/Runs & Segment & HQR & Comments \\
\hline 1 & $\begin{array}{c}\text { Pilot A } \\
\text { Hobaugh }\end{array}$ & $\begin{array}{l}2 / 2 / 95 \\
50602,05,10 \\
50702 \\
2 / 3 / 95 \\
50902 \\
51104\end{array}$ & $\begin{array}{l}\text { Approach } \\
\text { Hover acquisition } \\
\text { Vertical landing }\end{array}$ & $\begin{array}{l}4 \\
4 \\
3\end{array}$ & $\begin{array}{l}\text { Pitch control is highest work load. } \\
\text { Pitch reference is lacking. } \\
\text { Can maintain position and descent rate. }\end{array}$ \\
\hline 1 & $\begin{array}{c}\text { Pilot } \mathrm{C} \\
\text { O'Donoghue }\end{array}$ & $\begin{array}{l}5 / 3 / 95 \\
55302,04 \\
5 / 4 / 95 \\
55509 \\
55602\end{array}$ & $\begin{array}{l}\text { Hover acquisition } \\
\text { Vertical landing }\end{array}$ & $-5-6$ & $\begin{array}{l}\text { Would expect high workload to acquire and hold hover point. } \\
\text { Due to high workload for height control. }\end{array}$ \\
\hline 1 & $\begin{array}{l}\text { Pilot D } \\
\text { Stortz }\end{array}$ & $\begin{array}{l}6 / 21 / 95 \\
56209 \\
56401 \\
6 / 29 / 95 \\
55701-(05 \\
9 / 5 / 95 \\
58202.03\end{array}$ & $\begin{array}{l}\text { Approach } \\
\text { Hover acquisition } \\
\text { Vertical landing }\end{array}$ & 5 & $\begin{array}{l}\text { Control of attitude is smooth, but requires effort to stabilize. Heave response at nozzle drop is significant } \\
\text { and requires attention and effort to compensate. Abrupt lift loss at lower speeds requires significant } \\
\text { compensatory input with the throttle. None of these characteristics is conducive to a decelerating } \\
\text { approach in IMC. Yaw is easily excited during approach. especially in turbulence. } \\
\text { High workload associated with large attitude change for hover acquisition in combination with height } \\
\text { control. More comfortable to do it with visual references than HUD guidance. } \\
\text { Height control difficult. Vertical velocity wanders following initial input. Get better hoight control with } \\
\text { visual cues. Heading wanders. }\end{array}$ \\
\hline 1 & $\begin{array}{l}\text { Pilot E } \\
\text { Hardy }\end{array}$ & $\begin{array}{l}9 / 15 / 95 \\
58603.04 \\
9 / 19 / 95 \\
59201-04 \\
59303\end{array}$ & $\begin{array}{l}\text { Approach } \\
\text { Hover acquisition } \\
\text { Vertical landing }\end{array}$ & $\begin{array}{r}4 \\
4.5\end{array}$ & $\begin{array}{l}\text { Deceleration is comfortable-profile not too aggressive. Pitch control is principal contributor to } \\
\text { workload-large trim changes and pitch control of deceleration. } \\
\text { Final deceleration guidance fairly easy to use. but close attention required to avoid under-or } \\
\text { overshooting station-keeping point. } \\
\text { Workload maintaining altitude during translation to landing pad and maintaining control of sink rate } \\
\text { during descent is fairly high. Vertical-velocity caret gets lost in hover display. Attitude control } \\
\text { smooth. }\end{array}$ \\
\hline 2 & A & $\begin{array}{l}2 / 1 / 95 \\
50503.04 .09 \\
2 / 2 / 95 \\
50603,06.08 .11 \\
50703.07 .08 \\
50802.03 \\
2 / 3 / 95 \\
50904.06,07 \\
51004 \\
51105,08\end{array}$ & $\begin{array}{l}\text { Approach } \\
\text { Hover acquisition } \\
\text { Vertical landing } \\
\text { Slow landing }\end{array}$ & $\begin{array}{l}3 \\
3 \\
4\end{array}$ & $\begin{array}{l}\text { Easy to stabilize speed. Difficult to make small pitch changes in presence of trim followup. } \\
\text { Used nozzle for large adjustments. pitch attitude for small corrections to longitudinal speed and position. } \\
\text { Stick trim follow'up annoying-fights pilot's inputs. Roll axis too sensitive. } \\
\text { Improvement over AV-8B due to pitch decoupling from thrust control. }\end{array}$ \\
\hline
\end{tabular}


Table 2. Continued

\begin{tabular}{|c|c|c|c|c|c|}
\hline Config & Pilot & Dates/Runs & Segment & HQR & Comments \\
\hline 2 & $\begin{array}{c}\text { Pilot B } \\
\text { Mlnarik }\end{array}$ & $\begin{array}{l}2 / 9 / 95 \\
51401-03 \\
51501.06 \\
51601.03\end{array}$ & $\begin{array}{l}\text { Approach } \\
\text { Hover acquisition } \\
\text { Vertical landing } \\
\text { Slow landing }\end{array}$ & 4 & $\begin{array}{l}\text { Like perspective on ghost, flashing cues. Clear improvement in stablity from Configuration } 1 . \\
\text { Moderate compensation for desired performance. Directional stability goes away at about } 30 \mathrm{kts} \text {. Nose } \\
\text { wanders. Difficult to control hover symbology to station-keeping point. Clutter objectionable. } \\
\text { Drifted off touchdown point outside } 5 \text {-ft circle. Looking outside for cues. Still on learning curve. Liked } \\
\text { allowable-sink-rate bar. Easy to switch from approach to hover. } \\
\text { Easy to control to ghost aircraft. More stable than AV-8B. Stick torces high. }\end{array}$ \\
\hline 2 & C & $\begin{array}{l}\mathbf{5 / 4 / 9 5} \\
55402-07 \\
55502-06,08 \\
\mathbf{5 / 9 / 9 5} \\
55901-04\end{array}$ & $\begin{array}{l}\text { Approach } \\
\text { Hover acquisition } \\
\text { Vertical landing }\end{array}$ & 4 & $\begin{array}{l}\text { Definite improvement over basic YAV-8B SAS. Easy to fly approach. Almost an open-loop task. Nozzle } \\
\text { drop cues were clear and unambiguous. Control of deceleration straightforward and predictahle. Some } \\
\text { annoying pitch trim offloads. Roll response nice. Consistently achieved desired performance. Liked } \\
\text { throttle for thightpath control. } \\
\text { Achieved desired performance for position and altitude control. Workload higher for height control. } \\
\text { Height control with throttle is biggest difficulty. Tight throttle control required with frequent inputs to } \\
\text { control height. Pitch-attitude changes led to throttle adjustments to hold height. Control to initial hover } \\
\text { easy. Control of deceleration not difficult. although frequent stick inputs required. Liked having } \\
\text { velocity vector and predictor ball come on at } 25 \text { knots instead of } 20 \text {. } \\
\text { Desired to adequate performance with medium to high workload. Height excursions during translation to } \\
\text { landing point with frequent throttle inputs required to hold target height. Height control difficulty like } \\
\text { that with AV-8A. Control of horizontal position required small stick inputs to maintain desired } \\
\text { precision. Controlled velocity vector directly instead of using predictor ball. Coordination of control } \\
\text { inputs drove workload up. }\end{array}$ \\
\hline 2 & $\mathrm{D}$ & $\begin{array}{l}6 / 27 / 95 \\
56901-05 \\
57001-04 \\
6 / 28 / 95 \\
57201-06 \\
57301-04 \\
6 / 29 / 95 \\
57502\end{array}$ & $\begin{array}{l}\text { Approach } \\
\text { Hover acquisition } \\
\text { Vertical landing }\end{array}$ & $\begin{array}{l}5 \\
5\end{array}$ & $\begin{array}{l}\text { Similar difficulties to basic YAV-8B for flightpath control. Pitch-control forces feel nonlinear because of } \\
\text { way trim comes in to offload the series servo. Objectionable yaw excursions. } \\
\text { Fighting pitch trim to control to hover point. } \\
\text { Height control difficult as for basic YAV-8B. Roll response seems poorly damped. When series servo } \\
\text { limits, roll response more abrupt-acceleration type. }\end{array}$ \\
\hline
\end{tabular}


Table 2. Continued

\begin{tabular}{|c|c|c|c|c|c|}
\hline Config & Pilot & Dates/Runs & Segment & $\mathrm{HQR}$ & Comments \\
\hline 2 & $\mathrm{E}$ & $\begin{array}{c}\mathbf{9 / 1 9 / 9 5} \\
59301,02 \\
\mathbf{9 / 2 0 / 9 5} \\
59601-05 \\
59701,02\end{array}$ & $\begin{array}{l}\text { Approach } \\
\text { Hover acquisition } \\
\text { Vertical landing }\end{array}$ & $\begin{array}{r}4 \\
4.5\end{array}$ & $\begin{array}{l}\text { Pitch-attitude hold helps attitude control during deceleration. } \\
\text { Final deceleration guidance fairly easy to use but close attention required to avoid under- or overshoot- } \\
\text { ing station-keeping point. Like the attitude command force gradient to help gage the final deceleration. } \\
\\
\text { Workload maintaining altitude during translation to landing pad and maintaining control of sink rate } \\
\text { during descent is fairly high. Vertical-velocity caret gets lost in hover display. Attitude control } \\
\text { smooth. Attitude hold helps, but roll response is nonlinear-very solid at first, then takes off. }\end{array}$ \\
\hline 3 & A & $\begin{array}{l}\mathbf{2 / 1 / 9 5} \\
50505-08 \\
2 / 2 / 95 \\
50604,07,09,12 \\
50704,05,06, \\
09,10 \\
50804,05 \\
2 / 3 / 95 \\
50905.08,09 \\
51002,03 \\
51106,10\end{array}$ & $\begin{array}{l}\text { Hover acquisition } \\
\text { Vertical landing }\end{array}$ & $\begin{array}{l}3 \\
2\end{array}$ & $\begin{array}{l}\text { Rating depends on tight vs. loose control of ghost. Might like actual flightpath shown along with } \\
\text { quickened flightpath. Quickening not perfect. Easy to track ghost. Hands off much of the time. } \\
\text { Sometimes requires many small inputs. } \\
\text { Only a few thumbwheel inputs required to capture hover point and altitude. } \\
\text { Jerky longitudinal response. Smooth lateral response. Some lag apparent during tight longitudinal- } \\
\text { position control. Love translational-rate command. Sink-rate response lags thumbwheel. Significant } \\
\text { workload reduction. } \\
\text { Flightpath lag noticeable. Easy to set speed and flightpath. a task that is difficult in AV-8B. Good system } \\
\text { for austere site operations-narrow roads. }\end{array}$ \\
\hline 3 & B & $\begin{array}{l}2 / 9 / 95 \\
51404.06,07 \\
51502-05 \\
51602.04\end{array}$ & $\begin{array}{l}\text { Hover acquisition } \\
\text { Vertical landing } \\
\text { Slow landing }\end{array}$ & $\begin{array}{l}3 \\
3\end{array}$ & $\begin{array}{l}\text { Oscillatory tracking of ghost early in approach-fed by nozzle hysteresis. Can get performance with } \\
\text { thumbwheel. but would prefer to use throttle. Would like to see actual flightpath along with quickened } \\
\text { flightpath. } \\
\text { Easy to perform task. } \\
\text { Easy to perform task. } \\
\text { Holds speed well. Easy to set flightpath. Would like to select speed as a function of weight. }\end{array}$ \\
\hline
\end{tabular}


Table 2. Continued

\begin{tabular}{|c|c|c|c|c|c|}
\hline Config & Pilot & Dates/Runs & Segment & HQR & Comments \\
\hline 3 & C & $\begin{array}{l}\mathbf{5 / 3 / 9 5} \\
55002-06 \\
55101-08 \\
55201-07 \\
\mathbf{5 / 9 / 9 5} \\
55702-09 \\
55801-03\end{array}$ & $\begin{array}{l}\text { Approach } \\
\text { Hover acquisition } \\
\text { Vertical landing }\end{array}$ & . & 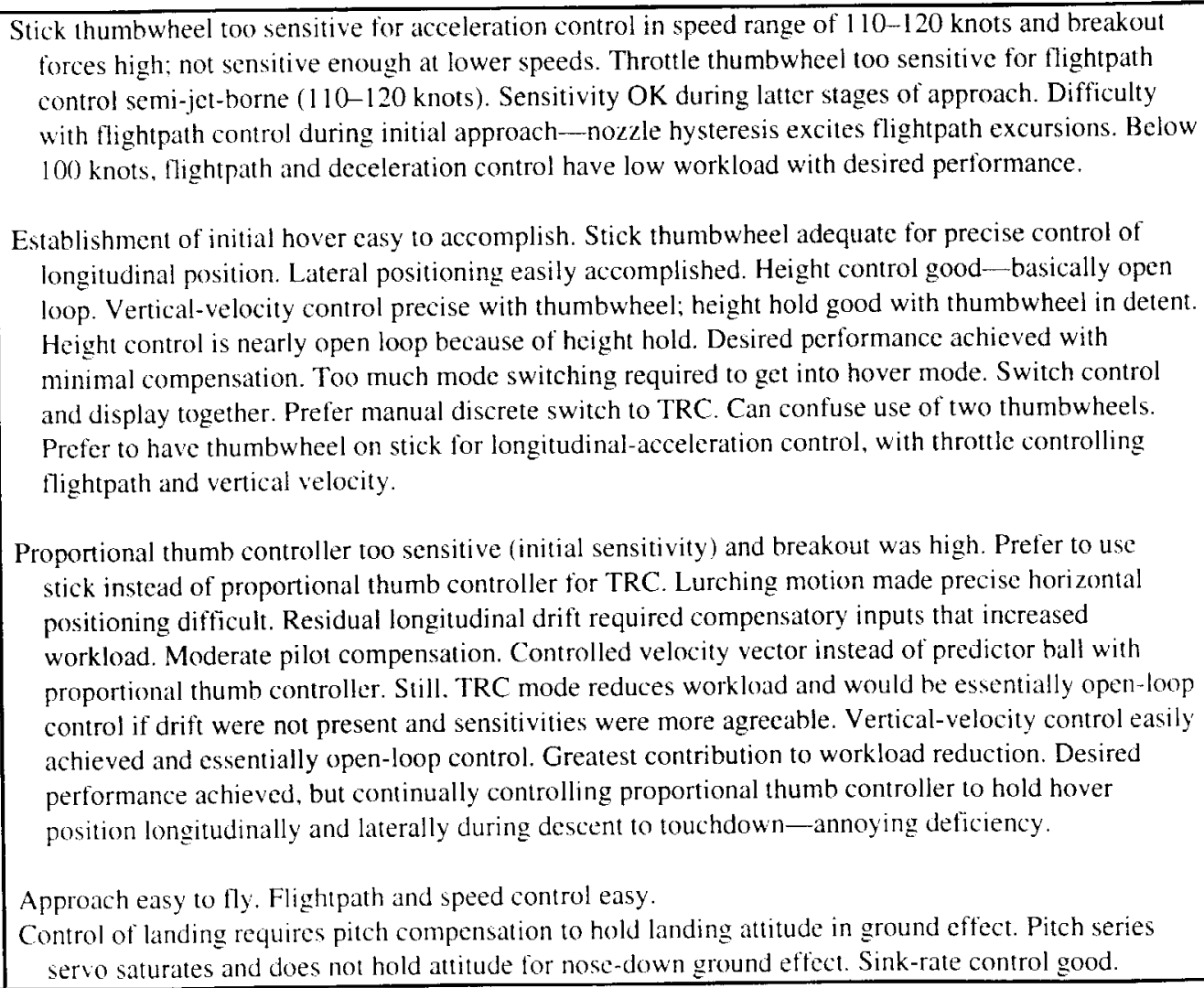 \\
\hline
\end{tabular}


Table 2. Continued

\begin{tabular}{|c|c|c|c|c|c|}
\hline Config & Pilot & Dates/Runs & Segment & $\mathrm{HQR}$ & Comments \\
\hline$\overline{3}$ & $\mathrm{D}$ & $\begin{array}{l}\mathbf{6 / 2 1 / 9 5} \\
56201-08 \\
56301-03,06- \\
08 \\
\mathbf{6 / 2 2 / 9 5} \\
56501-03 \\
56601.02 \\
\mathbf{6 / 2 7 / 9 5} \\
56801-06 \\
\mathbf{6 / 2 9 / 9 5} \\
57504,05 \\
\mathbf{9 / 1 / 9 5} \\
58101-04 \\
\mathbf{9 / 1 1 / 9 5} \\
58301-03 \\
58401,02 \\
\mathbf{9 / 1 8 / 9 5} \\
59002-04 \\
\mathbf{9 / 2 2 2 9 5} \\
59801-03 \\
59901,02 \\
510001-03 \\
\mathbf{9 / 2 5 / 9 5} \\
510101-04 \\
510201-04 \\
510301-04\end{array}$ & $\begin{array}{l}\text { Slow landing } \\
\text { Vertical landing } \\
\text { with } \\
\text { bandwidth } \\
\text { variations }\end{array}$ & $\begin{array}{l}5 \\
4 \\
5 \\
5 \\
5\end{array}$ & $\begin{array}{l}\text { Would like to initially engage system at normal pattern speed of } 130 \text { knots. } 40 \text { nozzles. Oscillatory } \\
\text { flightpath and speed response when tracking path prior to deceleration is objectionable. Cannot get } \\
\text { desired performance. Pitch-trim cycles chasing throttle and nozzle excursions. Difficult to use throtle } \\
\text { thumbwheel because not raised cnough above throttle body and not enough friction. Thumbwheel also } \\
\text { too sensitive. Would like to control fightphath with attitude early in approach while wing lift is } \\
\text { sufficient. Flightpath control during final stage of approach is good. Directional control weak. } \\
\text { Easy to come to precise hover. Only objection is switching guidance and display from approach to hover. } \\
\text { Height control is easy and precise. Eliminates workload of throttle control. Aggressive longitudinal } \\
\text { maneuvers with TRC causes disparity between predictor ball and velocity vector. Hover position } \\
\text { control precise-easy to stabilize over pad. TRC response is tight and crisp. Bank-angle excursions } \\
\text { are reasonable and comfortable. Heading wanders. Rearward drift noticeable in ground effect (IGE). } \\
\text { Did not have enough downward correction authority for flightpath control. Flightpath response sluggish } \\
\text { in flare. Lag of actual flightpath is noticeable. } \\
\text { Longitudinal TRC bandwidth }=0.18 \mathrm{rad} / \mathrm{sec} \text {. Very sluggish. hard to predict where it will stop when } \\
\text { proportional thumb controller is centered. } \\
\text { Long TRC bandwidth (BW) }=0.3 \mathrm{rad} / \mathrm{sec} \text {. Noticeably sluggish, but desired performance achieved. } \\
\text { Lateral TRC BW }=0.18 \mathrm{rad} / \mathrm{sec} \text {. Sluggish. Steady velocity and bank angle OK. Poor predictability for } \\
\text { closure on hover point. } \\
\text { Lateral TRC BW }=0.24 \text { rad/sec. Initial response OK. but still too sluggish. } \\
\text { Vertical-velocity command BW }=0.44 \text { rad/sec. Noticeably sluggish. Marginal for height control. } \\
\text { Borderline desired performance for shorebased landing; not desired performance for shipboard } \\
\text { recovery. } \\
\text { Vertical-velocity command BW }=0.54 \text { rad/sec. Still too sluggish. }\end{array}$ \\
\hline
\end{tabular}


Table 2. Continued

\begin{tabular}{|c|c|c|c|c|c|}
\hline Config & Pilot & Dates/Runs & Segment & HQR & Comments \\
\hline 3 & $E$ & $\begin{array}{l}\mathbf{3 / 2 4 / 9 5} \\
52901-08 \\
\mathbf{9 / 1 5 / 9 5} \\
58602,05 \\
58701-04 \\
58805 \\
\mathbf{9 / 1 9 / 9 5} \\
59104-06 \\
\mathbf{9 / 2 0 / 9 5} \\
59502-07 \\
\mathbf{9 / 2 8 / 9 5} \\
510901,02 \\
511001-04 \\
511301-05 \\
511401-03 \\
511501-03\end{array}$ & $\begin{array}{l}\text { Approach } \\
\text { Hover acquisition } \\
\text { Vertical landing } \\
\\
\text { Vertical landing } \\
\text { with } \\
\text { bandwidth } \\
\text { variations }\end{array}$ & $\begin{array}{l}3 \\
4 \\
3 \\
4 \\
3 \\
5\end{array}$ & $\begin{array}{l}\text { Throttle/nozzle oscillations noted during initial stages of the approach near } 120 \text { knots. Once deceleration } \\
\text { begins, these oscillations go away. Did not factor them into rating. Pitch and yaw can be active in } \\
\text { turbulence. Hard to make small inputs with either thumbwheel, leading to overcontrol. Deceleration } \\
\text { profile nice. Would be satisfactory with better inceptors. } \\
\text { Use acceleration command tape for final deceleration to determine when to center the thumbwheel for } \\
\text { hover. Leveling out before the hover helps separate the deceleration and height control. } \\
\text { Control of translation pretty nice, except response to the proportional thumb controller seems jerky } \\
\text { unless the inputs are smooth. Station keeping is excellent, holding position and altitude hands off for } \\
\text { extended times. Height control very easy: just set a sink rate and forget it. The landing task alone } \\
\text { would be HQR } 2 \text {. } \\
\text { Longitudinal TRC bandwidth }=0.3 \mathrm{rad} / \mathrm{sec} \text {. Smoother than baseline configuration with just a little looser } \\
\text { control. } \\
\text { Longitudinal TRC BW = } 0.18 \mathrm{rad} / \mathrm{sec} \text {. Control of longitudinal position definitely too loose. } \\
\text { Lateral TRC BW }=0.18 \mathrm{rad} / \mathrm{sec} \text {. Noticeably looser than baseline, but still satisfactory. } \\
\text { Lateral TRC BW }=0.12 \mathrm{rad} / \mathrm{sec} \text {. Quite loose for lateral positioning. } \\
\text { Vertical-velocity command BW = } 0.44 \mathrm{rad} / \mathrm{sec} \text {. Similar response for height control. Did not evaluate for } \\
\text { touchdown. } \\
\text { Vertical-velocity command BW = } 0.3 \mathrm{rad} / \mathrm{sec} \text {. Control of altitude changes loose. Held altitude well } \\
\text { during translations. During landing it acted like it could not get through ground effect. }\end{array}$ \\
\hline 4 & $\mathrm{C}$ & $\begin{array}{l}\mathbf{9 / 2 7 / 9 5} \\
510601-04 \\
510701-04 \\
510801-05\end{array}$ & $\begin{array}{l}\text { Approach } \\
\text { Hover acquisition }\end{array}$ & . & $\begin{array}{l}\text { Tracking ghost on approach easy and predictable. Below } 80 \text { knots, large nozzle movements during } \\
\text { deceleration require compensation with thrust to track the ghost. Corrections with acceleration } \\
\text { command thumbwheel in close also require corrections with the throttle to hold height at the station- } \\
\text { keeping point. } \\
\text { A litle compensation required if the station-keeping point capture is aggressive. Transition from } \\
\text { approach mode to hover mode very smooth and easy. Thumbwheel sensitivity OK. Need more } \\
\text { deceleration authority on the thumbwheel. Consider a blend of the deceleration from } 0.1 \text { to } 0.05 g \\
\text { instead of the step change. } \\
\text { Hover control almost open loop. Height control like vertical-velocity command. Proportional thumb } \\
\text { controller mechanical characteristics seemed good. If very aggressive with proportional thumb } \\
\text { controller during translation to the landing pad. some compensation required with the throttle. } \\
\text { Difficult to command so much vertical velocity that throttle series servo would saturate. }\end{array}$ \\
\hline
\end{tabular}


Table 2. Concluded

\begin{tabular}{|c|c|c|c|c|c|}
\hline Config & Pilot & Dates/Runs & Segment & HQR & Comments \\
\hline 4 & $\mathrm{D}$ & $\begin{array}{l}\mathbf{9 / 2 6 / 9 5} \\
510401-03 \\
510501-04\end{array}$ & $\begin{array}{l}\text { Approach } \\
\text { Hover acquisition } \\
\text { Vertical landing }\end{array}$ & 4 & $\begin{array}{l}\text { Natural to use throttle for flightpath control. Stick, throttle, thumbwheel, and appropriate combination of } \\
\text { inceptors. Mechanical characteristics of thumbwheel need work-too shrouded without enough of } \\
\text { wheel exposed to thumb, breakout; sensitivity too low. } \\
\text { Guidance needs to be fixed for closure to the station-keeping point. One level of deceleration would } \\
\text { suffice to carry into initial hover at station-keeping point. } \\
\text { Translational-rate command is straightforward. Natural to do height control with throttle. Good height } \\
\text { control. }\end{array}$ \\
\hline 4 & $\mathrm{E}$ & $\begin{array}{l}\mathbf{9 / 2 8 / 9 5} \\
511101-04 \\
511201-04\end{array}$ & $\begin{array}{l}\text { Approach } \\
\text { Hover acquisition } \\
\text { Vertical landing }\end{array}$ & $\begin{array}{l} \\
4 \\
3\end{array}$ & $\begin{array}{l}\text { Difficult to use thumbwheel for deceleration while using throttle for flightpath control. Likely a problem } \\
\text { of ergonomics of the controller rather than doing two things with one hand. Tended to chase flightpath } \\
\text { control at } 120 \text { knots. Quickening of flightpath symbol in response to throttle may be off for this } \\
\text { configuration. Could improve to HQR } 4 \text { with improved quickening. } \\
\text { Difficult to hold the throttle while reaching the thumbwheel. } \\
\text { Height control required a little effort without altitude-hold feature, but still a big improvement on } \\
\text { unaugmented height control. Vertical landing very easy and would warrant an HQR } 2 \text { by itself. }\end{array}$ \\
\hline
\end{tabular}





Public reporting burden for this collection of information is estimated to average 1 hour per response, including the time for reviewing instructions, searching existing data sources, gathering and maintaining the data needed, and completing and reviewing the collection of information. Send comnents regarding this burden estimate of any other aspect of this collection of information, including suggestions for reducing this butden, to Washinglon Headquarters Services, Directorate lor information Operations and Reports, 1215 Jefferson Davis Highway. Suite 1204, Arlington, VA 22202-4302, and to the Office of Management and Budget, Paperwork Reduction Project (0704-0188). Washington, DC 20503.
1. AGENCY USE ONLY (Leave blank)
2. REPORT DATE
3. REPORT TYPE AND DATES COVERED
April 1996
Technical Paper

4. TITLE AND SUBTITLE

Flight Evaluation of Advanced Controls and Displays for Transition and

Landing on the NASA V/STOL Systems Research Aircraft

6. AUTHOR(S)

$505-68-33$

James A. Franklin, Michael W. Stortz, Paul F. Borchers, and

Ernesto Moralez III

7. PERFORMING ORGANIZATION NAME(S) AND ADDRESS(ES)

8. PERFORMING ORGANIZATION REPORT NUMBER

Ames Research Center

Moffett Field, CA 94035-1000

A-961333

9. SPONSORING/MONITORING AGENCY NAME(S) AND ADDRESS(ES)

10. SPONSORING/MONITORING AGENCY REPORT NUMBER

National Aeronautics and Space Administration

Washington, DC 20546-0001

NASA TP-3607

11. SUPPLEMENTARY NOTES

Point of Contact: James A. Franklin, Ames Research Center, MS 211-2, Moffett Field, CA 94035-1000 (415) 604-6004

12a. DISTRIBUTION/AVAILABILITY STATEMENT

12b. DISTRIBUTION CODE

Unclassified - Unlimited

Subject Category 02

13. ABSTRACT (Maximum 200 words)

Flight experiments were conducted on Ames Research Center's V/STOL Systems Research Aircraft (VSRA) to assess the influence of advanced control modes and head-up displays (HUDs) on flying qualities for precision approach and landing operations. Evaluations were made for decelerating approaches to hover followed by a vertical landing and for slow landings for four control/ display mode combinations: the basic YAV-8B stability augmentation system; attitude command for pitch, roll, and yaw; flightpath/ acceleration command with translational rate command in the hover; and height-rate damping with translational-rate command. Head-up displays used in conjunction with these control modes provided flightpath tracking/pursuit guidance and deceleration commands for the decelerating approach and a mixed horizontal and vertical presentation for precision hover and landing. Flying qualities were established and control usage and bandwidth were documented for candidate control modes and displays for the approach and vertical landing. Minimally satisfactory bandwidths were determined for the translational-rate command system. Test pilot and engineer teams from the Naval Air Warfare Center, the Boeing Military Airplane Group, Lockheed Martin, McDonnell Douglas Acrospace, Northrop Grumman, Rolls-Royce, and the British Defence Research Agency participated in the program along with NASA research pilots from the Ames and Lewis Research Centers. The results, in conjunction with related ground-based simulation data, indicate that the flightpath/longitudinal-acceleration command response type in conjunction with pursuit tracking and deceleration guidance on the HUD would be essential for operation to instrument minimums significantly lower than the minimums for the AV-8B. It would also he a superior mode for performing slow landings where precise control to an austere landing area such as a narrow road is demanded. The translational-rate command system would reduce pilot workload for demanding vertical landing tasks aboard ship and in confined land-based sites.

14. SUGJECT TERMS

STOVL, V/STOL, Flight/Propulsion control, Flying qualities, 15. NUMBER OF PAGES Approach and landing, Flight research

\begin{tabular}{|l|l|}
\hline 17. SECURITY CLASSIFICATION & 18. SECURITY CLASSIFICATION \\
OF REPORT & OF THIS PAGE \\
Unclassified & Unclassified \\
\hline
\end{tabular}

19. SECURITY CLASSIFICATION OF ABSTRACT 20. LIMITATION OF ABSTRACT 

